Florida International University FIU Digital Commons

FIU Electronic Theses and Dissertations

University Graduate School

4-4-1995

\title{
A Cultural Historical Study of Land Use in Dade County, Florida
}

James R. Riach

Florida International University, Department of Environmental Studies, riachj@fiu.edu

DOI: $10.25148 /$ etd.FI07091101

Follow this and additional works at: https://digitalcommons.fiu.edu/etd

Part of the Sociology Commons

\section{Recommended Citation}

Riach, James R., "A Cultural Historical Study of Land Use in Dade County, Florida" (1995). FIU Electronic Theses and Dissertations. 1. https://digitalcommons.fiu.edu/etd/1

This work is brought to you for free and open access by the University Graduate School at FIU Digital Commons. It has been accepted for inclusion in FIU Electronic Theses and Dissertations by an authorized administrator of FIU Digital Commons. For more information, please contact dcc@fiu.edu. 
FLORIDA INTERNATIONAL UNIVERSITY

Miami, Florida

A CULTURAL HISTORICAL STUDY OF LAND USE IN DADE COUNTY, FLORIDA

A thesis submitted in partial satisfaction of the requirements for the degree of MASTER OF ARTS

IN

COMPARATIVE SOCIOLOGY

by

James Robert Riach 
To: Dean Arthur W. Herriott

College of Arts and Sciences

This thesis, written by James Robert Riach, and entitled A CULTURAL HISTORICAL STUDY OF LAND USE IN DADE COUNTY, FLORIDA, having been approved in respect to style and intellectual content, is referred to your judgement.

We have read this thesis and recommend that it be approved.

$$
\text { Bradley C. Bennett }
$$

Alex Stepićk

Dennis W. Wiedman

$\overline{\text { William T. Vickers, Major Professor }}$

Date of Defense: April 4, 1995

The thesis of James Robert Riach is approved.

DeanAArthur w. Herriott

Colldege of Arts and Sciences

Dr. Richard L. Camṕbell

Dean of Graduate Studies

Florida International University, 1995 


\author{
ABSTRACT OF THE THESIS \\ A CULTURAL HISTORICAL STUDY \\ OF LAND USE IN DADE COUNTY, FLORIDA \\ by \\ James Robert Riach \\ Florida International University, 1995 \\ Miami, Florida \\ Professor William T. Vickers, Major Professor
}

Humans have used the land within the area currently defined as Dade County, Florida since around 11,000 B.P., but did not significantly alter the local environment until less than one hundred years ago. These recent changes greatly affected many critical ecological factors, thereby reducing the sustainability of many types of life, including humans. This study explains how land use evolved from earlier sustainable systems for satisfying human needs into the current menacing patterns. This is done by examining the environmental, technological, social, and cognitive contexts of land use through time. Changes in all these areas have followed a general trend leading to increasing intensity of land use and environmental change driven by population growth and technological innovation. 
TABLE OF CONTENTS

CHAPTER

PAGE

I. INTRODUCTION . . . . . . . . . . . . . . . . . .

Foreword............................

Dade County .........................

Land Use and Environmental Problems..............

The Need for an Anthropological Perspective.........6

History of Ecological Anthropology and

Related Theories.......................

Environmental Determinism. .............. . .

Environmental Possibilism................ 13

Environmental Challenge................. . . . . . .

Culture Area Approach. .................. . . . .

Cultural Evolutionism................. . . .

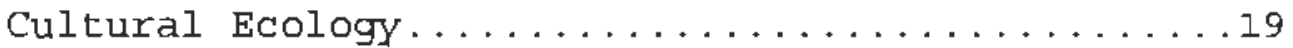

Ecosystemic Approach..................21

Neo-Darwinian Evolutionary Ecology.............22

Adaptive Dynamics . . . . . . . . . . . . . . . . 22

Cultural Materialism..................... . . 24

Concepts of Environmental Risks and Hazards........26

The Concept of Maladaptation.................27

Research Design........................... 29

Methods . . . . . . . . . . . . . . . . . . . . 31

The Significance of this Research.................. 34 
II. ENVIRONMENTAL DESCRIPTION OF DADE COUNTY . . . . . . . . 36 Biogeography ......................... 36 Sea Level Changes. . . . . . . . . . . . . . . . . . 37 Climate............................41 Physiographic Regions and Geographical zones........43 soils............................... 47 Vegetation Communities of Physiographic Regions......49 Everglades Region......................50 Marsh Flora and Fauna.................59 Tree Island Flora and Fauna............63 Changes to the Everglades...............64

Miami Rock Ridge Region. . . . . . . . . . . . . .66 Hammock Flora and Fauna..............68 Pineland Flora and Fauna...............70 Changes to the Miami Rock Ridge...........71 Biscayne Bay Region.................. . . . . Estuarine Flora and Fauna............... 73 Changes to Biscayne Bay................75 Coastal Region..................... 76 Mangrove Flora and Fauna.............. 77 Salt Marsh Flora and Fauna ..............79

Beach Strand Flora and Fauna.............79 Changes to the coast................. . 0

Big Cypress Spur Region................ 82

Cypress Forest Flora and Fauna...........83

Changes in the Big Cypress spur...........84 


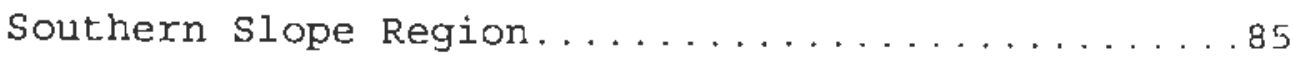

Changes to the southern slope...........86

Atlantic ocean Region...................

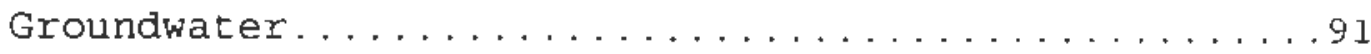

Summary of Chapter....................... 92

III. THE PRE-COLUMBIAN ERA (14,000 B.P.-A.D. 1512) .....94

Overview of the Pre-Columbian Era...............94

Paleo-Indian Period $(14,000-8,500$ B.P.) .........98

Environment.......................... . . . . .

Technology ............................ 101

Subsistence Selectivity..................103

Tools............................... . . . . . .

Social Dimension......................... 105

Cognitive Dimension....................... 106

Archaic Period $(8,500-2,500$ B.P.).............. 106

Sites in Dade County..................... 107

Environment . . . . . . . . . . . . . . . . . 109

Technology ............................. 109

Subsistence selectivity................110

Tools..............................12

House Structures.....................112

Social Dimension.....................112

Cognitive Dimension. . . . . . . . . . . . . . . 113

Formative Period $(2,500$ B.P.-A.D. 1512) ..........114

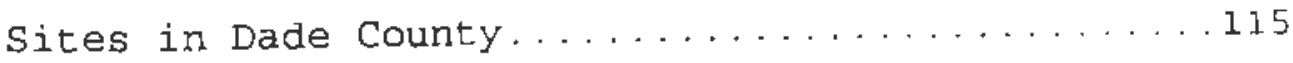




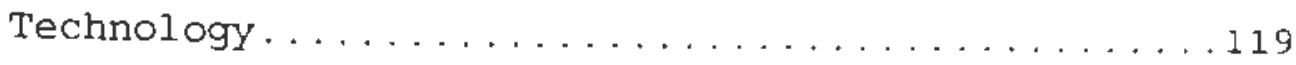

Coastal Zone Faunal Subsistence............ 120

Habitat-Specific Selectivity..........120

Coastal zone Floral Subsistence............ 124

Habitat-Specific Selectivity........... 125

Inland zone Faunal Subsistence............126

Habitat-Specific Selectivity............ 127

Inland Zone Floral Subsistence............ 129

Procurement and Use of Flora..............130

Procurement and Use of Aquatic Fauna.........131

Sharks............................ . . . .

Rays. . . . . . . . . . . . . . . . 132

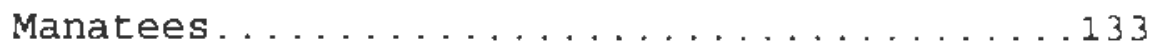

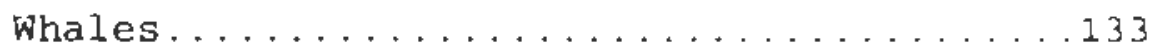

Small Bony Fish..................... . . . . . 34

Turtles......................... 135

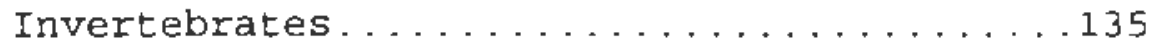

Procurement and Use of Terrestrial Fauna. . . . 136

Deer. . . . . . . . . . . . . . . . . 137

Smal1 Mamunals....................137

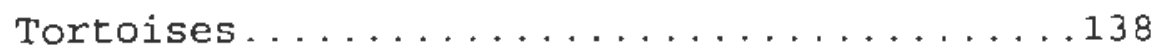

Snakes, Alligators, Amphibians, and Birds..138

House Structures.................... . 138

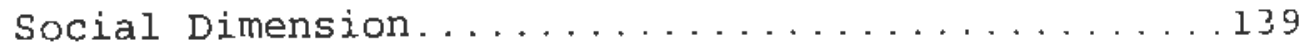

Migratory Patterns...................141

Population. ...................... 142

vii 
Socio-Political Organization............ . 143

Cognitive Dimension: Religion............... . . . . .

Summary of Chapter..................... 148

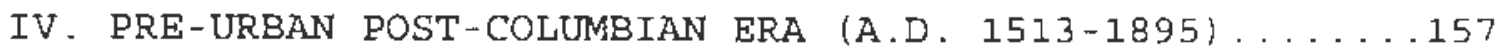

Introduction. . . . . . . . . . . . . . . . . . . . 157

Spanish Contact Period: A.D. 1513-1789..........158

Environmental Risks and Hazards.............. . . 159

Social Dimension: Population and Socio-Political

Relations...........................161

Technology . . . . . . . . . . . . . . . . . . 162

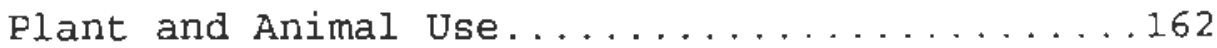

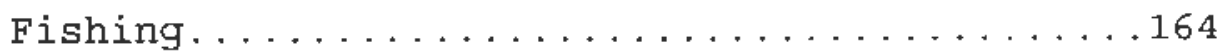

Agriculture and Drainage.............. 164

Land Surveys ........................ . . . . . . .

Cognitive Dimension: Mythology and Religion......165

Pioneer Settlement Period: A.D. 1790-1895........166

Environmental Risks and Hazards........... . . 168

Social Dimension........................ 170

Settlement........................ 170

Population....................... . 174

Technology ...........................174

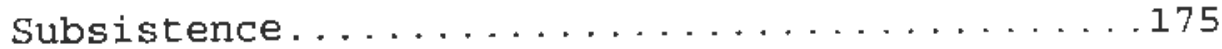

Houses. . . . . . . . . . . . . . . . . 177

Transportation....................... . . . .

Coontie Starch Industry.................179 
Hunting and Trading................

Agriculture....................... . . . . . .

Wrecking . . . . . . . . . . . . . . . 185

Cognitive Dimension: Perceptions of the Land....186 Indians in the Pioneer Settlement Period:

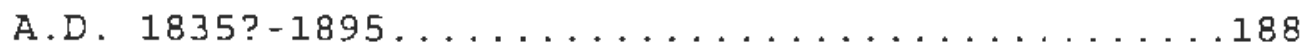

Environmental Risks and Hazards............191

Social Dimension: War, Migration, and

Population.............................. . . . . . . . . . .

Technological Dimension................... . . . . . . . .

Subsistence Resources.................. . . 195

Subsistence Techniques................ . 196

Houses. . . . . . . . . . . . . . . . . . . . 196

Trading. . . . . . . . . . . . . . . . . 197

Transportation..................... . . . . . . . .

Medicine. . . . . . . . . . . . . . . . . . 198

Summary of Chapter........................ 198

V. URBANIZATION PERIOD: A.D. 1896 -PRESENT ..........205

Overview of the Urbanization Period............205

Environmental Risks and Hazards.............211

Social Dimension. ....................... 212

Population Growth and Distribution..........213

Environmental Legislation.................221

Technology ............................... 222

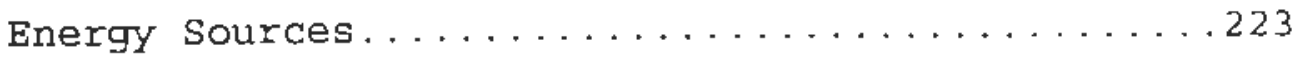


Drainage and Structural Controls............224

Marine Drainage.........................231

Residential and Commercial Development........232

Plant Cultivation..................238

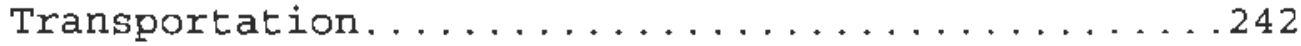

Oil Exploration......................... . . 244

Tannic Acid and Charcoal Production...........245

The Miccosukee and Seminole During the

Urbanization Period....................246

Environmental Risks and Hazards..............249

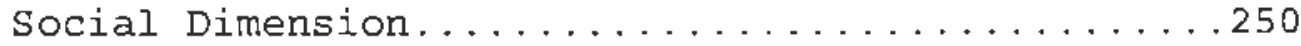

Technology. . . . . . . . . . . . . . . . . . 252

Cognitive Dimension....................255

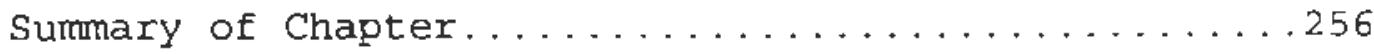

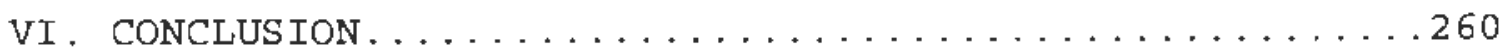

Summary of South Florida Land Use Patterns........ 260

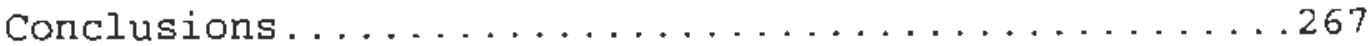

Future Land Use Suggestions....................271

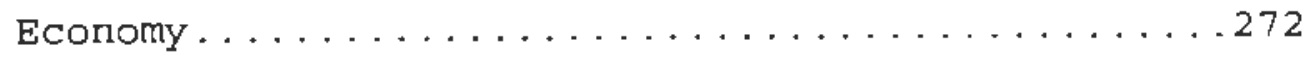

Development. . . . . . . . . . . . . . . . 272

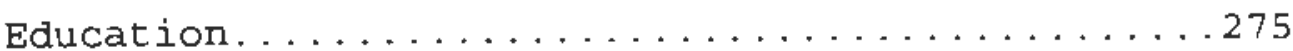

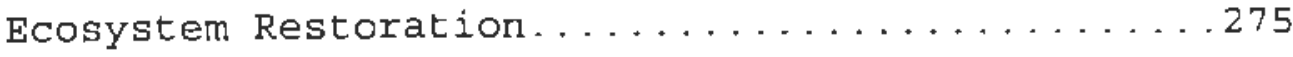

REFERENCES CITED . . . . . . . . . . . . . . . 278 


\section{LIST OF FIGURES}

1. Historic Boundaries of Dade County.................

2. Physiographic Regions of Dade County..............45

3. Topographic Cross-Sections.................46

4. Historic Vegetative Communities of Dade County.......51

5. Atlantic ocean Floor Profile................88

6. Archaeological sites in Dade county..............97

7. Urban Population Growth in Dade County, 1920-1975...218

8. Incorporated Areas of Dade County................. 219

9. Salt water Intrusion in Dade County............225

10. Drainage and Structural Controls in South Florida...228

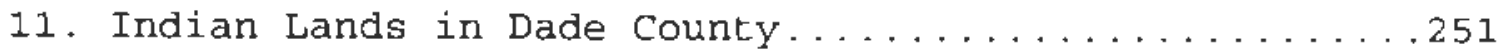




\section{LIST OF TABLES}

1. A Few Interpretations of South Florida Sea Level Changes of the Holocene..................... 39

2. Soils and Associations of Terrestrial

Physiographic Regions................... 48

3. Habitats and Uses of Dade County Flora and Fauna......52

4. A Few Interpretations of the Archaeological Culture Periods in south Florida..................96

5. A Few Interpretations of the "Glades Tradition"

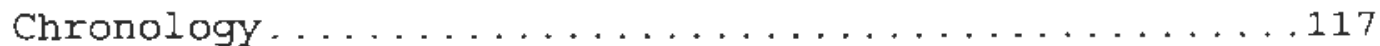

6. Ceramic Marker Types by Feriod.................118

7. Pre-Columbian Archaeological Site Characteristics.... 149

8. Population Growth in Dade County (1840-1992) ........215

9. Population Change in Incorporated Coastal Places

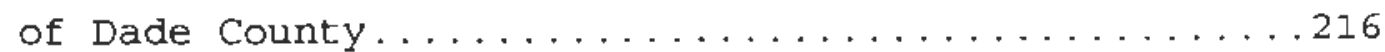

10. Population Change in Incorporated Inland Places

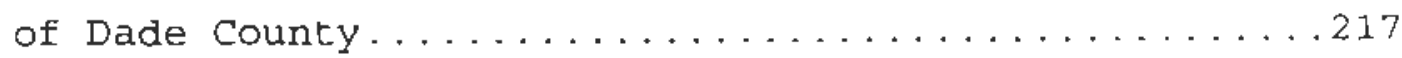

11. Current Economic Structure of Dade County.........270 


\section{CHAPTER I : INTRODUCTION}

\section{FOREWORD}

Land use within Dade County, Florida has undergone major changes during almost 12,000 years of human occupation. Each habitat found in the county has been subjected to changes in types and intensities of use through time. The most significant of these changes occurred within the last 100 years. Environmental degradation now threatens both humans and many other forms of life in Dade County. It is critical to learn how historical land use in Dade County led to the many environmental problems that exist today.

The relationship between culture and environment is the main interest of ecological anthropologists. Cultural ecology helps explain how particular cultural features originate and change under different environments and technologies. I examine land use change in Dade County from a cultural ecological perspective. This is achieved by analyzing land use during the Pre-Columbian and Post-Contact Eras. The Pre-Columbian Era is divided into the PaleoIndian (12,000 B.P. $-7,500$ B.P.), Archaic (7,500 B.P. -2,500 B.P.), and Formative $(2,500$ B.P.-1513 A.D.) Culture Periods. The Post-Contact Era is divided into the Spanish Contact (1513-1789), Pioneer Settlement (1790-1895), and Urbanization (1896-present) Culture Periods. 


\section{DADE COUNTY}

The study area is the politically defined region known as Dade County. It covers approximately 6,000 square kilometers of southeastern peninsular florida and the east coast barrier islands. The legal boundaries of the county have changed several times since its conception in 1836 (Figure 1). The original boundaries began at the west end of Bahia Honda Key, due north to the southern edge of Lake okeechobee, down the Hillsboro River to the coastline just north of Fort Lauderdale. Miami Beach, Key Biscayne, and Elliot Key also became part of Dade County. In 1880, the northern boundary was extended to the north side of the $S t$. Lucie River, and the western and southern boundaries were changed to the current locations. From 1880 to 1909, the northern boundary was north of fort Lauderdale. In 1915 , the present borders were established just south of Hallandale and Miramar (Blackman 1921; Unger 1992).

\section{LAND USE AND ENVIRONMENTAL PROBLEMS}

Dade County's environmental problems are recent compared to the length of time humans have resided in this area. paleo-Indians may have lived in this area as early as 11,000 B.P. (Carr 1986); evidence of substantial aboriginal occupation dates as far back as 2,000 years (Griffin 1988). 
Figure 1 Historic Boundaries of Dade County
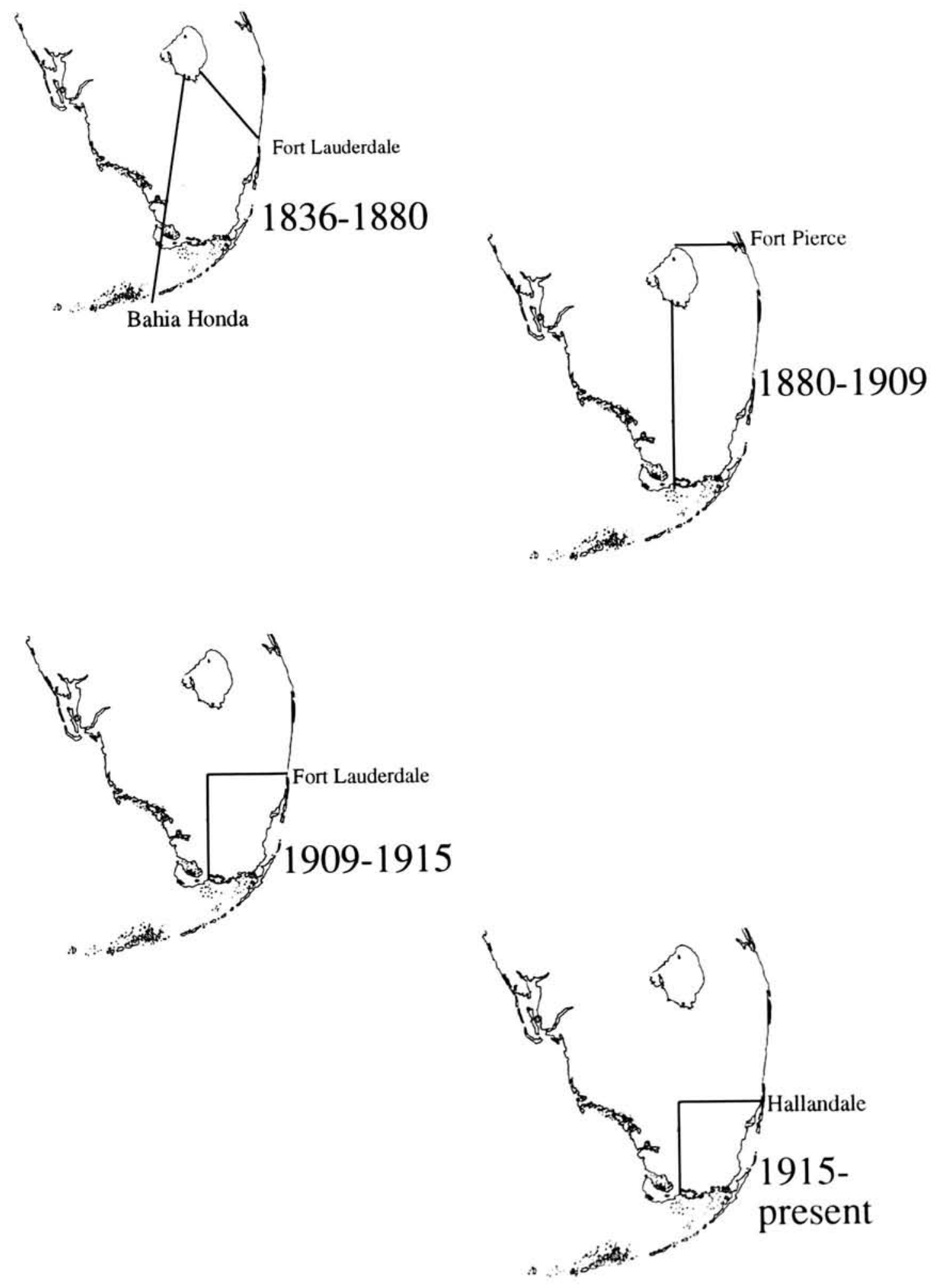
The first peoples that migrated to South Florida had to adapt to changes in their environment. Once they had adjusted, their cultural patterns did not change very much until their environment changed. Paleo-Indians practiced migratory hunting, plant gathering, shellfish collecting, and possibly fishing (Marquardt 1992:426). The peoples of the Archaic Period were more sedentary with increased reliance on small mammals and marine resources (Carr 1984; McGoun 1993; Milanich 1987). The Formative Period was characterized by a settlement and subsistence pattern known as the "Glades tradition" (Goggin 1949). This pattern may be described as broad hunting and gathering in various ecological zones with a possibility of horticulture or trade with horticulturalists.

The history of severe environmental problems begins about 100 years ago. It was then that land use practices caused drastic and harmful changes to the natural environment, most notably the hydrological systems and vegetation communities (Ewel 199I). Most of this damage was caused by the draining of the Everglades in order to provide lands for agriculture and urban development (Paige 1986). Indeed, urban and agricultural development have almost completely eliminated the pine rockland-tropical hammock community and about half of the Everglades marsh land. In 1975 only five percent of the original pineland and ten percent of the hammock communities still remained in Dade County (Shaw 1975). EY 
1990 only two percent of the original Miami rockridge pinelands remained intact (snyder et al. 1990). This number was further reduced following the impacts of Hurricane Andrew in 1992. Habitat destruction and drainage drastically decreased wildife population. Several mammals, birds, amphibians, reptiles, and fish species are threatened, endangered, rare, extirpated, or extinct.

The environmental impacts not only affect vegetation and wildlife but they also affect the human economy. For example, the continued disruption of water flow from the Everglades to the mangrove forests of Florida Bay could deplete fish populations. Such an ecological catastrophe would cost several hundreds of millions of dollars annually to the commercial and sports fishing industry (Gleason 1984).

The future of Dade county may depend on how well humans are capable of coping with the current environmental problems facing them, particularly in light of continued population growth. The county's population grew from 83 in 1860 (Department of the Interior Census office 1883) to almost 2 million in 1992 (U.S. Bureau of the Census 1994). Demand for space threatens the natural systems in the county. The only remaining areas available for development lie on the border of the coastal mangrove forests or in the interior marshes on the edge of the protected conservation areas (Gleason 1984). Population growth also increases 
demand for water that exceeds the rate of recharge of the aquifer. If the water level of this aquifer drops sufficiently below sea level, salt water intrusion will render the aquifer useless.

These environmental problems will increase unless change in land use occurs. In order to develop land use practices that are more cordial to environmental and cultural needs, a study that reveals the historical processes that caused the current situation is called for. It is hoped this may help to prevent repeating our past mistakes when making plans for future land use.

\section{THE NEED FOR AN ANTHROPOLOGICAL PERSPECTIVE}

Although there is abundant literature on the environmental problems of Dade County, most sources lack an anthropological analysis. This study addresses this gap by examining human ecological relationships. An anthropological perspective is valuable because of its multidisciplinary approach that combines data from the natural and social sciences and because of its focus on human cultural groups. This is preferable to studies of only natural or social science that consider humans to be separate from the natural environment. The idea that humans should be considered as part of the natural environment was advocated as early as 1963 by anthropologist clifford 
Geertz, and was reiterated by the ecologist Eugene odum in 1977.

The benefit of employing a holistic approach becones evident when considering studies that are narrower in scope and methodology. For example, studies from pure natural sciences may provide good data on the biological and physical environment, but usually exclude factors associated with human culture in their analyses. According to Bennett (1984), concepts such as politics, social change, greed, profits, self actualization, ethics, and philosophy are all involved in the interaction with the natural environment. Conversely, studies using only social or human data tend to provide good descriptions of social processes and behavior but lack biological and physical data on how they affect and are affected by the surrounding natural environment.

While some studies of South Florida combine data from natural and social sciences, they are limited by their disciplinary focus and do not attain a truly holistic perspective. For example, zucchetto (1976) studied energy flow in urban Dade County that flows from natural and cultural elements. However, he does not deal with the question of how humans develop or change their paxticular cultural systems in relation to their environment. Millicent (1948) provides a geographical analysis of how Miami's natural resources led to the urban development and settlement growth. Yet, his analysis does not examine 
biological or physical processes involved in these patterns nor does he include elements of the natural realm that were not considered to be natural resources or useful.

An anthropological perspective allows the focus of the analysis to be the human cultural groups as they exist within their environment. By viewing humans as part of the natural realm, one may ask whether humans behave in such a way as to satisfy their needs and wants while maintaining a sustainable system. This research design allows the examination of biological, physical and cultural data and how they relate to each other. The most relevant of these data are descriptions of the natural and cultural histories. Some of the more notable work includes documentation from explorers, botanists, ecologists, geographers, geologists, archaeologists, and historians.

\section{HISTORY OF ECOLOGICAL ANTHROQOLOGY AND RELATED THEORIES}

The anthropological perspective contributes a large body of work on studies of culture-environment relationships, particularly within the field of ecological anthropology. Many of these studies were influenced by the ideas that various students of humanity expressed prior to the formal development of anthropology as a legitimate disciplins, and include various interpretations of how the snyironment 
causes or shapes culture and civilization (Hippocrates, in Galen 1952; Huntington 1915; 1945; Ratzel 1882; Tacitus 1911). Some of the approaches developed in the ecological anthropology field include environmental possibilism (Boas 1896, 1911), the culture area approach (Forde 1934; Kroeber 1939; Wissler 1917, 1926), cultural evolutionism (White 1949, 1959), cultural ecology (Steward 1955), the ecosystemic approach (Geertz 1963), neo-Darwinian evolutionary ecology (Wilson 1975), adaptive dynamics, (Bennett 1976), and cultural materialism (Harris 1979).

\section{Environmental Determinism}

One of the oldest anthropological perspectives is that of environmental determinism. It assumes that the environment causes or shapes the culture. Several variations to this perspective have been presented by various students of humanity. The Greek physician Hippocrates expressed this view 2,400 years ago in his book, Airs, Waters, and Places (Galen 1952). Hippocrates believed that various patterns of health and the social character of a culture are shaped by variability in climate (pp. I8-19) and that these patterns then determine the capacity for success of these cultures. According to him, severe climates and climatic variability stimulate the body and the mind, while stable unchanging climates of moderate temperatures and low winds would create lethargic cultures. 
Hippocrates describes his belief that the congenial climate of Asia hindered their development of vigor, courage, and the capacity to endure suffering and to carry out laborious tasks, and caused the development of a monarchy and slavery (Pp. 14-15). He then describes how the severe and variable climate in other places in Europe contributes to warlike, intelligent, and moral characteristics. For example, he claims Greece's climate caused the inhabitants to have the capacity to endure dangers, valor, and a warlike manner. According to him, these attributes allowed them to stand for their independence and liberty under their government ( $p$. 16) .

The ethnocentric and deterministic view of how geography and climate shape culture is also exemplified in the writings of the Roman historian, Cornelius Tacitus. Around A.D. 98 he described English and Irish tribes in Agricola (1911) and German tribes in Germanica (1911). In these accounts he included descriptions of the geography and climate of the different tribes, and the inherited and acquired personality traits of their members. Tacitus believed the capacity for a successful culture, or civilization, was largely dependent on its ability to resist military conquest. According to him, these abilities were greatly influenced by geographical factors. His concern for geographical influences may be noted in his dedication of a chapter to the description of Britain's military customs, 
climate, and products of the soil (p. 12), suggesting he believed they were somehow interrelated. Furthermore, he describes the losses of the Roman battles against the Germans in terms of the vastness of the German encampments and the fierce independence of their inhabitants (pp. 114115). In addition to geographical determinism, it appears that Tacitus also believed in racial determinism. This belief is illustrated in his description of Germans as "a race without either natural or acquired cunning..." (p. 104).

By the late nineteenth century, the theories of how geography determined the development of civilizations had been highly refined. One of the individuals most responsible for the advancement of these ideas was the German geographer, Friedrich Ratzel, who in 1882 detailed them in his book entitled Anthropogeographie (Human Geography). It is important to note that he felt that in order to produce an English version of this book AngloCeltic and Anglo-American reformulations were necessary. In complying with this request, the American geographer Ellen Semple worked with Ratzel in order to present his ideas in a manner he found suitable for the American mind (Semple 1911: $v)$. It is from her work that I cite the ideas originally of Ratzel.

Ratzel's system of anthropogeography analyzed how general trends in cultural evolution affected the influences 
geography had in directing different forms of human development. According to this system, there are four main types of geographical influences upon human development, the physical, psychic, economic and social, and migration influences (Semple 1911:32-50). The effects of the physical influences were primarily the biological and cultural adaptations to climate. The different interpretations of the environment as reflected in the cosmology, ideology, religion, and language of a culture were considered to be the geographical influences on the psyche. The different quantities and qualities of natural resources associated with particular geographic locations influenced the economy and social organization since each resource requires different levels of technology and social adaptations for successful economic development. The geographic features were considered to be either impediments or ideal venues of transportation, the distribution of which influenced the direction of migration patterns.

Ratzel's system of anthropogeography, provided a framework for the analysis of how different cultures develop in different geographical area types, including coasts (pp. 242-291), continental land masses (pp. 386-403), peninsulas (pp. 403-406), islands (pp. 409-472), lowland plains, or deserts (pp. 473-520), and mountains (pp. 557-606). Although Ratzel believed that the particular form of development that occurred in any of these areas was 
dependent upon specific geographical features of the land, his descriptions of coastal and mountainous cultures were absolute. According to his model, the development of marine travel transformed the coasts into gateways for exploration, colonization, and ideologies from other cultures (p. 242). This allowed the coastal regions to become the first geographical regions to develop a cosmopolitan culture, which later spread to inland areas (p. 280). However, the accessibility to mountainous regions, and the availability of natural resources there, were defined to have remained constant throughout history leading to the isolation and conservatism of the people living in these regions. In the anthropogeographic analysis, mountainous populations were said to be suspicious toward strangers, extremely sensitive to criticism, superstitious, strongly religious, and intensely familial (p. 601).

Environmental Possibilism

One of the main critics against the ideas of geographical determinism was Franz Boas. Boas considered the environment to be influential in the development of cultural types, but not deterministic. He believed geographical conditions had the power only to modify culture, yet by themselves they were not creative. For him, the environment presents a set of opportunities and limitations from which humans make choices in order to achieve their goals. Boas felt that the 
environment always acted upon a pre-existing culture and its influence could only be understood in light of the culture's particular history. He indicated that the influence of culture over the environment may be noted in cases where ancient customs persist despite changes in the environment that make them disadvantageous. The chosen subsistence patterns and other related behavior then become the culture pattern of a given group (1911:174-176).

\section{Environmental Challenge}

Despite Boas' efforts to deemphasize the significance of geographical factors in the development of civilizations the ideas of geographical determinism had not completely died out. Ellsworth Huntington refused to believe that geography plays only a passive role in the development of cultural traits and civilization. He was interested in how variations in racial inheritance and physical environment are related to the growth of culture and the course of history of civilization (1945:9). He believed that civilization is formed by responses to environmental challenges, particularly the climate (pp. 383-389, 402). Using cross cultural data from around the world he identified patterns in the relationships between climate and the causes, direction, and success of human migration. He believed that different weather conditions, including temperature fluctuations, rainfall, and storms affect a 
series of social (pp. 276-306) and psychological conditions (pp. 369-382) of civilizations.

Huntington concluded that most mass migrations resulted from drastic and rapid changes in the local environment (1915:24-25), while other migrations were the result of changes in the stages of civilization. According to him, a progressive change was indicated by the development of new technology that allowed the more civilized groups to migrate toward the poles, and a regressive change was indicated by migration toward the equator (p. 396). Huntington also believed that the cooler polar weather contributed to intellectual curiosity necessary for the development of technology while the warmer weather led to a lack of control in organization $(1945: 365-374)$. Yet, he stressed that climate is not the sole determinant for the development of technology. He also considered human innate capacity and motivation, and the availability of fuel supplies as influential $(1945: 408)$.

\section{Culture Area Approach}

Around the same time that Boas was developing his arguments against geographic determinism, the method of culture area classification emerged. Ethnographic efforts at classifying and mapping North and South American Indian tribes led to the development of this approach by Otis Mason who identified eighteen American Indian "environments" or 
"culture areas" based largely on floral and faunal distributions (1895:646, 651). Variations of this approach were developed and gained popularity among anthropologists throughout the early half of the twentieth century. Clark Wissler classified ten culture areas based on the geographical distribution of six broad floral and faunal "food" (1917:1-27) and "ecological" (1926: 211-222) areas. These culture areas were eventually further refined by a more detailed ecological differentiation by Alfred kroeber. Towards this end, Kroeber provided a series of vegetation, physiographic, climatological, and culture area maps in his book entitled Cultural and Natural Areas of Native North America (1939).

Daryll Forde developed the idea of culture areas to the world level by stating that the world could be divided into a number of culture areas according to particular patterns of crafts, economies and social organization (1934:466-67). However, he also incorporated the Boasian belief that each culture had its own individual history when he suggested cultures should be studied as an historical development (1934:464-65). Kroeber would also eventually state the importance of historical analysis for the study of cultural processes (1939:1-3). 


\section{Cultural Evolutionism}

By the mid 1940 s there was a reemergence in the interest of explaining the causes of cultural behavior, particularly in terms of technological adaptations to the environment. This interest took the form of cultural evolutionary theories. One of the directions taken was Leslie White's explanation of the universal evolution of culture in general. Like Boas, white rejected the idea that the environment determines culture. Rather, he felt that the environment influences culture according to the particular level of development of a specific culture (White 1959:5051). For this reason, he felt that the study of environmental influence was relevant only to the study of particular cultures and not useful for the understanding of culture in general.

In order to explain the causes of cultural evolution White relied on his "Law of Cultural Evolution" (pp. 36869). According to this law, the different stages of culture evolve as the amount of energy harnessed per capita per year is increased, or as the efficiency of the means of putting the energy to work is increased. White saw culture as a thermodynamic system involved in the process of energy transformations (p. 38), harnessing it and putting it to work to serve the needs of humans (p. 40). According to White, there have been three main stages of evolution which can be differentiated according to the quality of technology 
and energy used.

White referred to the first stage as "savagery" and characterized it as one in which humans are the primary energy sources and wind, water, and fire are minimally used. He also indicated a reliance on hunting and gathering of wild foods during this stage. White believed this period lasted until the beginning of the domestication of animals and cultivation of plants, a period of about one million years (pp, 41-45).

White indicates that selective breeding, fertilization, and irrigation of plant crops helped to increase their yield per unit of human energy. He also mentions how the shift from hunting to domestication of animals significantly increased the yield of food and other useful animal products per unit of human energy. He suggests that herds of domesticated animals could be used as a source for various subsistence products, and to accomplish various types of work requiring motive power while simultaneously increasing the herd's population (White 1949:371*72).

According to white, the next major evolutionary stage occurred form the result of the fuel revolution at around 1800 A.D. Energy in the form of coal, oil, and gas were being harnessed by steam and internal combustion engines. White indicates that cultural changes associated with the agricultural and fuel revolutions included increased population, larger political units, bigger cities, 
accumulation of wealth and a rapid advancement of the arts and sciences (p. 373).

White also elaborates on the development of nuclear energy. He indicates that although the development of nuclear energy is significant technologically, no cultural advancement has yet been achieved by the development of this new energy source (p. 374). Instead, he warns of the potential threat that nuclear warfare poses mankind $4 \mathrm{p}$. 389) .

\section{Cultural Ecology}

Although white described a general trend in the evolution of culture, his work was criticized for not providing explanations of the causes for cultural change or of why individual cultures developed the characteristics they did. One of his main critics, Julian Steward, addressed these issues in his concepts of multilineal evolution and cultural ecology (1955). Multilineal evolution was described as a methodology for determining cultural laws (p. 18). Steward was most interested in examining how cultural change is influenced by the process of adapting to the environment, a

process he termed "cultural ecology" (p. 5). He believed that through the empirical analysis of cross cultural regularities, or patterns, of cultural change the development of cultural laws would be possible (p. 18). He considered culture and environment to be inter- 
dependent variables, which influence the process of satisfying human needs and goals. He described culture as consisting of two components, the core and the superstructure. The core is defined as the cross cultural regularities that occur in the functional interrelationship . resulting from local ecological adaptations and sociocultural integration $(p, 6)$. It is comprised of the patterns most closely associated with subsistence activity and economic arrangements and may include social, political, and religious patterns. The superstructure consists of the cultural features that are unrelated to environment and technology, these may be determined by historical influences, random innovations, or diffusion. The features of the superstructure tend to be more variable and may give the appearance of distinctiveness to cultures with similar cores (p. 37).

Steward provides a three step method of cultural ecology. The first step is to analyze the interrelationship between exploitative technology and environment. This requires the documentation of tools and techniques used in subsistence activities. The second step is the analysis of the patterns of social organization involved in the exploitation of a particular area by a particular technology. The third step is the analysis of the extent to which the behavior patterns involved in exploiting the environment affect other aspects of cultures (pp. 40-41). This approach indicates steward's 
belief that the economic relationship between environment and technology is the main cause of the different forms of social organization, ideologies, and other features of culture.

\section{Ecosystemic Approach}

Although steward believed subsistence oriented behavior affected other aspects of culture, he did not consider the effects of technology on the physical and biological environment. He also viewed the environment and culture as two distinct systems. In order to try to provide more detailed analyses of the relations between human adaptations, biological exchanges and physical processes, Clifford Geertz (1963:3) advocated the approach of viewing culture and environment as a single system. By doing so, he became the first anthropologist to borrow the term "ecosystem" from biology. Although the definition of the ecosystem concept has evolved since first introduced by the botanist Tansley (1935), its main idea that the environment is a system of interacting inorganic and biological

components has remained the same. Geertz believed that the central organizing force in the ecosystem is the natural tendency to approach a balanced state, or equilibrium. This equilibrium depends on the balancing of a complex set of interdependent natural elements, flora, and fauna in such a way as to ensure the continued existence of each other 
(Geertz 1963:4). According to Geertz, any adaptation to the environment which threatens to disrupt the equilibrium may be said to be maladaptive to the system. He believes human adaptations can either upset the balance of natural phenomena, maintain them, or create new balanced environments (pp. 1-5).

\section{Neo-Darwinian Evolutionary Ecology}

Following in the trend to explain human behavior by applying biological concepts, Edward O. Wilson (1975) proposes the evolutionary ecology approach in his theory of sociobiology. It is probably the most deterministic of all the approaches in ecological anthropology. The main concern of this approach is to try to explain the origin of social behavior. The basic premise of this theory is that social behavior is genetically determined (pp. 3-6). Therefore, human decision making is influenced by reproductive concerns such as inclusive fitness and the efficient use of resources for the benefit of self and kin (pp. 415-416).

\section{Adaptive Dynamics}

Following Geertz's idea that adaptations may produce detrimental consequences, John Bennett (1976) took the idea further in his concept of adaptive dynamics. Bennett indicates that adaptations are not absolute in their outcome. Adaptations are neither good nor bad, but they can 
lead to desirable or undesirable outcomes, stability or dynamism, satisfaction for some and disappointment for others, or destruction or construction (p. 252). Adaptations are based on human choices from a range of possible choices and susceptible to human error in the process (p. 166). He refers to adaptation as a process of coping with people and resources in order to attain goals and solve problems (p. 270). The process is dynamic because coping itself creates new goals or problems to solve (Bennett 1969:14).

The evaluation of adaptations is based on the level of goal satisfaction and on the degree of conservation of resources the adaptations achieve. The degree of conservation of resources is measured in terms of the opportunity costs of the adaptive use of a resource. Opportunity cost is defined as the difference between the value of a particular resource in its best alternative use and the value of the current use (Bennett 1969:13-14).

The adaptive behavior is seen as occurring in two time dimensions, short term and long term. The adaptive significance of any given behavior is defined in the context of the particular social and natural environment in which it occurs. Since both culture and environment are constantly changing, behavior that was adaptive in the short term may not be adaptive over the long run.

The actual behavior chosen to obtain and use resources or 
to deal with imnediate problems is defined as the adaptive strategy which is consciously chosen from a number of possible actions. The long term behavior patterns associated with adaptations are defined as the adaptive process. This process is an analytically constructed description of the observed changes in behavior that resulted from the long term use of adaptive strategies (Bennett $1969: 14$ ).

The main concerns of the adaptive dynamics approach are the interrelationships between population, cultural needs and wants, technology, subsistence, and the environment. Examining the changes in these variables over time makes it possible to better understand how certain adaptive processes respond to problems while generating new ones. Adaptations are driven by the technology used to attain the goals chosen by humans to satisfy needs and wants. Technology works on the natural environment by using resources to produce energy and goods. This process generates a series of feedbacks involving individuals and society, and shapes the culturally defined needs and wants that impact the enviromment (Bennett 1976:165-166, 270).

\section{Cultural Materialism}

Marvin Harris (1979) describes his cultural materialism theory as a strategy for explaining sociocultural behavior. The main assumption of this theory is that technical and 
environmental factors dominate social and ideological ones in shaping culture, and that the human relationship with the environment is inherently a practical one. This approach is fundamentally a neomarxist approach in which Karl Marx's explanations of how the economic structure of society gives rise to the legal and political superstructures (Marx 1904: 11-12) are refined. However, cultural materialism does not include Marx's dogmatic political perspective. Harris's model of culture is divided into three vertical levels. These include the infrastructure, structure, and superstructure. The infrastructure includes the modes of production and reproduction, which are the most important influences on culture. The structure consists of the family and politics that influences the superstructure, which consists of the arts, music, literature, science, and religion.

Harris's cultural materialist approach resembles Steward's cultural ecology in that both perspectives consider the relationship between technology and the environment as the most significant factors in shaping culture. However, they differ with regard to their views on human's ability to control their relationship with the environment. According to cultural materialism, sociocultural behavior is determined by the relations between technology and environment. According to all theories of cultural ecology, it is only an influence. 


\section{CONCEPTS OF ENVIRONMENTAL RISKS AND HAZARDS}

A main interest of this thesis is to explain the relationship between the environment and land use. This may be achieved by examining how humans have responded to different environmental conditions. The type of conditions that are of most concern are those that affect the chances of human survival. These would include any hazards that present a risk of disease or mortality to the population. The factors that influence the type of response to environmental hazards are their magnitude, extent, frequency, duration, and novelty (vayda and McCay 1975).

One major hazard that threatens survival is environmental extremeness. This refers particularly to environments that are extremely cold, hot, dry, or wet on a regular basis (Low 1990). They may also include periodic geophysical events such as floods, frosts, droughts, hurricanes, and tornadoes. A number of social events such as warfare, crime, and persecution likewise, may become extreme environmental problems (Vayda and McCay 1975).

Another major type of hazard is the risk that unpredictable variation in environmental variables, such as rainfall and subsistence resource availability, poses for subsistence satisfaction. Additionally, as periods of extremeness become more unpredictable, the magnitude of environmental risk increases (Low 1990:229). Other types of 
hazards are those that include the risks of disease, accidents, or attacks from wildlife present in ar environment (Baksh and Johnson 1990).

\section{THE CONCEPT OF MALADAPTATION}

The main difference between Bennett's model of adaptive dynamics, steward's cultural ecology, and Geertz's ecosystemic approach is the ontological significance given to the concept of adaptation. Steward's definition of adaptation does not consider whether strategies that are adaptive in the short run may not be sustainable in the long run, while Bennett and Geertz entertain this possibility. Bennett's adaptive dynamics model supports the idea that because adaptation is based to some degree on humar choice it is vulnerable to human error.

A more sophisticated analysis of the "errors" in adaptive processes is presented by Roy Rappaport (1978, 1984:422431). According to him, adaptation refers to the manner through which living systems maintain themselves or persist in the face of stresses resulting from both short-term fluctuations and long-term nonreversing changes in their natural and social environment (1984:413-417). Applying this definition, he interprets maladaptation to be that which impedes or inhibits the ability of living systems to cope with stresses. 
Rappaport (1978) refers to adaptations in terms of their cybernetic nature and their structure. According to him, adaptations occur in a self-regulating, cybernetic process. The mechanism responsible for this is a feedback system in which environmental stresses are perceived, analyzed, and responded to. He believes this process is structured according to a hierarchy of environmental monitors and managers. Individuals directly interacting with the environment comprise the bottom level. Those who manipulate the environment indirectly by controlling the behavior of individuals in the lower levels, make up the higher levels. He refers also to the structure of adaptations in terms of the patterns of environmental change they involve. Patterns range from responses that create minor and reversible environmental changes to those that generate large and permanent changes.

According to Rappaport (1978, 1984), maladaptations are closely related, if not mutually causal, disruptions of the cybernetic and structural features of the adaptive process. Impairments of feedback mechanisms include a loss, distortion, and misunderstanding of information concerning environmental stresses. These anomalies may delay or prevent adjustive responses to problems that threaten survival. Deficiencies in the structure include overresponses to problems, over-specialized use of geographical areas, and over-centralization of decision making. These 
structural flaws decrease the flexibility, and potentially, the efficacy of future responses to hardships, while increasing the potential of ecological problems.

\section{RESEARCH DESIGN}

I believe Bennett's (1976) adaptive dynamics approach is the anthropological perspective best suited for this study. The reason is that the objectives of this approach more closely resemble the objectives of my own research and it tends to be one of the least deterministic. A principal concern is to explain how particular land use practices originated and changed due to different environments and technologies. However, it is not enough to describe the process of adaptation, for one must also examine for aberrant trends in its mechanism, and explain their origins and consequences. For this reason, I chose to also implement Rappaport's $(1978,1984)$ concept of maladaptation in the analysis of the adaptive dynamics involved in the land use in Dade County.

In order to achieve a holistic viewpoint, I consider not only the environmental and technological context of adaptations but also the social and cognitive realms. Geology, climate, flora, and fauna represent the natural realm. Technology consists of tools and knowledge that people use to manipulate the environment, as well as the 
actual manipulative activity. Population and the Eormation and action of social groups involved in influencing decisions about land use represent the social realm. Attitudes, ideas, and perceptions about the use of the land represent the cognitive realm. Land use patterns and ethnohistoric sources provide insights into these attitudes and perceptions.

I expect to find that the sources of the environmental problems of Dade County result from anomalies in the adaptive process and structure arising from certain trends in general cultural evolution. At the technological level, the propensity towards an escalation of the manipulation of the environment and a reduction in the diversity of land use per land area leads to over-responses to problems and overspecialized uses of geographical areas. These trends prompt permanent environmental changes and a reduction in the flexibility to respond to ecological problems.

At the social level, population growth increases resource consumption and competition for access to scarce resources. Additionally, the tendency to increase centralization of social organization extends the information feedback network, increasing the number of nodes through which information must pass through before reaching the higher level decision makers, and subjects the information to disorientation or loss.

At the cognitive level, the inclination to increase the 
belief of human dominance over nature creates a bias that reduces the accuracy in perceiving both the severity of environmental stresses, and the abilities to respond to them. This allows the degradation of the environment to intensify, further exacerbating the anomalies of the adaptive process and structure.

By understanding the status of each of these realms at given times it is possible to evaluate their influence on the patterns of adaptation and their contribution to environmental change. Unfortunately, knowledge of the status of some of these realms during prehistoric or historic times is difficult, if not impossible, to obtain. For example, cognitive and social patterns may be inferred from land use patterns which are interpreted on the basis of material artifacts and other physical remains. Much of what is known about past adaptive systems is linked to subsistence and settlement (Struever 1968). Therefore, the level of analysis for prehistoric or early historic times focuses more on the technological and natural realms than the cognitive or social ones.

\section{METHODS}

My methods involve a detailed description of the natural environment and the social, technological, and cognitive aspects of land use during different time periods. Natural 
and social environment risks and hazards leading to the adaptation of specific land use strategies are identified. The responses of peoples from different periods to similar problems are compared. The strategies are analyzed to reveal both their short and long term adaptiveness. Long texm patterns are examined to identify trends that may have contributed to the current environmental problems.

There is little known about the natural environment or land use in Dade County during the Paleo-Indian and Archaic Periods. Therefore, the natural settings of the PaleoIndian Period and through most of the Archaic are described only in a broad and general way. Most of the existing data concerning environmental conditions during these periods have a regional and global focus. My depictions of the local environment for those periods are largely based on adjustments of these data for local factors.

The environment that was in place at the end of the Archaic Period (2,700 8.P.) experienced only slight changes until the beginning of the Urbanization Period (1895 A.D.). The major plant communities that existed then still exist today, but with many changes in the status of critical ecological factors such as hydrology, fire frequency, soil composition, biodiversity, and population size. In Chapter II, I provide a general overview of the Dade County natural environment along with a detailed description of these communities. This includes their original and current 
distribution along with a discussion of historical changes in the status of several critical ecological factors. A profile of the fauna associated with each plant community also is included.

I reconstruct the historic distribution of plant communities by using maps portraying the historic vegetation, and by following methods used by Scarry (1982). She relies on the close relationship between soil types and plant associations (Craighead 1971; Davis 1947) and additional information from eyewitness documentation. The historic soil distribution is based on the 1947 United States Department of Agriculture soil survey of Dade County. Eyewitness data are obtained from various sources including early explorers and botanists (Harper 1927; Harsheberger 1914; Marchmann 1947).

Land use are based mostly on literature reviews. For the Pre-Columbian Era, findings are limited to interpretations of the archaeological record of South Florida cultural groups and culture areas that extended into Dade County. For the periods of the Post-Contact Era, I rely on various publications including historical documents, government records, and other sources. These are examined for data on early settlement, population growth, local historical lifestyles and events, and many other issues related to land use. 


\section{THE SIGNIFICANCE OF THIS RESEARCH}

An examination of how land use patterns have led to the current environmental crisis in Dade county merits attention. This examination should include a critical review of human nature and of its institutionalized means of exploiting the land as a source for ever expanding economic growth. Understanding of the limits to which the environment may sustain human activity under conditions of changing population and technology is also called for. It is only through a better understanding of how humans and the natural environment affect each other that we may seek to ameliorate the current trend towards environmental degradation.

This thesis takes a first step in trying to understand the environmental problems facing Dade County today by viewing humanity and the environment as components of a larger system. The need to understand the history of how the relations between these two components have changed must not be underestimated. It is by understanding this history that we may gain insight to how particular human factors influenced the choices made and affect the ones yet to be made.

This thesis will not recommend turning back the clock so that we may live in the environment of prehistoric Dade County. We have distinct cultural and technological traits 
that prohibit us from even wanting to do so. We now have a much higher population, and each of us has expectations and desires to fulfill. Most of us have no desire to live in a wilderness, and our social system strives to fulfill our wants at the cost of the environmental degradation that threatens our long term existence. This thesis attempts to shed light on the processes of cultural adaptation so that the underlying causes of our environmental problems may be revealed. This includes not only the obvious problems such as drainage, overdevelopment, and pollution but also the more subtle factors that promote such land use practices. Some of these factors are as basic as perceiving the environment and humanity as distinct systems and that human needs supersede those of the environment. If we are to deal with the environmental problems we must understand the root of the problems. 
CEAPTER II: ENVIRONMENTAL DESCRIPTION OF DADE COUNTY

\section{BIOGEOGRAPHY}

The bedrock platform upon which Florida lies had its origins about 600 million years ago. At that time it was attached to Africa, forming part of the giant supercontinent known as Gondwanaland. It broke apart about 300 million years later, drifting around the oceans for another 80 million years until it became attached to the North American continent along the border of Georgia (Webb 1990). South Florida was submerged various times for extended periods of time during its geological history (Haq et al. 1987). Changes in sea level and climate conditions since then set forth a series of events that created many of the features still present in the modern Dade County natural environment. Around 100,000 B.P., South Florida was submerged under three meters of sea water. At that time, a layer of limestone, commonly known as Miami oolitic limestone, was being formed over most of the eastern coast of Dade County. This layer was produced as a result of marine chemical reactions which produced small spherical or ovoid pellets of calcium carbonate, called ooids. As the sea level fell, they solidified together into one consolidated mass, the outer layer of which was now exposed to the air. The exposed ooids hardened while those underground remained 
somewhat softer (Hoffmeister 1974). This feature of the limestone allowed early settlers to quarry the underground limestone for purposes of shaping it as desired and then allowing it to harden in the air (Webb 1990). Due to the lower sea level, the basin areas comprising Florida and Biscayne Bay also became covered with a hardened layer of oolitic limestone (Wanless 1976).

Around 17,000 B.P. global temperatures and sea levels began to rise (Fairbridge 1984). By 5,000 B.P., a warm, moist climate permitted a change to the modern South Florida flora (Long 1984). As a result of these changes, new coastal environments began to stabilize and receive fresh water drainage from the Everglades thus forming the Biscayne and Florida Bay estuarine environments. Archaeological evidence indicates South Florida human population began increasing at this time. The climate continued to change until, at around 2,700 B.P., the vegetation reached its present distribution, and the bay estuaries were fully formed and highly productive (Griffin 1988).

\section{SEA LEVEL CHANGES}

Around 18,000 B.P., the global sea level reached its lowest point in recent geological times at an estimated level of 135 meters below the present mean sea level (Fairbridge 1984). It is generally accepted that the global 
sea level rise during 17,000 to 6,000 B.P. Cof approximately one meter per century), is the fastest sea level rise in the geological record (Milliman and Emery 1968). The data that are disputed are the exact times and rates of sea level change during the Holocene Period (10,000 B.P. to present). In addition, different coastlines from around the world undergo distinctive sea level fluctuations due to variation in local factors (Bloom 1983). Although there are numerous interpretations of Holocene Period sea level fluctuations, only a few are based on data collected from South Florida. The interpretations of the South Florida sea level changes based on those studies are presented in Table 1 and discussed below.

Studies based on radiocarbon dates from peat deposits along the southwest coast of Florida indicate that the sea level rose continuously to the present time, but that the rate of rise decreased with time. Although the studies suggest that fluctuations above the current sea level did not occur, researchers do not discard this possibility (Scholl and Stuiver 1967; Scholl et al. 1969). Fairbridge (1974, 1984) synthesized geomorphological data and radiocarbon dates of coastal features from around the world, including Florida, for his estimate of South Florida sea level changes. According to these studies, the sea level has fluctuated to points above and below the current sea level several times since 6,000 B.P. Robbin (1984) 
Table $1 \mathrm{~A}$ few interpretations of South Florida sea level changes of the Holocene.

\begin{tabular}{|c|c|c|c|c|}
\hline YEARS B.P & $\begin{array}{c}\text { Scholl et al } \\
\text { (1969) }\end{array}$ & $\begin{array}{c}\text { Fairbridge } \\
\text { (1974) }\end{array}$ & $\begin{array}{l}\text { Robbin } \\
(1984)\end{array}$ & $\begin{array}{c}\text { Stapor et al. } \\
\quad(1991)\end{array}$ \\
\hline 14000 & & & -9.2 & \\
\hline 13000 & & & -8.9 & \\
\hline 12000 & & & -8.6 & \\
\hline 11000 & & & -8.3 & \\
\hline 10000 & & -32 & -8 & \\
\hline 9000 & & -14 & -7.7 & \\
\hline 8000 & & -16 & -7.4 & \\
\hline 7000 & -4 & -6 & -7 & \\
\hline 6000 & -3.5 & 0 & -5.8 & \\
\hline 5000 & -2.5 & +3 & -4.6 & \\
\hline 4000 & -1.5 & +2 & -3.4 & \\
\hline 3000 & -1 & -3 & -2.2 & -.6 \\
\hline 2500 & -.75 & -2.5 & -1.6 & -.6 \\
\hline 2000 & -.5 & -2 & -.75 & +1.2 \\
\hline 1500 & -.4 & -.5 & -.6 & -.5 \\
\hline 1000 & -.25 & +1 & -.45 & +.3 \\
\hline 500 & -.13 & -.5 & -.3 & -.3 \\
\hline 0 & 0 & 0 & 0 & 0 \\
\hline
\end{tabular}


developed a model based on dating of peat deposics along the southeast coast of Florida. According to his study, the rate of sea level rise has fluctuated in a slow-fast-slow trend beginning 14,000 years ago never exceeding current levels. He estimates a $0.3 \mathrm{~mm} / \mathrm{yr}$ rise $(14,000$ to 7,000 B.P.) followed by a faster rate of $1.2 \mathrm{~mm} / \mathrm{yr}(7,000$ to 2,000 B.P.), then a return to a $.3 \mathrm{~mm} / \mathrm{yr}$ rise $(2,000 \mathrm{~B} . \mathrm{P}$. to present).

Most sea level variability studies, including those described above, focus on broad time resolutions of a thousand or more years. An exception to this trend are the studies of Missimer (1973) and Stapor et al. (1991), based on radiocarbon dating, geomorphology, and the elevation of beach ridges of barrier islands along Florida's southwest coast. The results of these studies indicate that the sea level in South Florida fluctuated above and below the current levels several times since 3,000 B.P. The findings of these studies are similar to Tanner's (1991) sea level change model for the Gulf of Mexico. Despite the disagreement concerning past sea level rises, there is a strong consensus with regard to recent changes in sea level. Several scientists agree that the global sea level has been rising at a rate of about $1-2 \mathrm{~mm} / \mathrm{yr}$ during the last century (Gornitz et al. 1982; Warrick and Oerlemans 1990; Woodworth $1990)$ 


\section{CLIMATE}

The climate of most of Dade County is subtropical, with exception of the southern tip of the peninsula, which is tropical (Fernald and Purdum 1992). The annual average temperature of Dade County is 75- $\mathrm{F}$. The mean daily maximum

summer temperatures are around $91 \mathrm{~F}$, while in winter they range between $75-79^{\prime} \mathrm{F}$. Relative humidity averages about 70 percent and winds are light to moderate under normal conditions. The average rainfall is about 59 inches per year. In general, the rainfall is seasonally distributed with most of it occurring between June and october. The rainy season is a little longer in the Everglades. Periodic variations from the average climatic conditions are also normal in Dade County. Some of the most common fluctuations in the climate include periods of drought coupled with increased average temperatures, seasonal hurricanes and tropical storms, and freezing temperatures. These periodic fluctuations may lead to stressful conditions for vegetation (Chen and Gerber 1990).

Droughts are most common in spring, at the end of the dry season (Ibid 1990). They can increase fire frequency and reduce the water table of the Biscayne aquifer. The reduced water table increases the probability for salt water intrusion near the coast (Kreitman and Wedderburn 1984) and hyper-salinity in brackish waters (Griffin 1988). 
Between 1871 to 1964 an average of 4.6 hurricanes per year have struck in the Caribbean area (Alaka 1976). The frequency of hurricanes in this area structures natural ecosystems (Walker et al. 1991). A study in South Carolina found that pines, oaks, and cypress were some of the most common vegetation in areas where hurricane frequency is highest (Gresham et al. 1991). That is not to say that hurricanes do not affect these trees, for population abundance and size structures are affected by hurricanes (Belnigham 1991).

Freezes are infrequent natural events in Dade County. In recent times, most of the concerr has been with the sensitivity of commercial citrus plants. However, given the decreasing populations of the original vegetation, their susceptibility to cold-induced damage is also a concern. Some of the more freeze-sensitive original vegetation, listed in order of decreasing sensitivity, includes the manchineel (Hippomane mancinela), guava (Psidium guajava). cocoplum (Chrysobalanus icaco), buttonwood (Conocarpus erectus), and fig trees (Ficus spp.). The mangrove species are also sensitive to freezes, the white mangrove being the most sensitive (Craighead 1971). The freezes tend to limit the tree size and distribution. The more tropical species tend to remain smaller in the northern extreme of their distribution, and larger in the southern extreme (Myers 1986). 
Freezes also affect some animal populations. In general mammals are the best suited to survive in the cold weather. The manatee (Trichecus manatus) is the most cold sensitive mammal. Some of the animals most sensitive to the cold are fishes. Since 1856, cold-induced fish kills in the Biscayne Bay have occurred at the rate of one every ten years (Myers $1986)$

\section{PHYSIOGRAFHIC REGIONS AND GEOGRAFHICAL ZONES}

Several authors have proposed classifications of the modern physiographic regions for South Florida (Brooks 1981; Craighead 1971; Davis 1943; White 1970). The main factors considered in distinguishing the different regions include local geology, soil, elevation, hydrology, and salinity. The flora and fauna are greatly influenced by these factors and their characteristic presence is the basis of the naming of the physiographic regions.

The categories for physiographic regions described in this thesis are largely adapted from White's (1970) map of the physiographic regions of South Florida. He differentiates four major regions within Dade County; these include the Everglades, Atlantic Coastal Ridge, Southern slope, and Big Cypress spur. I have slightly modified this scheme to more accurately depict Dade County by considering only the section of the Atlantic Coastal Ridge that falls in 
Dade County (the section usually referred to as the Miami Rock Ridge), and also adding the Biscayne Bay, Coastal regions, and Atlantic ocean. The addition of these three new regions is vital for completing the description of the land types that comprise Dade County. Although the Atlantic Ocean does not lie within the boundaries of Dade County, lower sea levels during the Pre-Columbian Era made it accessible to human groups that presided in the county area. Even today, the ocean is used for deep sea fishing, scuba diving, and other recreational activities, representing an economic resource for the county. The physiographic regions described in this thesis are illustrated in Figure 2. The topographic profile from the barrier islands to the western boundary of Dade County is presented in Figure 3.

Throughout this thesis, I also refer to the coastal and inland geographical zones. The classification of these zones is based on the proximity of particular locations to the shoreline. During the paleo-Indian to the middle Archaic Periods, the shoreline and coastal zone were located farther east then at present due to a lower sea level. There are two known sites that were occupied during this time of lower sea level. One is the old Cutler fossil site, which although now almost directly on the shoreline, was then located over 12 kilometers. to its west. The other site was about 17 kilometers farther west, near what is now the Monkey Jungle recreation park in south Dade. Since 
Figure 2 Physiographic Regions of Dade County
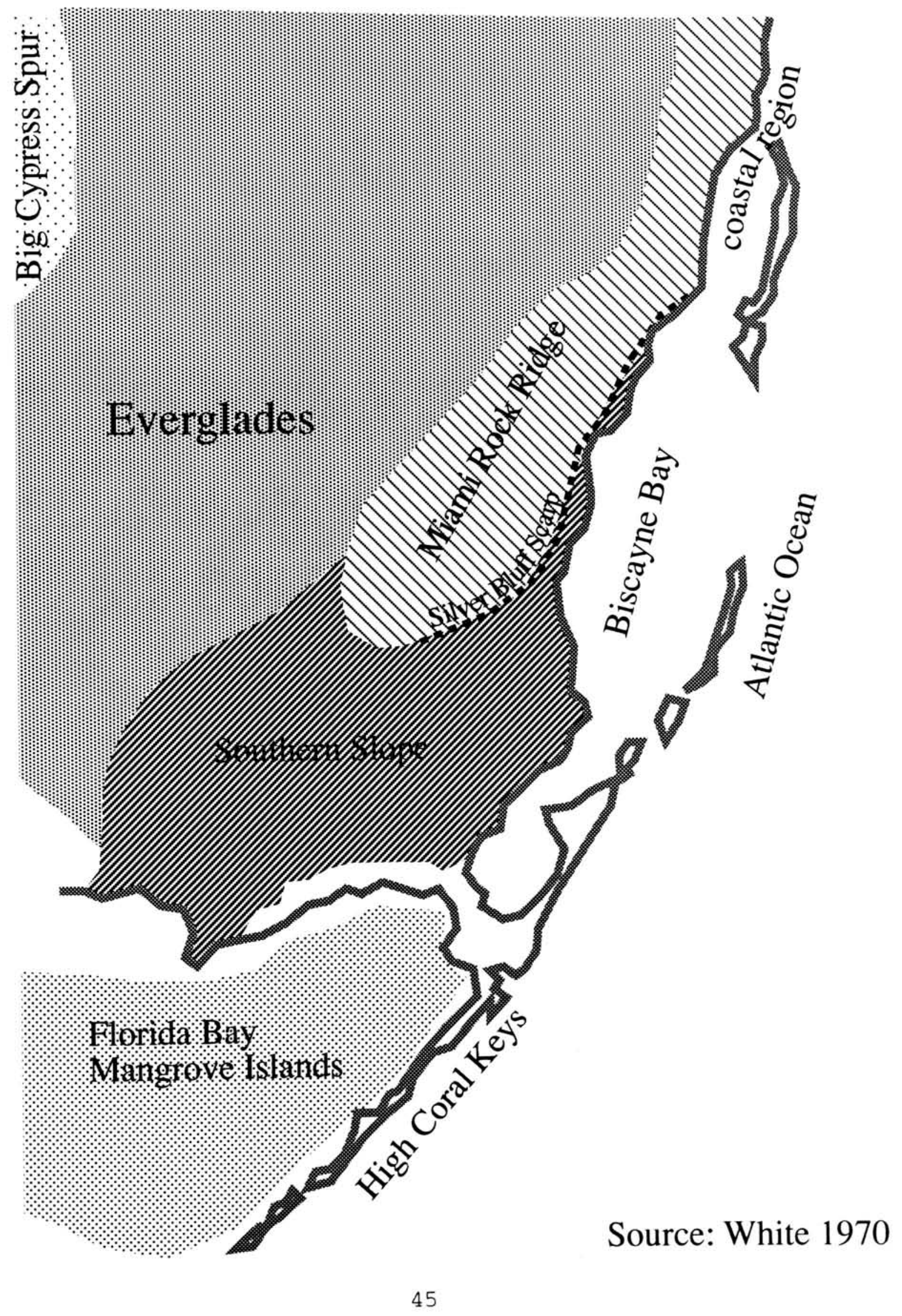

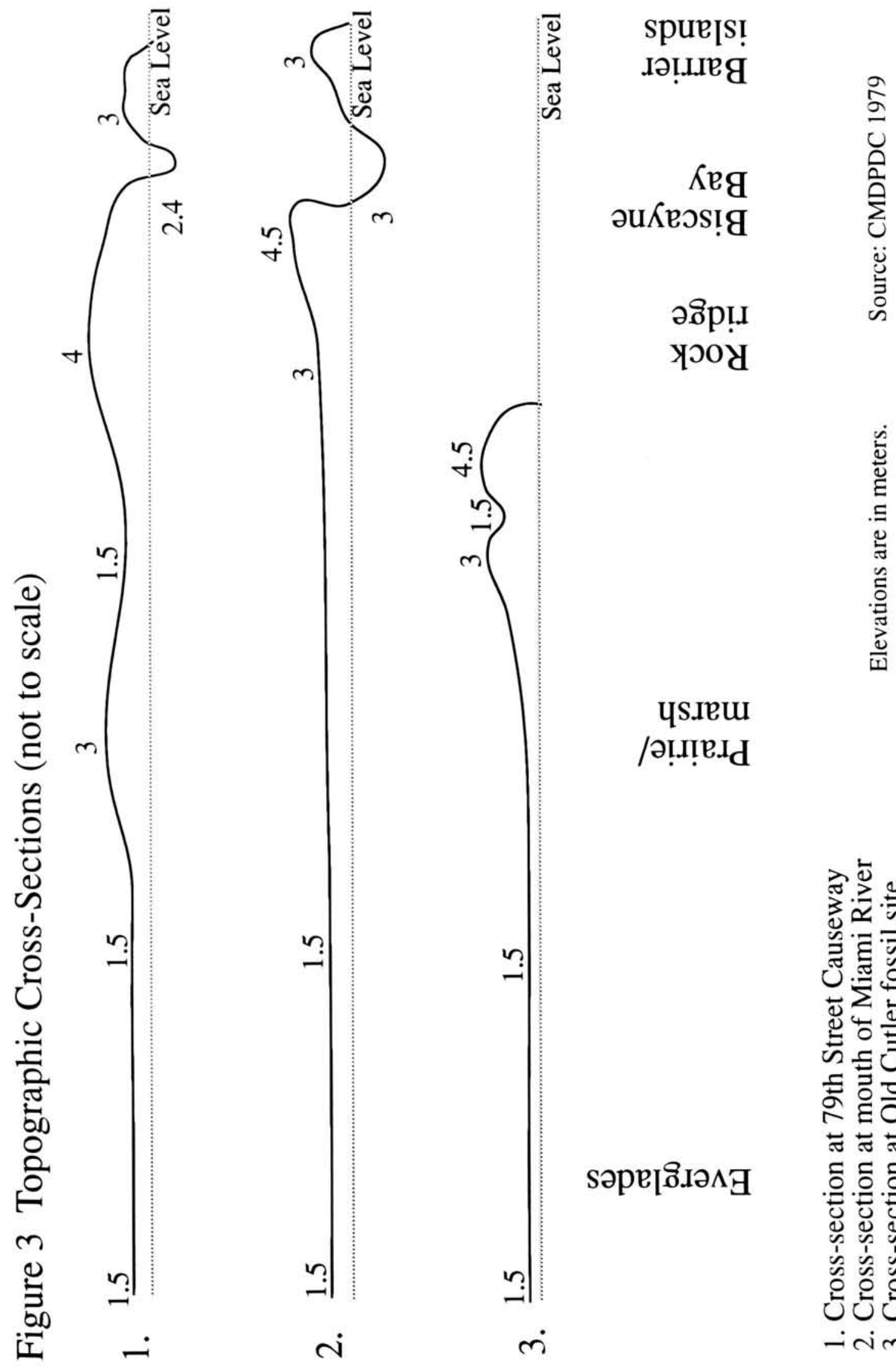

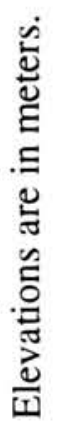

USITUU

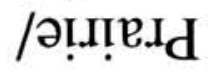

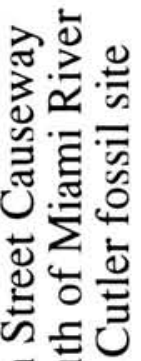

동흐음

츄

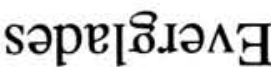

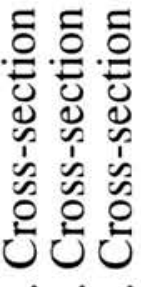

- ता 
these sites were then located well west of the shoreline, they are considered to have lied in an inland zone. During all other periods, the coastal zone is defined as the area east of, and on, the seaward sloping side of the Miami Rock Ridge. The inland zone includes all lands on and west of the western sloping side of the ridge.

\section{SOILS}

The reconstruction of the historic environments is based on correlating the historic soil distribution with the plant associations of the different soil types. This technique relies on the historic U.S.D.A. soil survey of 1947. The soil names have changed since the survey was conducted. Some of the changes reflect a change in soil types resulting from the process of grinding the limestone subsurface with rock plows, a technique referred to as "scarification." other name changes represent a more particular differentiation between soil types. The different plant communities and urban activities associated with the historic and modern soils are listed in Table 2. The soils are listed according to their historic and modern names and placed into their taxonomic orders. This chart is not intended to be comprehensive of all the soil types found in the county. Instead, it lists only the predominant soil types found in the terrestrial physiographic regions 


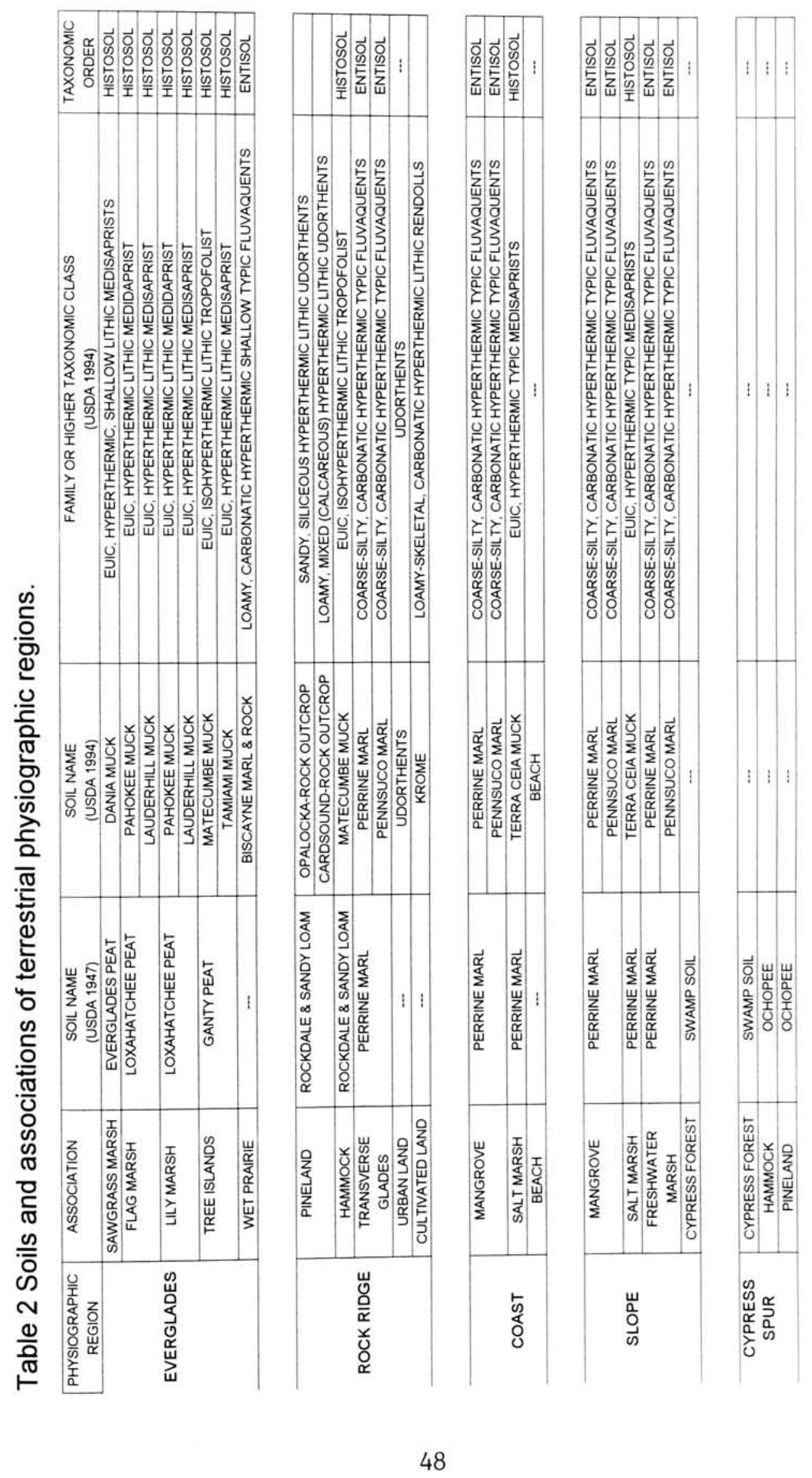


detailed in this study.

The soils found in Dade County are representative mainly of the Entisol and Histosol orders. The soils associated with the excavation of canals, rock quarries, or lakes are classified into the Udorthent soil series, which have not yet been assigned to a taxonomic class or order (U.S.D.A. 1994). The majority of the natural soils in the county are classified as Entisols. They have few gtratigraphic levels and may vary in degree of wetness, depth to bedrock, and natuxe of parent materials. Histosols are wet soils composed mostly of organic materials, such as peat and muck (Brown et al. 1990).

\section{VEGETATION COMMUNITIES OF PHYSIOGRAPHIC REGIONS}

The plant community categories were adapted in large part from the South Florida vegetation maps of McPherson et al. (1976) and Davis (1943). The categories I use in this thesis include: freshwater marshes, tree islands, hammocks, pinelands, cypress forests, mangroves, saltwater marshes, beach strands, and seagrass estuaries. The distribution of the vegetation prior to urban development is illustrated in Figure 4 .

Throughout Dade County, the majority of the fauna is of North American origin with some west Indies influence. The bird populations in general and hammock flora in particular 
have the highest degree of west Indian or tropical influence. It would be impossible to list all the abiotic and biotic characteristics of each of these communities. Therefore, I will discuss the most characteristic features of each, including some of the more distinguishing geological and topographic features and some of the most common or endemic plant and animal species.

Several of the floral and faunal resources found in each community have been or are currently of importance to humans. Some of the more important biotic resources along with their common habitats and a general description of their use are listed in Table 3.

\section{Everglades Region}

The Everglades area is the main physiographic region of South Florida and a major portion of Dade County. The elevation of the Everglades varies from about six meters above sea level at the southern edge of the Lake Okeechobee down to sea level at the southern tip of the peninsula (Griffin 1988:13). Its geology consists of a layer of permeable limestone that formed on top of a bedrock basin which extends from Lake okeechobee to Cape Sable. The portion of this region that falls within Dade County extends from the Broward-Dade county line in the north to the edge of Florida Bay in the south (White 1970). It is bordered on the east 
Figure 4 Historic Vegetative Communities of Dade County

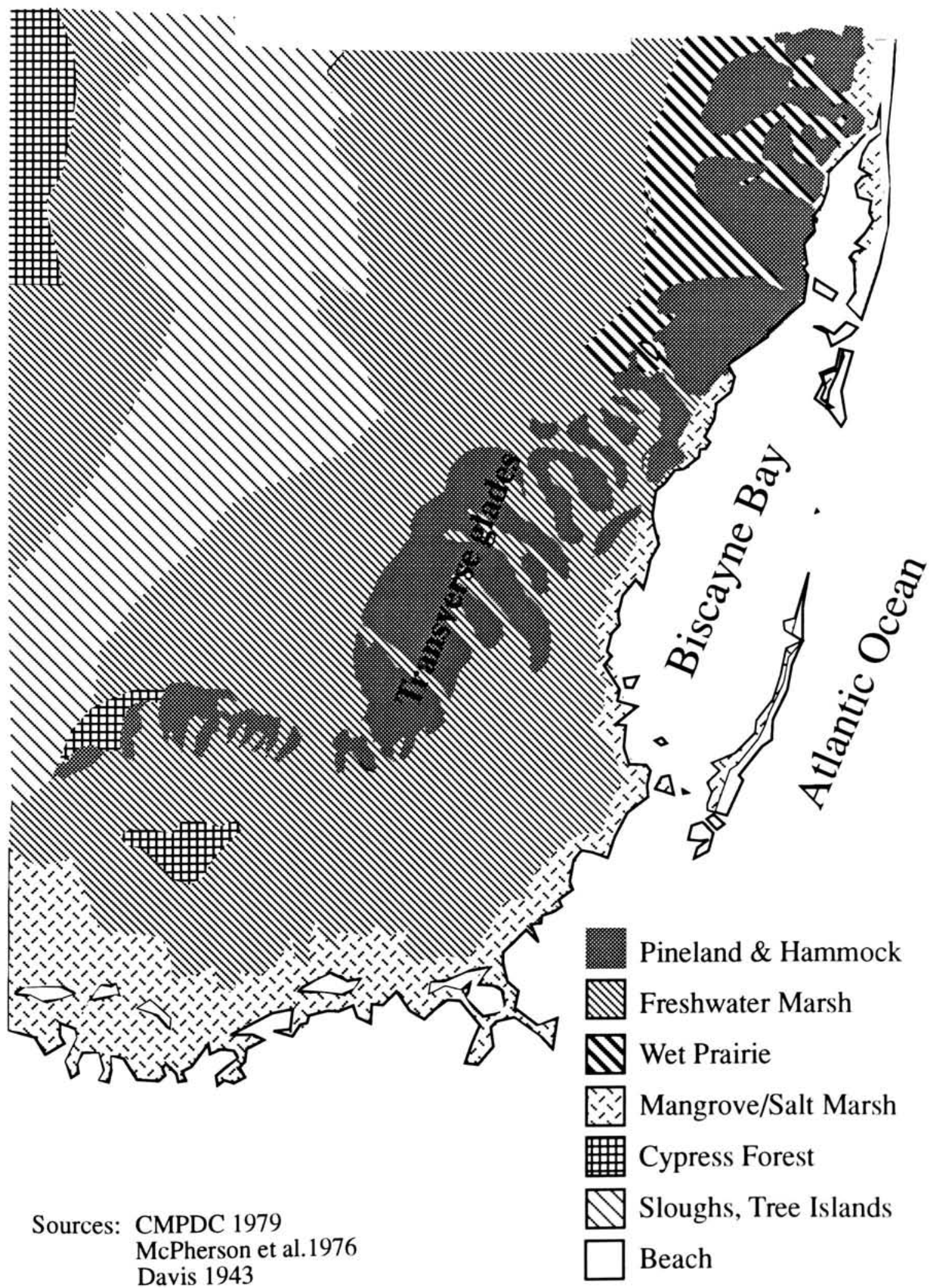




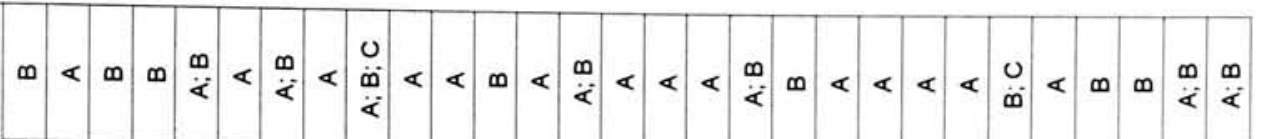

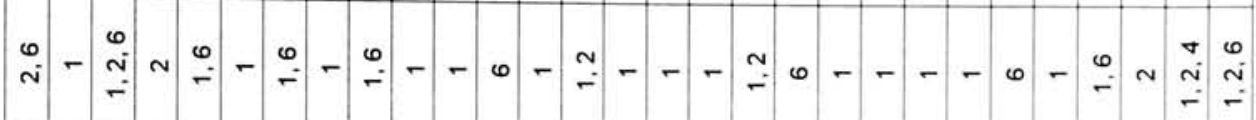

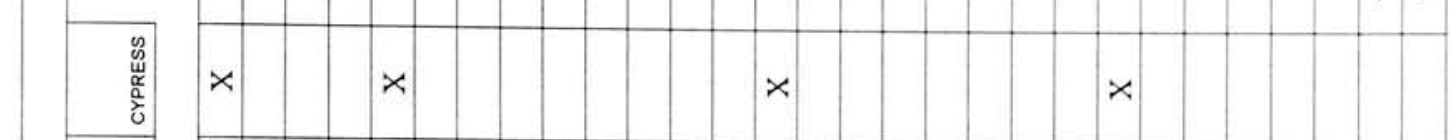
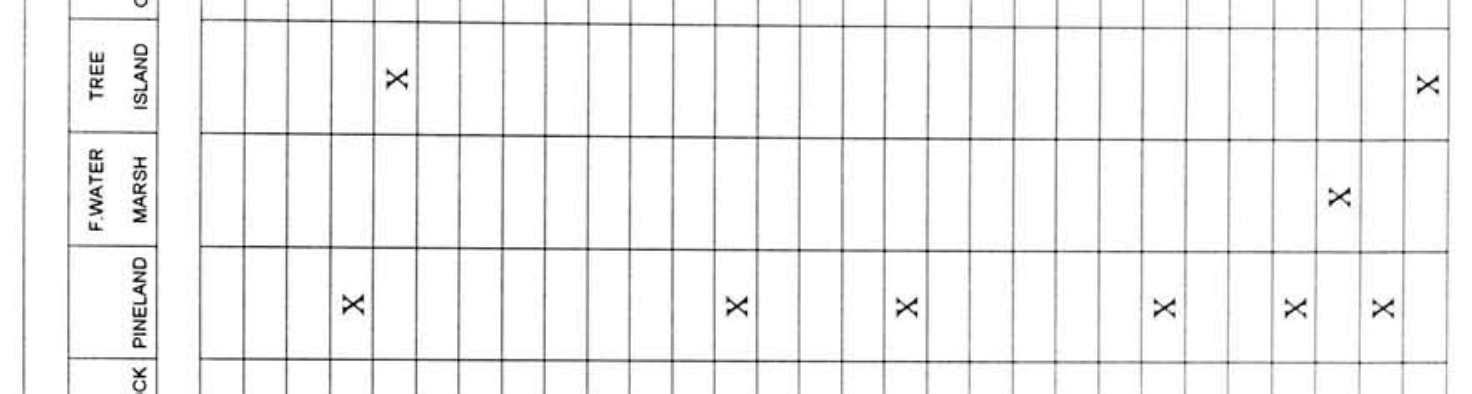

\begin{tabular}{|c|c|c|c|c|c|c|c|c|c|c|c|c|c|c|c|c|}
\hline$\stackrel{n}{\llcorner}$ & $\frac{\sum_{x}^{\underline{x}}}{\underline{x}}$ & $x$ & $x$ & $x$ & $x$ & $x$ & $x$ & $x$ & $x$ & $x ;$ & $x \times$ & $x$ & $x$ & $x$ & $x$ & $x$ \\
\hline 产 & 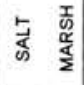 & $x$ & $x$ & & & & & & & & & & & & & \\
\hline
\end{tabular}

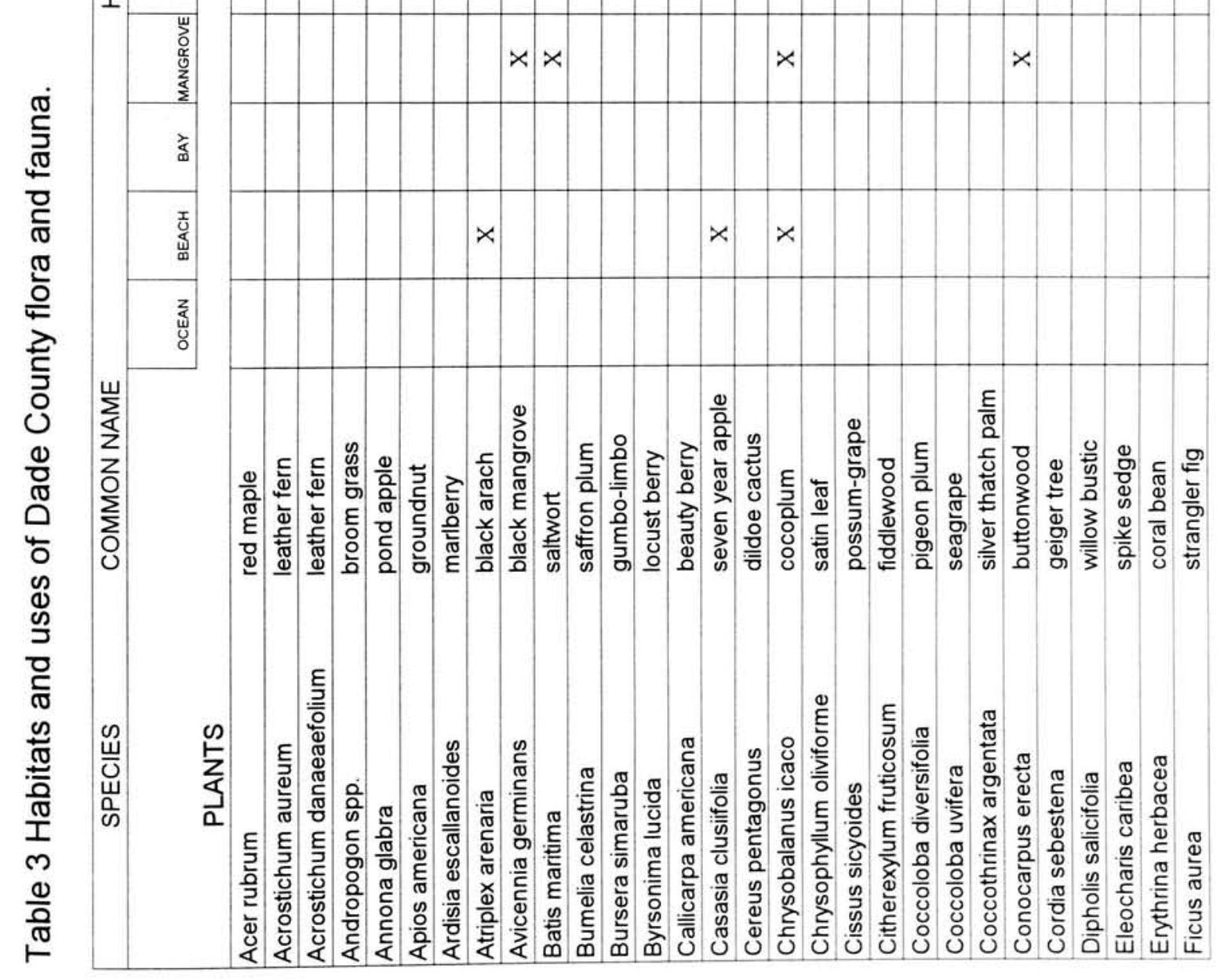




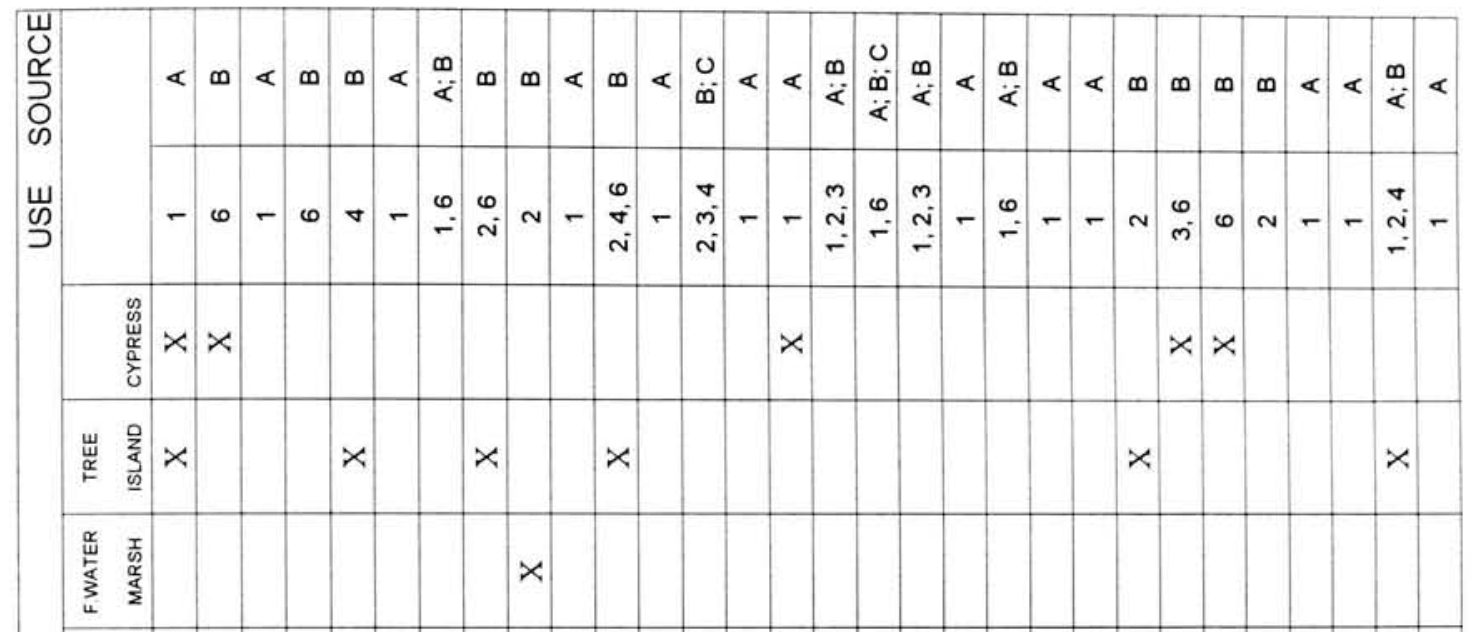

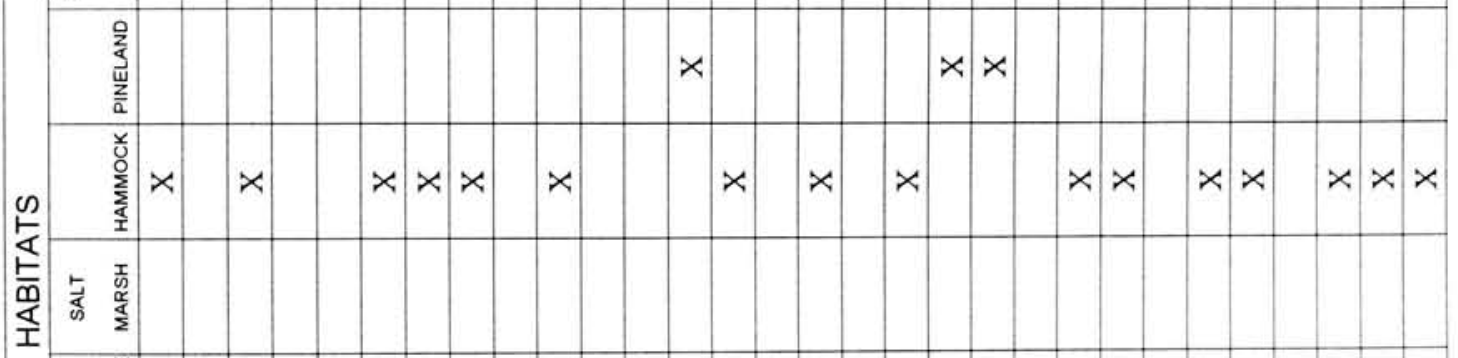

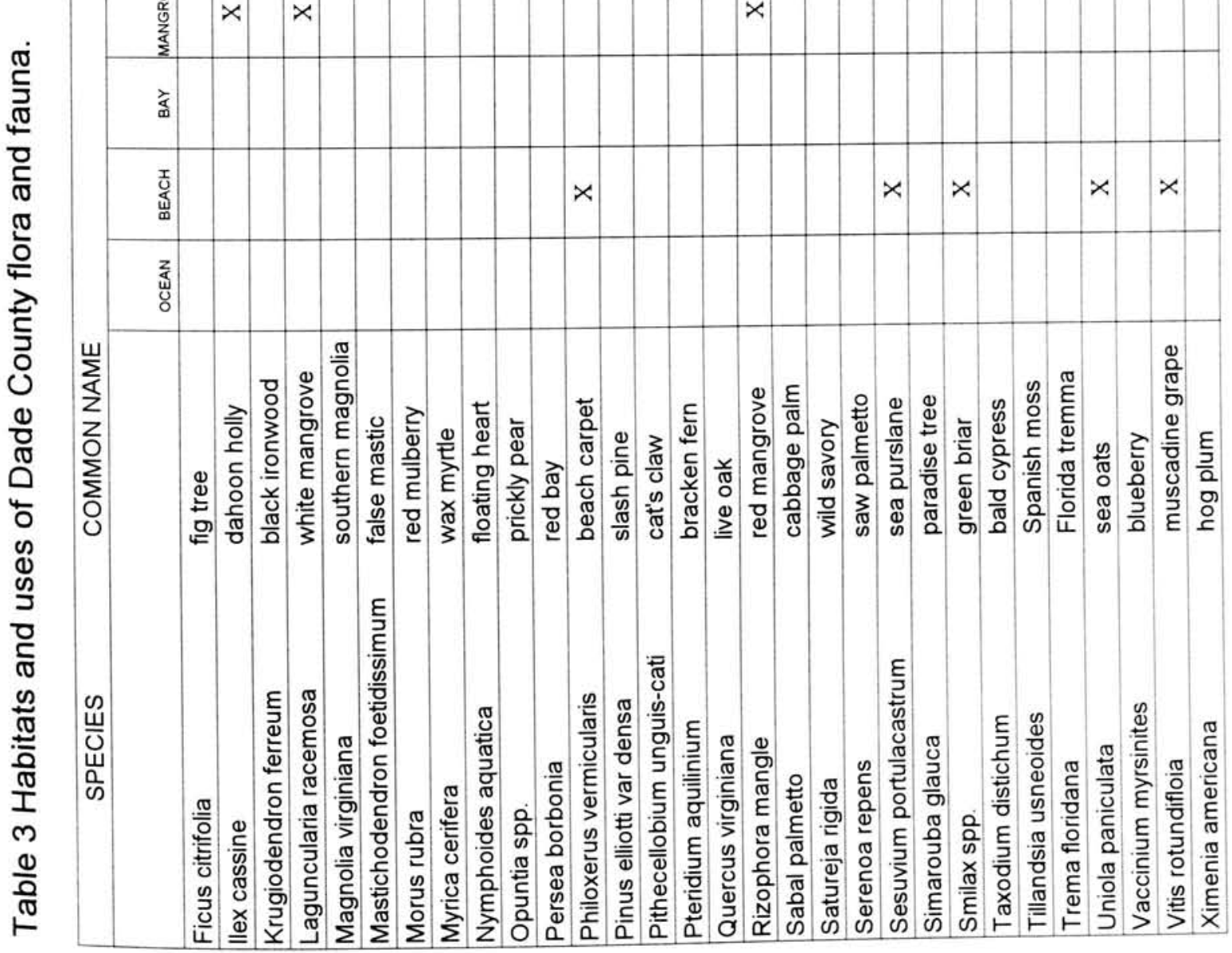




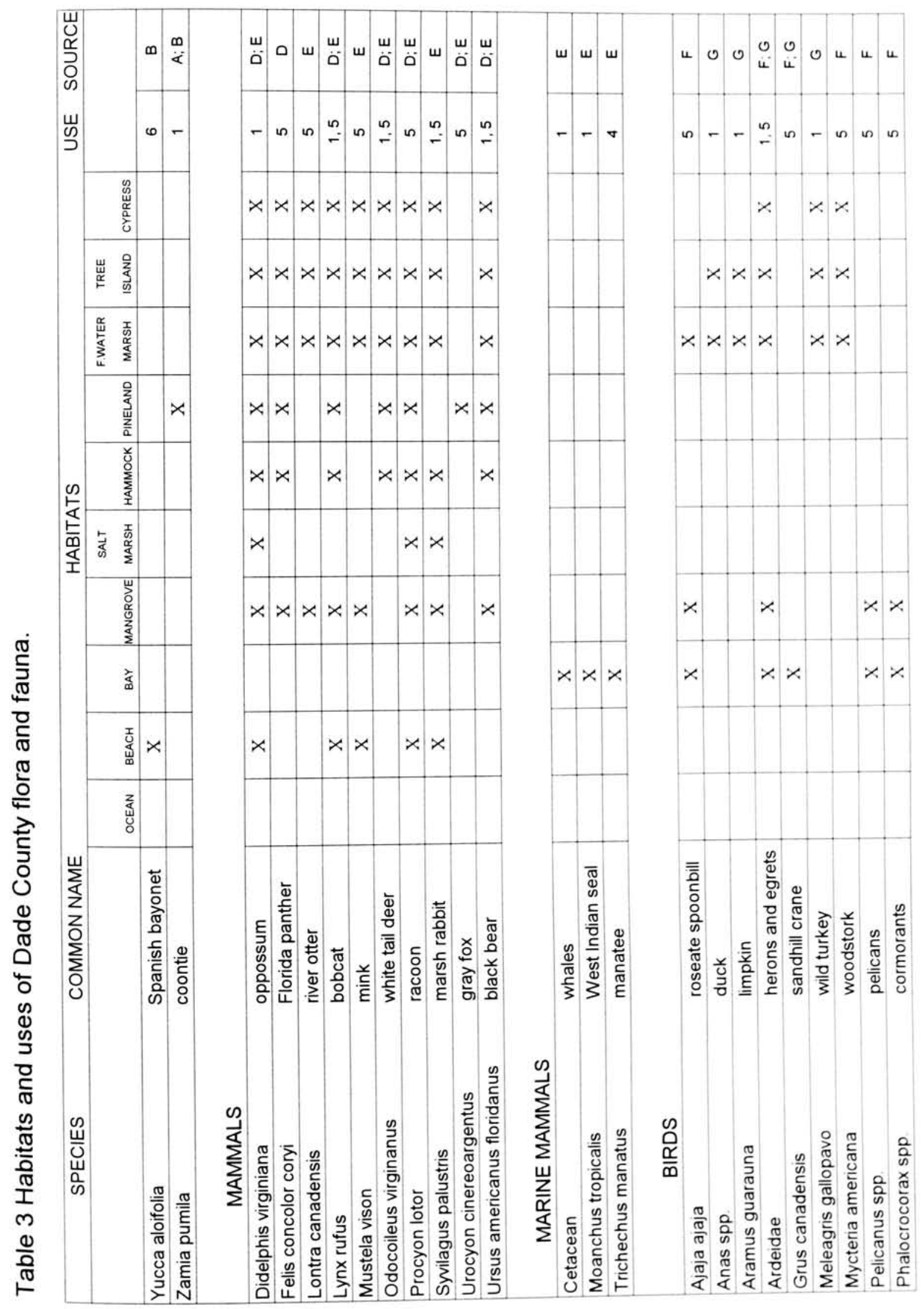




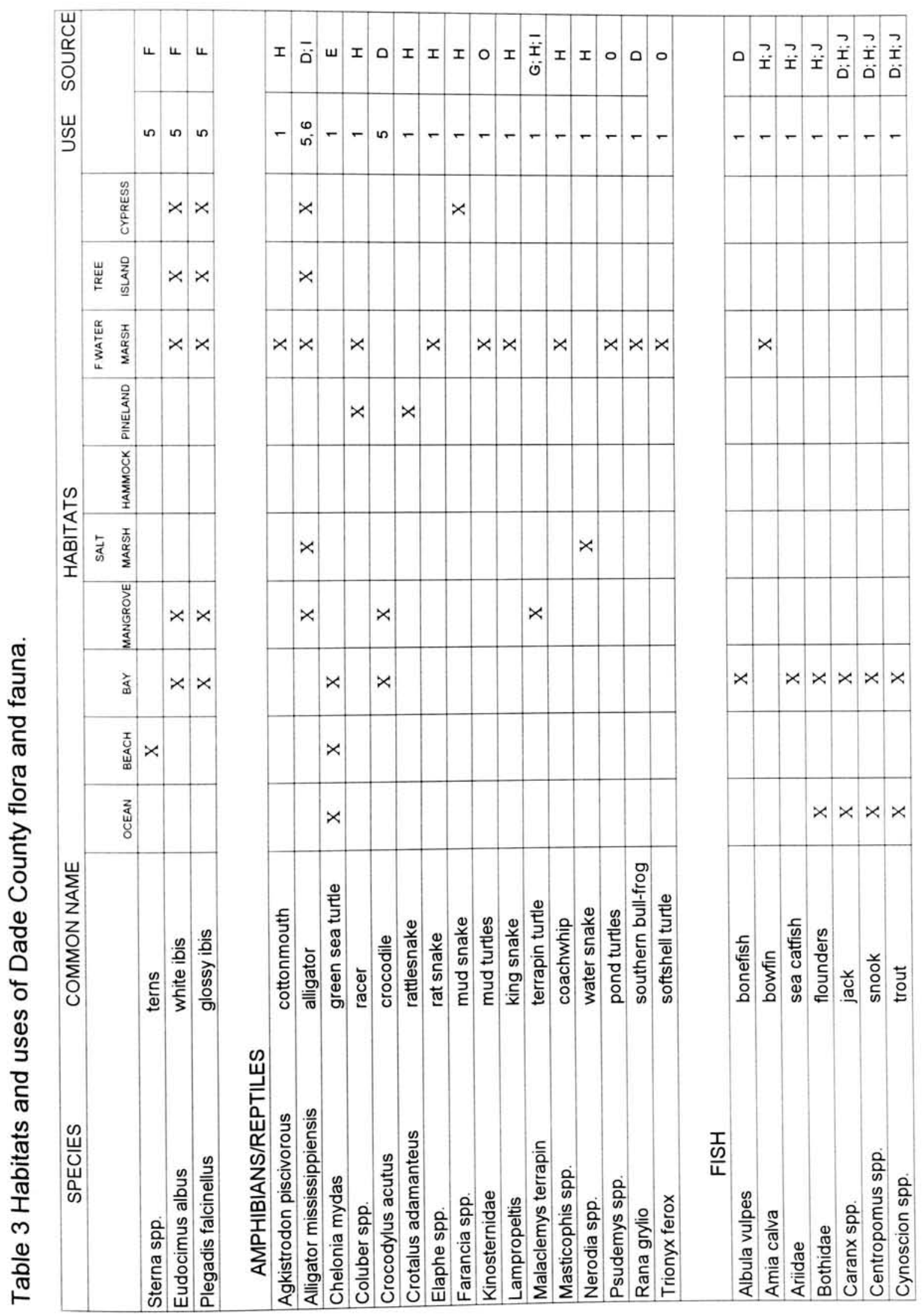




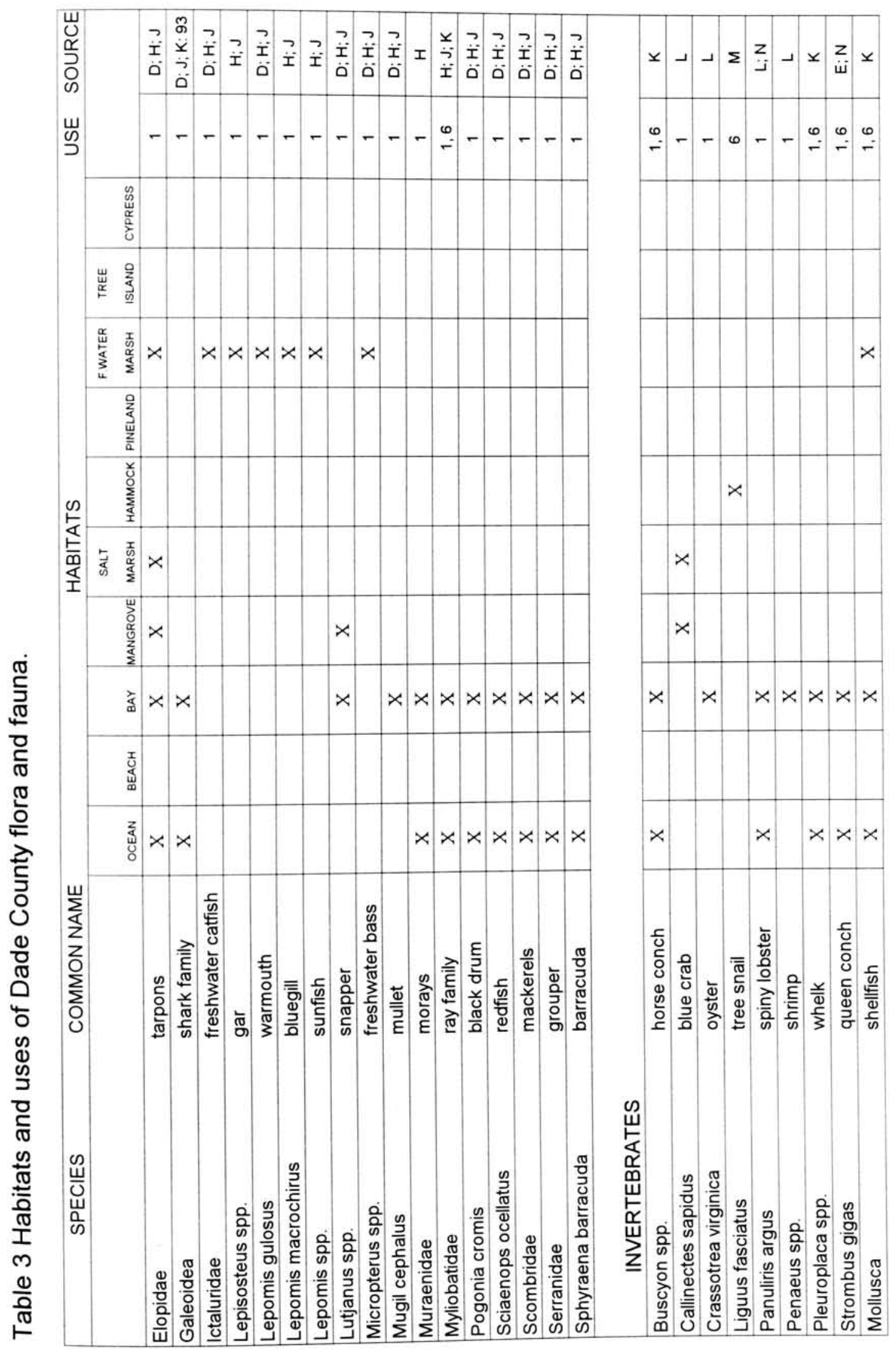




\section{$\underline{\text { NOTES FOR TABLE } 3}$}

The flora and fauna listed in table 3 are not meant to be exhaustive. They do not include exotic species and represent only the species whose use is most commonly referenced. References to edible plants by Scarry (1982) represent a "potential" use of plants backed up with paleoethnobotanical evidence of their prehistoric or historic presence. The animals that are listed are those for which a use is known, or for where there is strong archaeological evidence of their use.

\section{$\underline{\text { CODES FOR TABLE } 3}$}

USE:

1: food; 2 : medicine; 3 : construction; 4: ceremony, myth, religion; 5 : skins, plumes, pelts, hides; 6 : other

\section{SOURCES:}

A: Scarry 1982; B: Sturtevant 1955; C: Harper 1927; D: Davis 1943; E: Larson 1980; F: Paige 1986; G: Marchmann 1947; H: Wing and Louck 1982; I: Kersey 1975; J: Francis 1966; K: Griffin 1988; L: Montague and Wiegert 1990;

M: Snyder et al. 1990; N: Livingston 1990; O: Masson and Hale 1991 
By the Miami Rock Ridge and to the west by the Dade-Monroe county line and the southeastern tip of the Big Cypress. It is mainly a flat, nearly treeless region with freshwater marshes and wet prairies with many scattered clumps of trees growing on slightly elevated ground (Davis 1943:241). The soil profile of this region indicates the continuous deposition of peat over approximately the last 2,700 years, preceded by alternating layers of peat and Perrine marl (Altschuler et al. 1983). The U.S.D.A. (1947) soil charts identified Everglades, Gandy, and Loxahatchee peat in the Dade County portion of the Everglades region. These soil types have poor drainage and a nearly neutral $\mathrm{pH}$. The most common was the Everglades peat, which is associated with sawgrass (Cladium jamaicensis), wax myrtle (Myrica cerifera), and sedges (Cyperaceae). Loxahatchee peat was found more frequently on the western edge of the Everglades region, near the shark River slough. Its plant associations include arrowhead (Sagittaria latifolia), sawgrass, and several sedges. Ganty peat was found on tree islands. It is associated with white bay, wax myrtle, small fig (Ficus spp.) trees, and ferns.

Scarry (1982) does not believe marshes provided humans with many edible plants. However, cattail (Typha spp.), Thalia, Cladium, and Sagittaria have edible parts and may have been some of the few important starch resources available to the Archaic and Formative Period residents. In 
addition, Table 3 indicates that many animals used by humans are associated with marshes. The tree islands of this region have long been connected with the settlement of humans. Unfortunately, due to the lack of ethnobotanical. studies of this habitat, very little is known about how people used the surrounding vegetation. However, sturtevant (1955) has documented the use of several plants by the Miccosukee of the Big Cypress reservation. Many of these plants are also present in the tree islands in this region. Some of these plants and their uses are listed in Table 3.

\section{Marsh flora and Eauna}

Based on the dating of peat deposits, it is likely that the Everglades region has been largely represented by freshwater marshes over the last 2,700 years (Altschuler et al. 1983). Marshes are shallow water comunities with extensive vegetation in which emergent plants are dominant and submergent plants are abundant. Marshes result from inundation or the conversion of shallow ponds and lakes (Pritchard 1978:xi-xii). There are several types of plant associations in the Everglades marshes. Some of these include wet prairies and sawgrass, water lily, and flag marshes. Sawgrass marsh was and still is the predominant Everglades plant community. The overlap between the marshes is so great that any one of them may include portions of any of the other marshes (Hartman 1978:xv). All freshwater 
marshes share similar general appearances, species composition, and limiting factors. However, differences in the timing and extent of water level fluctuations play a major role in determining the biotic characteristics (particularly vegetation composition and animal feeding and reproductive patterns) of specific freshwater marsh communities (Kushlan 1990).

The Shark River slough is the main area associated with sawgrass marshes. Their nearly contiguous growth pattern forms a southwesterly arch down the center of the county from the Dade-Broward county line towards Whitewater Bay. They require a hydroperiod (yearly time period of standing in at least 2-3 inches of watery of 6 to 9 months. Their peat accumulation fluctuates between levels below and above one meter (Kushlan 1990). Fire has been consistently frequent in prehistoric sawgrass marshes (Cohen 1984). In fact, fire helps preserve sawgrass marshes (Craighead 1971). Wet prairie marshes were historically found in the Everglades region directly west of the northern extent of the Miami Rock Ridge (Davis 1943), but today much of this area is developed. They require the shortest hydroperiod and are the most vegetationally diverse of the marsh types (Kushlan 1990). Long (1984) identified 172 species of plants in this type of community. In natural conditions, wet prairie marshes have the highest fire frequency and lowest levels of peat accumulation of any of the marshes. 
Some of the dominant species include maidencane (Panicum hemitomon) and cordgrass (Spartina bakeri) (Kushlan 1990).

The Flag marsh community requires a similar hydroperiod and in ideal conditions have a similar amount of peat accumulation as that of sawgrass marshes. It grows in shallow ponds and sloughs. Plants with flag-like leaves like pickerelweed (Pontedaria lanceolata) and arrowhead, and rushes like spikerush (Eleocharis spp.) and bulrush (Scirpis spp.) dominate (Ibid 1990).

The water lily marsh is usually the deepest water marsh in which floating-leaf plants, including the white water lily (Nymphea odorata), are dominant. Due to its occurrence in deeper marshes, it has the lowest fire frequency of all marshes. Historically, it grew along natural bodies of water like ponds, sloughs, cypress swamps, and streams. Today, it also grows along man made bodies of water including rivers, and flooded water conservation areas (Ibid $1990\rangle$.

The largest percentage of animal diversity associated with marshes is represented by birds, followed by fish, reptiles and amphibians, and mamals. Mamuals and birds can forage in the shallow marshes and settle in the tree islands. An exceptionally large population of birds results from the combination of permanent residents and migratory species. The majority of the bird species are fish eaters that forage in the marshes. Historically, the most common 
birds have included various species and varieties of herons and egrets (Ardeidae family), and ibises (Threskiornithridae family) (Beard 1938:6-7). Several raptor frequent the marshes, including the bald eagle (Haliaeetus leuccocephalus) and snail kite (Rostrhamus sociabilis), which is also known as Everglades kite (Migliaccio 1985).

A review of the collection of fish in the entire Everglades region over a 12 year span documented only 43 species (Dineen 1984). This study found the majority of the fish to be small and living within the marshy areas while most of the larger fish were new to this environment, located mainly in the drainage canals and riverbanks. One of the largest families of little fish represented were the killifishes (Cyprinodontidae family). Some of the more common of the larger species included the members of the catfish family (Ictaluridae) and gar (Lepisosteus spp.). These marshes probably lacked large fish prior to the dredging of canals due to the absence of large and easily navigable waters.

Most of the manmals associated with marshes today are small and found in shallow marshes. This would include the round-tajl muskrat (Neofiber alleni) and marsh rabbits (Sylvilagus palustris) (Layne 1984). In the past, marshes supported the then much larger populations of black bear (Ursus americanus floridanus), and white tail deer (Odocoileus virginanus). The reptiles and amphibians are 
also common to the shallow marshes, including the American alligator (Alligator mississippiensis), cottonmouth water moccasins (Agkistrodon piscivirous), and pig frog (Rana grylio) (Kushlan 1990).

In addition to the wildlife, an abundance of a few pesty invertebrate species such as the mosquito, gnat, deerfly, and horsefly inhabit the marshes (Kushlan 1990). Additionally, the explorer James Pierce, in his expedition across the Everglades, made note of the abundance throughout the Everglades of an "alligator flea" whose bite caused as much pain as a hornet's sting loriginally in Pierce 1825 , reproduced in Marchmann 1947:26). Unfortunately, I have not been able to identify the species to which he refers.

\section{Tree island flora and fauna}

In addition to the marsh habitats, the Everglades region includes several scattered areas of higher elevation. I refer to these as tree islands. The most outstanding characteristic of these tree islands is their teardrop shape, caused by the flow of water around them (Craighead 1984; Davis 1943:174-175). Most of the vegetation on these tree islands is found on rocky heads and is typically surrounded by sawgrass (Craighead 1984). The origin of these tree islands may be the result of the rooting of floating mats of vegetation during periods of low water levels (Stone 1977). As the peat accumulates on these 
rooted mats of vegetation, sawgrass gives way to willows (Salix spp.) and eventually to bays (Persea borbonia and Magnolia virginiana), wax myrtle, cocoplum, and dahoon holly (Ilex cassine), and finally to a fully developed hammock tree island (Migliaccio 1985). The composition of animals in tree islands is almost the same as that of the marshes since animals that forage in the marshes tend to use the tree islands for shelter.

\section{Changes to the Everglades}

Many of the major problems in the environment of the Everglades region have been associated with changes of its natural hydrology. The alteration of the natural fire frequency, introduction of exotics, and contamination from agricultural fertilizers and pesticides have also created severe problems. As a result of these and other activities related to human population growth, several plants and animals of the Everglades region are currently threatened or endangered (most are listed in the series of pritchard 1978).

Early efforts to drain the area began in the late $1800^{\prime} \mathrm{s}$ with the development of a canal from Lake Okeechobee to the Gulf coast (Paige 1986:142). By 1909, dredges cut into the Everglades, and through the falls of the Miami River, emptying the water into the Atlantic Ocean Griffin 1979:2829). Drainage of the Everglades has been the single largest 
cause of marsh loss. In Dade County, the wet prairie and sawgrass marshes of the eastern Everglades have been particularly reduced as the result of draining (Birnhak and Crowder 1974; Hull and Meyer 1973).

The implementation of flood control and water management policies in the 1940 s greatly affected the marsh communities. For example, in the northern extreme of the county, within Conservation Area 3, swamp trees and shrubs have almost completely disappeared, and sawgrass marsh has been displaced by water lily marsh due to prescribed periods of flooding (Mcpherson 1973).

Other activities that have altered the hydrology of this area includes the introduction of exotic plant species. of particular concern are the cajeput tree (Melaleuca quinguenervia) and water hyacinth (Eichornea crassipes). $M$. quinguenervia grows aggressively in wet environments and transpires large amounts of water absorbed by its roots cause a drain in the water levels (Migliaccio 1985). The water hyacinth's aggressive growth strategy on top of bodies of water prevents light from reaching submerged native vegetation and animals and clogs water ways. Other exotic plants that are of concern due to their aggressive growth strategy in disturbed areas of the Everglades include the Brazilian pepper (Schinus terebinthifolius) and Australian pine (Casuarina spp.) (Kushlan 1990).

Animals have also been affected by changes in the 
hydrology of the region. Wading bird populations have decreased in numbers as a direct result of hydrologic changes (Kushlan 1990b). The increase in alligator nest flooding (Kushlan and Jacobsen 1990) has affected the breeding cycle of many birds that depended on food sources in the alligator holes during the naturally occurring dry season (Migliaccio 1985). Other alterations to the composition of animal life in this region are the result of over-hunting. Some of the most over-hunted animals include birds for their plumes and of panthers due to their predation of cattle, chickens, and other farm animals. In addition there was a period of deer eradication due to the fear of deer-tick infestation of cattle.

\section{Miami Rock Ridge Region}

The Miami Rock Ridge starts at the Broward-Dade county line and continues south to Mahogany Hammock in the Everglades National Park. This ridge is composed of permeable Miami oolitic limestone that ranges from over seven kilometers to fifteen kilometers in width, while decreasing in elevation from over six meters to three meters as it extends in a southwesterly arch (Griffin 1988:14). The original soil type in this region was mostly a well drained, nearly neutral $\mathrm{pH}$ rockdale with sandy loam (the northern half being sandier than the southern half). In addition, several sthall channels of poorly drained, highly 
basic Perrine marl running ran east to west throughout the ridge (U.S.D.A. 1947). These channels, usually referred to as transverse glades, can be noted in Figure 4. Today, most of the ridge is covered by Udorthent soil types associated with urban land, excavated land, and fill (U.S.D.A. 1994).

The topography of the ridge is uneven, having a pitted irregular surface marked with several solution holes, basins, and caves (Craighead 1971). Large solution holes served as planting holes for settlers of the Pioneer Period (Harsheberger 1914) During the dry season, hunters used them as "wells" for water, fish, or other small aquatic animals (Craighead 1984). Before canals were cut into the ridge to help drain the Everglades during the Urbanization Period, the ridge served as a natural dam for its waters, holding them in excess of three meters above sea level (Parker 1984). Around fifteen sloughs, ran across the ridge, carrying the overflow from the interior sawgrass marshes into the coastal area. These were the transverse glades. After drainage, these dried up sloughs were converted into the first farm areas (Craighead 1984).

The areas of the ridge covered with rockdale and sandy loam soil used to be covered by pinelands interspersed with upwards of 500 hammocks which ranged from 0.1 to 40 ha in size (Craighead 1974). Pinelands have open canopies with the shallowest soils in the county while hammocks tend to be densely forested and covered with some organic soil (Snyder 
et aI. 1990). These features led pioneers in the Miami area to choose hammock habitats as sites for plant cultivation while pinelands were converted to homesteads, and sometimes, livestock ranges (Marchmann 1947).

The Perrine marl soils of the transverse glades supported grasses and sedges (U.S.D.A. 1947). I refer to these areas in Figure 3 as freshwater marshes based on the similar nomenclature of Davis (1943) and McPherson (1976). The sawgrass marsh community was described in the discussion of the Everglades physiographic region.

As indicated in Table 3, hammocks are particularly rich in food species. The table also indicates that the pineland supported more animals used by humans than did the hammocks. However, when compared to other regions, the abundance of animal resources in the Rock Ridge is scant.

\section{Hammock flora and fauna}

The origin of the hammocks on the Rock Ridge has been suggested as the result of the succession from pinelands in the absence of fire (Simpson 1920). The vegetative characteristics of hammocks are determined by various local conditions including climate, surrounding vegetation, elevation and limestone composition (Snyder et aI. 1990). Approximately 306 species of plants have been accounted for in hammocks (Long 1984). In general, South Florida hammocks consist of broad-leaved evergreen and deciduous trees, many 
vines, air plants, and ferns (Davis 1943:166-171). Most of theses plants are common to the Bahamas and Greater Antilles. Due to the great diversity of plant species in hammocks, no single species dominates (Snyder et al. 1990). Some of the most common tree species of the hammocks include several varieties of the fig tree, gumbo limbo (Bursera simaruba), live oak (Quercus virginiana), pigeon plum (Cocoloba diversifolia), wild tamarind (Lysiloma latisliqua), false mastic (Mastichodendron foetidissimum), and paradise tree (Simarouba glauca) (Davis 1943:166-175; Long and Lakela 1978).

The historic range of the Florida black bear, Florida panther, bobcat (Lynx rufus), and white tail deer used to include hammocks, but most of the animals of the hammocks were smaller. Today, the much reduced population of the larger mammals and the conversion of the rock ridge to urban lands has further increased the dominance of small mammals in the hammocks. Two of the most common hammock mammals, the opossum (Didelphis virginiana) and raccoon (Procyon lotor), are common also to all other natural areas of Dade County. The hammock birds are mostly songbirds that feed on fruits, insects, or small lizards. Some of the most familiar and abundant species include the blue jay (Cyanocitta cristata), mockingbird (Mimus polyglottos), and cardinal (Cardinalis cardinalis). Some of the more common amphibians and reptiles include the southern toad (Bufo 
terrestris), green treefrog ( $H y l a$ cinerea), black racer (Coluber constrictor), and green anole (Anolis caroliniensis) (snyder et al. 1990).

\section{Pineland flora and fauna}

Over 300 species of plants have been accounted for in the rockland and flatland pinelands (Long 1984), many of which are indigenous herbaceous species. Fire plays a major role in the maintenance of these plants in this habitat. Due to the open nature of pinelands, fires in this habitat tend to be limited to surface burning of litter and understory vegetation, including the saplings of hardwood trees. Since pineland plants are adapted to fires, they recover quickly. The establishment of pine seedlings after fires is improved (Klukas 1973; Snyder 1986). The flowering and growth of herbaceous species are intensified (Robertson 1953, 1962), and growing conditions of the saw palmetto are improved by fire (Taylor and Herndon 1981). It is estimated that if fire is excluded from pinelands in this region for a period of twenty to thirty years, the natural succession would be tropical hammocks with a relict overstory of pines (Robertson 1953).

The dominant tree species of the Miami Rock Ridge pinelands is the south Florida variety of slash pine (Pinus elliottii var. densa), and the principal shrub is saw palmetto (Serenoa repens). According to Davis (1943:163), 
wire grass (Aristida spp.) and broom grass (Andropogon spp.) used to be common species in all pinelands. Although he also reported an historical abundance of coonti (Zamia pumila) in pinelands, no physical evidence of coonti from any archaeological site in South Florida has been found (Griffin 1988:298; widmer 1988:230). This led to Sturtevant's (1960:12-13) hypothesis that early seminole settlers were responsible for its introduction and that prehistoric Indians never utilized it. The issue remains unresolved.

Some of the animals associated with the rock ridge pinelands include the pine warbler (Dendroica pinus), redshoulder hawk (Buteo lineatus), eastern diamondback rattlesnake (Crotalus adamanteus), and pigmy rattler (Migliaccio 1985). Pinelands are also considered to be one of the habitats most frequented by the white tail deer (Layne 1984), which has been one of the sources of meat for humans in South Florida across time (Davis 1943:238; Griffin 1988:295; Widmer 1988:225-228).

\section{Changes to the Miami Rock Ridge}

The most recent human activities in the Miami Rock Ridge region have brought about the biggest change in the natural environment of Dade County. Logging of the pinelands began in the early 1900s. The development of the rock plow in the 1950 s allowed their conversion into farmlands. The land on 
the rock ridge has been and continues to be a favorite choice for residential development. All of these activities have led to a 98 percent depletion of the population of the original Miami rock ridge pineland (Snyder et al. 1990).

Several of the hammocks have also disappeared or have been altered by human activities. Of special interest are two very large hammocks that existed in this region prior to the Urbanization period. One used to stand as an unbroken hammock ranging from Key west to Palm Beach (Craig 1991). The other began at the southern banks of the mouth of the Miami River and extended south about 3.2 kilometers and 1.6 kilometers to the west (Harsheberger 1914:119). Some of the alterations to hammocks include the recent introduction of exotic plant species. For example, citrus, guava (Psidium guajava), and several medicinal plants were introduced as early as the sixteenth century by spaniards, and troublesome weedy species such as the Australian pine tree, cajeput, and Brazilian pepper were introduced in the early $1900 \mathrm{\prime s}$ (Craighead 1984). As a result of human predation and the loss or alteration of their habitat, many animals which used to occupy this region are either threatened or endangered and a few have recently become extinct (Pritchard 1978).

\section{Biscayne Bay Region}

Biscayne Bay is bordered to the east by several islands including Miami Beach, Key Biscayne, Cedar Key, and Key 
Largo, and to the west by the mainland. It is a shallow basin with an average depth of three meters depth. The basin lies on top of a solid layer of oolitic limestone that is covered with solution holes that are filled with recent sediment. These holes are commonly 5 to 10 meters in diameter and less commonly up to 60 to 100 meters across. Biscayne Bay is characteristically estuarine in nature, and prior to human intervention, it received its fresh water supply from surface and groundwater flow from the Everglades system (Wanless 1976). All natural sources of sediments in the bay are the result of calcareous and siliceous skeletal remains of benthic organisms (Ginsburg and Lowenstam 1958; stockman et al. 1968). An increase in non-natural sediments is likely to have occurred in the 1900s due to the pollution from increased human population.

Several of the organisms that are found in the Biscayne Bay area have been and continue to be of importance to the residents of Dade County. Various fish, water mammals, shellfish, and birds found in this habitat have served as subsistence and used to provide an economic livelihood by residents of different time periods. Some of these resources and others are listed in Table 3.

\section{Estuarine flora and fauna}

One of the most important and characteristic features of the estuarine habitat is the seagrass bed community. 
Seagrass beds consist of seagrasses, and the plants and microalgae that grow on them. The dominant species of seagrass in Biscayne Bay is turtle grass (Thalassia testudinum) some of the other common species include manatee grass (Syrijgodium filiformis), Cuban shoal weed (Halodule wrightii), and Halophila spp. These beds are used by several animal species as a food source, as a protected area for laying of eggs, and as refuges from predation. They also help control some of the abiotic factors important for the maintenance of the estuary ecosystem. They help stabilize the sediment by preserving water clarity and preventing sediment erosion. In addition, they are an important chemical sink in the cycling of elements (Thorhaug 1976).

The Biscayne Bay estuaries are the base of a food chain which includes a large diversity of fishes, aquatic birds, invertebrates, and a few marine mammals. There have been 512 fish species accounted for in Biscayne Bay (de Sylva 1976). Some of the more notable of these include various species of sharks (Galiodea family) and rays (Myliobatidae family) and various sport or game fish. Birds forage for fish in the open waters, shallow perimeters, or exposed tidal flats of the bay (Owre 1976). Some of the more familiar birds include cormorants (Phalacrocorax auritus), egrets and herons, brown pelicans (Pelecanus occidentalis), bald eagle, various hawks and falcons (Buteo spp. and Falco 
spp.), and several smaller waterbirds and songbirds. Invertebrates include barnacles, oysters (Crassotrea spp.). shrimp (Penaeus spp.), blue crabs (Callinectes sapidus), queen conch (Strombus gigas), and spiny lobster (Panulirus argus). Marine mammals include West Indies manatee and the bottlenose dolphin (Tursiops truncatus) (Livingston 1990). The manatee population has been greatly reduced in recent times. One of its greatest threats is mutilation from power boat propellers. Ethnohistorical reports of whales (Cetacea family) being caught eaten in the southeastern coast (Larson 1980:146-152) indicate that they may have also frequented the bay area during prehistoric times.

\section{Changes to Biscayne Bay}

The natural environment of Biscayne Bay has undergone very recent natural and human induced changes. The natural changes include the development of Bear Cut within the last 500 years and of Norris cut within the last 150 years, and the closing of the Boca Ratones inlet on the northern extent of the bay by 1822 A.D. The human induced changes of the environment did not become significant until the mid-1700s as the result of overfishing by Cuban fishermen. The changes intensified with the beginning of migration to and settlement in Dade County in the early 1800s (Chardon 1976).

The Bay's ecology is highly influenced by its water circulation, one of the features most affected by dredging 
and filling operations of the twentieth century. The resulting change in circulation caused an intensification of the erosion of the beaches along Fisher Island, Virginia Key, and Key Biscayne. The changes in circulation also improved the water quality of the bay, however the benefits of this improvement were offset by the increased pollution generated by a booming population growth and the industrialization that Miami was experiencing (Michel 1976).

The effects of the pollution have been most notable in the reduction of sea grass beds in the bay area. Reductions in submerged aquatic vegetation has been associated with thermal effluents, toxic agents, dredging, industrial discharges, oil spills, commercial fishing, and human influenced changes that affect light transmission (de sylva 1976; Livingston 1990).

There has been a shift in the distribution of the saline and brackish waters of the bay which has also affected the biotic distribution. The shore around the Little River area was historically more estuarine in nature and the Key Biscayne coast more saline. Today, the southwestern coast is more brackish than saIine (de Sylva 1976).

\section{Coastal region}

The Coastal region includes the entire eastern and southern coast of both Biscayne and Florida Bay where it supports mangroves and saltwater marshes. It also includes 
both sides of the islands of Miami Beach and Key Biscayne. On the east side it supports a beach strand community while on the west side it supports a mangrove community. The soil in mangrove areas is a highly alkaline, poorly drained, tidal phase Perrine marl associated with salt tolerant plants (U.S.D.A. 1947, 1994). Salt marshes are associated with a deep, level, acidic to neutral, very poorly drained Terra Ceia muck (U.S.D.A. 1994). The soil in the small section in northern Miami Beach is the only natural coastal beach, while all of the eastern coast of Key Biscayne is artificially introduced Palm Beach sand (U.S.D.A. 1947).

As Table 3 indicates, this region has been a very important source for food and other economic resources in Dade county. Humans have found many more animal resources in mangrove and salt water marshes than in beach strands. The beach strand has provided more floral resources than the other Coastal region habitats.

\section{Mangrove flora and fauna}

What I identify as the mangrove community is represented as the coastal forest area by McPherson (1976), and the mangrove forest area by Davis (1943). This habitat supports approximately thirteen plant species (Long 1984). The three most dominant species are usually arranged into zones which rarely cover an area more than 500 meters wide. The distribution of these species within the community is 
influenced by climate, differences in substrate type and wave energy, local variations in the subsidence rate of the land, and sea level fluctuation (Odum and McIvor 1990). The general pattern is that the outermost, lowest elevation zone is represented by the red mangrove (Rizophora mangle), the middle zone by black mangrove (Avicennia germinans), and the inner, highest elevation zone by buttonwoods (Davis 1943:189). Another of the most dominant species is the white mangrove (Laguncularia racemosa) which usualiy appears at lower elevations than the buttonwoods in patches of disturbed areas (Odum and McIvor 1990).

The mangrove habitat supports a large faunal population of low diversicy. Of the different types of animal life found in this habitat, the greatest diversity is found among birds, many of which nest in the mangroves. The majority of these birds are the same that forage in the Biscayne Bay and Everglades region. Fish diversity is also very high here with various fish like the tarpon (Megalops atlanticus) and mangrove snapper (Lutjanus apodus) using the mangroves as a nursery ground. The reptiles, amphibians, and mamul population are much less diverse (Odum and McIvor 1990). One of the most common mammals is the raccoon. Several animals whose population is greatly diminished may be found in the mangrove habitats of this region, such as the crocodile (Crocodylus acutus) and bald eagle. 


\section{Salt marsh flora and fauna}

The coastal region also supports salt marshes, which are ecotones between salt tolerant vegetation and freshwater vegetation or uplands. According to Davis' (1943) vegetation map, salt marshes were found either just north of the mangroves or intermingled with them. Although salt marshes tend to have the highest rate of net primary production of all the ecosystems in the world in general (Montague and wiegert 1990), this is not the case for those in southern Florida. Long (1984) found 23 different plant species growing in the salt marshes of Dade County. The most common species of plants associated with this plant community include the black needlerush (Juncus roemarianus) and smooth cordgrass (Spartina alternifolia).

Like the mangrove habitat, salt marsh animal populations are high with low diversity. Due to the harsh condition of this habitat, many animal populations are transient predators, and their composition is similar to that found in the mangrove habitat.

\section{Beach strand flora and fauna}

Beaches represent the third habitat found in the Coastal region. They are found primarily on the eastern edge of the barrier islands, which are located between Biscayne Bay and the Atlantic ocean. Wind, waves and longshore currents are the primary forces that shape the topography and influence 
the distribution of vegetation on the beach. The wind causes sand shifting and salt sprays to which vegetation must adapt to in order to survive. Waves cause erosion, accretion, and overwash, shaping the contours of the islands (Johnson and Barbour 1990).

Over 115 different species of plants occur in this type of community (Long 1984). The most seaward beach vegetation includes railroad and morning glory vines (Ipomoea spp.). sea grape (Cocoloba uvifera), sea ats (Uniola paniculate) and sea purslane (Sesuvium portulacastrum). Some of the more common plants found farther inshore include half-eaten flower plant (Scaevola plumieri), Spanish bayonet (Yucca aloifolia) (Johnson and Barbour 1990; Long and Lakela 1978). The most abundant of the animals found in these beaches includes several birds such as terns (Sterna spp.), gulls (Larus spp.), and plovers (Charadrius spp.), land crabs, Iand hermit crabs, raccoons and opossum. In addition, the green sea turtle (Chelonia mydas) uses the beaches for nesting of its eggs (Johnson and Barbour 1990).

\section{Changes to the coast}

The coastal biotic communities were not greatly altered by human activity until the beginning of this century. The mangrove communities have been most modified by killing of the mangrove species either by outright removal or as the result of activities which lead to clogging of their roots 
by water, mud, or pollutants. The actions most responsible for causing this include dredge and fill operations, diking, and impounding (Odum and Johanes 1975). In addition to the mangrove areas located on the coast, Harsheberger (1914:78) documented scattered patches of mangroves forming a thin border along the Miami River, which have since disappeared. It is likely that the borders of the various creeks and rivers throughout the county also used to support mangroves. These would include Arch Creek, Snapper Creek, Little River, Oleta River, and Uleta River.

Salt marshes were not exploited very much until the last fifty to sixty years, during the Urbanization Period. These habitats then became a dumping ground for domestic and industrial waste. With the increased demand for space created by a growing population, more of these marshes were bulkheaded and filled for commercial or residential development. However, the biggest anthropogenic change resulted from mosquito control. Tactics employed included spraying with DDT and impoundment of the marshes. As a result of the DDT spraying, many forms of fish and wildlife were negatively affected. The impoundment altered the vegetation types from a salt water community to one dominated by freshwater species and in turn affected the animal life dependent on the salt marsh vegetation (Montague and Wiegert 1990).

The major changes to beach strands have been the real 
estate development and erosion caused by altered circulation of the bay waters. Introduction of various exotic species of plants also has altered the natural characteristics of the environment. Some of these exotics include the coconut (Cocos nucifera) and two of the most invasive species in South Florida, the Australian pine tree and Brazilian pepper (Johnson and Barbour 1990).

\section{Big Cypress Spur Region}

The Big Cypress Spur region in Dade County is located at the very northwestern corner of the county. It is represented by approximately 90 square kilometers of the southeastern tip of the Big Cypress. It is bordered on the west by Collier and Monroe Counties, to the north by the Broward County, and on the east and south by the Shark River slough. Two type of highly alkaline poorly drained soils predominate within the Dade County portion of this region, Ochopee fine sandy marl and unclassified Cypress swamp soil (U.S.D.A. 1947).

This area is comprised mainly of a mosaic of cypress forests, hammocks, pinelands, wet prairies, and marshes. The roughly scattered higher, drier areas support pineland and hammock communities. The lower areas are represented by the cypress habitats. The hammock and pineland communities have already been discussed within the sections of the Miami Rock Ridge region description. However, the pineland 
communties within the cypress region are very different from the ones in the Miami Rock Ridge region. Although Florida slash pine is abundant, a less xeric (dry environment tolerant) plant conmunity is represented in the cypress region. As Table 3 indicates, this region has an abundance of important resources.

\section{Cypress forest flora and fauna}

Some plants commonly found in the cypress forests include cypress (Taxodiun distichum), willow (Salix caroliniensis), dahoon holly (Ilex cassine), pond apple (Annona glabra), southern red maple (Acer rubrum), sweet bay (Magnolia virginiana), and myrsine (Myrsine guaianensis). In addition, many species of bromeliads, orchids, and ferns are abundant growing in the cypress trees (Davis 1943:177; Long and Lakela 1978).

The cypress community is associated with many species of wildlife. Some of the more common birds include the limpkin (Aramus guarauna), ibises, wood storks (Mycteria americana), several species and varieties of herons and egrets wild turkeys (Meleagris gallopavo), and swallow-tail kites (Elanoides forficatus). This community also supports the less frequently occurring bald eagle and used to support the now extinct the ivory-billed woodpecker (CampephiIus principalis) (Ewel 1990).

Several small mammals live in cypress swamps, including 
the southeastern shrew (Sorex longirostris) cotton mouse (Peromyscus gossypinus), and raccoon. Additionally, currently threatened species including the Florida panther, Florida black bear, mangrove fox squirrel (Sciurus niger), and mink (Mustela vison) are found in the cypress swamps and mixed swamps of the Big Cypress (Ewel 1990).

Several amphibians and reptiles are common to cypress swamps. Some of the most obvious reptiles include the American alligator, cottonmouth water moccasin, and several anoles (Anolis spp.). These reptiles are also found in other habitats throughout Dade County. Several rarer or endemic species of amphibians and reptiles also are found in cypress swamps, including the glossy crayfish snake (Regina rigida) and the striped crayfish snake (R. alleni). Both of these species feed on the abundant crayfish (Procambarus alleni) (Ewel 1990).

\section{Changes in the Big Cypress spur}

Changes in the original natural environment of the Big Cypress Spur include a reduction in the area of cypress forest habitats and an associated decrease in the vegetation and wildife population of those areas. These changes have been the result of logging practices and altered water quantity and quality. Logging began in the late 1800 s and continued until 1950. Much of the area surrounding the cypress swamps was greatly altered in the efforts to provide 
access roads to the loggers. As a result, the topography and drainage patterns of the swamps were altered, affecting the natural hydrologic cycle (Ewel 1990).

More direct changes in the water quantity were caused by drainage and subsequent flood control and water management policies. In some areas the effects of drainage included a shift in the biotic composition of the cypress forests. More specifically, a decrease in successful reproduction of cypress trees has been coupled with an increase in the population of shrubs and hardwoods (Marois and Ewel 1983), and the animal population has shifted from aquatic herbs to terrestrial tree species (Harris and Vickers 1984).

\section{Southern Slope Region}

The southern slope, is located on the southeast tip of the peninsula, mostly south and southwest of the Miami Rock Ridge. It is bordered on the northwest by the Everglades and receives water flow from the Taylor slough. The predominant soil type in this region is the poorly drained, highly alkaline Perrine marl (U.S.D.A. 1947, 1994). According to the vegetation maps of Davis (1943) and McPherson (1976), this entire region used to be a wet prairie marsh community with several interspersed hammocks and two main areas of cypress forests. The cypress regions are located near the center of the southern slope within the Taylor slough. These communities have already been 
discussed in either the description of the Everglades, Miami Rock Ridge, or Cypress physiographic region, therefore, they will not be discussed here. Instead, some of the changes that have occurred in the natural environment of this region will be presented.

\section{Changes to the Southern slope}

Recent aerial photographs (TRW REDI 1993) reveal that most of the natural environment of this region remains undeveloped with a few areas on the southwestern section converted for agriculture. The less developed marsh areas are important nesting and feeding areas for several aquatic birds that frequent the Everglades and Coastal regions. The more developed areas tend to be located in the eastern half of the Southern slope region, south and east of Homestead.

One area of particular interest is about 7,500 acres of land near the center of this region. This area, termed the "Hole in the Doughnut," sustained farming activity between 1916 to 1975 . This land became part of the Everglades National Park in 1970 and today is the site of the South Florida Research Center. The vegetation of this area is now a mixture of exotic and native vegetation (Van Smith 1975:47). 


\section{Atlantic Ocean Region}

The Atlantic Ocean physiographic region described in this thesis begins at the seaward side of the barrier islands and extends to the east about eight kilometers, or approximately thirteen kilometers east of the peninsular coastline. The northern and southern boundaries of this region are respectively, the Broward and Monroe county lines. A profile of this extent of the ocean floor is provided in Figure 5. This range was chosen because it represents the approximate distance covered by exposed land during the low sea level stand of around 18,000 B.P. This allows a better understanding of both the terrestrial and marine environment during all periods, including that of the Paleo-Indians.

About a little over one kilometer seaward of the barrier islands the ocean floor reaches a depth of about 4.5 meters below current mean sea level. The descent then becomes more gradual, at a rate of approximately $-1.25 \mathrm{~m} / \mathrm{km}$ for about 2 kilometers. The rate of descent then begins to steepen rapidly at about $-30 \mathrm{~m} / \mathrm{km}$ for a distance of about 2 kilometers. This is followed by an even steeper drop of about $-57.5 \mathrm{~m} / \mathrm{km}$ for $3 \mathrm{kilometers,} \mathrm{reaching} \mathrm{depths} \mathrm{of} \mathrm{around}$ 135 meters close to 13 kilometers east of the peninsula (N.O.A.A 1986, 1992).

Today, the Atlantic Ocean physiographic region supports several biotic communities, including sea grass communities and worm, patch, and bank coral reefs. Sea grass 


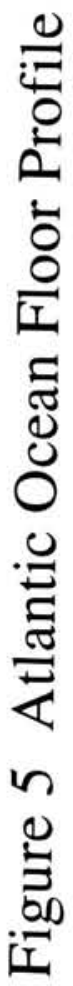

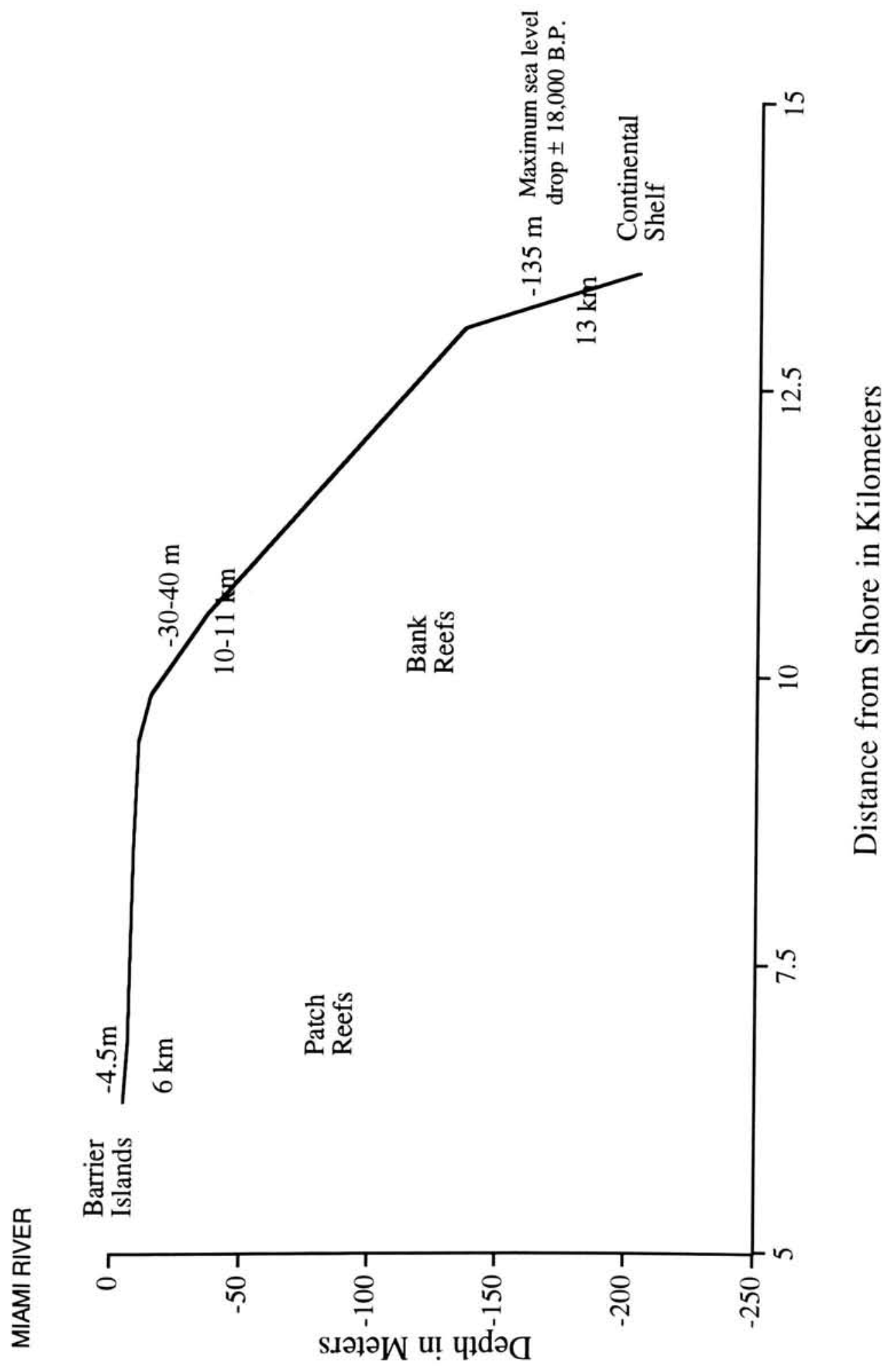


communities and their animal associations have already been described in the discussion of the coastal region. The Eish commonly associated with the patch and bank reefs include grunts (Haemulon spp.), tiger shark (Galeocerdo curieri), lemon shark (Negaprion brevirostris), and sharpnose flying fish (Exocoetus volitans), barracuda (Sphyraena barracuda), porgies (Calamus spp.), jacks (Centropomus spp.), and groupers (Serranidae), snapper (Lutjanus spp.), and parrot fish (wing and Loucks 1982). Provided below is a brief description of the distribution and general characteristics of the reef systems along the east coast of Dade County. Phragmatopoma Iapidosa worm reefs occur in waters less than ten meters deep from Cape Canaveral southward to Key Biscayne. Patch reefs are found to the south and seaward of the barrier islands in depths of about two to nine meters. To the south and east of these lie the bank reefs, which begin around 7.4 kilometers seaward of the Florida Keys. The deepest sections of these occur in 37-40 meter depths (Jaap and Hallock 1991).

At around 100,000 B.P., while South Florida lay 7.5 meters below sea level, the present upper keys existed as patch reefs and the present patch reefs existed as bark reefs (Migliaccio 1985). The present coral reefs began their growth between 5,000 to 7,000 B.P. Since then, they have grown vertically at rates ranging from 0.65 to 4.85 meters per 1000 years (Shinn et al. 1977; Shinn 1980). 
Worm reefs consist of tubes made out of sand grains, which have been cemented together with protein by the tropical marine worm Phragmatopoma lapidosa. These reefs support lobster and various fish popular among recreational fishermen. In addition, the reefs provide a safe haven that serves as a nursery for many coastal fish (Jaap and Hallock 1991).

Patch reefs usually have a circular contour, which ranges from 30 meters to 700 meters in diameter. Areas directly adjacent to patch reefs tend to be barren due to the grazing of algae and sea grasses by the herbivores that live in the reefs. The upper central portions of patch reefs are usually occupied by dense populations of various soft corals. The margins of the reef are dominated by hard stony corals. Star coral (Montastraea annularis) is one of the most abundant of the hard corals found in these reefs (Jaap and Hallock 1991).

Bank reefs are characterized by a series of reef formations several hundred meters in length, which may extend laterally for one to two kilometers, paralleling the coastline. The formations are usually aligned perpendicular to the coast, facing into the predominant wind-sea direction. The elkhorn coral (Acropora palmata) is the most common species of elongate coral found in these reefs (Jaap and Hallock 1991). 


\section{GROUNDWATER}

Groundwater represents one of the most important abiotic resources in Dade County. The sources for this groundwater are the Biscayne and Floridan aquifers. Due to the high salinity of the Floridan aquifer, all of the water consumed in Dade County comes from the Biscayne aquifer. The Biscayne aquifer is an underground water store largely composed of oolitic limestone and sand which extends throughout most of Dade County. Its water table is relatively flat and close to sea level. The aquifer varies in depth from about zero on the western border of the county to over 80 meters along the coast (Kreitman and Wedderburn 1984) .

The water supply of the aquifer is approximately 9,000 billion gallons (zucchetto 1973). Water is removed from the aquifer by wells at the rate of about 10 million gallons per day (Kreitman and wedderburn 1984). It is re-charged by rainfall that penetrates the limestone. The annual rainfall is around 222 million gallons (Zucchetto 1973). However, most of the rainfall goes back to the atmosphere at the average evaporation rate of about 85 percent. In addition, some of the rain may either run off into canals or storm drains, or collect to form ponds and marshes (Migliaccio 1985). The result is a water budget that operates at an average loss of more than 350 million gallons per year. 


\section{SUMMARY OF CHAPTER II}

Dade County is a diverse collection of natural environments that took thousands of years to form. The climate and unusual geological formations provided the conditions necessary for the development and support of various forms of life. By 2,700 B.P., the Everglades lay as a shallow river of grass embanked on the east by the Miami Rock Ridge formation. The water fluctuations from this river directly affected the flora and fauna whose reproductive and developmental strategies were based on the cyclical nature of the alterations. The flow of water from this river also affected the nature of the Biscayne Bay and the salt marsh and mangrove coastal areas. In fact, this whole area functioned as an ecosystem full of interconnected water and nutrient energy cycles. The ecosystem was abundant and diverse enough so that humans were able to find multiple subsistence resources from several of its many different communities, Recent human activity changed the characteristics of this enviromment to such a degree that most of the natural ecosystem is gone.

Some of the ecological factors most critically affected by recent human activity include biodiversity, water, and soil. Most of the negative effects on these factors may be traced back to the drainage of the Everglades, flood control policies, water management, agricultural practices, and 
pollution. Other causes for changes in the natural environment are the removal of vegetation and killing of animals in order to satisfy the growing need for urban space and other needs. Additionally, the growth of Dade County as an international center has facilitated the introduction of various exotic species of plants and animals, many of which are aggressively dominating some local communities. Details on how and why the different resources were used by the people that inhabited Dade County and the patterns of cultural-environmental relations that they forged will be provided in the following chapters. 


\section{CHAPTER III: THE PRE-COLUMBIAN ERA}

$(14,000$ B.P.-A.D, 1512)

\section{OVERVIEW OF THE PRE-COLUMBIAN ERA}

The Pre-Columbian Era of human occupation of Dade County refers to the time prior to 1513 A.D., when the first contact with Spaniards occurred. The cultural continuum represented during this time period ranges from the PaleoIndian (14,000-8,500 B.P.), to the Archaic (8,500-2,500 B.P.), and eventually the Formative "Glades" Culture Period (2,500-500 B.P.). These categories serve to differentiate common patterns of behavior associated with cultural evolution in North America in general.

The Paleo-Indian Period is associated with band-level semi-nomadic hunting of megafauna, scavenging, and the manufacture and use of simple tools. The trends in the transition to the Archaic Period include increased sedentism and population, the selection of a broader spectrum of hunting and gathering resources, and increased tool sophistication. These trends continue until a sufficiently distinct set of patterns emerge to enable differentiation between the Archaic and Formative Periods. For most of North America this includes the establishing of permanent villages, ceramics, and some sort of food production technology. 
In Dade County, the time frame for each of these cultural stages is not clearly delineated by archaeological evidence, causing some minor variation among the definitions of their chronological sequence. Interpretations of the chronology of cultural stages of Dade County by several archaeologists are presented in Table 4 . The chronological sequence represented in this thesis is based on Carr and Beriault's (1984) representation of the archaeological record.

Archaeological sites from the Pre-Columbian Era in the southeast coast of Florida have been greatly exposed to the destruction by intense development over the last hundred years. As a result, it is not possible to determine whether the scant archaeological evidence from Dade county is the result of the destruction of sites or a limited preColumbian human presence. Figure 6 illustrates the location of known archaeological sites located in Dade County. Most of the named locations represent major pre-Columbian sites. An exception is the Honey Hill site, which although not a major site, has been extensively studied. Findings from the unnamed sites range from pottery fragments to remains of human bones.

The majority of archaeological sites found in Dade County date to the Formative and early historic periods. Most Formative Period sites are clustered along the Biscayne Bay and between the Miami Rock Ridge and the Everglades, but some are also located near the Shark River and Taylor 


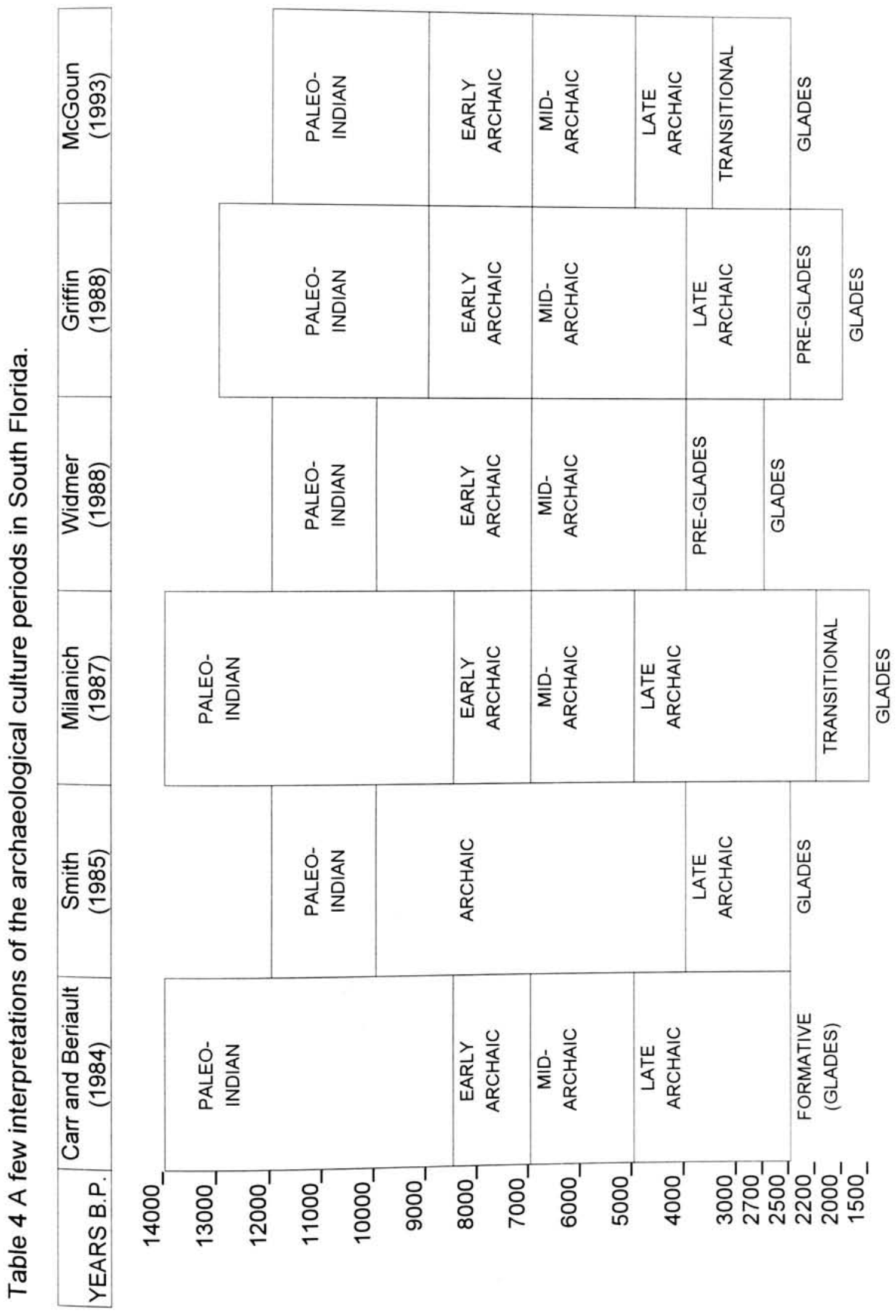


Figure 6 Archaelogical Sites in Dade County

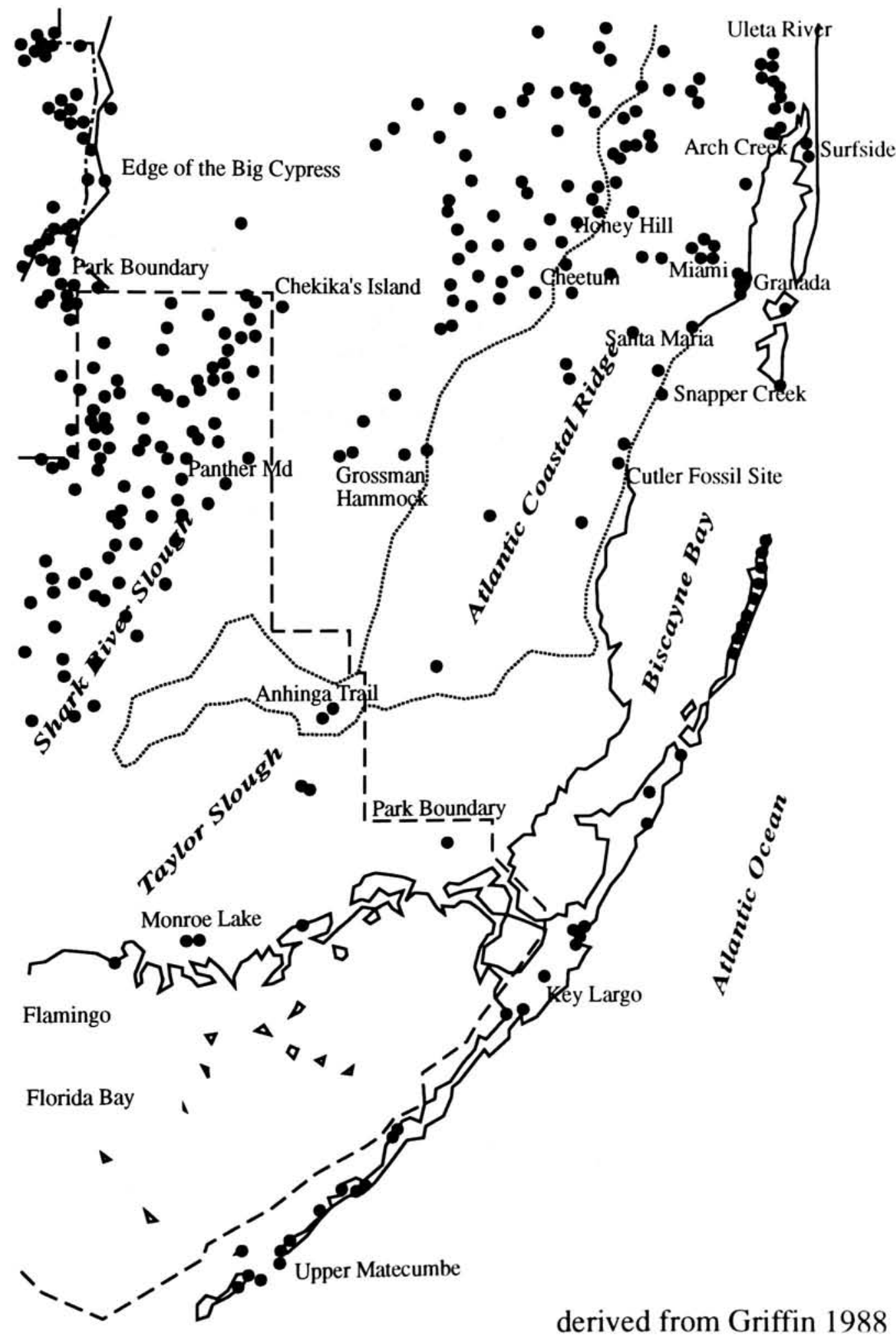


sloughs. Many post-Contact finds of Indian origin are located on tree islands near the Big Cypress and Shark River Slough areas. The Cheetum and Santa Maria sites date to the Archaic Period. Other evidence from the Archaic Period includes a number of cemeteries along Biscayne Bay (Carr et a1. 1984) and sone unclassified sites in the tree islands of the eastern Everglades (Carr and Beriault 1984). At the time of the writing of this thesis, an archaeological site dating to the Paleo-Indian Period was found near the Monkey Jungle recreation park, joining the old Cutler site, as the only finds of Paleo-Indian origin in Dade County.

In this chapter I provide an overview of the features characteristic of the different cultural periods in the PreColumbian Era. The discussion provides a general description of the particular cultural periods followed by specific descriptions of their features within Dade County. Since the quality and quantity of information available about each period varies, their particular description will vary accordingly, particularly with regard to their technology.

PALEO-INDIAN PERIOD $(14,000-8,500 \quad$ B $-P$.

The first humans to reach Florida were members of highly nomadic bands of hunters and gatherers that migrated from across the Bering strait at the end of the last Ice Age. 
They may have reached north Florida as early as 17,000 B.P. (Milanich 1987). Smith (1985) believes Paleo-Indians periodically used what is now the Everglades region as early as 14,000 years ago. According to Widmer (1988:195), it is possible the southwest Florida population numbered around 5,000 at its peak. The population in Dade County would be much smaller, comprising of only a few hunting bands.

Archaeological evidence of the earliest human presence in Florida comes from Sarasota County in the Little Salt spring site dating to around 12-14,000 B.P. (Clausen et aI. 1979). Most of the Paleo-Indian archaeological sites are limited to northwestern and central Florida. A notable exception is the recent discovery of the Cutler fossil site, which indicates that Paleo-Indians may have found hunting and gathering resources in south Dade County as early as 11,000 B.P. $(\operatorname{Carr} 1986)$.

\section{Environment}

The natural environment of South Florida during the Paleo-Indian Period was very different Erom the contemporary environment, posing different problems to be coped with. The sea level at around 17,000 B.P. was 100-130 meters below the current level (Fairbridge 1984) extending the potential occupation area in South Florida well past current shorelines. On the west coast, the lower sea level would expose about 270 kilometers of land west from the current 
shoreline. On the east coast, there would only be about an additional 12-14 kilometers exposed on the Atlantic Ocean side. The climate in the Paleo-Indian Period was much drier with cooler sumners and warmer winters (Carbone 1983), with high winds and shifting dunes throughout most of northern and central Florida (Watts 1980).

Unfortunately, no archaeobotanical evidence dating to the Paleo-Indian Period has been collected from south Florida. The closest evidence comes from pollen samples collected from Lake Annie, which is located in central Florida. Based on this evidence, some geobotanists (Delcourt and Delcourt 1981; Watts 1975) believe that the predominant south-central Florida vegetation comnunity was of a xeric quality characterized by rosemary (Ceratiola), spikemoss (Selaginelia spp.), myrtle (Myricaceae), and sandhill polygonella (Polygenella fimbriata) interspersed with scrub oak (Quercus champanii). However, it is unlikely that this type of vegetation existed in Dade County. Instead, this type of vegetation was limited to sandy soils and higher elevations more typical of certain inland and coastal areas of central and northern Florida. BY 10,000 B.P., a moister climate influenced the replacement of sand dune scrub by oak savannahs characterized by oak, hickory, and pine (Diploxylon and Haploxylon spp.) trees as well as various herbaceous species (Delcourt and Delcourt 1981; Watts 1975). The great difference in sea levels between the present 
and Paleo-Indian Period may explain the lack of additional Paleo-Indian sites within Dade County. Additional sites may exist, but could be submerged off the Florida coastlines (Cockrell and Murphy 1978).

Other evidence of the presence of Paleo-Indians in south Florida comes from underwater archaeologists working primarily in the Little salt spring (Clausen et al, 1979) and to its north, in Warm Mineral Spring (Cockrell and Murphy 1978). They have been able to find evidence that has added to the knowledge of subsistence strategies and technologies of Paleo-Indians. For example, evidence of the earliest known predation of deer and the discovery of a nonreturning oak boomerang similar to the ones of the northern Territory of Australia has been found in Little Salt spring. The find of the boomerang is particularly interesting since it may be the oldest specimen of its type in the world (Clausen et al. 1979).

\section{Technology}

The paleo-Indian subsistence technology involved bandlevel nomadic hunting of large game, supplementary foraging of smaller game, gathering of plant foods (Milanich 1987: 38-48; McGoun 1993:39-51), and possibly fishing and shellfish foraging (Marquardt 1992:426). The nomadic patterns were probably influenced by the movement of the big game herds and the distribution of water resources. Due to 
the importance of scarce freshwater resources, camp sites would have shifted from water source to water source. In addition to these adaptations, Paleo-Indians may have also altered the environment to adapt it to their needs (McGoun 1993:3). Big-game hunters may have set fires to clear off old growth, thereby allowing the sprouting of new green shoots, which are a preferred grazing resource. This would attract big-game herds, facilitating their predation by the Paleo-Indians. Towards the end of the Paleo-Indian Period, evolutionary changes of the flora and fauna was followed by changes in the adaptive strategies of the people. As big game became scarcer, Paleo-Indians emphasized smaller game and a broader selection of plant resources (Milanich 1987).

Although most archaeological studies have emphasized the big game hunting strategy of the Paleo-Indian, McGoun (1993:47-49) points out various reasons for why plant use should not be overlooked. He believes the emphasis on hunting may be based on the better preservability of artifacts associated with hunting, such as stone points and faunal remains, over that of rapidly decomposable plant remains. According to him, several grinding stones found in archaeological sites farther north may have been used for the preparation of plant products. McGoun believes that plant materials may have been used in addition to animal skins to make clothing and windbreaks or shelters. 


\section{Subsistence selectivity}

The Old cutler fossil site in south Dade has provided some clues as to the different availability and choice of faunal resources by early and late Paleo-Indians. Carr (personal communication 1993) believes this site used to be an ancient water hole. According to McGoun (1993: 46) it was probably a dry waterhole that cut into an abnormally high deposit of ground water. Within this site there is an area which contains two layers of cultural and faunal artifacts. Charcoal from the top layer has been dated to $9,670 \pm 120$ years B.P. The layer beneath it has not yet been dated but is older than the top layer. The predominant faunal remains from the top layer include those of the white tail deer and the cottontail rabbit (SyIvilagus spp.) along with various other small mammals including the coyote (Canis Iatrans), opossum, and bobcat. Other animals represented to a smaller degree included several unidentified turtles, frogs, and snakes along with a raptor (Accipitriformes), a hawk, and unidentified birds. The only extinct species represented by the faunal remains included the giant armadillo (Dasypus bellus). The bottom layer contained remains from over 70 different species including several extinct species consisting of mammoth (Mammuthus jeffersoni), bison (Bison antiquus), horses (Equus spp.), short limbed llama (Palaeolama mirifica), peccary (Mylohyus fossilis), North American spectacled bear (Tremarcatus 
floridanus, and dire wolf (Canis dirus).

Considering the size of some of these animals, the hunters had to deal with the potential danger of attack. They also had to cope with the problem of what to do with so much meat. The meat obtained from these animals could have sustained the small bands for a long time if the PaleoIndians could preserve it. It could also sustain several bands if they could transport it. This could have been achieved with some success if the meat were cut into short strips, air and sun dried, and then carried in specially made carrying devices.

As of yet there is no evidence of which floral resources may have been used by Paleo-Indians at this site, however, there was a piece of wood tentatively identified as douglas fir (Pseudotsuga menziesii) (Personal communication with Robert Carr 1993). The natural distribution range of this species ranges from British Columbia into North Mexico and Colorado (Bailey 1949). Therefore, if the presence of $P$. menziesii is confirmed, it opens up many questions about the previous knowledge about the pre-historic environment of this area and possibly about the technology of the PaleoIndians, For the time being, it is considered an anomalous find. 


\section{Tools}

Lithic, shell, and bone artifacts have been uncovered in both the Monkey Jungle and old Cutler Fossil site. As yet, only the ones from the old Cutler fossil site have been documented. The lithic artifacts include various drills, scrapers, and points made of finished chert rock. Chert may have also been used to make flints for starting lighting, heating, cooking, and hunting fires. Since the closest outcroppings of chert occur in the Tampa Bay region, the rocks or tools themselves would have had to been transported from there or other more northerly regions. This in itself posed many difficulties, considering it involved walking a long distance with short water supplies in a disagreeable climate among potentially dangerous animals. The shell remains, including fragments from a whelk (Buscyon spp.) and conch may have been used as pounders. Bone was used to make pins, awls, and needles (Carr 1986).

\section{Social Dimension}

All knowledge of the social organization of the PaleoIndians is based on theory. McGoun (1993) indicates that the Paleo-Indians probably had the typical egalitarian sociopolitical organization associated with bands. He believes the only forms of differentiation may have been based on the capacities to do work according to sex and age. In addition, some form of authority may have been required 
to have the degree of discipline required from the band members involved in large hunting missions.

\section{Cognitive Dimension}

There is no archaeological evidence to indicate what beliefs the paleo-Indians may have had and how they may have related to land use patterns. Following wallace's (1966) scheme of the evolution of religion, it is plausible that some form of animatism or animism existed. The belief that animatism predated animism was suggested by R.R. Marett (1909). He defined animatism as the belief in impersonal supernatural forces that can bring good and bad luck. Animism, as defined by TYlor in 1871 (1958), provided the belief in the existence of souls living in an invisible dual universe. This belief serves to help explain death, dreams, or trance-like episodes associated with illnesses. According to Malinowski's (1948) interpretation of magic, there may have also been belief in magic for the purposes of obtaining some control over daily hazards.

\section{ARCHAIC STAGE $(8,500-2,500$ B.P. $)$}

During the Archaic period, southern Florida experienced the most significant natural changes to the environment while under human occupation. The increase in sea level which began during the Paleo-Indian Period continued. This 
may have caused a problem to coastal residents due to the associated flooding of coastal land. Robbin (1984)

estimates the sea level around 8,500 B.P. was approximately

8 meters below current levels (see Table 2). If his model

is applied, approximately seven to nine kilometers seaward

of the current eastern coastline would have been exposed.

By the end of the Archaic Period, the sea level and

coastline were at near present levels (Smith 1985).

Additional changes in the climate and vegetation were

followed by changes in cultural features of the peoples of

South Florida. These cultural changes are differentiated

into three subperiods, the Early Archaic Period (8,500-7,000

B.P.), Middle Archaic (7-5,000 B.P.), and Late Archaic (5-

2,500 B.P.) (Milanich 1987).

\section{Sites in Dade County}

Archaeological evidence from the early and mid-Archaic periods is almost nonexistent for South Florida and Dade County. The only major sites located in Dade County include the Cheetum site (Newman 1986) and the Santa Maria cemetery (Carr et al. 1984). The low number of Archaic period sites has led to much speculation about population size and migration patterns during this period. One explanation is that the carrying capacity for South Florida may have dropped during this period due to environmental stresses brought on by a hot and dry climatic interval, leading to an 
exodus (Widmer 1988:203). Another explanation is that sites from this time period just have not been located yet. It is also not known if the late Archaic sites located in South Florida represent the descendants of the northern PaleoIndian or a new group that migrated from the circumCaribbean area (McGoun 1993:66-68).

The Cheetum site is located in the ecotone between the Miami Rock Ridge and the Everglades (see Figure 6). Evidence from this site indicates a possibility of human occupation as early as 5,000 B.P, but most remains found date to the Glades II period (700 A.D. to 1100 A.D.). The Santa Maria cemetery is located on the peninsular coast approximately 3.7 kilometers south of the mouth of the Miami River. It dates to around 3,000 B.P. At least six other sites dating from around 4-3,000 B.P have been found scattered throughout the county (Carr et al. 1984).

Another site which contains cultural artifacts from the late Archaic period is the Honey Hill site in the east Everglades. Paleoethnobotanical (Scarry et al. 1991) and paleoethnozoological (Masson and Hale 1991) research at this site has provided some information on the patterns of inland floral and faunal use in Dade county during the Archaic period. However, the majority of the artifacts found in this site are also from the Formative rather than the Archaic Period. 


\section{Environment}

During the early Archaic the climate became even drier than before, possibly leading to an evacuation of South Florida humans (watts 1975: 346; widmer 1983; 339). By 6,500 B.P. all of the megafauna became extinct (Carr and Beriault 1984). Around 6,000 B.P. the climate started to become moister (Watts 1975). Around 5,000 B.P. the vegetation began developing into the modern south Florida flora (Long 1984) and by the end of the Archaic Period it reached its present distribution (Griffin 1988:47). The moister climate must have also attracted more hydric animal species, including amphibians and mosquitos.

The distribution pattern of south Florida's plant species may provide evidence about how humans influenced the appearance of the natural environment. Over 60 percent of these species originated from the southern west Indies (Long 1984), suggesting human migration from the south as vectors for their distribution in South Florida. However, the migration of many of these species into South Florida can also be explained by natural causes such as being carried by wind and migratory animals.

\section{Technology}

The general trend from Paleo-Indian cultural patterns to Archaic patterns may be seen as a shift towards a more sedentary lifestyle, evidenced by the appearance of some of 
the earliest pottery (around 3,000 B.P) known in the continental United States (Griffin 1988: 131). Only three sites within Dade County contain this semi-fiber-tempered type of pottery- These include the Atlantis (Carr 1981) and Santa Maria Cemetery sites (Carr et al. 1984) near the mouth of the Miami River, and the 202nd Street site in Homestead (Laxson 1962). All of these are located in the ecotone between the Bay and Miami Rock Ridge. The shift towards sedentism was also reflected in the new forms of hunting, foraging, fishing, and gathering. Like Archaic Indians elsewhere in North America, they slowly developed a broader range of plant and animal subsistence and an increase in the diversity tools. The increased sea level and development of freshwater streams and lakes provided an increase in aquatic resources, particularly shellfish. The main terrestrial resource was deer (Milanich 1987).

\section{Subsistence selectivity}

Due to the paucity of sites from this period it is difficult to describe a selectivity pattern of Dade County as a whole. Instead, only inland sites provide evidence of subsistence selectivity specifically in Dade County. Faunal Eragments of turtles, bony fish, snakes, and deer dating to the late Archaic were collected at the Honey Hill (Masson and Hale 1991) and Cheetum sites (Newman 1986).

The turtle remains found in the Honey Hill site included 
those of mud turtles (Kinosternidae), pond turtles (Psudemys spp.), and softshell turtles (Trionyx ferox). The bony fish included bowfin (Amia Calva), gar (Lepisosteus platyphinchus), sunfish (Lepomis microlophus), catfishes (Siluriformes), and bass (Micropterus salmoides). Less frequently found were non-limbed remains of alligators. This indicates that alligators were killed away from the site, bringing back only the useful slaughtered remains. The single most common terrestrial species was white tail deer (Odocoileus virginanus). Other terrestrial species found included various rodents and rabbit. Bird remains were of species that could be found in either freshwater or terrestrial habitats (Masson and Hale 1991). Found only at the Cheetum site were various marine and freshwater shelled invertebrate remains dated to the Archaic Period. These were tools and ornaments brought from the coastal zone (Newman 1986).

According to the above evidence, the most intensively exploited animals in the inland zone were those associated with the wet vegetation communities. The most frequently found remains were probably the most frequently eaten. These were the turtles, bony fish, and deer. The biomass estimated for the number of these species found was greatest for turtle, followed by bony fish, and deer. 


\section{$\underline{\text { Tools }}$}

A wide range of shell, lithic, and possibly bone tool artifacts were found in the cheetum site. The largest number of shell species were of marine origin followed by terrestrial and freshwater species. Several of the lithic tools were made of non-local chert, indicating the possibility of an interregional exchange network similar to the one of the Paleo-Indians. Considering that the climate was becoming moister toward the end of the Archaic Period, this network may have required a canoe transportation technology to cross the Everglades.

\section{House structures}

Based on the nature and quantity of artifacts that were found in the Santa Maria and Cheetum sites, there is sufficient evidence to indicate that these sites served as a habitational areas (Carr 1981; Newman 1976). However, information regarding the types of house structures or the seasons during which these sites served as foraging bases still remains elusive.

\section{Social Dimension}

According to McGoun (1993:63-64), social differentiation among the Archaic Indians was probably very similar to that of the Paleo-Indians. That is, it was probably based on perceptions of appropriate age and sex roles and by the 
acknowledgement of specialized talents. The type of resources being collected and the need for sharing or nonsharing probably dictated whether social groups would consist of small family based bands or larger groups that extended beyond the family (Milanich 1987).

Evidence from the Santa Maria cemetery site suggests that inter-group warfare may have existed during the Late Archaic period. This assumption is based on the interpretation of the condition of some of the buried remains. Some individuals appeared to have died of sudden violent traumas to the skulI, indicative of battle injuries. In addition, the hands and feet of some individuals were found to be missing, possibly removed as trophies by the victors (Carr et al. 1984). I suggest that it is possible that ecological stress and consequential shortages of needed resources may have precipitated such hostile relations due to competition.

\section{Cognitive Dimension}

Again, as in the Paleo-Indian Period, data concerning the cognitive dimension of the Archaic Indians must be largely inferred from theory. It is likely that the shamanic type of religion along with the associated beliefs in magic persisted from the Paleo-Indian into the Archaic Period. Evidence of some sort of belief in the supernatural has come from burial patterns. Several remains have been found buried under water. This has led to the hypothesis that 
water had a special significance to the Archaic people. However, it has also been suggested that this manner of disposing of the dead has certain practical advantages (McGoun 1993:61), such as the control of the odor of decomposition and the disease carrying pests it attracts.

\section{FORMATIVE PERIOD $(2,500-500$ B.P. $)$}

By the beginning of the Formative Period, the oceans were near their current levels and the vegetation communities attained their modern distribution. The animal associations of the vegetation communities matured, approximating the distribution and population levels encountered in the Pioneer Settlement Period (A.D. 1790-1895). The human response to this environmental change led to a basic cultural pattern for all South Florida, lasting until the appearance of the spaniards in the sixteenth century (Milanich 1987). Goggin (1949:28) termed this pattern the "Glades Tradition." This particular tradition was represented in Dade County by the lifestyle of the culture group known as the Tequesta (Smith 1986:6).

The Glades Tradition may be described as the development of various specialized forms of subsistence technologies in several ecological zones. This included the development of both inland and coastal strategies such as hunting, fishing, foraging, and gathering. The Glades Tradition is also 
characterized by the beginning of formal, settled commities, accelerated population growth, and the development of more complex forms of political and religious community organization. These phenomena are discussed in more detail later in this chapter in the discussion of the social and cognitive dimensions of the Formative period.

The chronology of the Glades Tradition is subdivided into sub-periods based on differences in ceramic decorative patterns rather than subsistence strategies. Varying interpretations of this chronology have been offered by several anthropologists. However, the difference is relatively minor. A few models of the chronology of the Glades sub-periods are presented in Table 5. The chronology followed in this thesis is based on Griffin's (1988) model. The ceramic sequence upon which the Glades periods were subdivided by Griffin is presented in Table 6 .

\section{Sites in Dade County}

There are no major sites located in Dade County dating from 2,500 B.P. to 800 A.D. (MCGoun 1993:72). All of the major sites of the Formative period date to 800 A.D. or later, and are located in the coastal zone. These include the Uleta River and Arch Creek sites in the north, Granada and Snapper Creek sites to the south, and the Surfside site in the east (p. 94). A few small coastal sites have also been located along the mangrove fringes along Florida Bay. 
Several small inland sites have been found on the northern tips of tree islands in the Shark River slough area and in the wet prairies and marshes at the eastern edges of the Everglades. In addition, three small sites have been located along the Anhinga Trail near the Taylor Slough. All the inland sites are small earth middens covering an area in average of 0.3 acres per site. Due to the small size of these sites and the quality of the remains found there, it has not been possible to determine the seasonality of use nor whether the sites were habitation or foraging sites. Linear earth embankments, similar to those found at Fort Center near Lake Okeechobee, have been documented at three Everglades sites (Carr 1985). According to Sears (1982), these mounds are indicative of early drainage efforts for the purpose of introducing maize horticulture from south America. McGoun (1993:74-84) believes instead, that they are the remains of elaborate decorative, ceremonial, or burial mounds. His argument is based on the similarity of these mounds to those built by a vast number of widely distributed North American culture groups said to follow a generalized "Hopewellian Tradition." As yet, the issue remains unresolved and highly controversial among archaeologists. 
Table 5 A few interpretations of the "Glades Tradition" chronology.

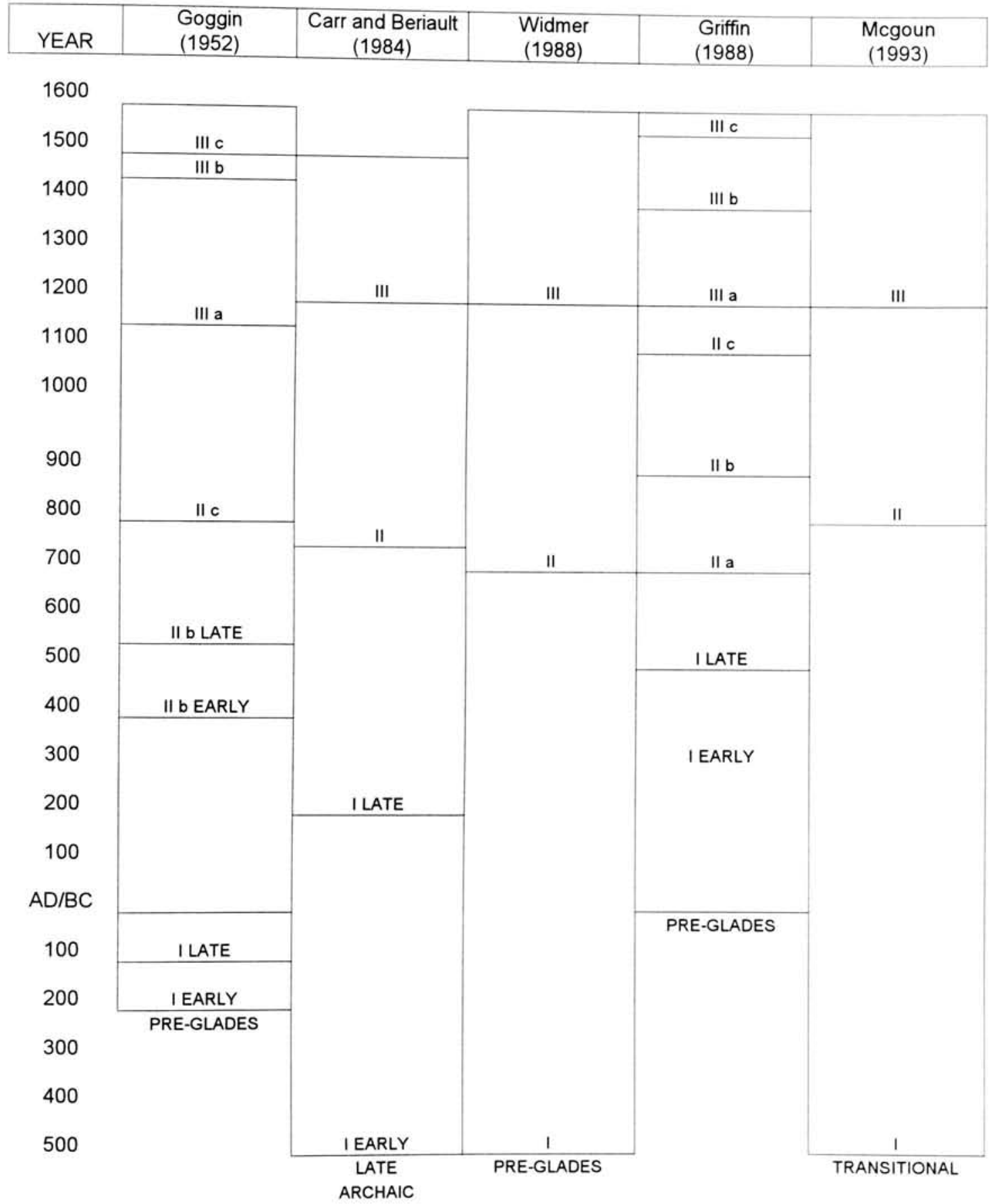




\section{Table 6 Ceramic marker types by period.}

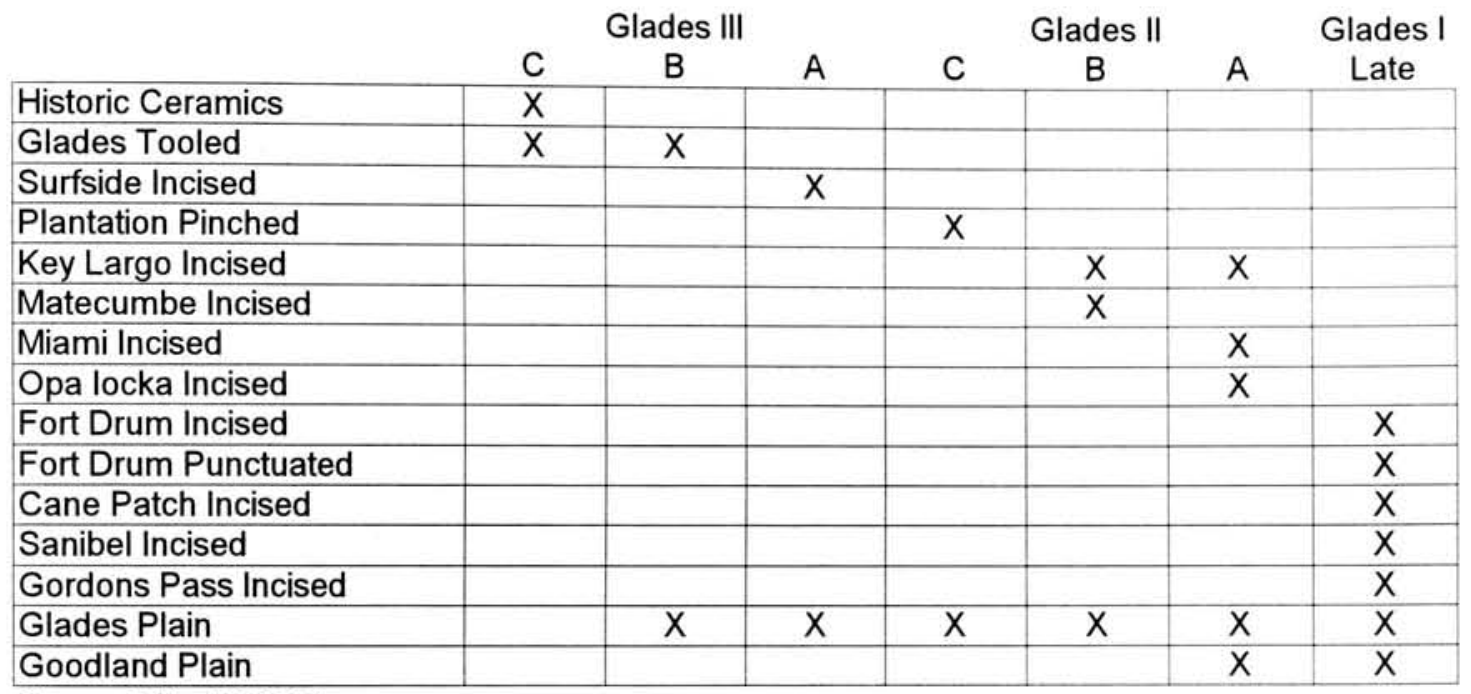

Source: Griffin 1988:124 


\section{Technology}

This section presents a detailed review of the coastal and inland subsistence strategies of the Glades Tradition. The discussion of subsistence strategies includes a profile of faunal and floral habitat-specific selectivity and techniques of procurement and use of resources. It is assumed that the subsistence strategies described in this section typify those of the Tequesta culture group. In addition to the subsistence strategies, a brief discussion of the house structures is also provided.

Most coastal sites were located in a close geographical proximity to the Granada site making it likely they shared a similar set of subsistence strategies. The only exceptions were the coastal sites located in the mangrove fringe near Florida Bay, which have not yet been studied. Therefore, the majority of the discussion on coastal subsistence is based on documentation from the Granada site (Scarry 1982; Wing and Loucks 1982).

The studies of inland sites are very limited in number, so the extent to which the Everglades region was exploited during the Formative period is unclear. Carr (1984) believes that the interior of the Everglades was heavily utilized, while Milanich (1987) suggests it underwent only minor occupation. Griffin (1988:277) believes that the Shark River slough may have been a major district of settlement used for hunting and gathering by Indians from 
the east coast. Yet, he indicates that additional research is recessary to establish specifics regarding the seasonality of use and the particular strategies used during different seasons (p. 341).

In order to add insight to the use of the Everglades region, evidence from two of the most documented inland sites is analyzed to reveal subsistence patterns. The data reviewed includes zooarchaeological finds from the Panther Mound site (Griffin 1988:252-257) and paleoethnobotanical (Scarry et al. 1991) and paleoethnozoological reports (Masson and Hale 1991) of the Honey Hill site.

\section{Coastal zone faunal subsistence}

Bony fish were consistently the most frequently exploited species in coastal sites, followed in decreasing number by reptiles, mamnals, birds, and amphibians. Yet, the largest proportion of the estimated biomass was represented by nonbony sharks and rays, which together accounted for over 50 percent of the total biomass, followed in decreasing order by sea turtles and deer (Griffin 1988:289; Wing and Loucks 1982).

\section{Habitat-specific selectivity}

Scarry (1982) estimates the catchment area of the Granada site to be the surrounding circular area with a ten kilometer radius. If all major coastal sites are considered 
to have a similar catchment area radius, they would all have had access to the same types of vegetation comunities. The prehistoric vegetational communities of their catchment area would have included mangroves, hammocks, salt marshes, wet prairies, dry prairies, pinelands, scrub, and beaches.

Wing and Loucks (1982) defined four major faunal habitats represented by these commuities. These include, the terrestrial, freshwater, bay, and reef habitats. They found the bay to have been by far the single most intensively exploited habitat. This was followed accordingly by reef, terrestrial, and freshwater exploitation.

The bay habitat was defined as the estuarine area of Biscayne Bay, represented by the seagrass beds and sandy bottoms. Most of the arimals characteristic to the estuarine habitat were popular food resources. The most intensively exploited animals from this habitat were requiem sharks (Galeoidea) and sea turtles (Cheloniidae). other species included the marine catfishes (Ariidae), toadfish (Spheroides nepheIus), and snappers (Lutjanus spp.) (Ibid).

Notably missing in the archaeological assemblage from the estuarine habitat are the remains of mullet (Mugil cephalusl. This is significant since these animals are anomolousiy large herbivores and as such would have provided a substantial amount of food at a very low energy cost (widmer 1983). It has been suggested that this anomaly may be the result of a low concentration of prehistoric mullet, 
a mullet taboo, or a poor preservation quality of mullet remains due to particular preparation techniques (McGoun 1993:94).

Another bay associated animal that was an important. source of food for the coastal residents was the whale (Cetacea). Whales were frequent in the bay during winter, particularly in January (Griffin 1982:387). The most frequent was the North Atlantic right whale (Eubalaena glacialis), which, although usually captured in the bay, is a wide ranging migratory species (Larson 1980:160).

There has been only one whale vertebrae specimen found in Dade County, in Key Biscayne (Bob Carr personal communication 1993). This lack of evidence does not necessarily mean that whale was not an important resource. Rather, the paucity of evidence may be the result of the practice of cutting and carrying away the whale meat while leaving the heavy skeletal remains on the shore to decompose or wash away. In fact, the popularity of whale meat is supported by the number of eyewitness accounts with regard to whale hunting techniques in the Tequesta region, many of which have been documented and summarized by Larson (1980: $145-162)$.

The reef habitat is represented by the patch and bank reefs east of the barrier islands. The reef fish most commonly exploited were also those most commonly associated with this habitat (Wing and Loucks 1982). The two most 
intensively exploited fish included the barracuda (Sphyraena barracuda) and jacks (Centropomus spp.). Other fish included grunts (Haemulon spp.), tiger shark (Galeocerdo curieri), lemon shark (Negaprion brevirostris), sharpnose flying fish (Exocoetus volitans), porgies (CaIamus spp.), and groupers (Serranidae).

The terrestrial habitat was defined as the wet prairies, hammocks, and pinelands. The most commonly used species from this habitat was white tail deer followed by the gopher tortoise (Gopherus polyphemus). Although deer remains were infrequently found in comparison to marine resources, they represented the third highest total yield of estimated biomass found in the Granada site throughout the Formative Period (Ibid).

The freshwater habitat was defined as swamps, freshwater marshes, ponds, streams, and rivers. The most popular food resources from this habitat included bowfin, gar, sunfishes and largemouth bass (Ibid).

The archaeological evidence suggests that resources from the bay alone could have supplied the caloric and protein intake required for survival on a year round basis. Yet, it was probably less utilized during the cold months during which time whales may have been the predominant source of meat. The majority of the total estimated biomass of the animals exploited around the Granada site throughout the Formative Period, was represented by three bay species, the 
requiem sharks, rays, and sea turtles. These would be available year round, but would be more easily caught during summer and early fall due to behavioral patterns associated with their reproductive cycles. Deer would be more commonly hunted during the wetter fall months, between July and August. They could also have been easily hunted on high grounds during wet winters or during their spring rutting season.

\section{Coastal zone floral subsistence}

The diversity of available edible floral resources from the combined vegetational communities represented in the catchment area of the Granada site (Scarry 1982) is extensive. Despite the high diversity, the remains of only a few edible plant species dating to the Glades Period have been found. This may be due to both poor preservability of plant remains and a low intensive exploitation of plants in comparison to animals.

The paleoethnobotanical evidence indicates that the most consistently and intensively exploited plants by coastal residents included the false mastic, cocoplum, cabbage palm, saw palmetto, sea grape and pigeon plum, and hog plum (Ximemia americana). The fruit of all of these species and the terminal buds of the palms are edible.

All of the remains of edible plant are of species supported by hammock communities, but some may also occur in 
pinelands, beaches, and mangroves. Most of these plants fruit in the fall, except for the false mastic, which is available throughout the year. This led Scarry to believe that the various plant foods were probably collected during the fall.

\section{Habitat-specific selectivity}

Hammocks support the highest variety and abundance of edible wild fruits of any plant community in Dade County. Although several fruits in hammocks are available year round, the main fruiting seasons are in the spring and fall. Pinelands support several species of fruits the most important and abundant of which is the saw palmetto. Other significant species include locust berry (Byrsonima cuneata), silver thatch (Coccothrinax argentata), and cabbage palm. There are a few species that are available all year, but spring and fall tend to be the main seasons of abundance followed by summer and winter.

Beaches support the, sea grape, and Spanish bayonet, and a few other plants with edible parts. The majority of these plants are available either in the summer or year round, but a few are available only in the spring or fall. In mangrove communities, the plant most represented in the floral record is cocoplum. However, several other plants from this community are known to have edible by-products, including the pond apple (Annona glabra), black mangrove, and red 
mangrove. The majority of the edible plants in the mangrove community are available year round or only in the summer. but a few are also available in the spring or fall.

Scrub, salt marshes, freshwater marshes, and wet and dry prairies have a more limited variety of edible plant species. The most significant plant food available in scrub communities included oak, hog plum, and several green briar (Snilax) species. The salt marshes provided red and black mangrove sprouts year round (Scarry 1982). Some of the most significant plants in freshwater marshes include cattails, Cladium, Thalia, and Sagittaria spp. whose rhizomes are a valuable source of starch and could have represented one of the staple foods. Dry prairies supported small number of saw palmetto and various edible grasses (Poaceae). The wet prairies also supported some edible grasses.

\section{Inland zone faunal subsistence}

The subsistence diet in inland areas was predominantly from animals associated with localized inland habitats. Turtles and bony fish were the most intensively exploited animals in inland sites during the Formative period, representing the highest biomass of all species. Less frequently exploited were snakes and alligators, mammals, birds, and amphibians. Modified remains of some marine species are sometimes found in inland sites, these are most commonly shark teeth and ray spines. It is assumed that 
these were transported from the coast to be used as tools. Marine bony fish vertebrae have also been found in inland sites. These were likely food sources that were preserved to be used in route to the inland locations or once at the site.

\section{Habitat-specific selectivity}

The catchment area for the Honey Hill site was defined as the area most readily accessible by canoe transportation. The catchment area was divided into terrestrial (hammocks and pinelands) and wetland (swamps, marshes, rivers, ponds, sinks, and canals) habitats (Masson and Hale 1991). The remains dating to the Formative Period found in this site are of the same types of species as those I previously listed in the Archaic Period section, but are found in larger quantities. All remains found in the Honey Hill site were of inland zone habitats. The most common remains of species found were those of turtles and bony fish. Turtles represented the highest biomass, but fish represented the highest number of individual species caught.

Dating of the Honey Hill remains indicates that turtles were caught more frequently in the late Archaic and Glades II and III Periods than the Glades I Period. During the Glades I Period, fish were caught more frequently, but still represented a lower biomass than turtles. This may indicate periodic overexploitation of turtles leading to their 
depletion and consequently, a use of fish as an alternative resource. It also raises the question as to whether turtles may have been cultivated in the later Glades periods accounting for their resurgence (Masson and Hale 1991).

The Panther Mound site is located on the northern tip of a tree island in the Shark River slough, about eight kilometers south of the Shark valley lookout tower. No catchment area has been defined for this site, but the most significant environmental features in the surrounding area include the Shark River Slough, freshwater marshes, and tree islands. The remains found at the panther mound site were predominantly of species associated with local habitats, but some remains of marine species were also found. The most commonly found remains of local species included those of turtles and alligator, followed by bony fish, mammals and birds (Griffin 1988:252-255).

The most abundant remains found at Panther Mound were those of several turtles including the softshell turtle, snapping turtle (Chelydra serpentina), and box turtle (Terrapene carolina). Gar vertebrae were the only identifiable freshwater bony fish remains. Deer and raccoon bones were the only identifiable mammalian remains. Great egret (Casmerodius albus) remains were the only identified for bird species (Ibid).

The marine species remains included a few shark vertebrae and teeth and ray spines, some shellfish, and a considerable 
amount of bony fish vertebrae. The most common marine bony fish remains found were those of crevalle jack (Caranx hippos) and black drum (Pogonias cromis). The shark and ray artifacts were brought from the coast probably to be used as tools. The substantial amount of marine bony fish vertebrae indicates that they were a food source. In order to be used as food they must have been preserved, possibly by smoking or drying (Ibid).

Based on these finds, I believe that the wetland habitats provided the largest number of the staple foods in inland areas. The terrestrial inland habitats were exploited mainly for deer. The combination of turtles, bony fish, and deer represented the overall inland diet. Although this would have been more likely in the wet season, due to the increased availability of deer at that time. During the dry season, small mammals might have replaced deer as a source of meat, yet this would still be secondary to turtle and fish.

\section{Inland Zone Floral Subsistence}

The diversity of available edible plants within the catchment are of the Honey Hill site is somewhat less than that of the Granada site, but nonetheless still quite extensive. Yet, like the Granada site, the number of species consistently used was very limited. The single most zommon species was the false mastic followed by saw 
palmetto, pokeweed (Phytolacca spp.), cabbage palm and various grasses (Poaceae). All of these species could have been located in hammock communities. Of the three resource areas comprising the catchment area of Honey Hill (as defined by Scarry et al. 1991), the Everglades represents the highest diversity and abundance of edible plants followed by hammocks and pinelands.

\section{Procurement and use of flora}

The methods used for gathering plants and plant parts probably involved manual picking, cutting, or chopping and different carrying techniques. The non-food use of specific floral resources is not well known. Based on some findings in the Key Marco area, it has been hypothesized that some type of palm fiber may have been used to make the cordage for fishing nets (Gilliland 1975:237). Spanish accounts of the Indian clothing described breech-cloths woven of palm and dresses from a grass that resembled Spanish moss fiber (Griffin 1988:148). In addition, due to the various physical properties of the different plants, many of the basic uses may have been similar to those of later culture groups. For example, cypress is rot and termite resistant making it an ideal wood for canoe making and chickee construction by the Florida Miccosukee, the hard and sturdy Dade County slash pine was used by early settlers for construction, and the large palmetto fronds are still used 
for the thatched roofs of the chickees. Several other uses of plants by the Miccosukee are listed by sturtevant (1959), many of which could also have been used by the Tequesta.

\section{Procurement and use of aguatic fauna}

There were various specialized techniques employed to capture aquatic fauna. The techniques varied in complexity according to the type of fauna being procured. The techniques used to hunt sharks, rays, and sea mammals involved the greatest technological complexity. The techniques used to procure small bony fish were less complex but more involved than those used for procuring turtles and most invertebrates. Shark teeth frequently were modified for use as tools or ormaments. Barracuda jaws were also frequently modified (Griffin 1988).

\section{Sharks}

Sharks would have been caught either in the Biscayne Bay area or Atlantic Ocean regions. In the Biscayne Bay, sharks, particularly Requiem sharks, would have been most frequent during their nursing period, between July to October (Griffin 1982:387). Many techniques for catching sharks have been proposed. Borhegyi (1961) suggests that the pre-contact Maya hooked sharks with a leaderless line bringing them up to their canoe and then clubbing them to death. Larson (1980:81-95) presents a number of arguments 
to show why these techniques could not have worked. Wing and Loucks (1982) report that spears, nets, traps, and weirs were likely used to catch sharks and other more dangerous fish. Larson (1980:99) believes that sharks were primarily caught in the shoal waters of tidal estuaries using these techniques. This would be particularly efficient since the schooling habit of sharks would have resulted in a relatively easy capture of large numbers of sharks.

Archaeological evidence indicates that shark's teeth were used for making various cutting and carving tools, adzes, and weapons (pp. 101-102). Although not evidenced in the archaeological record, their tough scaly epidermis may have also been used as a type of sandpaper. Another notable use of shark may have been the use of the shark liver as the most abundant source of edible oil in South Florida.

\section{$\underline{\text { Rays }}$}

Rays also tend to travel in large schools, suggesting weirs and traps may have been an attractive means of capturing them. Larson (1980:99) suggests that the natural rise and fall of the tide in areas where weirs were constructed may have served as holding pens where the rays could be contained until used. Other than food sources, modified stingray spines indicate that they may have been used as piercing tools. 


\section{Manatees}

The best description of the techniques used to catch and kill manatees is presented in the eyewitness account by Velasco (1569), which is reprinted in Parks (1982:30). Although recorded after contact, this practice probably existed before contact.

In winter all the Indians go to sea in their canoes to hunt for sea cows. One of their number carries three stakes fashioned to his girdle and a rope or his arm. When he discovers a sea cow he throws a rope around its neck, and as the animal sinks under the waves the Indian drives a stake through one of its nostrils and no matter how much it may dive, the Indian never loses it because he goes on its back.

According to Velasco, manatees were important in a ritualized Tequesta religious practice, the meaning of which is not clear. After killing of the manatee, they would cut open its head and remove the two largest bones. These bones would then be placed with the bodies of the dead (Hollingsworth 1949:11).

\section{Whales}

If a whale was spotted in shallow waters several canoes would set out from shore for the hunt. After surrounding or 
impounding the whale, a single Indian would jump on its back and drive a stake into its blowhole eventually causing asphyxiation. The whale was then towed to shore and butchered (Larson 1980:152). Due to the considerable amount of meat obtained, surplus whale meat may have been a stored food resource.

\section{Small bony fish}

Some of tools that may have been involved in fishing activities include hooks, line, line floats and sinkers, nets, net floats and plummets, spears, and traps. of these. the hooks and plummets are the best represented in archaeological collections. Wood and bone points resembling hooks and several modified whelk columnela and stone plummets have been found. It is possible that the other tools made out of plant materials (gourds for floats, plant fiber for nets) are not well represented due to their poor preservation characteristics (Larson 1980:115-126).

Angling, spearing, and trapping were methods that could be carried out by individuals, while the use of weirs probably required a group effort. Alternating flow of water in coastal areas would have made trapping more difficult there than in small freshwater streams. Bony fish in the freshwater habitat were probably caught during the dry season when they became more concentrated. Marine fish were available year round except in the coldest months (Ibid). 


\section{Turtles}

The freshwater turtles could be caught by hand or in basket traps. They were available throughout the year except in the coldest months (Ibid:131). Sea turtles were most frequent during their egg laying season beginning in April, when they would have been easy catch on full moon nights as they came upon the beach to nest. In the water, they could have been caught by spearing, noosing, or by nets. They could also have been taken by hand by divers. It is not clear whether freshwater turtles and sea turtles were kept in holding pens, or possibly bred. If sea turtles were kept, they could have been maintained over spring and summer to be used during the winter shortage lGriffin $1988: 293-294)$.

\section{Invertebrates}

The mollusca such as oysters, and clams could be collected using sticks and hammers. The collection of these species was easy enough so that women carrying infants and children of both sexes could participate in it. The high degree of participation in mollusc collection from this sector of the population may help explain the large number of collected species in the archaeological record. Gastropods such as the queen and horse conch and the whelk required diving skills and manual collection. Crustaceae such as shrimp and crabs were probably collected with the 
aid of nets or with the use of baited lines and sticks (Larson $1980: 66-80)$.

According to Griffin (1988) the large number of shell artifacts found throughout South Florida may actually be due to a more valued importance in non-food usage than as food. He provides an extensive list of many of the different shell tools and componerts, ornaments, and other implements which have been found in South Florida (pp. 80-91). Many of the larger shellfish, like conchs and whelks were modified to be used as tools such as hammers, adzes, picks, blades, celts, chisels, awls, knives, drinking vessels, saucers, spoons, as well as beads, gorgets, and pendants. According to Hollingsworth (1949:11), a special drinking vessel made out of large conchs was used exclusively by chiefs and shamans in an anmual "Black Drink" ceremony.

\section{Procurement and use of terrestrial fauna}

There were a limited number of techniques used in the procurement of terrestrial fauna. For terrestrial resources, hunting deer was more complex than that of smaller mammals or other fauna. The finding of modified bones may indicate they were used as tools or for other reasons. Intentionally modified bones were predominantly long, straight limb bones from deer. 
Deer

There is some question as to seasonal patterns of use of the terrestrial habitat, particularly with regard to deer hunting. Several models of deer hunting strategies have been proposed. One model suggests that rainy season hunters found deer on dry ground. An alternative view suggests that late fall and winter would have been seasons of more intensive deer hunting. The second model is based on the assumption that deer would have been attracted to horticultural gardens where the people tending them would have then killed them (Larson 1980:166-172). Another hypothesis is that hunting occurred during the spring rutting season, when large groups of deer congregate on high ground.

\section{$\underline{\text { Small mammals }}$}

Small mammals like rabbits, raccoons, bobcats, and opossum probably were trapped. Trapping was facilitated by the territoriality of the bobcat, and nocturnal nature of opossum. Small mammals were likely to have been more valued for their skins than for food. Although the ease of trapping them could have provided substantial yield of meat on a regular basis (Ibid:175-181). 


\section{Tortoises}

Another important terrestrial species was the gopher tortoise, endemic to scrub and beach strand communities. They were most easily collected during spring, the season in which they leave their burrows (Ibid:136-137).

Snakes, alligators, amphibians, and birds

The methods of snake, alligator, amphibian, and bird collection are unknown. It is assumed that snakes were not regularly preyed upon but rather were incidental resources that were caught by chance. It is possible that due to the low number of alligator remains found in south Florida, that they may have been considered to be a taboo species (Griffin $1988: 293)$.

\section{House structures}

There is a scarcity of archaeological evidence regarding the distribution or structural design of shelters or houses of the Formative Period. Most of the information about houses comes from ethnohistorical descriptions of large coastal houses believed to be either the residence of chiefs or ceremonial structures. In 1566, Menendez mentions that a large Formative Period house located in the southwest coast had windows and enough room for more than two thousand men (Kerrigan 1951:104). Another description of a similar structure, but near the Miami River area, was provided by 
Brother Villareal in 1743. He also mentioned the existence of five "huts," which together housed around 180 Indians (Griffin 1988:147).

\section{Social Dimension}

Although the Calusa were the most significant of the PreColumbian Era culture groups in South Florida there were several other smaller groups of importance. The Tequesta were the most notable of these several small, similar sociocultural groups which extended from Broward county south and west into Collier County as far as the Ten Thousand Island area (Milanich 1987:232). The name "Tequesta" was coined by Spanish explorers who followed a practice of naming the Indians and their settlements according to their understanding of the name of the person they perceived to be the chief who lived there (Parks 1982: 14). There is no ethnographic mention of the exact spot of the major Tequesta village. However, early descriptions of the site by the geographer Juan Lopez de Velasco (in Parks 1982:27, translated by John Hann) indicate that the area around the mouth of the Miami River was the location of the main village and the residential area of the man perceived to be the chief.

The first recorded contact with the Tequesta Indians of South Florida was that of Juan Ponce de Leon on 1513. However, there were indications that this was not the first 
contact between the South Florida Indians and outsiders. On the east coast, he was met with hostility by the Indians (Ais?), probably due to earlier experiences with Europeans. On the west coast, at or near charlotte harbor, he encountered a Spanish speaking Indian among the Calusa (Griffin 1988:143). According to Davis (1935: 20), it was believed this individual may have originated from Hispaniola or another island occupied by the Spaniards.

Some of the best inferences about the culture of the precontact Tequesta are based on the menoirs of a shipwrecked Spaniard, Hernando Fontaneda (1944). He lived among the South Florida Indians (Calusa) during 1549-1566 until he was rescued by Pedro Menendez de Aviles (Lyon 1976:148) who had been sent in an attempt to colonize Florida for Spain. The Spaniards brought along Jesuit priests between 1566-1568 and stationed them in various Indian towns, including Tequesta, in an attempt to convert the Indians into Christians (Griffin 1988:144). Other known ethnography of South Florida at the time of contact is based on various letters and reports written by Menendez, and several Jesuit priests. Other first-hand information written about the Tequesta includes some accounts from the Spanish historian, Barcia (translated by Kerrigan 1951), and descriptions of the Tequesta village by the Spanish geographer velasco (memoirs originally published in 1893, translated version by Hann published in Parks 1982). Much of this information has been 
summarized by Goggin (1940), McNicoll (1941), Goggin and Sturtevant (1964), and Parks (1982).

\section{Migratory patterns}

It is apparent that Tequesta settlement was not completely sedentary, nor were they free wandering nomads. Evidence from the Granada site indicates that they practiced fixed migration patterns on a seasonal basis. The Granada coastal site was occupied during the dry season beginning in fall until the end of spring (Griffin 1982:382-389), when they shared the marine resources. A Jesuit priest stated in a letter dated 1567 A.D. that for three or more months following spring, almost the entire village population would go to an island (Key Biscayne?) to escape from the mosquitos (Parks 1982). However, some of the population also went to the Everglades during the wet season for hunting purposes (Griffin 1988:388). Milanich (1987:235) believes they divided into smaller groups, perhaps families or lineages, and moved farther inland to use the animal and plant resources of the marshes and swamps.

Another regular migration pattern was based on the communication networks the Spaniards noted between the Tequesta and the Calusa on the west coast. Unfortunately, the Spaniards did not indicate which route was followed. McGoun (1993:31) posits that the main route was probably by sea. This he believes was due to the lack of resources or 
human presence that would have been encountered if they traveled through the Everglades. The issue remains unresolved.

Population

There are few sites throughout South florida having Glades I characteristics compared to a much higher number having Glades IIa characteristics. This indicates that the population was steadily growing during this time period. The quantity of ceramic artifacts begins to decrease with the beginning of the IIb period, and by IIC the number of sites containing diagnostic pottery is greatly reduced. The Iargest abundance of archaeological sites from Glades IIC and IIIa have been found near Taylor slough and Monroe Lake, in the southern Everglades region. The significant absence of IIc and IIIa ceramics has been tentatively explained by Griffin (1988:137-141) as a consequence of a reduction or move of the population from previous sites due to an anomalous warm speil during A.D. 900-1200. He believes that a trend towards population growth did not start until the beginning of Glades IIIb (ca. A.D. 1400). He bases this belief on the abundant appearance of a new style of ceramic design at that time (pp. 141-142). The emergence of the new ceramic style has also been hypothesized to indicate increased contact with other culture areas, particularly the central Gulf Coast (McGregor 1974:27). 
There is some disagreement with regard to estimates of actual population size of the Indians of South Florida at time of contact. Griffin (1988:151) provides a review of some of the historical figures. These included early estimates of 10,000 for Florida as a whole to Dobbyn's (1983) calculations of 195,200 for South Florida alone, including 48,800 in the southeast coast. Goggin and Sturtevant (1964) calculate the Calusa population ranged from about 4,000 to 7,000, while Milanich (1987) believes it to was around 10,000 to 15,000. McGoun (1993:30) agrees with Milanich and estimates the Tequesta population at about 2,000. Dobbyn's (1983) high estimates are based on his belief that the Calusa had established maize agriculture prior to contact with the Europeans. This issue remains unresolved.

\section{Socio-political oxganization}

The Tequesta are believed to have been a daughter settlement of the Calusa chiefdom. The relationship between the two may have been influenced by relative efficiency each group exhibited in the exploitation of natural resources. According to McGoun (1993:93) and Widmer (1988:272-3), the Calusa maintained a ramage type chiefdom during the period of expansion, from 500 A.D. to around 800 A.D. Once the daughter settlements increased their control over the resources in their local environment, a unilineal descent 
group type of chiefdom developed. In ramage chiefdoms, the daughter settlements would have maintained ties to the parent settlement while in the unilineal system they became self reliant, but maintained lineage members in their village.

This trend towards economic self reliance eventually influenced the political sphere of the Tequesta. This may be noted in the behavior witnessed and described by Barcia (Kerrigan 1951:134). He indicates that Carlos, the CaIusa chief, had traditionally requested the Tequesta chief to turn over shipwrecked or captured prisoners for execution. He complied at first but with time refused and eventually battled Calusa soldiers in the struggle to establish political independence.

The political independence of the Tequesta permitted distribution of resources and power exclusive of the calusa. This distribution was highly stratified according to the different positions of individuals in the society. The top class consisted of the king and his nobles and captains, followed by the vassals, and finally the common people. Also included among the top class were individuals with religious statuses such as priests and sorcerers, and warrior statuses. From this top class, a council of leading men may have been selected (Griffin 1988:148).

In addition to the uneven distribution of resources, there was a geographic pattern in their exchanges. This 
pattern may be described as a form of redistribution characterized by a trading system between coastal and inland zones and also between the east and west coasts. Based on the artifacts found in inland sites, the coastal resources traded would include only non-food marine resources such as shark teeth, shell tools, or ray tail points. More difficult to determine is the nature of the inland resources that may have been traded. They may have traded vegetable material including root crops, fruits, berries, and nuts not available along the coast. They may have also traded hides from animals more abundant in the inland areas. With regard to trade between the coasts, widmer (1988:275) believes that shipwrecked captives may have been the most important trading resource.

\section{Cognitive Dimension: Religion}

Just as the sociopolitical organization of the Tequesta was similar to that of the Calusa, the type of religion practiced was probably similar. I base this hypothesis on the probability that the two chiefdoms may have been closely related cultural groups and therefore, shared similar beliefs about the supernatural. Additionally, according to Wallace's (1966) model of religious evolution, the type of religion practiced by a society is closely associated with its level of sociopolitical organization. In his model, chiefdoms are closely associated with what he calls olympian 
religions, which are characterized by the belief in a hierarchical pantheon of gods and the existence of full time priests.

The characteristics of an Olympian religion were indeed present in the Calusa religion. They may have been present in the Tequesta religion as well. The Calusa believed in a three-god hierarchical pantheon. The first, and most powerful god, ruled the celestial matters and the climate, the second was involved with the rule of kingdoms and empires, and the third, and least powerful, dealt with warfare (Griffin 1988:149; Mcgoun 1993:18). In addition, each of the separate Calusa settlements had a shaman (called an obispo in Spanish) who was believed to have the power to call the wind by whistling and to divert storms with other cries. Another type of shaman could foretell the future and cure the sick (Mijanich 1987:236).

Although plants and animals provide food and material, their role in religious rituals also is significant. One of the best sources of information concerning the role of plants and animals in the religion of the Tequesta comes from the letter written by Father Joseph Maria Monaco and Joseph Xavier Alana to the King of Spain in 1743 (translated by Hann 1987). An excerpt of this letter is provided below (an earlier translated version appears in its entirety in Parks 1982:56-65). Since the Indian population in 1743 consisted of remnant Indian populations from all of South 
Florida, it is not possible to say that these practices were particular to the Tequesta. Rather, the persistence of these practices should indicate that certain beliefs were acceptable to, if not characteristic of, their religion.

We saw two idols. The principal one (called Sipi or Sipal) is a board sheathed in deerskin with its poorly formed image of a fish that looks like the barracuda and other figures like tongues...

The other idol, which is the God of the cemetery, the theater of their most visible superstitions, was the head of a bird, sculptured in pine, which in the matter of hideousness well represented its original... We also saw a large log which, on certain days, they adorn with flowers and with feathers and celebrate...

(Parks 1982:56-65)

Unfortunately, it is not clear from the above translation what type of bird represented the God of the cemetery or what types of flowers or feathers held ceremonial value. Other roles for plants and animals in the religion of the Tequesta came into play in their behavior associated with the treatment of the dead, who were greatly feared by the Indians. Names of the dead could not be said and the dead were buried in graveyards located away from the villages. The temple in the graveyards also contained masks used inby 
the Miami Rock Ridge and to the west by the Dade-Monroe rituals held to honor the barracuda idol. Daily offerings like turtles, barracuda, and tobacco and other herbs were placed on the graves to pacify the dead Milanich 1987:23637).

\section{SUMMARY OF CHAPTER III}

Evidence about Pre-Columbian land use in Dade county is limited by a paucity of local archaeological sites, particularly those dating to the Paleo-Indian and Archaic periods. A substantial amount of evidence concerning coastal subsistence has been found, but restricted to Formative period sites. In contrast, only a limited amount of data concerning inland subsistence have been documented, but found in sites from all Pre-Columbian periods. A summary of the information discussed about the archaeological sites examined in this chapter is presented in Table 7. Presented below are some of the environmental conditions encountered by the peoples of the different PreColumbian periods and some of the land use strategies that were developed to respond to them.

During the Paleo-Indian Era, the climate was much drier with cooler summers and warmer winters, with high winds and shifting dunes throughout most of northern and central Florida. These climatic conditions meant residents of what 


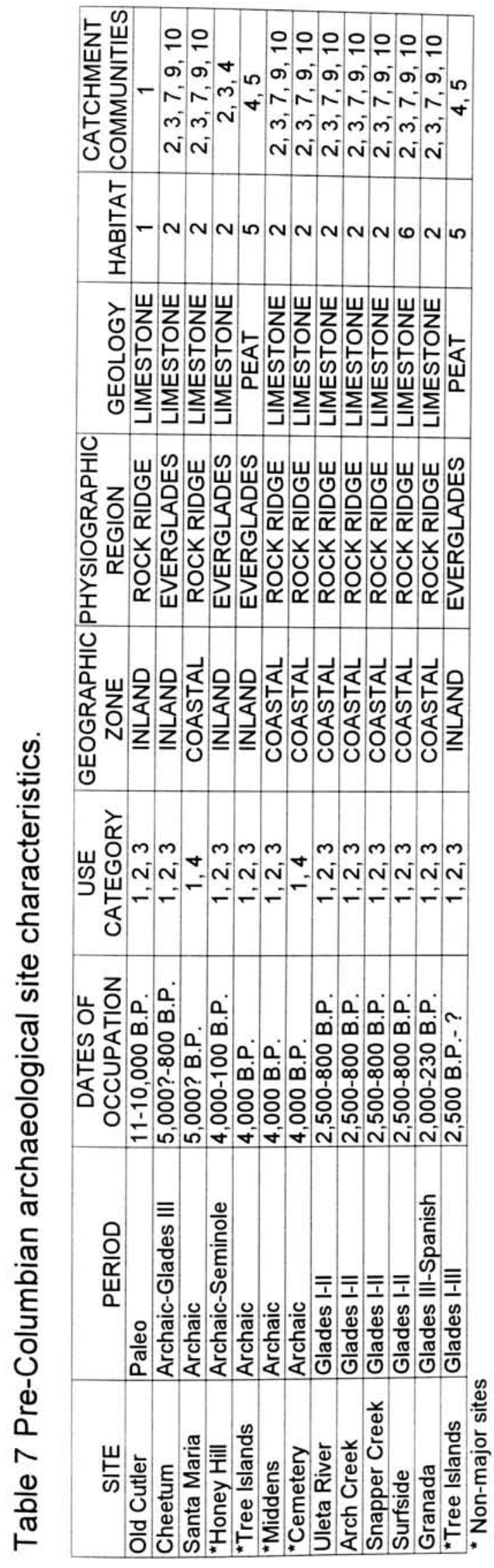

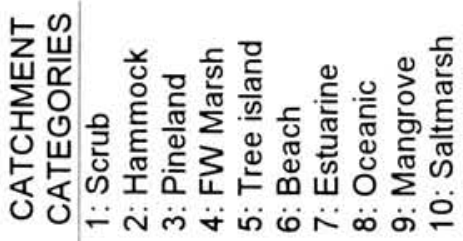

品
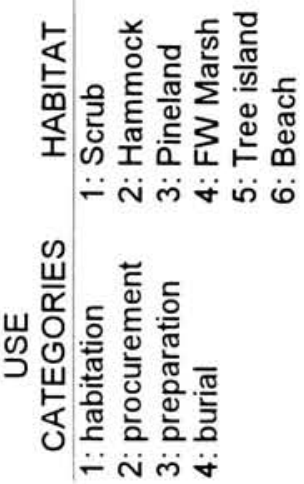
is now Dade County had to cope with scarce Ereshwater resources and a barren landscape. This was in addition to the problems created when short periods of environmental stress resulted from sharp variations from the average climate patterns.

Some of the latent enviromental benefits included the presence of large-game and various smaller animals, and possibly shellfish and other marine life. In order to take advantage of these, Paleo-Indians had to find, catch, and kill the animals, and then prepare, and possibly store the flesh from such animals. These would have been particularly difficult tasks when the prey were potentially dangerous and large.

Only two Paleo-Indian sites have been found in Dade County. At time of occupation they were both inland sites. Evidence from these sites indicates that prior to 10,000 B.P., Paleo-Indians were predominantly big-game hunters. Successful hunts of big-game would provide Paleo-Indians with caloric and protein intake requirements for long periods of time if the meat could be preserved. Since the natural migration patterns of these animals followed the distribution of freshwater resources, hunters could also resolve the problem of finding water. In between successful hunts, nutritional requirements could have been provided by smaller game, which could be caught more easily and Erequent1y. By 10,000 B.F., successful big game hunts 
became less frequent, and smaller animals were hunted more intensively. This shift may have been due to a decrease in big-game population caused by the combination of a reduction in big-game habitats associated with a changing climate and Paleo-Indian predation.

Evidence found in the old Cutler site indicates that hunters used lithic tools and weapons, mostly from chert. Chert must have been of extreme importance, particularly if it was also used for making fire stones. Fire could have been used to cook meat, provide heat and light, and possibly to attract big game by burning scrub to induce herbaceous growth. Given the importance of chert and the lack of local sources, Paleo-Indians developed communication and transportation networks for its import from outside sources.

Although no evidence of Paleo-Indian botanical subsistence has been obtained, most archaeologists believe that plant foods served only as a supplement to the paleoIndian diet rather than as staples. Nonetheless, plants probably were important for other uses, such as for making of tools, shelters, and clothing.

There are only two major sites in Dade County dating to the Archaic Period. These are the Cheetum and Santa Maria cemetery sites, Of these, only the Cheetum site provides some insight regarding Archaic Period subsistence. The only other Dade County site for which Archaic period subsistence data exists is the Honey Hill site. Both of these sites are 
located in the inland zone.

There is about a 6,000 year gap in most of south Florida's archaeological record between the Monkey Jungle and old Cutler fossil sites (ca. 11-10,000 B.P.) and the Cheetum and Honey Hill sites (ca. 5-4,000 B.P.). One possible explanation suggested for this absence is that an South Florida experienced an exodus during this time period. The reasons may have been due to problems caused by drastic environmental changes associated with an excessively warm and dry period during 9,000 B.P. to 7,000 B.P., and the extinction of all megafauna by 6,500 B.P.

By 5,000 B.P. the climate was moister, sea levels were at approximately the present levels, and the modern South Florida flora began to develop. The moister climate allowed freshwater to accumulate and must have also attracted hydric animal species, including amphibians and mosquitos. The inland Everglades environment was still incomplete and many of the present tree islands were still under water. It was in this environment that the subsistence strategies of the Cheetum and Honey Hill sites unfolded.

Although scant, evidence from the Cheetum and Honey Hill sice indicate that the three most important subsistence sources were turtles, bony fish, and deer. These were probably supplemented by snakes and small mammals. The most common plant remains dating to the Archaic Period found in the Honey Hill site were those of false mastic. In addition 
to localized resources, a wide range of marine shell and non-local chert artifacts dating to the Archaic Period have also been found in the Cheetum site.

During the Archaic Period, the biggest man-induced impact to the natural environment were periodic depletions of bony fish and turtle populations that were over-exploited. The response to this was to alternate between the two resources. It has also been suggested that the technology of turtle farming may have been developed as an alternative strategy to cope with this problem.

By the beginning of the Formative Period, the sea level reached its modern level and vegetation communities extended to their present distribution. The peoples of the Formative Period likely faced problems and opportunities similar to those of the Archaic peoples. However, the resources may have been more productive and the social organization of the Formative people more capable of directing successful exploitation of resources. Therefore, the main difference between the Archaic Feriod subsistence and that of the Formative period is likely one of quantity rather than quality.

During the Formative Period, the coastal zone was more intensively exploited than the inland zone. The Biscayne Bay and Atlantic ocean were the most valuable regions for basic subsistence. The Biscayne Bay also provided materials modified into tools, decorations and other utilitarian 
goods. To take advantage of the marine resources available, Indians developed specialized fishing tools and some form of canoe or boat technology. The Miami Rock Ridge was most important as an area suitable for the building of large permanent or semi-permanent house structures. In the inland zone, freshwater marshes and bodies of freshwater were the most exploited habitats for food and tree islands were consistently utilized as settlement areas.

I believe resources from the bay region alone could have supplied the caloric and protein intake required for survival on a year round basis during the Formative Period. Yet, it is likely that some degree of seasonal exploitation existed. For example, the bay exploitation would be most intensive during the dry months, when mosquito populations were tolerable. During the wet season, mosquitos would become intolerable, leading to migration to Key Biscayne or other barrier islands. While on the barrier islands, exploitation of the Atlantic ocean would have been easier and may have been intensified. If hunters could tolerate the mosquitos, wet seasons would also be ideal for deer hunting in the inland zone. The subsistence strategies in inland areas were similar to those developed during the Archaic Period, but more intensive.

Coastal residents relied predominantly upon five or six plant species, all of which are associated with hammock communities. However, some may also have occurred in 
pinelands, beaches, and mangroves. Inland residents relied on a less diverse selection of plants, all of which were also associated with hammock commities. It is likely that the various plant foods were collected during the fall. The only fruit available throughout the year comes from the false mastic, which was also provided the single most commonly found fruit remains from both the coastal and inland zone.

Social and cognitive evolution was closely associated with changes in the technology. The degree of differentiation among the cultural groups increased with time from egalitarian bands to a stratified chiefdom as kin groups increased their control over particularly productive ecological areas. There was an increase in the degree of organized regulations over, and integration of, the members of the cultural groups as the efficiency of exploitation of resources generated surplus. Although there were some periodic fluctuations in the rate of population growth, there was an overall increase in population size and distribution. At the cognitive level, the susceptibility of hunting success to such factors as skill, luck, and climate may have led to the development of religious or magical practices that provided the belief of control over such factors.

In summary, cultural groups predominantly developed strategies to adapt to the natural environment. Less used, 
were the strategies involving the modification of the natural environment. These would include techniques such as the igniting of fires by Paleo-Indians to increase big-game yields and the construction of weirs by the Tequesta to catch fish. Additionally, the low population density during the Pre-Columbian Era did not require excessive exploitation of the environment. Most decisions about land use were made locally, based on first hand knowledge of environmental conditions. An exception may have been caused by the reliance on outside chert resources. As a result of all of the above patterns, the Pre-Columbian Era land use was typified by a series of technological developments that remained adaptive for extended periods of time. 


\title{
CHAPTER IV: PRE-URBAH POST-CONTACT PERIODS (1513-1895)
}

\author{
INTRODUCTION
}

The Post-Contact Era begins in A.D. 1513, Eollowing the first contact between the Indians living in the Dade county area and Spanish explorers. Historians typically divide the history of Florida since then into five periods based on political claims to the land. These historical periods include the Spanish Period (1513-1762), the British Period (1763-1783), the Second Spanish Period (2784-1820), the Florida Republic Period (1812-1816), and the American Period (1821 to the present). By relying on cultural adaptations to the environment as my criteria, I identified three periods of land use that overlap these historical periods. The three periods of land use are defined as the Spanish Contact Period (1513-1774), the Pioneer Settlement Period (1774-1895), and the Urbanization Period (1896-present). This chapter deals with the Pre-Urban culture comprising of the Spanish Contact and Pioneer Settlement Periods.

The periods of land use I refer to are based on land use developed by non-Indians. From the time the Indians arrived in Dade county their land use has been markedly different from that of non-Indians. However, Indian land use during the Pioneer settlement and Urbanization periods was greatiy influenced by recently arriving Europeans. 


\section{SPANISH CONTACT PERIOD: A.D. 1513-1789}

This period begins with ponce de Leon's arrival in the Biscayne Bay on July 3, 1513 (Parks 1982:15-16). During this period, all attempts to settle in Dade county ended in failure. The first of these occurred in 1567 and 1568 , when the Spaniards attempted to establish missions near the northern bank of the mouth of the Miami River (Chapman 1991; 31). By 1570, these missions were abandoned and no renewed attempts by the spanish to settle in this area occurred until 1743, when a mission named St. Ignacio was established on the southern bank of the mouth of the Miami River. However, the mission closed in 1744 due to the Jesuits frustration with the failures in trying to convert the Indians (Parks 1982:65).

During the interval between the establishment of the missions, Key Biscayne served as a stopping off place for firewood and freshwater for explorers of the 1500 s (Chapman 1991). It also served as a temporary base for wreckers, and slave ships that travelled along the Gulfstream in the $1600 \mathrm{~s}$ and early 1700 s (Miller 1985). In addition, it was during this interval the South Florida Indian population was nearly decimated.

Following the closure of the St. Ignacio mission there was no attempt at settlement in the Dade County area until the first land grants during the British period of 
occupation of Florida (1763-1783). The first land grants were awarded to the British officers who were involved in fighting in Florida. The size of these grants was determined according to rank. The first grant in the Dade county area was awarded in 1774. However, by 1783 the British ceded Florida back to Spain and the English settlers left to other locations in the West Indies (Hollingsworth 1949:17). It was not until the Second Spanish period of occupation in Florida (1783-1821) that land grants led to permanent settlements. The first of these grants was awarded to Pedro Fornells in 1790 for 175 acres in "Key Biscayno" (Marks 1958:15-17).

\section{Environmental Risks and Hazards}

During the Spanish Contact Period both the Indians and the Spaniards faced the problems of a new environment. The arrival of the spaniards altered the social environment of the Indian residents, which created a series of new problems for them. In addition to the killing of the Indians by warfare and diseases introduced by the spaniards, the Indians also had to cope with increased competition for the resources. The spaniards required food, a resource that appeared abundant to Fontaneda (1940:27), but may not have been so plentiful year round among the Indians. This can be noted in a document written by Brother Francisco de Villareal's in 1568 (McGoun 1993:31). He states that there 
were periods of two to three months during which the Indians would go to an island (Miami Beach or Key Biscayne?) to search for edibles and some would ask the Spaniards for food. This shortage in food may have been intensified by the increased consumption caused by the newly arrived Spaniards .

The Spaniards and other individuals wishing to go to what is currently Dade County had many social and natural environmental factors to cope with. The first problem was the navigation of hazardous seas in route to South Florida. Seasonal storms and hurricanes and the Florida coral reefs proved to be a dangerous combination to many of the ships that ventured into the area. Another threat to marine travel were attacks on ships by pirates who would steal their valuables. By the 1600s, Spaniards responded to the marine problems by developing a wrecking industry. Wreckers helped recover goods from ships that had crashed in the Florida straits or that had been rummaged by pirates lParks 1982). Once on land, they had to deal with the presence of other human groups and dangerous or bothersome animals. If they wanted to remain they had to find food, shelter, and water. These issues were coped with mostly by strategies developed at the social and technological levels. However, it is also helpful to understand the cognitive context in which these problems occurred. Therefore, a brief discussion of the strategies and cognitive dimension is 
presented below.

Social Dimension: Population and Socio-Political Relations

The Spaniards influenced the social dimension of the South Florida Indians by affecting their population and political relations. The south Florida Indian population decreased rapidly following the initial contact with the Spaniards. By 1743, the total population of these Indians consisted of about 180 individuals from various remnant cultures (Parks 1982). Although all the factors leading to this decimation may never be fully uncovered, European diseases, warfare with the Spaniards and perhaps with other Indian groups are likely to have been significant (McGoun 1993: 110-114).

The relationship between the Spaniards and Indians changed with the abandonment of settlement attempts during 1570-1743. The Spaniards developed and maintained friendly alliances with the Indians during this period for several political and economic reasons. The spaniards wanted the Indians on their side in international warfare for the New world, and to ensure the safety of Spanish castaways. In addition, the Spanish benefitted from the Indian's adeptness in salvaging goods from wrecks and their willingness to provide them with these items (Parks 1982). 
Technology

of all the technologies developed by the spaniards during this period, it was those involved with subsistence that were most likely to incorporate land use. Most of the land use technologies developed were highly significant in bringing about change in the natural environment. The Spanish introduced exotic plants and animals, and practiced cultivation, fishing, and hunting technologies new to the area. In fact, the beginning of drainage activity for the purpose of creating agricultural land dates to the second Spanish period of occupation (1784-1820).

Another significant technological development during this period was the enhancement of scientific knowledge about the land and its people through the practice of land surveys. Unlike the other technologies, this activity did not involve altering the natural environment. However, this knowledge was later used to help evaluate the potential for agriculture and settlement.

\section{Plant and animal use}

Some of the earliest evidence of plant use among the Spaniards comes from a document written by Pedro Menendez in 1579. In this document he describes the presence of severaI varieties of exotic figs, pomegranates (Punica spp.), oranges (Citrus sp.), grapes (Vitis spp.), and mulberries (Morus spp.) growing throughout the St. Augustine region of 
north Florida (Reuther et al. 1967). This would suggest that these fruits were introduced by the early spanish explorers. The presence of some of these fruits in Dade County makes it likely that the spaniards also introduced them there during their early stay.

There is scant historical documentation on the arimal use by the early Spanish missionaries. Archaeozoological evidence indicates that the Spanish animal diet was similar to that of the Indians, which was limited by what was available in the local environment. The majority of the Spanish missionary's animal subsistence consisted of a number of native terrestrial, riverine, and estuarine animals (Reitz 1990; Scarry and Reitz 1990). The main exotic domesticated animals brought by the spaniards for food included hogs (Sus scrofa) and cattle (Bos taurus) (Reitz 1993).

Some insight about what other plants and animals may have been brought in by the spaniards may be gleaned from the documentation of the cargo Spanish explorers brought to Florida. In 1539, Hernando De Soto set off on an expedition through Florida and several southeastern states. De Soto's cargo ships came by way of Cuba, bringing plants and animals found in Europe and Cuba. In addition to the hogs and cattle for food, animals such as the horse (Equis cabaIIus) and mule (Equis ssp.) were brought to Florida for transportation and labor. Some of the plant crops 
indigenous to Cuba that were brought included the cacabi (Palmata aipi), and cassava (Manihot escuelenta). In addition, seeds of several other garden variety crops such as lettuce (Lactuca sativa) and radishes (Raphanus sativus) were also carried into Florida (Baber 1942)

\section{Fishing}

During the 1500 s through the $1700 \mathrm{~s}$, the marine environment was more important than the terrestrial environment for the spaniards. One of the most important uses of the seas was for subsistence. By 1750, Spaniards were regularly fishing in the Floxida Bay and southwest coast region and possibly in the Biscayne Bay area. This type of fishing activity lasted through the 1840s. It would be impossible to list all of the species of fish that may have been caught but the primary ones included mullet, kingfish (Menticirrhus spp.), and mackerel (Scombridae) (Paige 1986:16, 83). The spaniards set up seasonal fishing camps on offshore islands from around August to the following March (McGoun 1993:109).

\section{Agricultuxe and drainage}

The earliest evidence of a desire to drain the Everglades dates to 1743, when father Joseph Alana wrote a letter to the Governor of Cuba describing the desire to develop some form of cultivation in a pineland area near the mission. He 
indicated that due to the harshness of the labor required to clear the land, that it should be provided by convicts in letter excerpted in Parks 1982:63). This ambition to develop cultivation led to the first attempts to drain the Everglades during the second Spanish period in Florida. However, only small-scale drainage activity was carried out (Chapman 1991).

\section{Land surveys}

Although it is possible that the Spanish may have explored the east coast of South Florida, they never documented this activity. It was not until the period of English occupation that scientific studies of the land and its people were made. By 1771, the British begin to carry out the first survey of Florida's east coast (Romans 1775) and the first scientific studies of the natural environment and its Indian inhabitants (Bartram 1791).

\section{Cognitive Dimension: Mythology and Religion}

Mythology played a role in the Spanish discorery of Florida and religion influenced the decision to colonize the Dade County area. Ponce de Leon arrived in Dade County as a result of a quest to find what he believed to be the mythical island of Bimini. It was believed that Bimini was an island which held great wealth (Paige 1986:12). On Fpril 1513, Ponce left from puerto Rico in search of eimini but 
instead made landfall on the east coast of Florida, somewhere near Jacksonville and st. Augustine and several months later arrived in Biscayne Bay (Parks 1982:13-14). The attempt to colonize the Dade County area was driven by the belief that the Indians that lived there may be open to Christianization and not as aggressive as the west coast Indians of carlos (p. 25).

\section{PIONEER SETTLEMENT. PERIOD: A.D. $1790-1895$}

This period is marked by the beginning of continuous settlement and land use by non-Indians. It was a period with a very low population density in which the population of the current Dade County area never reached 1,000 residents. The most influential groups of settlers included the recipients of land grants during the second spanish period, descendants of the British-American Torys icommonly called "Conchs"), black Bahamians, farmers and hunters from the American southeast, Indians (Seminole and Miccosukee), and British and French Europeans. According to Parks (1985:39), some of the other permanent or temporary settlers in South Florida at this time included Caribbean pirates, Cuban fishermen, and runaway slaves. The significant land use activity during this period included various subsistence practices, building of houses, transportation, and comercial activities such as a coontie starch industry. 
trading, agriculture, and wrecking. This period is also distinguished by the growing desire to drain the Everglades for agricultural and settlement opportunity by members of the federal government.

Between 1790 and 1825 , the settlers subsisted primarily on marine resources supplemented with hunting, foraging, and tropical fruits and vegetables. Commercial activity did not begin in this area until the introduction of the coontie industry, perhaps around 1825. This was followed by the introduction of plantation agriculture in the $1830 \mathrm{~s}$. Yet, due to activity related to the seminole wars, these early attempts at agriculture soon failed.

In the 1850s, individuals (commonly called "crackers") from North Florida, Georgia, Mississippi, Alabama, and the Carolinas began arriving. Many were hunters and trappers who opened trading posts near the Miami River. Around the same time, the Indians were driven into permanent settlement in the Everglades region in the northwest section of the county.

Between 1860 and 1880, several individuals significantly involved in the urbanization of Dade County purchased land or settled in the area. By the 1880s, tourism began with the opening of the Peacock Inn in Coconut Grove. This facility attracted many northern tourists who later decided to become permanent residents and turned Coconut Grove into the first social center of Dade county. 
The beginning of the end of the Pioneer Settlement Period occurred as a result of heavy migration from central and northern Florida farmers between 1884 to 1896. This migration was stimulated by a series of freezes that devastated their crops to the north. These new settlers opened up the occupation of the inland areas, developing homesteads ten to eleven kilometers west of Biscayne Bay (Merrick 1941). Also as a consequence of the freezes, Miami became considered as an ideal location for cultivation. This helped convince Henry Flagler of the lucrative potential involved in extending a railroad to Miami. The railroad proved to be the critical factor necessary for enhancing population growth and urbanization in Dade County.

\section{Environmental Risks and Hazards}

Just like the spaniards before them, the pioneers arrived to South Florida by boat, facing numerous navigational hazards on the way. Once there, the pioneers faced several of the same climatic hazards that the Indians of the Formative Period had faced, such as thunderstorms, hurricanes, droughts, freezes, and lightning ignited fires. These hazards threatened both the physical well being of individuals and the availability of subsistence resources. The main social problem during the Pioneer Period was warfare with the Seminole and Miccosukee Indians. Another factor of great concern to the pioneers was the presence of 
wildlife. Despite the paucity of reported attacks of humans by wildlife, pioneers feared several species, like alligators, bobcats, panthers, and snakes. The large cats would sometimes venture into human settlements and prey upon turkeys, chickens, cows, and other farm animals (Dupuis 1954:133). These animals would sometimes be hunted purely for sport or as revenge after an attack. Pioneers also had to cope with pests like mosquitoes and other insects, accidents, and diseases. Most of these problems were dealt with by using "home remedies." Some of the more creative "remedies" were the techniques used to deal with mosquitoes. One was to rub on natural repellents such as foul smelling bear grease and brown bar soap (made from animal oils) or the more aromatically pleasant aloe (Kuhn 1992). Another technique was to burn pyrethum powder (an insecticide) inside the house (Garcia 1992).

Many of the problems encountered by the pioneers were due to trying to live in the same style they were accustomed to in a land with a different natural and social environment. The cultural ideology of the pioneers dictated their criteria for acceptable food, housing, hygiene, and sanitation. However, the material needed to provide these was largely absent or difficult to obtain in the new land. Various social, technological, and cognitive strategies were developed in attempts to cope with the hazards and problems encountered by the pioneers. These strategies formed the 
patterns of land use that defined the Pioneer settlement Period. Provided below is a brief discussion of some of these strategies.

\section{Social Dimension}

In this section I provide a historical account of the settlement patterns and population growth of the pioneers within the current boundaries of Dade County. By settlement patterns, I refer to the patterns in the means by which land became privately owned, and the patterns in the geographical distribution of settlement.

The description of the population growth within the current boundaries of Dade County during the Pioneer settlement period does not include specific numbers. The main reason for this is due to changes in the boundaries of Dade County prior to 1920. The other reason is the lack of information about the Indian population that resided in the currently defined Dade County area. As can be seen in Figure 1, the county boundaries changed twice during the Pioneer Settlement Period.

\section{Settlement}

The first areas successfully settled by non-Indians in the Dade County area were those awarded by the King of Spain. Wanting to accelerate the rate of permanent settlement of Florida following Britain's return of Florida 
to Spain in 1783 , the King of Spain awarded several 1 and grants near the Cape Sable area (Hollingsworth 1949), the southernmost point of Key Biscayne, to individuals of different nationalities and religions that had previously been denied grants (Chapman 1991). As mentioned earlier, the first of these was awarded to Pedro Fornells in 1790 for 175 acres in Key Biscayne. This was followed by the awarding of four grants for 640 acres each between 1805 and 1813. The recipients and locations awarded included Mary Lewis and her brother-in-law Jonathan Lewis along the south bank of the Miami River, James Egan, also along the south bank of the Miami River, and James' mother Rebecca Egan, along the north bank of the Miami River. Although these grants were awarded by Spain, the United States agreed to recognize them as part of the sales agreement made in 1821 (Marks 1958:16-17) when Spain sold Florida to the United States for \$5 million (Chapman 1991).

Some of the other early settlers in the Dade county area included several descendants of the American-British Torys. They occupied the coastal areas between Key West to Palm Beach throughout the nineteenth century. These individuals left the coastal parts of the thirteen colonies, receiving land grants in the Bahamas in the late $1700^{\prime} \mathrm{s}$ from the King of England. Their population spread to the Florida keys and lower east coast by the beginning of the nineteenth century. Their living areas were limited to the coastal areas without 
access to the inland. They lived in small villages scattered along the beaches. These had no roads, but only paths through the bush and the pines (Merrick 1941).

One of the more significant real estate transactions that took place in the early half of the nineteenth century occurred between 1830 and 1835. It was during this period that Richard Fitzpatrick purchased a large amount of land, including the Lewis lands, in order to establish a plantation. The plantation was eventually abandoned upon the start of the Second Seminole War. This land became the site of Fort Dallas in 1834 and was later sold to Fitzpatrick's nephew William English in 1843 who named it the "Village of Miami." English attempted to restore the plantation including the addition of a limestone rock house in 1849. However, he departed for California in 1851, prior to accomplishing the restoration. In 1874 , the limestone rock house was converted into a trading post operated by James Ewan. The land on the northern half of Fitzpatrick's plantation was purchased by Julia Tuttle in 1891 (Marks $1958: 18-19)$.

In the early 1850 s northerners, mostly from North Florida, Georgia, Mississippi, Alabama, and the Carolinas began arriving into the lower east coast. These individuals became hunters and trappers and opened trading posts near the Miami River (Merrick 1941). Despite this immigration, population in the southeast of Florida decreased between 
1840 to 1860. According to census information taken during these years, population in the historically defined Dade County (West Palm Beach to Key Largo) dropped from 446 to 83 (U.S. Census 1983).

A period of critical land purchasing and/or settlement began in the 1860s. In 1865, Edmund Beasley received title to the site which today is known as Coconut Grove in honor of his services in the Civil war (Buchanan 1978). Disabled in the war, he was not directly involved in any type of land use in the area. However, portions of his land were later sold to individuals, such as Ralph Munroe and Charles Peacock, whose activities were significant in the development of Coconut Grove as both a social and tourist center (Munroe and Gilpin 1966:113, 116, 217).

The individuals purchasing land in the 1870s, were some of the most significant figures responsible for attracting northern attention to Miami. In 1870, William Brickell bought 640 acres on the south side of the Miami River and built one of the most famous Indian trading posts at Brickell Point. In 1873, Julia Tuttle, also known as the "Mother of Miami," bought 640 acres of land on the north side of the Miani River. The following year, Janes Ewan, known as the "Duke of Dade," moved into Fitzpatrick's old plantation and built a trading store on the south side of the Miami River (Kersey 1975). In 1875, Charles and Isabella Peacock arrived (Parks 1977), and by 1884 they 
opened a hotel in Coconut Grove (Buchanan 1978), the first in Dade County. The development of this hotel created the first nor-Indian social center in Dade County. In addition, the Peacock's brought black Bahamians to work at the hotel. which resulted in the development of a small black community known as "Kebo" (Chapman 1991).

\section{Population}

During 1880-1895, population growth in Dade County was accelerating with settlement in Coconut Grove and Lemon City (north Miami) increasing the most rapidly. Yet, the population was still under 1,000. The small, diverse population was made up of black and white Bahamians, Cubans, Seminole war veterans, European immigrants, Southern farmers, carpetbaggers, American capitalists and assorted adventurers (Parks 1985).

\section{Technology}

During the Pioneer Settlement Period most of the technology associated with land use was related to providing subsistence, shelter, and transportation. The predominant source of energy for these activities was of human, animal, and plant origin. The use of steam power did not become common until the 1880 s with the appearance of steam powered lumber mills and boats. Provided below are descriptions of the preference and procurement of subsistence items, types 
of housing structures and construction technologies, transportation technologies, and commercial activity.

\section{Subsistence}

During the late 1700's and early 1800's, the white Conchs introduced many West Indian fruits and vegetables to the lower east coast which they planted around their houses for sustenance. Some of the vegetables included yams (Dioscorea spp.), cassava, eddys, pounders, and benni (unidentified) (Merrick 1941).

Beginning in the $1870 \mathrm{~s}$ and through the 1890s, Bahamian blacks were used as the primary source of labor in the lower east coast. When they arrived they brought with them several of their preferred trees, vegetables, and fruits. Some of these included the pigeon pea (Leguminosae), soursop (Annona muricata), star apple (Averrhoa carambola), sugar apple (Annona squamosa), Jamaica apples, and the caneps, sapote (Calocarpum sapota), and dilly anons. These

Bahamians also brought knowledge of construction of houses and roads using coral rock (Merrick 1941).

In the early 1880 s women were responsible for cooking for their families. Coontie starch and corn meal gruel served as basic ingredients in several recipes. Deer, wild turker, wild hog, gopher (tortoise?), and manatee meat was also prepared either roasted or in stews. Guavas, limes reitruz sp.), sapodillas (Sapotaceae), and pomegranates wers l ht 
primary cultivated fruits used in cooking (Monroe 1943). other cultivated fruits included mango (Mangifera indica) and avocado (Persea americana).

The reason for the presence of such a variety of tropical fruit trees may be partially explained as a result of Bahamian influence. When the Bahamian settlers arrived, they brought with them seeds of tropical fruits. When the settlers from the north came down, they purchased some of these seeds. As a result, most of the homesteads prior to 1896 included many of the trees grown from these seeds (Blackman 1921:62-63). These were supplemented with various wild fruits including the hog plum, cocoplum, huckleberries (Vaccinium sp.), seagrape, wild grape, custard apple (Annona spp.), pawpaw (Asimina incarna), ground gooseberry (Ribes sp.), and Indian possomon (persimmon?) (Diospyros virginiana). Other cooking items like flour, salt, coffee, and grits were brought in from key West (Monroe 1943).

Some of the adaptations related to cooking included the designs of fireplaces, techniques for storing meat prior to refrigeration, and the protection of food from pesty insects or other creatures. Mary Conrad (1957) describes how she imitated the seminole practice of building fireplaces by arranging the logs like the spokes of a wheel with the fire at the center in order to cut down on wood cutting. Whenever a section of a log burned down the log would be shoved until it was back in the fire again. Deer meat could 
be stored by drying it in the air by hanging it in a high place.

Houses

Although there was some individual variation in the styles of the houses constructed by the early pioneers, the basic building materials and tools limited the variation in structural designs. Most of the building material was obtained from shipwrecks. The house-building tools available at this time were greatly limited to ripsaws, axes, and a frow (Munroe and Gilpin 1966:113-114; Parks 1977:72). The frow is like a machete with the handle perpendicular to the blade, which was used to make shingles.

The salvaged lumber was used to make walls for cabins. These walls were occasionally joined together with a mixture of lime, sand, and water. Some of the pioneers lined the inside portion of the walls with a thin layer of plaster made from this same mixture. The earliest houses were protected by a thatched roof made out of palmetto fronds. Later, houses with wooden roofs and shingles replaced the thatched roofing. Some cabins also sported a stone chimrey and fireplace, but cooking was usually done outdoors over an open fire. Commonly, separate chickee-like structures were built as kitchens or resting spots. Outhouses were also built separate from the house. When possible, the houses were elevated from the ground in order to protect it from 
termites, other insects, and flooding. Due to the unpleasant lime taste of aquifer water, many houses had a rain barrel under a roof spout to collect drinking water. Some of the houses and use of cotton netting on the windows to keep out the mosquitoes while others used solid wood shutters that were closed at night (Conrad 1957; Monroe 1943; Parks 1977).

\section{Transportation}

In reading some of the accounts of the lives of Dade County pioneers of the 1800s (Conrad 1957; Merrick 1941; Monroe 1943; Munroe and Gilpin 1966; Wagner 1949) it becomes evident that water transit was the dominant means of transportation, particularly in the earlier half of the century. Travel between villages or homesteads by individuals or families was usually by dugout canoes or small boats like dinghies or sloops along the channels or by walking through the bush and pines by paths along the beach (Conrad 1957).

The emphasis on terrestrial transportation did not begin until the late 1800 s with the arrival of central and northern Florida farmers that were escaping a series of devastating freezes between 1884 and 1896. These new settlers opened up the occupation of the inland areas 10 to 11 kilometers west of Biscayne Bay. The paths between homesteads became trails and the trails became roads. The 
first rock paved roads and limestone sidewalks were being developed and terrestrial transportation was replacing the use of canoes and boats along channels (Merrick 1941).

Although terrestrial transport such as wagons, horses, and bicycles, was becoming more common within Dade county in the $1880 \mathrm{~s}$ (Dupuis 1954), marine transportation was still a significant factor for the residents of this area. Most of the horses had to be shipped in by way of Key West from Kentucky (Conrad 1957). These were likely brought in on large three masted sailing ships. In addition, prior to the introduction of the railroad into Dade County, the majority of all resources, including humans, coming to and going from this area had to be transported by sea. Small groups of migrating families usually travelled in the larger schooners (Parks 1977). Many tourists took advantage of the steamboat and steamship travel that was available from 1880 to 1900 . The routes of these steamers was from Miami to Key West and Havana, to Havana, or to Nassau, Bahamas (Patton and Purdum 1992).

\section{Coontie Starch Industry}

The origins of the coontie industry in Dade County are uncertain. The seminoles usually receive credit for discovering starch could be extracted from coontie roots, but it is not known if they learned this from other Indian groups. A good description of the tools and techniques used 
to extract the starch from the roots is provided in Ernest Gearhart (1952) and Mrs. Henry Burkhardt (1952).

The date of the first non-Indian coontie starch industry establishment is not well known either. However, as early as 1825, William Cooley had been farming and manufacturing coontie starch in Fort Lauderdale (Black 1981:35). Fitzpatrick may have been involved in the coontie industry in the 1830s. However, Buchanan (1978) places the origins of this industry in Dade County on the Miami River in 1845. One of the last coontie mills was shut down in 1925 (Gearhart 1952:56). It was located near the Kendall area. The coontie industry was responsible for the first damming of rivers in Dade County. This was done to power the mills that were driven by a water wheel. The first of these may have been in Arch creek. A byproduct of coontiestarch was a very fertile soil. The water from the mills would spill into the grounds and enrichen it for cultivation of various fruits and vegetables. Some of the first fruit trees cultivated in the Miami area were located around these mills. Sweet, sour, and bittersweet oranges, avocado, mangos, momie apples (Mamea americana?), sapodilla, sugar apples, soursop (Annona muricata), grapefruit (Citrus paradisi), citron (Citrus medica) and bananas (Musa sp.) were just some of the fruit trees cultivated in these areas (Wagner 1949). 
Hunting and Trading

One of the other technologies that developed during the Pioneer Period was that of a trading, which relied on hunting. Spanish traders from Cuba traded for fur and hides with the Indians during the eighteenth and nineteenth centuries. During the Seminole Wars, American troops hunted animals for food and sport. By 1840, trading posts emerged to deal in hides, pelts, and plumes (Paige 1986:95). One of the first trading posts in the Miami area was that of Robert Fletcher, who around 1850 opened a store on the south bank of the Miami River near its mouth (Carr 1981). Yet, trading did not reach its peak until the 1870 s.

The most popular animals or animal products in the $1870 \mathrm{~s}$ included alligator hides and teeth, birds and plumes, deer meat and skins, and otter (Lontra canadensis) pelts. Less popular was the meat and the skins of raccoons, bobcats, panthers, bears, and other game animals. These items were provided by either Indians or white hunters (Paige 1986: 95).

In the nineteenth and into the early twentieth century, one of the most hunted animals was the alligator. Its belly skin was the most desirable due to its good tanning quality. Small live or skinned alligators would be sold as souvenirs to tourists. Several techniques were employed in the hunting alligators. A twelve to eighteen foot long cypress pole with a metal hook on the end was used to probe the 
water of swamp ponds to locate the alligators. When the alligators surfaced, they were shot between the eyes. At night, lanterns were used to temporarily blind and light the alligators, at which time they were either shot or axed across their backbone (Paige 1986:95, 98).

Fur-bearing animals were trapped during winter months, when their furs were longest and glossiest. The most valuable and desirable was the otter. Yet, the highest paying animal products were the exotic bird plumes. These could be obtained only during mating season. This activity led to the near extinction of several of the preferred species. Plume selling began in the 1870 s and increased in popularity until the early 1900s (Paige 1986:98, 167-172).

The plumes in greatest demand in the $1880 \mathrm{~s}$ included that of sandhill cranes (Grus canadensis), egrets, spoonbilis, cormorants, pelicans, terns, flamingos (Phoenicopterus ruber), glossy white ibises (Plegadis falcinellus), herons, and a few other species (Kersey 1975:76; Paige 1986:167,. The head, legs, and sometimes wings would be remored from the birds and the skin flattened and sold. Indiridual feathers from the head, back, and breast would also be sold. The hunters favorite weapons were shotguns and .22 caliter rifles. They used torches and fires at night to blind the birds that were then clubbed or shot to death. Fish ret: were placed around rookeries and birds were driven inte tir: nets and slaughtered. The smaller caliber I flofi wis. 
preferred because they reduced the amount of damage to the plumes, while producing less sound that could disturb the flocks. Since the best season for hunting was the mating season, many fledgling birds were still in the nests. The killing of their parents would lead to the starvation or predation of these young fledglings, thereby contributing to the decrease in the population of these birds (Kersey 1975:76; Paige 1986:167).

\section{Agriculture}

The earliest use of the land in Dade County for commercial cultivation dates to around 1830, with the development of Richard Fitzpatrick's plantation and tropical fruit tree grove. The main crops were sugar cane (Saccharum officinarum) followed by corn (Zea mays) and pumpkins (Cucurbita moschata), sweet potatoes (Ipomea batatas), plantains and bananas, Bermuda arrowroot (Maranta arundinacea), limes, coconuts, and guavas. He also raised various animals including hogs, ducks (Anas spp.), turkeys, and guinea fowls (Numida spp.) (Black 1981:35-36). The construction and operations of his plantation was carried out by slaves which he purchased from South Carolina (Black 1981).

In 1838, the United States Congress awarded the first agricultural land grant to Henry perrine and two associates on lower Biscayne Bay for the cultivation of tropical 
plants. However, Perrine never occupied this land due to fears of Indian attacks during the ongoing Second Seminole War. Instead, he headed to Indian Key and established a small experimental agricultural station for the introduction of various tropical plants. Perrine was most interested in the prospects of cultivating sisal (Agave sisalana) for the development of a hemp fiber industry in Florida. Perrine was killed in an Indian attack in 1840, and the hemp industry never developed. Yet, sisal became naturalized and spread through both coastal areas of Florida (Robinson 1942).

No attempts at commercial agriculture occurred again until the 1880s. The first vegetables sold in the northern market were planted by Adam Richards in 1882. The vegetables were grown in the northern bank of the mouth of the Miami River. He planted tomatoes (Lycopersicon esculentum), beans (Phasedus sp.), and eggplancs (Solanum melongena). By this time there were already several tropical fruit trees in cultivation near the mouth of the Miami River. These trees included Maumee apples (Mamea americana?), sapodillo, avocado, mango, and oranges (Blackman 1921:15-16). Some of the locations of other pre1896 citrus, avocado, and mango groves in Dade County included an area seven kiloneters west of Miami, one just west of Coconut Grove, one bordering Biscayne Bay, one on a hammock on a bluff south of the Brickell's land, and sevent; 
acres in Kendall (Blackman 1921:62-63).

Another interesting account of an attempt at commerciul agriculture occurred when Harry Lummus and his son char lus planted more than three million coconut palms in 1885 on a tract of land in Miami Beach that they bought from the government. Most of the terminal buds of the sapling coconuts were eaten by the rats and rabbits that lived in the nearby swampy areas. One of the investors in this project, John Collins, came to see the land and found freshwater aquifers on the island. As a result he decided to plant avocados, fruits, and vegetables (Millas 1985).

\section{Wrecking}

Prior to the establishment of light houses in the lower east coast in the $1860 \mathrm{~s}$ and $1870 \mathrm{~s}$, wrecking was considstad to be a legitimate industry. The salvaging of goods from ships that wrecked along the coast between Key west and Falm Beach provided much of the needed materials for the sarl $\because$ pioneers living along the coast or on Key Biscayne. Construction materials, food, appliances, Eurniture, clothes, and various miscellaneous resources were obtained by salvaging the wrecked ships (Merrick 1941). 


\section{Cognitive Dimension: Perceptions of the Land}

After Florida was purchased by the United states, settlers wanted the natural rivers of the Everglades to be widened and deepened to drain the interior lands. Included below are various examples of some of the most popular attitudes that Americans had about the Everglades and agriculture during this period.

In 1823, the Secretary of War John Calhoun ordered Colonel James Gadsen to survey the Indian boundary Iine in Florida. When Gadsen reached the northern limits of the Everglades, he described the region as "interposing and impenetrable swamps" that extended in the savannahs and ponds of the lower peninsula. Gadsen believed that this type of land was of little value to whites and that Indians did not use the land other than as a means of reaching their seasonal hunting grounds farther down south. For this reason he felt that the Indians should be allowed to continue using this land (Carter 1956:906-7 in paige 1986: 25). Gadsen was also the first person to use the binomial term "Ever Glades" to refer to this region (Carter 1956:302 in Paige 1986:25). Eventually, in the 1920s and 1930s the term was modified into the current single-word common name "Everglades."

In 1823, Vignoles described the area of the Everglades with regard to its distribution and general features, commenting on its potential for cultivation and its 


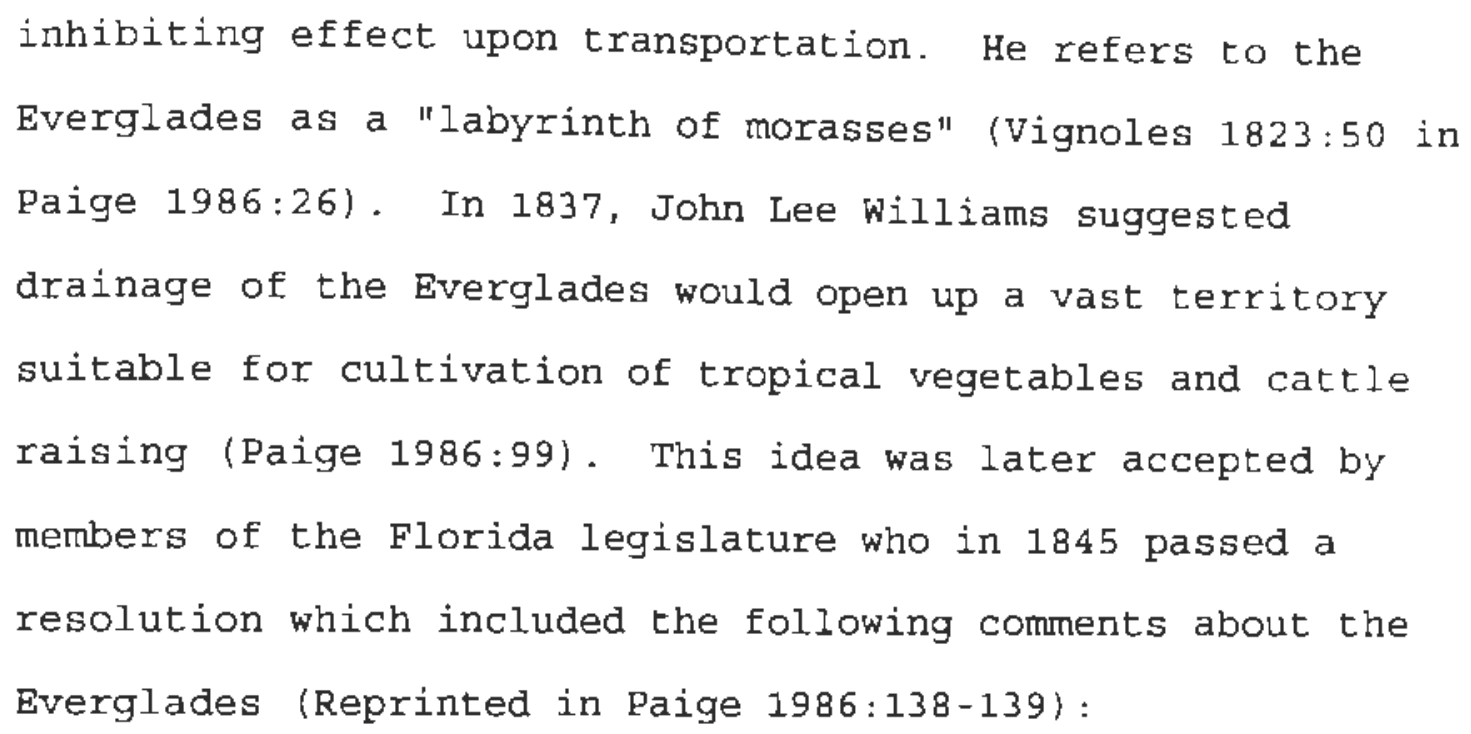

(The Everglades) has hitherto been regarded as wholly valueless in consequence of being covered by water at stated periods of the year, and the supposed impracticability of draining it. And whereas recent information, derived from the most respectable sources, has induced the belief, which is daily strengthening, that these opinions are without foundation, and, on the contrary, that at a comparatively small expense the aforesaid region can be entirely reclaimed; thus opening to the habitation of man an immense and hitherto unexplored domain perhaps not unsurpassed in fertility and every natural advantage by any other in the globe. (U.S. Congress 1846 ) 
In 1848 Buckingham Smith was assigned the task of studying the feasibility of draining the Everglades. He described the Everglades to the Secretary of Treasury as ". . suitable only for the haunt of noxious vermin, or the resort of pestilent reptiles..." (Gleason 1984:ix). He went on to indicate that any man who converts this useless land into agricultural land will contribute to the wealth and independence of the country and would merit the high favor of his countrymen for all posterity. He indicated that although the task would require the loss of life of many swamp animals, that this would be inconsequential in comparison to the benefits of newly created agricultural land (Paige 1986:138-140).

\section{INDIANS IN THE PIONEER SETTLEMENT PERIOD: 1835?-1895}

In most ethnohistoric literature the Indians that migrated into Dade County during the Pioneer settlement Period have been classified as "Seminoles." However, those Indians recognize themselves as members of two distinct bands, the Ila-ponge (of the Miccosukee Tribe) and the Ishaponge (of the seminole Tribe). The full cultural historical account of these Indians and their ancestors is long and complex. A good summary of the bibliography on this subject is provided by Kersey (1987). Rather than a full and detailed anaiysis of their ethnohistory, I provide a brief 
summary of their history in florida.

The Miccosukee and Seminole Indians of Florida are descendants of several southeastern United States Indian tribes. Most of these tribes were loosely organized into the Creek Confederacy. This Confederacy was dominated by the Muskogee-speaking Creek of the upper towns, near the tributaries of the Alabama, Coosa, and Tallapoosa rivers (Kersey 1987:11). The majority of tribes of the Creek Confederacy were located in Georgia, Alabama, and South Carolina. The first known migration of Indians from this Confederacy toward Florida occurred sometime in the early 1700s. It was then that the Oconee Indians left their habitation site in what is today Milledgeville, Georgia. By 1750, some had arrived in a site a few kilometers south of the present location of Gainesville. These migrating Indians became known by outsiders as "Seminoles" regardless of their own perceptions of ethnic difference.

European diseases and raids of the Creek and English into South Florida during Queen Anne's War (1701-1714) neariy decimated the Apalachee of north Florida and Timucua of central florida. The resulting empty space was initially settled by tribes from the Hitchiti-speaking lower Creek towns (Sturtevant 1955:68), which were located 185 kilometers south of the upper Creek towns and east of the Chattahoochee, Flint, and Ocmulgee rivers (kersey 1987:11). Some of these new settlers included the Sawokli, Tamathli, 
Apalachicola, and Chiaha. Several Muskogee-speaking Indians joined as they migrated southward (Neill 1956:8), but it was not until the Creek war (1813-1814) that large scale immigration by Muskogee-speaking refugees occurred. This shifted the balance from a Hitchiti to a Muskogee cultural element among the new Florida Indians (Sturtevant 1955:68). Other southeastern United States Indian groups that Iater migrated to Florida include the Yuchi, Alabama, Yamassee, and Apalachee. It is possible that these new Indians combined with remnants from the Pre-Columbian south Florida Indian groups. In addition, many runaway slaves originally captured from African warrior tribes such as the Ibo, Egba, Senegales, and Ashanti merged with some of these new Indian groups. In fact, by 1821 of 34 "Seminole" settlements, 31 were occupied by native Americans and 3 by runaway slaves (Neill 1956:8-9).

During the Pioneer settlement Period, these new Florida Indians were involved in three wars against the United States. They were targets of an expulsion and annihilation campaign carried out by American Eorces. Of the survivors of these three wars, those who remained in Florida were mostly Hitchiti-speakers. 


\section{Environmental. Risks and Hazards}

One of the most serious environmental problems encountered by the Indians during the Pioneer Period was the expansion of the non-Indian population. This social phenomenon led to the fighting of three very destructive wars. Problems incurred during these wars were responded to at the social and technological levels of Indian culture. Presented below is a brief summary of the Seminole wars and their effects on the migration patterns, population, and ethnoecological adaptations of land use.

Social Dimension: War, Migration, and Population

The First Seminole War (1817-1818) broke out largely due to a desire to harm the Indians for their alliances with the British or their involvement with runaway slaves, or both (Kersey 1987:31). At the beginning of the war the Indians were living in northern Florida and southern Georgia. By the end of the war they were migrating into central florida to escape the American forces (Paige 1986:29).

The Second Seminole War (1835-1842) broke out because most Florida Indians resisted the 1830 federal policy of removing all Indians to an Indian Territory in oklahoma (Paige 1986:30). Many of the Indians sought refuge in south Florida and some reached northwest Dade County. The Second Seminole war ended in 1842 with the agreement that the few remaining Indians would be allowed to stay in the Big 
Cypress area south of Peace River and northwest of Shark River (Paige 1986).

The Second Seminole war was influential in the emergence of new Indian cultural adaptations to the environment. Many of the adaptations they developed as a result from this war helped them to later settle in the Everglades region of Dade County. It also affected the quality and quantity of knowledge that non-Indians had of the territory within the Everglades (Paige 1986:74). This knowledge later influenced the particular strategies developed to drain or otherwise exploit this land.

The Third Seminole war (1855-1858) was precipitated by an increasing tendency to view the Everglades wetland regions as drainable and as potentially valuable for agriculture. In 1850, the federal Swamp Lands Act returned all swamp lands to the states for reclamation. As a result, the Everglades was perceived as having a great investment potential for land development companies and railroads that bought rights to submerged lands. These businesses placed pressure on the government to survey the land, drain the Everglades, and open the area up for settlement, including areas in negotiated Indian territories. This eventually led to bloody conflicts between the Indians and the surveyors and homesteaders (Kersey 1975:4).

By 1851, Florida Governor Thomas Brown requested the Secretary of war to remove all Indians from the Everglades 
and to open the area to white settlement (Paige 1986:58) This action led to the Third Seminole war and drove the Indians into permanent settlement in the Everglades. Although they had previously used the Everglades, they had not settled there prior to this time (Griffin 1989).

There is virtually no historical documentation on thf South Florida Indians for a period of nearly twenty yedis following the end of the Third Seminole War ISturtevant 1955). It was not until the 1870 s that a few explorers. naturalists, or hunters once again started to venture into the Everglades and into Indian terricory. It was also in the 1870 s and 1880 s that white traders like Brickell and Ewans began to do business with Indians near the mouth of the Miami River (Griffin 1989).

There is very little documentation on the populaticu statistics for the Indians residing in the currently defined Dade County area throughout the pioneer Period. It is believed that prior to the second Seminole War, several thousand of them were limited to areas of north and centrai Florida. By the end of this war, about 400 Indians remained in Florida, perhaps some in south Florida. By the eno of the Third Seminole war, less than 200 Indians remained in Florida (Sturtevant 1955:76-77).

The only empirical accounts of Indian population withit. the currently defined area of Dade County cums in. ' ... ..." ."

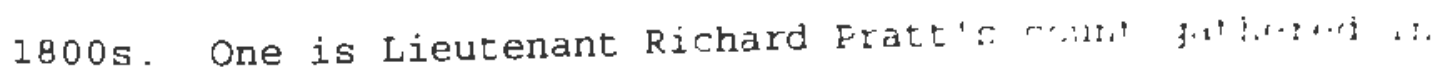


1879 (Sturtevant 1956), and the other is Reverend clay MacCauley's (1887) count gathered in 1880-1881. Fratt placed their population around the vicinity of Miami a around 80, while MacCauley estimated 63. Howeve:, bot h at these estimates may be low since it is likely that sumpl Indians resided in obscure and isolated tree islands not encountered by either men during their census.

\section{Technological Dimension}

Various Indian technologies emerged during the Pionfer Settlement Period to cope with problems encounterfd duing the Second Seminole Indian war. The coping stratsgifs involved moving deeper into the Everglades and breakind ut, the different bands into smaller groups to prevent thas capture of large numbers of individuals in an $Y$ one confrontation (Paige 1986). The movement into the Everglades required changes from the subsistence, !rust. transportation, and clothing technologies used ia t.te northern territories (Kersey 1975:8). Thers is nct midrl. knowledge about the medical technologies of these Indiaris prior to their move into south Florida. Howerer, it is likely that the change in environment forced them to chastge their botanical pharmacopeia to include more readij; available plants. The technologies significart to land use are briefly discusesed t.r. 


\section{Subsistence resources}

The large scale stock raising and communal farming practices of the northern "Seminoles" gave way to small plut cultivation on tree islands at the family level in thw south (Kersey 1975:8). Several U.S. military patrols into th Everglades reported finding sugar cane, corn, potatoes (Solanum tuberosum), and rice (Oryza sativa) growing on tree islands during the Third Seminole War (Paige 1986: 60). Although many of these crops had been cultivated by the Creeks and other Muskogean groups, the small-plot cultivation technique was new to these Indians. They also increased their reliance on hunting, fishing and gathering activities during the wars (Kersey 1975:8).

From 1870 through the 1890 s the Indians and white settlers had some subsistence patterns in comnon. Mumars and Gilpin (1974:91, 100) and Conrad (1957) proride an account of many subsistence items provided by the Indians ir. trading activities. Some of the items included deer meat, bear, wild turkey, terrapin turtle (Maclaclemys terracinl, gopher tortoises, pumpkins, sweet potatoes, coontie starch, chickens (Gallus), and huckleberries. The Seminolss alst relied on feral hogs raised from the descendants of the one's introduced by the spaniards (Sturtevant 1955:73), various fish, and several other cultivaced crops and wild native and exotic Eruits.

One of the preferred fish was the gar iStefhetl Tijr.r 
personal communication 1994). Some of the cultivated crops included various types of citrus, pineapples (Ananas sp.). coconuts, guava, taro (Xanthosoma spp.), cassava, and bananas (Neill 1956:40). The native and exotic fruits grew mainly in hammocks and pinelands.

\section{Subsistence techniques}

One of the more interesting cultivation techniques used by the Indians was vertical horticulture. Pumpkin was cultivated in the hammocks using this technique. This involved planting the pumpkin at the butt of a dead tree, and letting the vines climb up the tree and branches. This technique helped to keep the fruits out of the way of the hogs, saved ground space, and protected the fruit from the soil dampness (Gifford I944).

Indians had firearms by the beginning of the Pioneer Period and used them in conjunction with the bow and arrow in hunting activities. One of the most characteristic fishing tool used was a three-pronged gig (Neill 1956:70). It is likely that basketry made from different types of palm fronds was used to carry the gathered fruits.

\section{Houses}

The large villages of log cabin houses the "Seminole" had used in the northern prairies gave way to hidden, small family clusters of houses or huts called "chickfos" tyracen" 
1975:8). These chickees were open sided with palm-thatched roofing and a supporting structure of made of cypress logs. The thatching was made from cabbage palm or saw palmetro fronds. The floor of most of these chickees consisted of a platform made of split logs of cabbage palm. This plat form was elevated about half a meter to a meter off the ground. Some chickees had open spaces of bare ground and others still had no platform at all (Sturtevant 1955:77). Cooking was carried out in separate partially or entirely floorless chickees usually located in the center of the camps. The bare ground permitted the building of an open fire for cooking. Food and utensils were kept on the floored sections, while pots and pans would be hung from the rafters: (Neill $1956: 64)$.

\section{$\underline{\text { Trading }}$}

Trading was very important to the Indians of the Pioneer Period. It was through trading that they were able to obtain resources that their subsistence activities could rot produce. One of the best accounts of the Indian trading activities is provided in Kersey's (1975) book entitled Pelts, PIumes, and Hides. A discussion on the main animals hunted and items traded has already been presented abc:s in the section of non-Indian technologies and Indian subsistence resources. 


\section{Transportation}

As the Indians moved into the wetland areas of South Florida, foot travel, horseback, and ox-carts became impractical means of transportation. Instead, dugout canoes and push poled made from bald cypress logs were made to travel in the Everglades, which when fitted with masts and sails they could be used for ocean travel (Neill 1956:59, 70).

Medicine

The Miccosukee relied heavily on the use of plants for medicine. Sturtevant (1955) provides a list of the plants used by them for this purpose. According to this list the Miccosukee distinguished nearly 250 types of native and exotic plants, many of which were used for medicine or healing ceremonies. Some of these plants and several other plants were used also for various types of foods, construction, making of everyday utensils, and various other miscellaneous purposes.

\section{SUMMARY OF CHAFTER IV}

During the Pre-Urban Post-Contact periods, several social and natural environmental problems confronted the different residents that occupied Dade County. Some of these problems were similar to those faced by residents as early as the 
Paleo-Indian or later Archaic Period, while others were nit. Some of the responses to these problems were later abandomi or modjfied, while others continue today. The predominumt groups that occupied Dade County during the Pre-Urban post Contact periods included Tequesta Indians (1513-1743), Spaniards (1513-1821), pioneers of mostly European descent (1790-1895), and Indians (ca. 1835-1895). The majority of these periods are typified by a coastal lifestyle. The only exception to this was the inland lifestyle of the Indians.

When the Spaniards arrived in Dade County (A.D. 1513, they aitered the social and natural environment of the Tequesta residents by introducing warfare and disease. Thr Tequesta were not capable of responding to these changes and by A.D. 1743 their culture was nearly extinct. Howertr, th: strategies the spaniards employed in trying to cope with thr: problems they encountered were also not successful, and their permanent settlement and population growth in Dads County was deterred.

The Spanish twice tried to develop permanent settlements in the Dade County area before abandoning all attempts. The first effort was in 1567, with the creation of Spanist. missions near the northern bank of the mouth of the Miami River. By 1570, these missions were abandoned because of the inability of the Spaniards to cope with the Indian presence. The second attempt occurred in $17 \mathrm{~A} 3$, whan mission named St. Ignacio was established on thr :ir.ur. 
bank of the mouth of the Miami River (Chapman 1991:31).

During their brief stays in the Dade County area, some of the problems the Spaniards faced included the Tequesta presence, providing subsistence and shelter or protection from potentially dangerous weather, wildlife, and bothersome mosquitos and other pests. The problem that proved to be the most difficult for the spaniards to cope with was the presence of the Tequesta. The Spanish perceived the Tequesta as savages that should be converted to Christianity. Some of the Tequesta resisted and fought back, reportedly killing several spaniards, a cost the Spaniards were unwilling to tolerate.

Another area of concern regarding land use by the Spaniards relates to the long term consequences of the strategies they developed to provide subsistence. The Spanish diet consisted predominantly of local faunal and floral resources similar to those of the Indian's subsistence diet. It also included various exotic animals and plants that they introduced, bred, and cultivated on a small scale. Many of these introduced species persevered and have remained as characteristic of the environment with a mostly neutral effect upon critical ecological factors. The Spaniards also introduced large scale net fishing to the Florida and Biscayne Bay areas. This activity affected the water quality and marine life population of the bays. In addition, the spaniards conducted some minor drainage 
activity for the purpose of creating agricultural land sometime near the beginning of the nineteenth century. However, the extent of the drainage was so minor that ics influence in altering the environment was insignificant.

During the 1700 s, the environment was undergoing a tremendous social changes due to the near decimation of the Indian population in South Florida and the disputes for land during the colonial wars between the Spanish, French, British, and Americans. In 1790, the land grants that led to the first permanent settlements in Dade County were offered by the king of Spain. In 1821, Americans purchased Florida, and subsequently, a southern migration of pioneers into Dade County began.

The first problem these pioneers faced was reaching Dade County. Land travel down the peninsula involved crossing over wet marshes and rough pinelands. Instead, most pioneers arrived by boat. Due to the shallowness of Biscayne Bay, they had to travel to key west in large bcats and then come to Dade County in smaller boats. This ocean travel exposed pioneers to seasonal storms and the potential of sea wrecks, particularly during hurricane season.

Once in Dade County, all pioneers lived on the coastal geographic zone since the inland zone was submerged and difficult to reach without canoes or other small boats. The: first task of these new residents was to prepare their homesteads. Pioneers had to clear a piece of land, usuall: 
on pinelands, and then find materials and tools to build their houses. The land was cleared by hand, a time consuming and back-breaking task. The locating of building materials usually depended on luck in finding shipwrecked lumber and other materials. The design of the houses incorporated safeguards against flooding, termites, and mosquitos. Tools for clearing the land and construction were simple and manually operated.

Subsistence usually involved hunting, fishing, some gathering of and preparing of plant foods, cultivating of a few select exotic fruit trees and vegetables, and more infrequently, receiving food supplies from sources outside of Dade County. Cultivation of crops was usually done in hammock lands where the natural limestone holes could be utilized for planting. Food preservation also posed a problem, since there was no ice or refrigeration available. Instead, pioneers dried their meat and canned or pickled their fruit and vegetable products.

In 1835 the social environment again experienced a drastic change with the beginning of the second seminole War. During this war, Indians escaped the U.S. military by migrating into the south Florida Everglades region. Some reached Dade County and settled near the Big Cypress and Shark River slough areas. The movement into the Everglades posed problems that required changes from the subsistence. house, transportation, and clothing technologies used in the 
northern territories (Kersey 1975:8). Their new subsistence relied on small-plot cultivation of exotic plants on tree islands, hunting of mammals, reptiles, and birds, and fishing and gathering activities. All of their staple requirements could be fulfilled by their most popular foods including coontie, corn, pumpkin, deer, gar, and frogs. The Indians lived in small family clusters of open sided palm thatched houses. These allowed breezes to provide some comfort from the heat. They relied on dugout canoes made from local plant materials to travel in the Everglades. When fitted with masts and sails they could be used for ocean travel.

Towards the end of the Pioneer settlement Period, the Indians and non-Indian settlers gave up the practice of warfare. By 1870, the Indians and white settlers took advantage of the fact that they shared similar subsistence patterns. They became involved in a trading network in which many subsistence items were provided by the Indians (Munroe and Gilpin 1974:91, 100; Conrad 1957). The hunting techniques used to obtain these items were very specialized and efficient and by the early twentieth century led to the depletion of various animals, particularly birds.

In conclusion, the land use of the few individuals that resided in this area during the pre-Urban Post-Contact periods did not bring about major changes to the natural environment. This is because the resident groups during 
these periods had neither the technology nor the numbers necessary to respond to the limiting environmental problems through permanent alterations of the land. Instead, the solutions to the problems were simple and carried out on a small-scale. This allowed most man-made changes to the land during these periods to remain relatively reversible.

Some of the more permanent changes to the natural environment during these periods were the result of the introduction of many exotic plants and a few exotic animals. large-scale net fishing, and the hunting of animals for skins, pelts, and plumes by the Indians and white pioneers. Despite the effect these activities had on the land, it was the perception of the Everglades land as "dangerous" and "worthless" and the desirability to drain it for settlement and agriculture that was the most serious contribution to later environmental problems. The effect this attitude had on the changes to the environment are discussed in greater detail in the following chapter dealing with the Urbanization Period. 


\section{CHAPTER V: URBANIZATION PERIOD : (1896-PRESENT)}

\section{OVERVIEW OF THE URBANIZATION PERIOD}

The pivotal event for the beginning of Urbanization Period was the introduction of Flagler's East Coast Railway into Miami in 1896. The railroad connected the relatively isolated Dade County to a vast network of social and technological influences that helped shape the process of urbanization. This process was characterized by rapid population growth, the incorporation of several cities, and increased alteration of the natural environment. By 1903, the railroad extended to Homestead, but unlike Miami, it remained a rural town whose residents shared a pioneer-1ike lifestyle until the 1930s. Agriculture, not tourism, led to Homestead's growth.

Much of the land use in Dade County during the Urbanization Period was influenced greatly by national events. Some of these events include the development of automobiles, World War I (1914-1918), the Great Depression, World War Two (1939-1945), the development of commercial aviation, and the Cuban Revolution (1959). Other influences on land use included more localized environmental variables. Some of these included, hurricanes, flooding, soil and water quality, floral and faunal composition, and sanitary conditions. 
During 1896-1925, automobiles, the railroad, and postWorld War I prosperity helped influence Dade County's first significant real estate and population growth booms. As a result, new types of land uses related to transporting, accommodating, and supporting the growing population were developed. Most of these involved drastic alterations of the environment. These new activities included draining and dredging, constructing thousands of buildings, discharging sewage into the Miami River and Biscayne Bay, connecting water supply lines from the Everglades and Biscayne aquifer, building paved roads and highways, and introducing many new exotic plants.

The initial drainage progressed at a slower pace and cost more than anticipated by real estate investors. In 1926 the Miami boom ended. That year in Dade County banks failed, land speculators went bankrupt, land prices dropped, construction stopped, and many new residents returned to the north (Blake 1980:134). But it was a devastating september 1926 hurricane and a less powerful one in october, striking Miami, that put an exclamation mark on the end of the boom. Most land development projects and population growth were further slowed down by the world-wide Great Depression of the 1930 s.

By the mid-1930s, while the rest of the nation was caught in a global depression, Miami began experiencing a new period of population and development growth. One of the 
factors responsible for this was the development of Miami's aviation industry in 1930, which allowed its tourism industry to prosper. Another factor was the "New Deal" program of economic recovery instituted by Franklin D. Roosevelt when he was elected President in 1932. A part of this program provided many gloridians with jobs creating parks such as Matheson Hammock and Greynolds. The program also involved other land use activities such as constructing housing projects, fire stations, schools, and the overseas Highway to Key West (Chapman 1991:39).

To accommodate the growing population of the 1930 's, development spread to Miami Beach, previous agricultural lands, and wetlands. Land was used up in coastal, rock ridge, and Everglades regions. The type of development that typified this period was based on automobile transportation. A series of roads were laid out in parallel grids intersecting each other at right angles regardless of natural features, in a style named "unplanned urban sprawl" (Sul1ivan 1985:113) .

The 1940's experienced another global event that contributed again to population growth and intensified urban sprawl. Upon the outbreak of world War I, Miami Beach and the Homestead Air Force Base became training bases for thousands of American soldiers. The military also established a small airport in the Everglades. This airport later became Miami International Airport. When WWII ended 
in 1945 over 50,000 war veterans per year started to relocate to Dade County. To accomodate the growing population, land reclaimed from the east Everglades was turned into instant subdivisions (Parks 1985:42).

In September 1947, a hurricane hit south Florida, causing severe flooding. Congress authorized the Army Corps of engineers to develop a flood control project. The project involved the construction of canals, locks, and levees that drained thousands of acres for future development. The project destroyed a large portion of the eastern Everglades and seriously impacted the groundwater supply of South Florida (Chapman 1991).

The fear of losing what remained of the natural environment of the Everglades to drainage and development led to the creation of the Everglades National Park. Although such an idea had been suggested as early as 1905 (Blake 1980:169), it was not until December 1947 that the park officially opened (Paige 1986:208). The park consists of 1,398,800 acres of terrestrial and marine preserve, of which 416,000 acres lie within Dade County (Brown 1985).

By 1950, population growth and urban sprawl had reached such a level that less than one third of the Dade County population lived within the boundaries of the City of Miami (Chapman 1991). In 1957 the current metropolitan government was created. The following year Homestead Air Force Base, which had been closed since the end of WWII, reopened, 
leading to a population and building boom in south Dade. But, this boom paled in comparison to the over 100,000 Cuban exiles that arrived in Miami in the months following Fidel Castro's 1959 overthrow of Fulgencio Batista's government in Cuba (Chapman 1991).

Population growth in the county continued, and by 1960 the population approached one million (U.S. Department of the Census 1990). Development continued in an unplanned sprawling fashion, spawning shopping center "malls" and roadside "strips" throughout the 1960 s and into the $1970 \mathrm{~s}$. For the first time in history, air conditioning became the norm for coping with the climate. The 1960 s were also characterized by droughts, intense muck fires in the Everglades, increased saltwater intrusion and toxic pollution of the freshwater aquifer, and a decrease in fishing yields. Most of these problems were tied to urbanization.

By the end of the 1960s, the growing seriousness of environmental problems led to a shift towards a more controlled and planned land use. In 1968 Congress passed the Biscayne National Monument Act, establishing a marine preserve of 96,000 acres in Biscayne Bay and prohibiting offshore development there (Blake 1980:215). In 1974 Biscayne Bay became Dade County's second national park (Evoy 1985). The following year Dade County issued the first Comprehensive Development Master Plan (Brown 1985:190), 
which was readopted in the 1985 state Comprehensive Flan (Fernald and May 1992:237).

Along with the new spirit of planned land use, the "Planned Unit Development" concept was created in the 1970 s. This new concept involved housing development designs of large areas with comprehensive master plans. The master plans considered the development of schools, parks, open spaces, bike paths, walkways, and shopping areas. The townhouse communities of today are examples of this design (Sullivan 1985).

The 1980 s began with a rapid rise in population. In 1980, over 125,000 Cuban refugees arrived at South Florida in one month during the Mariel boatlift. Many stayed in Dade County (Chapman 1991). Since then, South Florida's environmental problems have continued to intensify and expand along with population growth. Numerous attempts to resolve these problems have emerged, particularly in the field of education. In fact, the $1980 \mathrm{~s}$ has been referred to as the "decade of environmental awareness" by some environmentalists (Ross 1990:65).

In 1992, Dade County experienced a tremendous environmental impact caused by one of the most damaging hurricanes in U.S. history. The human alteration of the natural environment caused by land use patterns affected the extent of the hurricane damages and now influences the recovery of natural areas. Recovery is of particular 
concern considering the presence of exotic plant species and their ability to dominate in disturbed habitats (Lord 1993: 20-21).

The hurricane severely damaged the mangrove forests along the coastline. Over 10,000 acres of red, black, and white mangroves were destroyed. Their recovery may take over 25 years. This will impact Biscayne Bay's water quality as well as the animal species that were supported by the mangrove habitats. Also severely damaged was one of the largest hardwood hammock of the United States, located in Matheson Hammock, and pinelands bordering the eastern Everglades (Ibid).

\section{Environmental Risks and Hazards}

Dade County's current residents face many of the fundamental environmental problems faced since the end of the Archaic Period. However, technological developments allowed people to either cope with these problems or to modify the natural environment to make it better suit their needs. As a result, the land that had been considered a dangerous wilderness became perceived as favorable for settlement.

The developments of transportation helped make many external resources available to the local population. Dade County residents became less dependent on their own local resources and relied more on imports. Drainage and land 
clearing altered the land and its aquatic systems so that it could support human settlements and exotic plant and animal species. Technological adaptations like air conditioning and concrete houses helped individuals to cope with the natural threats such as wildlife, mosquitoes, and severe weather events.

Unfortunately, many of the technological adaptations of the Urbanization Period also caused several environmental problems. One of the first set of problems to be noticed included an increase in the incidence of epidemics and infectious diseases. Many of these diseases were introduced by the growing number of tourists arriving from around the country by way of the railroad (Dupuis 1954:46-49, 86-90). However, the most severe of the environmental problems are associated with declining freshwater, soil, and biodiversity and increasing wasteful consumption. The response to these problems is leading to new developments in the cognitive, social, and technological dimensions. Although it may be too early to say a new period of land use patterns has emerged, there do appear to be some changes.

\section{Social Dimension}

Sudden population growth and settlement of sensitive natural areas were two of the most noticeable changes in the environment of Dade County during the Urbanization Period. This expansion persisted uncontrolled until the local 
environmental problems it caused became too severe not to notice. Since the 1970 s environmental legislation pertaining to Florida and Dade County has been on the increase. Provided below are descriptions of some of the patterns of population growth and distribution and the development of environmental legislation that occurred during the Urbanization Period.

\section{Population growth and distribution}

The population statistics of Dade County are presented in Table 8. The Table includes actual population and the percentage change in population. Due to the difference in the defined boundaries of Dade County prior to the 1920 census (see Figure 1), estimates of the population within the current boundaries are not very accurate. Still, it is possible to note that population has been increasing continuously throughout the Urbanization stage. However, the rate of growth as measured by percentage change in population decreased since the 1960s.

The non-Indian population of what is now Dade County, experienced a sudden burst in the years from 1896 to 1897. Most affected by this rapid growth was the area that is now Miami. In 1896, the population numbered around 300 (Chapman 1991), but by 1897 it nearly reached 2,000 (Shappee 1959). The concurrent Indian population estimates within the same area remain uncertain. They probably remained relatively 
constant since the end of the pioneer days. Therefore, by 1896 they would still be close to MacCauley's (1887) estimate of a little over 200 during the 1880-1881 count. Today, the only native American Indian tribe located in Dade County is the Miccosukee Indian Tribe. The number of Miccosukees residing in Dade County is currently 94 (Bureau of the Census 1994).

The changes in population of the incorporated areas of Dade County are presented in Tables 9 and 10 . The incorporated areas are listed according to their geographical distribution as either "coastal" or "inland" (illustrated in Figure 7). According to these tables, Miami has constantly maintained the highest population of any single area. Other areas with high concentrations of population include Hialeah and Miami Beach. The number of individuals scattered along the unincorporated areas of the county have also represented a large percentage of the total county population since the 1940s.

A map of the distribution of the population expansion during 1896-1975 is presented in Figure 8. Growth expanded around the mouth of the Miami River in a series of concentric semi-circles. However, the expansion was not exactly symmetrical. Until 1930 the population within the City of Miami grew at a faster rate than the county as a whole. Between 1940 and 1945 expansion was fastest among the areas north and west of Miami (Carney 1946), 
Table 8 Population growth in Dade County (1840-1992).

\begin{tabular}{|r|r|r|}
\multicolumn{1}{c|}{ YEAR } & POPULATION & \multicolumn{1}{c}{ \% GROWTH } \\
\hline $1840^{\star}$ & 446 & \\
\hline $1850^{\star}$ & 159 & $-64.3 \%$ \\
\hline $1860^{\star}$ & 83 & $-47.8 \%$ \\
\hline $1870^{\star}$ & 85 & $2.4 \%$ \\
\hline $1880^{\star \star}$ & 257 & $202.4 \%$ \\
\hline $1890^{\star \star}$ & 861 & $235.0 \%$ \\
\hline $1900^{\star \star}$ & 4,955 & $475.5 \%$ \\
\hline $1910^{\star \star \star}$ & 11,933 & $140.8 \%$ \\
\hline 1920 & 42,753 & $258.3 \%$ \\
\hline 1930 & 142,955 & $234.4 \%$ \\
\hline 1940 & 267,739 & $87.3 \%$ \\
\hline 1950 & 495,084 & $84.9 \%$ \\
\hline 1960 & 935,047 & $88.9 \%$ \\
\hline 1970 & $1,267,792$ & $35.6 \%$ \\
\hline 1980 & $1,625,781$ & $28.2 \%$ \\
\hline 1990 & $1,937,094$ & $19.1 \%$ \\
\hline 1992 & $1,982,901$ & $2.4 \%$ \\
\hline
\end{tabular}

* County Boundaries: (S.W.) East Cape Sable, (N.W.) Lake Okeechobee,

(N.E.) North Fort Lauderdale, (S) Bahia Honda

** North boundary at St. Lucie River, Fort Pierce, others current.

${ }^{* * *}$ North boundary at North Fort Lauderdale, others current.

Source: U.S. Bureau of the Census 1983,

Bureau of Economic and Business Research 1993. 


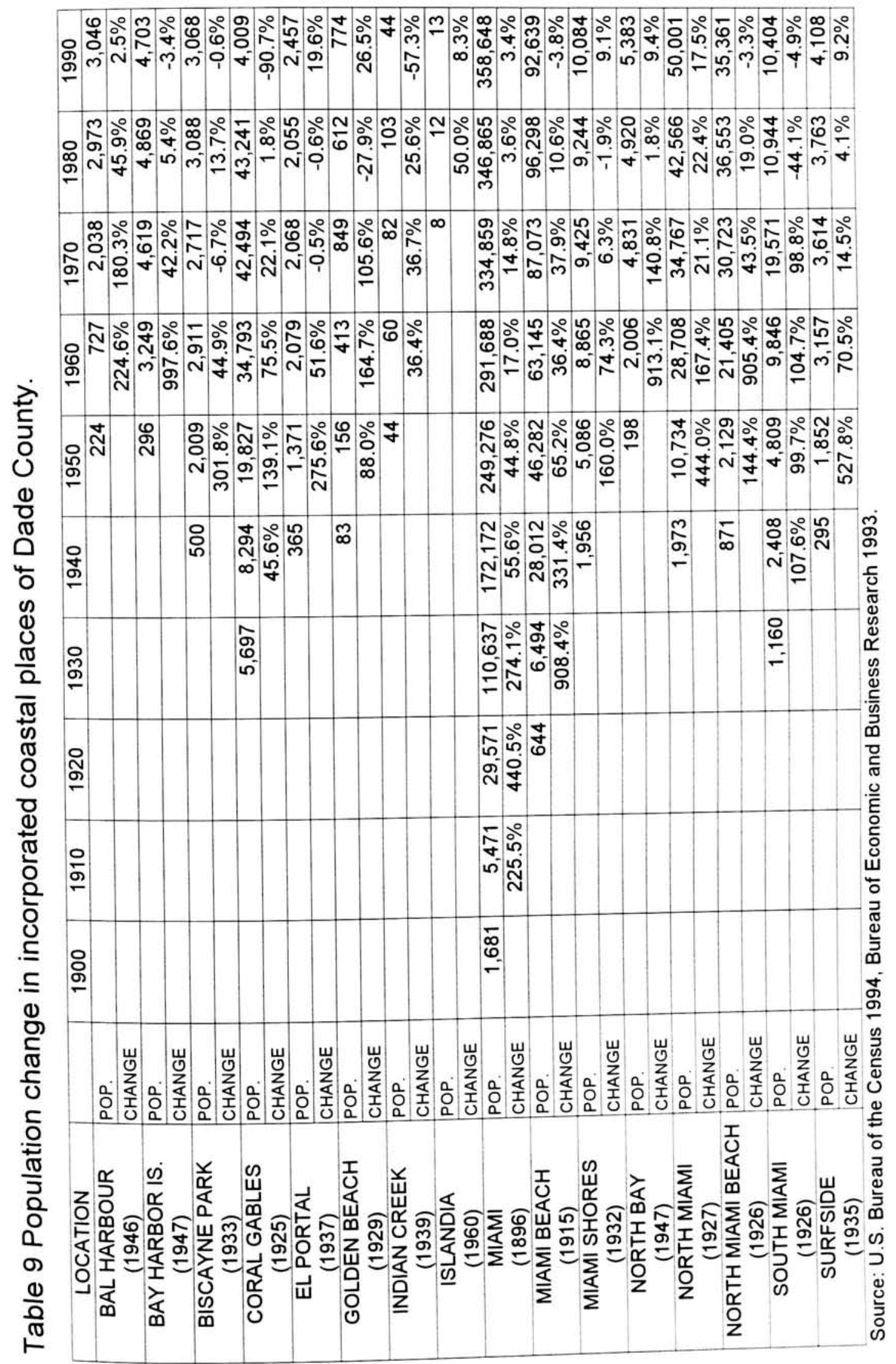




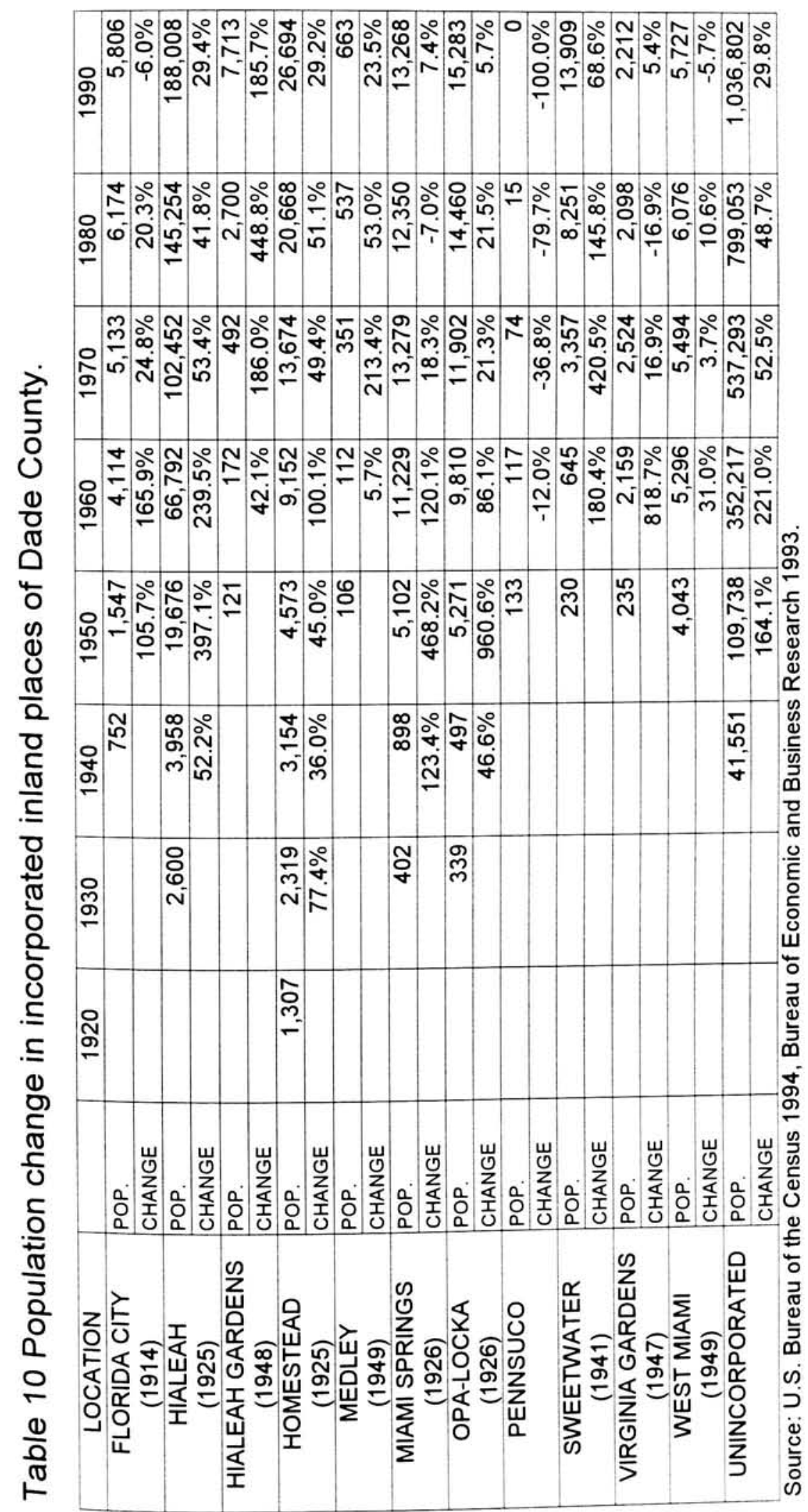


Figure 7 Incorporated Areas of Dade County

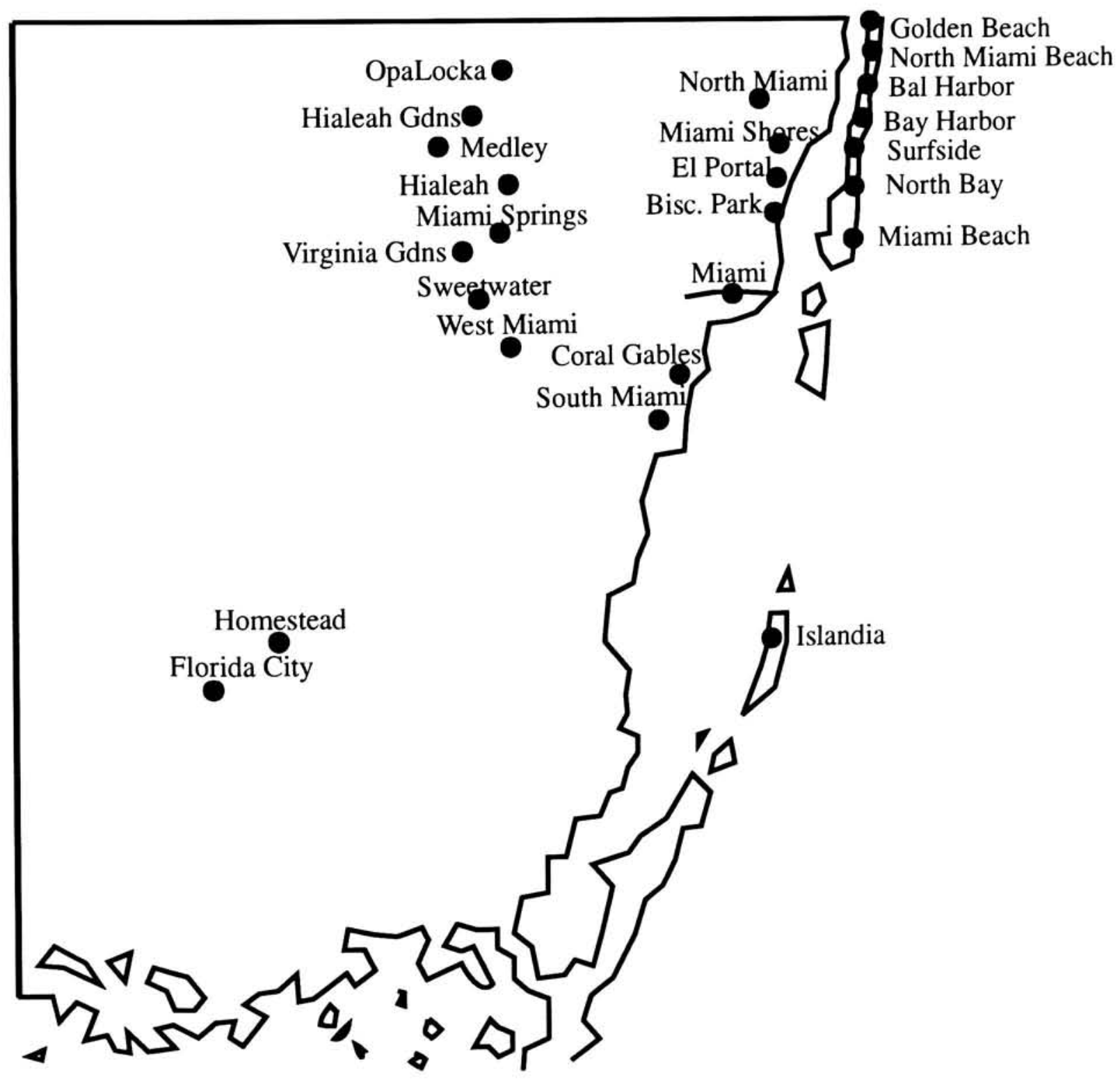


Figure 8 Urban Population Growth in Dade County 1920 - 1975

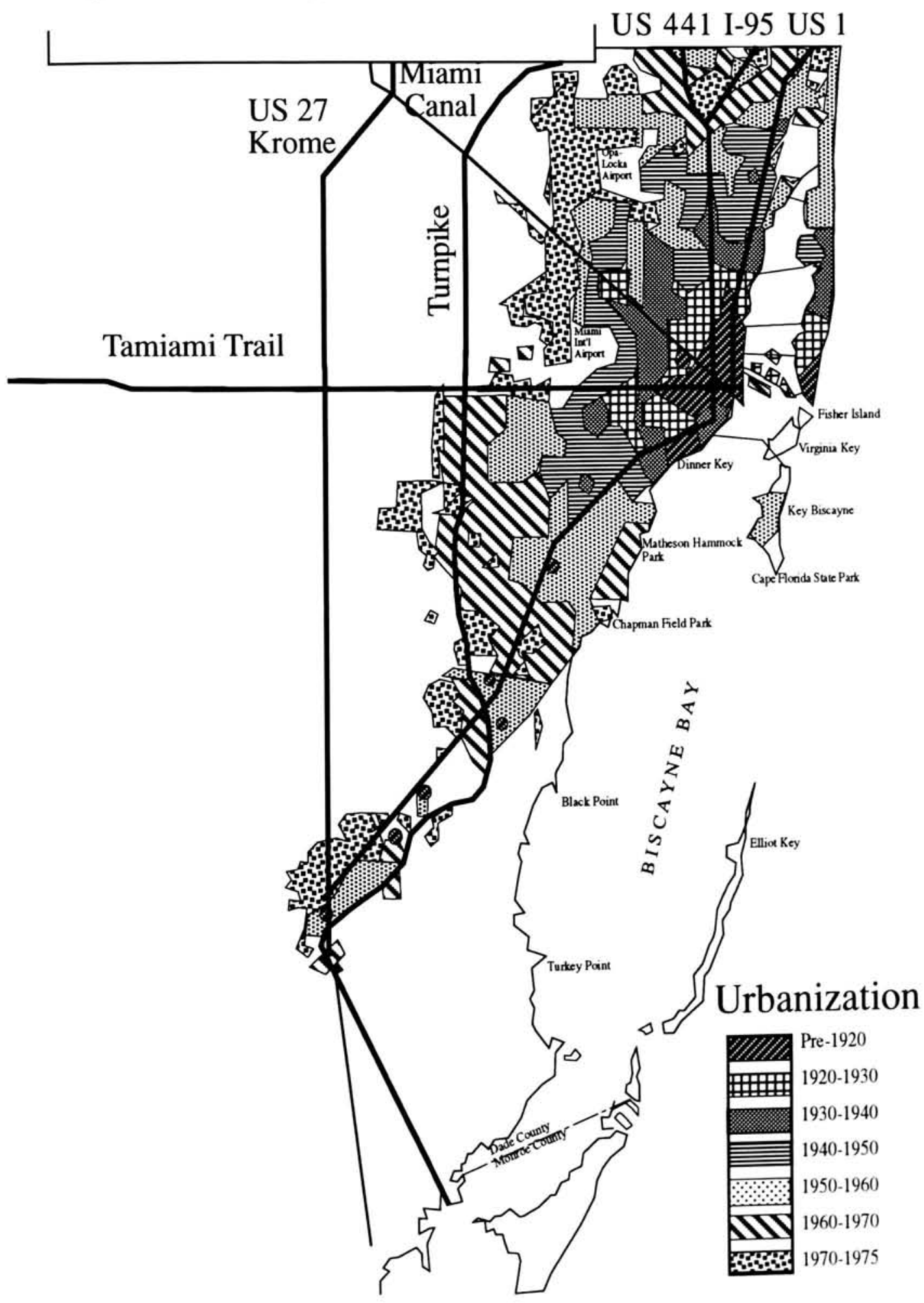

Source: Comprehensive Master Development Plan Dade County 1979 
particularly in North Miami, Hialeah, Miami Springs, and opa-Locka. Beginning in the 1950s the expansion started heading to the south, and in the $1970 \mathrm{~s}$ it expanded to the west.

By comparing the map of historic vegetative communties (Figure 2) to that of population expansion (Figure 8), it is possible to determine the chronology of natural land displacement by urban development. Prior to 1920, the population of Dade County was concentrated in Miami, on a small area of the rock ridge near the banks of the Miami River. Urban development replaced pinelands and hammocks and a section of wet prairie to the west of the mouth of the Miami River. In Miami Beach, the mangrove, beach, and hammock areas of the southern tip were destroyed. In Homestead a few individuals began to settle on the southern extension of the rock ridge among the pinelands and hammocks .

The population "boom" of the 1920's affected the population growth in all areas simultaneously, but primarily around the Miami River area. Development continued along the rock ridge, the wet prairies to the west of the mouth of the Miami River, and on the coastal environment of Miami Beach. Expansion to the north and south displaced not only pinelands and hammocks but also the "transverse glades" marshes that cut across the ridge and salt marshes to south and the east of the ridge. This pattern continued until the 
westward expansion of the 1940 s reached into the Everglades region, also displacing freshwater marshes and tree islands.

During 1950-1970, development in the south expanded along the eastern edge of the rock ridge, displacing coastal freshwater marshes. To the north, it creeped westward into the Everglades region, displacing freshwater marshes and tree islands. Development during 1970 through the present has been primarily to the west, expanding further into the Everglades and destroying freshwater marshes and tree islands to the north and wet prairies in the south.

\section{Environmental legislation}

One of the ways of gauging the shifting attitudes towards the relationship between urbanization and the environment is to examine the history of environmental legislation. Prior to the 1960 s environmental legislation was extremely limited. However, there were a few individuals and organizations who expressed their concerns over the environmental threats of urbanization. One of the first well known individuals to do this was probably Ralph Munroe. Within the first decade of the Urbanization Period he was already voicing his concern over the destruction of the aesthetic beauty of the natural environment and the fact that developers did not know enough about how the natural environment functioned (Munroe and Gilpin 1966:333-344). The botanist John Small warned of the dangers of salt 
intrusion and muck fires from drainage activities even before any drainage began (Blake 1980:166). One of the most influential environmental organizations during the early years of urbanization was the Florida Federation of Women's Clubs. The efforts of these women greatly motivated the creation of the Everglades National Park (Paige 1986: 179209).

Environmental legislation affecting Florida has been on the rise at the federal, state, and local levels since the 1960s. In 1969, the statutory Revision Division of the Joint Legislative Management Committee did not provide a single "environmental" heading in their publication of Official Florida Statutes. By 1971 they listed one, and by 1993 there were eight pages of "environmental" statutes. Environmental legislation has focused on balancing the interests of several groups including agriculturalists, developers, conservationists, preservationists, hunters, and fishermen. One of the areas in which this has become most noticeable is in water management policies.

\section{Technology}

During the period of urbanization, several developments in the field of energy production led to the use of various machines that helped to intensify land use. Land use became predominantly associated with various forms of commercial activity rather than subsistence. The technological 
developments most significant in influencing land use during this period were those of dredging and structural controls of water. These technologies were used for the development of agricultural and urban land and the alteration of the Biscayne Bay environment. Other significant technologies include those involved in the extensive construction of commercial and residential areas, plant cultivation, and transportation. Provided below is a description of these technological developments and commercial activities associated with land use during the period of urbanization.

\section{Energy sources}

Most of the machinery developed during the Urbanization Period was powered by gasoline or electricity. Petroleum replaced steam as the main energy source for most forms of transportation and heavy machinery, including that used to generate electricity. Electricity is used to power an innumerable variety of electrical machines including household appliances that do much of the work traditionally done by human labor.

In the 1970s, oil prices skyrocketed and alternative energy sources were sought. Some of the other energy sources that became more utilized since then include coal, natural gas, nuclear energy, and commercial solar energy. Today, most of the county's energy sources are still supplied by gasoline, most of which is imported, as is most 
of the natural gas and all of the coal (Winsberg 1992).

\section{Drainage and structural controls}

All activities related to drainage or the development of structural controls of water in South Florida affect Dade County either directly or indirectly. However, a detailed history of these activities would be beyond the scope of this thesis (see Figure 9). Even the activity limited to Dade County is extensive. Therefore, I present below a sumnary of the different trends of these activities along with a chronology of some of the more significant events that occurred specifically in Dade County.

Drainage during $1882-1949$ was promoted by wealthy individuals and powerful organizations for the purpose of developing massive urban and agricultural projects. The trend towards structural controls exploded in the 1950s with the development of canals, dikes, and water conservation areas. Most of these activities were also primarily in interest of urban development and agriculture. Yet they also helped serve several other purposes, such as flood control, storage of surface water, prevention of soil subsidence, protection and improvement of municipal water supplies, prevention of saltwater intrusion, and maintenance of habitat for fish and wildlife in the water conservation areas. Since the 1980s, the use of structural controls has been deemphasized. Instead, some have been eliminated and 


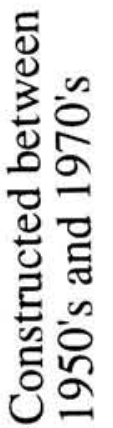

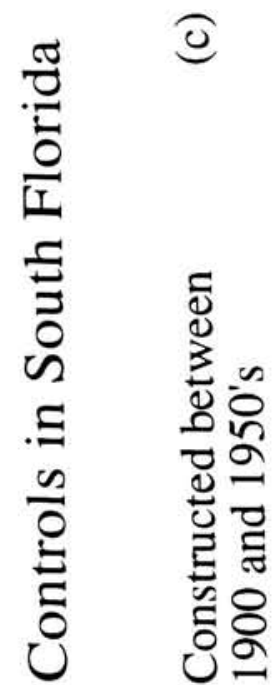

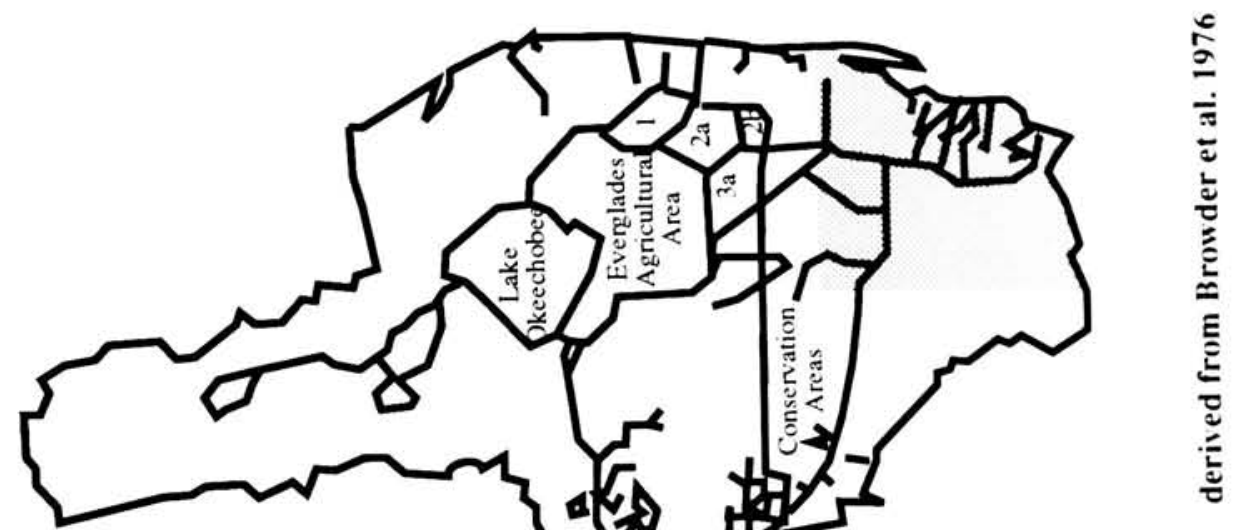

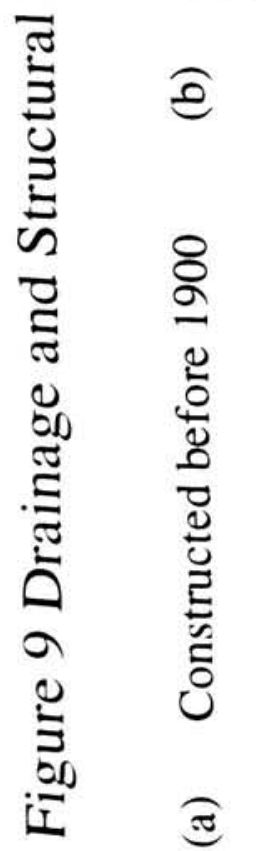
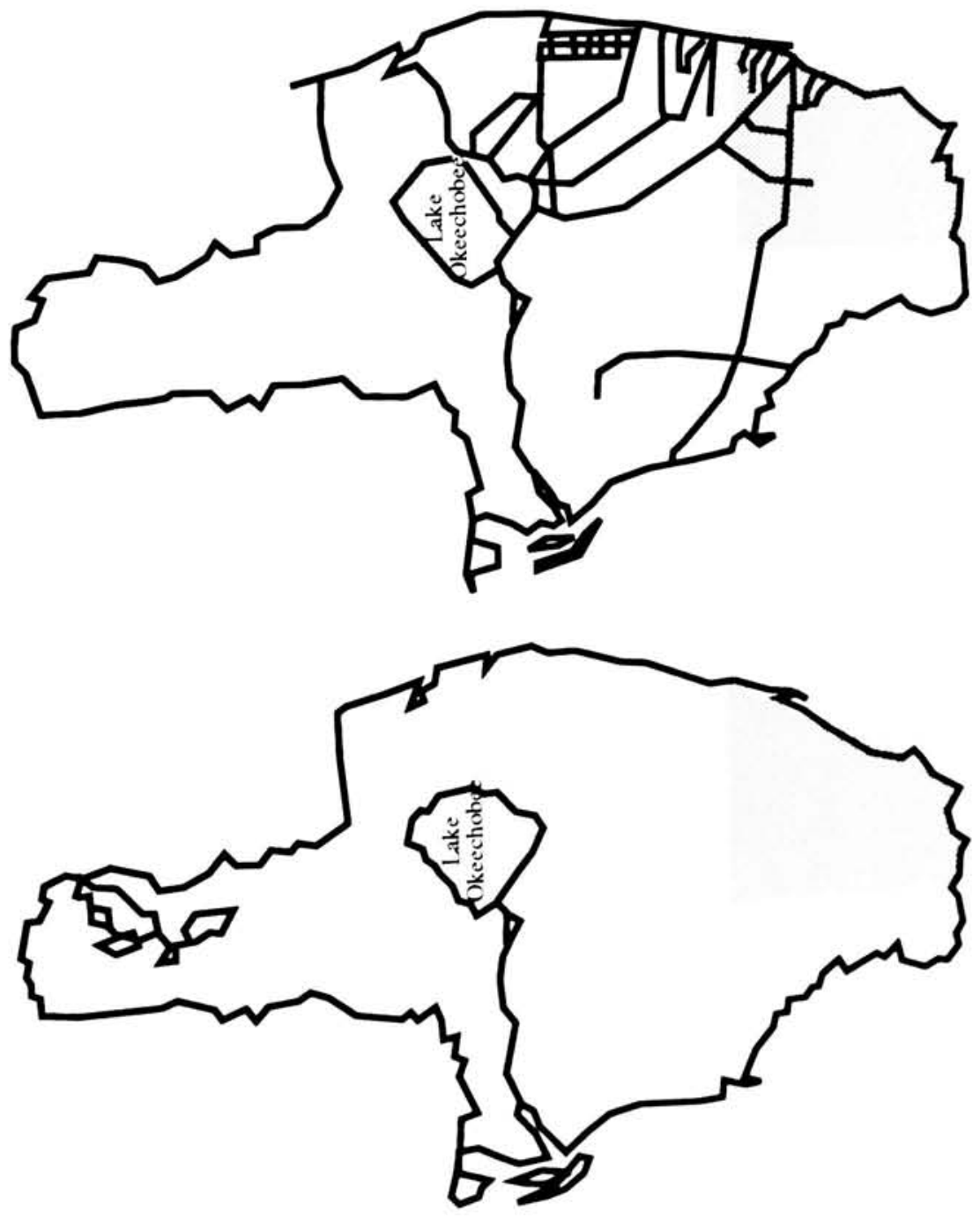
policies for the better use of the remaining ones have been implemented (Gleason 1982).

In 1907 the state legislature created a drainage taxing district in the Lake Okeechobee area. In 1913 it was named the Everglades Drainage District and charged with the task of designing and constructing a project for draining the Everglades for farming (Canter and Christie 1985; Tebeau 1980:347-348). Drainage in the Dade County area did not begin until 1909 with the dredging of the extension of the Miami River to Lake okeechobee. This involved blasting through the waterfalls and rapids of the Miami River (Griffin 1979:28-29), and digging a 60 feet wide, 10 feet deep ditch by a floating steam powered dredge, which worked 24 hours a day. As a result of the dredging, the water level of the river dropped so much that a dam had to be built between the dredge and the ocean. The dam trapped the water allowing the dredge to remain afloat. By 1912 the canal was completed and the dam removed causing the Everglades water level to drop by a meter or more and drying up several freshwater springs along the previous Miami River and down the coast (Ross 1990).

Due to several unforeseen problems in the drainage process, the drainage plans had to be revised several times over the following twenty years (Chapman 1991). As a result, the only other major dredging activity in Dade County until the 1950s was the construction of the Tamiami 
Canal and the development of a canal connecting the Miami and Tamiami canals.

The impacts of the drainage activity began to be felt throughout South Florida by the 1920s. Several dxoughts during 1920-1925 caused a lowering of groundwater levels, rather than just the intended surface water level. Heavy rainfall from huxricanes that hit South Florida between 1922 to 1928 caused severe flooding in areas developed over natural floodplains. The state began a program of flood control in response to the dangers of flooding. By 1930, the federal government authorized the U.S. Army Corps of Engineers to build the Hoover Dike around Lake Okeechobee (Huber and Heaney 1985; Tebeau 1980:354).

A period of extended drought persisted during 1931-1945. The combination of the drought and the drainage and flood control projects intensified the existing environmental problems and caused several new ones to occur. The lowered water levels increased the oxidation of muck soils in the Everglades, lowering ground elevations by over 2 centimeters per year and causing muck fires in the dry seasons. The lowering of ground water levels allowed saltwater intrusion into the coastal areas, contaminating some of the domestic water supplies (Huber and Heaney 1985). Since then, saltwater intrusion has extended farther west along the Coastal areas, particularly around Miami River (see Figure 10). Some of the other factors responsible for salt water 

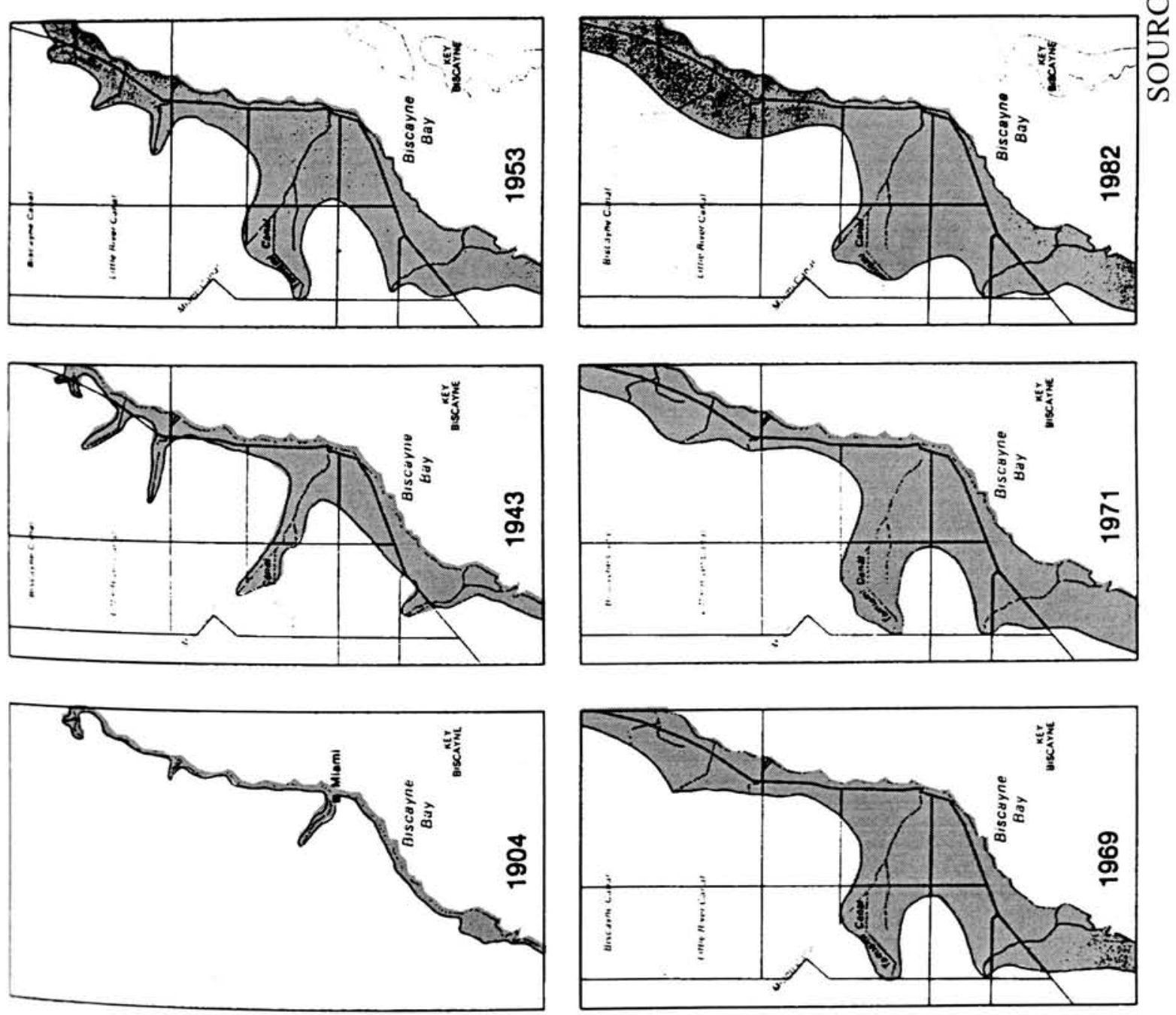

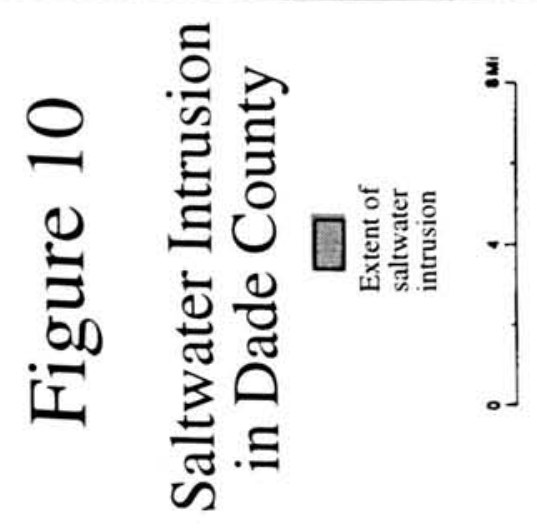

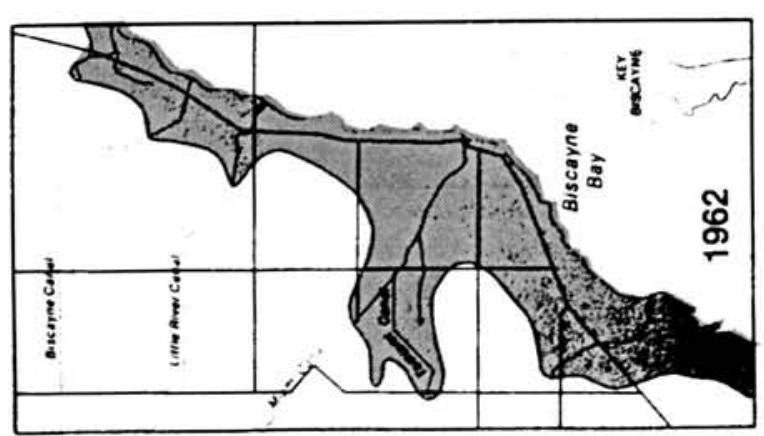


intrusion into the Biscayne Aquifer include the trapping of sea water in the aquifer since ancient times and the leakage of brackish water from the Floridan Aquifer by way of abandoned artesian wells (Van Arman et al. 1985:149).

The end of the droughts of the 1930 s and 1940 s was marked by a series of severe hurricanes hitting the southeast coast in 1945 and 1947. The canals and levees constructed for flood protection failed and the newly reclaimed agricultural and urban areas were devastated. In 1948 the Congress adopted the Army Corps of Engineer's plan for flood control. The following year the Everglades Drainage District was reorganized into the Central and Southern Florida Flood Control District, and charged with the task of overseeing a monumental flood management project (Canter and Christie 1985). This marked the beginning of the shift in emphasis from drainage activities towards structural controls. By 1961, the Flood Control District was again reorganized and renamed the South Florida Water Management District (Paige $1986: 138-48)$.

In the period during 1950 to 1973 , a series of extensive flood control and water conservation structures were built in the Flood Control District (see Figure 10). This included the construction of the Kissimmee Canal and of four Water Conservation Areas that act as artificially controlled pools of water (Huber and Heaney 1985). The Kissimmee Canal involved straightening a $167 \mathrm{kilometer} \mathrm{long} \mathrm{meandering}$ 
stream into a straight channel 96 kilometers long extending southward from Orange County to Lake Okeechobee. This process was carried out despite the objections of the U.S. Fish and Wildlife Service and the Florida Game and Fresh Water Commission that it would seriously disturb the ecology of the region (Blake 1980:260-261).

The bottom of Conservation Areas $3 \mathrm{~A}$ and $3 \mathrm{~B}$ fall in the northwestern sector of Dade County in the Everglades region. These Conservation Areas are managed by the Florida Game and Fresh Water Fish Commission whose primary goal is flood control with recreation and wildlife preservation as secondary objectives (Blake 1980:185-187). When the Conservation Areas get too full of water, discharges are made into canals that empty either into Biscayne Bay or the Everglades. When they get too dry, the water flow to the canals is stopped. This artificial control of water flow changed the natural wet-dry cycle of the Everglades, affecting the vegetation and reproduction and feeding cycle of many of the animals supported by the Everglades (Ross $1990: 48$ ).

Since the 1970s, and particularly in the 1980s, the development of structural controls as a means of water management has been deemphasized. Instead, water management is currently more involved with instituting water use policies to balance the concerns of agriculturalists, developers, conservationists, preservationists, hunters, and 
fishermen. Despite these efforts, the water problems in South Florida are currently among the most frequent and severe in Florida and the nation. Residents in Dade County are faced with the problems of freshwater availability. saltwater intrusion, pollution, undependable weather patterns, and competition for water among several interest groups (Patton and Fernald 1985:6-7).

\section{Marine dredging}

The first marine dredging activities of the urbanization period were begun in 1896 by the Florida East Coast Railroad. The railroad dredged a basin north of the mouth of the Miami River and in the river itself. Around the same time a channel was cut from Cape Florida out to sea. By 1905 the Arny Corps created Government Cut and the Miami Ship Channel through the southern tip of Miami Beach. The dredgings from this project helped to form Fisher Island, which had previously been a shallow bank. In the process, mangroves along the coast were cleared and the resulting areas filled and bulkheaded. Dredging activity was also responsible for the creation of several other islands by 1919, and for the creation of Haulover cut in 1924. In addition to this, the Venetian and 79 th street Causeways, built around this time, involved dredging activities (Chardon 1976; Michel 1976).

The dredging activity had both short and long-term 
consequences. The immediate effects were felt by the boaters in the Miami area. The navigable water in the upper bay became limited to the cuts themselves and these were obstructed with unlit telegraph-poles. After several years of exposure to the elements these piles rotted and broke at the surface of the water, leaving sharp pointed stubs. This created a potential threat for boaters (Munroe and Gilpin 1966:256-57). The long-term effects, which have intensified with the deepening of Government Cut and Ship Channel, were alterations of the water currents in Biscayne Bay leading to coastal accretion and erosion, and water quality changes. The most affected areas include beaches along Fisher Island, Virginia Key, and Key Biscayne (Chardon 1976; Michel 1976).

Following the end of the 1920 s boom there was no dredging in the Bay area until the construction of the Rickenbacker Causeway in 1947. By 1951 the Broad Causeway was constructed on the northern side of the Bay, and in 1960 construction began for the new port for the City of Miami. The Julia Tuttle Causeway was also constructed around the same time (Michel 1976). There have been no major marine dredging operations since that time.

\section{Residential and commercial development}

Most of the residential and commercial development in Dade County during the first few years of the period of urbanization occurred in the Miami area under the control of 
Henry Flagler. In 1897, nearly half of Miami's population comprised of his employees (Shappee 1959) who lived mainly in tents, chickees, or shacks of driftwood or crates (Peters 1984:182). That year Flagler's company installed a waterworks system, cleared, graded, and paved streets, constructed the Royal Palm Hotel, and installed the first sewage lines in Miami. Flagler also proposed the building of several small cottages. These cottages measured about seven meters by nine meters. They were two stories high with six to ten rooms, with and without baths (Shappee 1959).

Water was supplied to Miami by a seven to eight kilometer long pipeline that stretched from wells in the Everglades to a water storage tank. Street clearing involved blasting the surface rock and crushing the loosened rock. The largest rocks were placed at the bottom of the excavation with smaller pieces towards the top. The surface was brushed with very fine rock, wetted and rolled down. The sidewalks consisted of elevated strips of rock that had been chiseled and graded into a smooth surface (Shappee 1959).

Flagler's Royal Palm Hotel was the first structure of considerable size built in Dade County during the Urbanization Period. It was located along the northern banks of the mouth of the Miami River. Although several other hotels were already in existence at this time, none measured up to the dimensions of the Royal Palm. It was 
over 200 meters long, 81 meters wide and 6 stories high with 450 rooms and 100 baths with hot and cold water. It had its own ice and electric plants, laundry, elevators, swimming pool, and sewage lines. The water for the pool came Erom the Miami River from an inlet about half a kilometer downstream from the raw sewage outlet (Shappee 1959).

In 1903 the railroad reached Homestead and opened up pioneer style homesteading in south Dade for the first time. This type of settlement continued until the real estate boom of the 1920s. The U.S. Federal Homestead Act required that the homesteader improve the land. It had to be cleared, a dwelling had to be erected, and residence established for five years. Land that had been homesteaded could then be purchased for $\$ 1.25$ an acre. Veterans got credit of one year of homesteading for each year of service. By 1912 Homestead had several commercial structures including a general store, a barber shop, a hotel, a drug store, a post office, a pool hall, a grocery store, a rooming house, jail, garage, and newspaper all centrally located by the railroad terminal (Taylor and Buskirk 1985).

Meanwhile, back in Miami, a second luxury hotel, the Halcyon, was built in 1906. The most significant feature of this hotel was the limestone rock from which it was made. Although a few structures had been made out of this material during the Pioneer Period, the Halcyon was by far the largest limestone rock structure of its time. It required 
more than 2,000 cubic meters of quarried oolitic limestone. This came from a single quarry located in the south side of the Miami River. The limestone blocks were sawed out of the ground using a machine specifically designed for that

purpose. The construction of the Halcyon helped to promote the use of limestone rock as a building material. The courthouse, jail, and Miami City Hall were originally built of this rock. By 1909 Miami's only quarry was cutting over 600 cubic meters a day (Peters 1984:74-83).

By 1909 Miami had fifteen kilometers of sewage line, which discharged raw sewage in one spot into the Miami River. The result was the creation of a noxious breeding ground for fish and a potential hazard to those who fished in that area and for the swimmers in the Royal Palm pool. Later the same year, one sewage line was still dumping in the river while several others were extended over 100 meters offshore into the bay. Despite the expansion of the sewage system, not all residents had access to it. Blacks living in Colored Town were not hooked up to the sewer system for many years yet to come. Instead, they relied on a human waste collection system that dumped the waste into a sewer junction under a manhole (Peters 1984:183-84). This practice of dumping sewage into the Biscayne Bay continued until the development of the sewage treatment plant at Virginia key in 1956. During this time, the amount of sewage increased with population growth, intensifying the 
pollution of the bay area and increasing the amount of fresh water lost for reuse (D'Amato 1973). The underwater line that connects the mainland to the treatment plant on virginia Key became highly corroded and in danger of leaking. At the time of this writing, work to replace it with a new larger line was completed.

In 1912, Ocean Realty of Miami Beach became the first real estate company in Dade County. The founder and president of this company, J.N. Lumrnus, developed a residential city that faced the ocean with blocks that ran parallel to the ocean. John Collins and Carl Fisher soon started their own real estate companies on the island, and by 1913 there were three real estate companies on the beach. Collins built a wooden bridge connecting the island to the mainland, while Fisher focused on trying to make Miami Beach a self reliant city. The clearing of the land was achieved with the labor of Rosie the Elephant (Millas 1985).

By 1915 the leaders of the three real estate companies influenced the passing of a charter incorporating the Town of Miami Beach. Plans were developed for electricity, telephone, sewage, and city water, which at that time was supplied mainly by windmill powered underground wells and rooftop tanks. Together, Lummus, Collins, and Fisher were responsible for a series of projects that included the clearing of the Miami Beach's mangrove habitats and the dredging of the Biscayne Bay area. The dredging was carried 
out in order to obtain fill material for the lowland areas of the beach. In the winter of 1920-21 the real estate boom hit Miami Beach. By the end of 1925 it had 56 hotels with 4,000 rooms, 178 apartment houses, 858 private residences, 308 shops and offices, 8 bathing "casinos," 4 polo fields, 3 golf courses, 3 schools, and 2 churches (Millas 1985).

During the 1920s boom, skyscrapers were built by the mouth of Miami River and George Merrick developed Coral Gables. Coral Gables was the first planned community in Dade County. The town was conceived by George Merrick who saw it as a master suburb of Miami. By 1926 it became known as "The City Beautiful." Coral Gables was unique in its accomplishment of creating parks, open spaces, and public facilities. In addition, districts were zoned for business or residence. These different districts were integrated by a system of mass public transportation including, buses, trolleys, and interurban railcars (Sullivan 1985).

Beginning in the 1930s, the development of South Florida was typified by unplanned urban sprawl. During this time, the trolleys and interurban railcars were replaced by the automobile as the main form of transportation. This led to the emergence of the automobile oriented roadside strips. This practice was intensified following the post-WWII population boom, leading to shopping mall strips, a development practice that prospered in the 1960 s and early 1970s (Sullivan 1985). It was also not until after WWII 
that serious development began in Key Biscayne, when the Rickenbacker Causeway connecting it to the mainland was built in 1947. The central portion of the island was developed for residences and businesses (Miller 1985).

In the 1970s a new concept in development called Planned Unit Development emerged in Dade County. This style of development is characterized by having comprehensive master plans for the development of large tracts of land. These master plans include the development of schools, parks, open space, shopping and public facilities, and residences. This style of development provides a greater percentage of open space as compared to buildings, considers the protection of natural areas, watersheds, and recharge areas, and provides shopping areas within walking or biking distance of the residences (Sullivan 1985).

\section{Plant cultivation}

Plant cultivation for the purposes of ornamentation, food, and various miscellaneous uses has persisted throughout the Urbanization Period. The majority of these plants are exotics. Many of the tropical fruits and regetables first introduced by the early pioneers are still cultivated today, and many new ones have since been added. The Plantfinder Wholesale Guide to Foliage and Ornamental Plants (Galleta 1992) provides a list of several hundred exotic ornamental plants that are available to Dade County 
residents.

The cultivation of ornamental plants for commercial sale was of minor significance until the 1950s. Until then, most of the plants were grown for local use. The nursery business boomed after the construction of highway systems that connected Dade County with the rest of the nation. However, the amount of land used for cultivation is still much less than that used for vegetables. In spite of this, the amount of money generated per acre of ornamental plants is much higher than that earned by vegetables (winsberg 1991).

Commercial vegetable cultivation in Dade County began in Homestead. The cultivated area consisted of a series of rock ridge outcrops surrounded by lowland marshes to the west and south. During the summer months the lowlands were covered with water, but in the winter months they were dry and the higher of the lowlands was farmed. This land was very fertile and was used to grow tomatoes, green beans (Leguminosae), peppers (Capsicum spp.), and eggplant. Access to this land required building "corduroy" roads over muddy terrain. These were built by laying down pine saplings side by side and covering them with mud to hold them down. In the pineland, farmers planted their groves by poking holes in red clay pits in the limestone rock. These clay pits gave rise to the common name of this area the "Redlands" (Taylor and Buskirk 1985). 
By the beginning of the twentieth century tomato farming became the main occupation of settlers in Dade County (Blackman 1921:61). One of the tomato centers, known as the "Hole in the Doughnut," lay within an area of about 7,500 acres currently in the southeastern Everglades National Park. This agricultural land was developed in 1916 by draining of the swamplands near the present Royal Palm visitor Center. The soil in this area is very poor in nutrients and susceptible to many insects. As a result, heavy applications of fertilizer and pesticides were required for vegetable cultivation. As farming activity intensified in the surrounding areas, several studies documented adverse effects on animals and plants within the Everglades National Park and to the water from Taylor Creek Slough and the Florida Bay due to pesticides and fertilizer contamination. In 1970, the Congress condemned farmlands in this area and purchased the existing fields for the Everglades National Fark, and by 1975 all tomato growers had abandoned this area (Paige 1986:105).

The 1920 s was a period of land and agricultural industry boom for Homestead. Homestead was shipping out more avocados and tomatoes than any other part of the country. The 1926 hurricane caused millions of dollars of damage. After cleaning up and replanting some of the groves the second hurricane of the year struck in October. This disaster was followed by the Great Depression. This series 
of incidents caused Homestead to struggle economically until World War II (Taylor and Buskirk 1985).

Historically, the coastal ridge areas of the county were the most extensively used for agriculture. Millicent (1949: 101) estimated that in 1931 there were about 50,620 acres of farmland in Dade county, mostly in the pinelands. Some of the tropical fruits cultivated included avocados, pineapples, papayas (Carica papaya), mangos, sapodilla, coconut, guava, and several citrus species including grapefruit, oranges, and limes. Cultivating in the pinelands involved blasting a hole in the limestone, filling it with planting soil and then planting the trees.

Today the coastal ridge is used mostly for residential development. Farming is now carried out in the lands near the southeastern Everglades and the marshes south and east of the Miami Rock Ridge. This land is less suited to farming due to poorer soils (mainly oolitic limestone and marl) and frequent flooding. Farming techniques in these lands requires drainage, rock plowing, and heavy applications of pesticides, herbicides, and fertilizers. Since farming is done during the naturally dry months, irrigation is also necessary. These activities affect soil chemistry, water quality, and plant and animal life of the local area and also into the Everglades National Park and Florida Bay regions (Brown 1985).

Limestone can only be used for farming after it has been 
scarified, a technique possible only after the development of the rock plow in the 1950s (Snyder et al. 1990:272). The process results in the creation of a new, richer, Krome series soil (U.S.D.A. 1994). It supports about 200 varieties of fruit, including avocados, mangos, limes, lemons (Citrus spp.), papayas, grapefruit, tangelos (Citrus $x$ - tangelo), oranges, kumquats (Fortunella japonica), lychees (Litchi chinensis), jujube, calabaza, sapote, and mamey (Mamea americana) (Taylor and Buskirk 1985).

The marl soils are used for cultivating annuals such as various members of the Fabaceae family, including pole beans, bush beans, and peas. Some of the starchy crops cultivated in marl includes potatoes, corn, malanga, and cassava. Garden crops harvested in this area include yellow squash, cucumbers (Cucurbitaceae), lettuce, cabbage, greens, okra, strawberries, and soybeans (Taylor and Buskirk 1985; Winsberg 1991).

\section{Transportation}

The introduction of the railroad, automobile, airplanes, and metro rail occurred during the Urbanization Period. The first railroad to reach Dade County was Flagler's East Coast Railroad in 1896 (Shappee 1959). The first cars arrived in 1905 (Dupuis 1954:34), and the first airplanes by 1914 (Munroe and Gilpin 1966:330). The extension of the Florida East Coast Railway to Key West began in 1905 (Munroe and 
Gilpin 1966:259) and construction on the first highway, the Tamiami Trail, began in 1916 (Pierce 1986).

The railroad and cars required the construction of rail and paved roads, activities that involved clearing of the right of ways. This includes clearing trees, removal of brush, burning of slash pines, and blasting of limestone rock. Some trees were used in construction. Armed guards were responsible for shooting all reptiles and other dangerous animals ahead of the workers. Behind the clearing crew was a track-laying crew for the drilling machine. The machine drilled holes for the placement of ten to forty sticks of dynamite that blasted the limestone. The blasted rock was used for raising the ground and forming the roads. However, this rock was not enough, so quarries were opened up in the Big Cypress in order to supplement the supply of crushed rock. The supplies were brought to the workers over pine and cypress bridges, which required the establishment of logging operations. The workers sometimes supplemented their diet with deer and wild turkey, which were purchased from the Miccosukee and Seminole living in the area (Paige $1986: 122)$.

Although the techniques and tools utilized to make roads have changed, the basic process is still the same: clearing the land and using the crushed limestone to raise and develop the roads. The practice is so common that the crushed fill has been given its own name in soil taxonomy. 
It is called Udorthent soil (U.S.D.A. 1994).

Aviation technology is less directly involved with

changing of the land. Rather, its indirect consequences are of more concern. Aviation helped to foster the financial comeback from the Great Depression and to increase tourism. These effects of aviation helped to increase the rate of population growth in Dade County.

The aspects of aviation more directly involved in land use include the building of airports. The building of the first airport dates back to World War I (1917) and the establishment of the Dinner Key Naval Station at N.W. 17th Avenue and the Miami River. By 1927 Pan Am provided mail service between Key West and Havana. Soon after, it built the Pan American air field over what had previously been freshwater marsh and tree islands in the Everglades region. When the Dade County Port Authority was created in the 1940s it puxchased the Pan Am Field and merged it with the Army Transport Field. Today this is the site of Miami International Airport (Chapman 1991) .

\section{Oil exploration}

The Tamiami Trail opened up the interior of the Everglades to oil exploration. This began in 1932, but it was not until 1943 that oil was discovered in the Sunniland oil field. Oil exploration in the Everglades continued throughout the 1950 s and 1960 s with the drilling of several 
wells despite the lack of much success. Most of these test wells are located in the western section of the Everglades (Paige 1986:133-134).

Tannic acid and charcoal production

In 1904 the Manetta Company developed a two and a half acre tannic acid factory on Shark River. The tannic acid was extracted from the mangrove trees in the surrounding swamplands. In addition to the tannic acid, the mangroves were used to extract dye and as a potential lumber source. However, mangrove wood tended to crack upon drying, making it unsuitable for use as lumber. Operations in the factory began in 1908 and were temporarily halted by the 1910 hurricane that destroyed the factory. The factory was eventually rebuilt and continued in operation until 1923 . when for economic reasons it was forced to close down (Paige $1986: 106-107)$.

In the early 1900s the buttonwood trees in the coastal areas surrounding the Everglades National Park were used comercially to make charcoal. Early pioneers and Indians also had used these trees as a source of firewood. To make charcoal land was cleared and up to ten cords of buttonwood was stacked up into a conical pile. The pile would be covered with grass and sand with vent holes on the top and around the bottom to provide an even burn and to let out the gases. The fire was watched constantly to prevent it from 
completely burning the wood into ashes. At night the vent holes would be covered up to smother the fire (Paige 1986: 108).

THE MICCOSUKEE AND SEMINOLE DURING THE URBANIZATION PERIOD

The Indians residing in Dade County experienced many changes in their way of life during the Urbanization Period. One of the most significant factors in bringing change to was the drainage of the Everglades. Another factor was the rapid settlement of non-Indians following the introduction of the railroad to Miami in 1896. Many of these settlers chose to make their homes in the traditional Indian hunting and camping grounds, driving the Indians to new environments (Kersey 1992:105). Despite these changes, the Indians still retain many of their traditional beliefs and customs related to their material culture, sexual division of labor, fishing, hunting, gathering, kinship, religion, magic, and medicine.

Indian trade with whites, which had peaked in the 1870s, continued until the 1930s. However, it had been declining ever since the beginning of drainage in the Everglades. Drainage altered the habitat of many of the and animals that the Indians relied on for commercial hunting. The lower water levels in the Everglades made canoe transportation nearly impossible. As a consequence, the practice and 
knowledge about seasonal migrations, certain hunting techniques, and sailing were quickly outdated (West 1981). Indians could no longer find the animals as easily as before, nor could they transport them back to the city for trade.

By 1919 the Miccosukee and Seminole trading activities became so impacted that some Indians sought wage-paying jobs in Miami's tourist attractions. Their first "job" was to stay in their camps so that tourists could look at them. The Indians made handicrafts and put on shows for tourists at these sites. By 1930 over half of the total Indian population was working in commercial villages (Nash 1931: 39) Sometimes so many Indians wanted to move to them that some had to be turned away due to lack of space (West 1981).

The Great Depression also forced changes upon the Indians. It brought a period of relocation and federal relief programs. Many of the South Florida Indians chose to relocate to the Dania reservation grounds southwest of Fort Lauderdale. Here the Indians could take advantage of the federally subsidized programs developed as part of the New Deal. One of these programs was the Indian Emergency Relief Work, which employed Indians for a variety of urbanization projects including land reclamation, road construction, and housing construction. Due to the help the Indians could receive at the reservation, they had little interest in moving to urban areas and seeking employment. However, a 
few Indians chose not to relocate to Dania. Most of these Indians were members of a conservative political group who spoke the Hitchiti based Miccosukee language and who lived near Tamiami Trail and in the Western Everglades (Kersey 1991). This marked the beginning of the Dade County settlement of the Miccosukee Indians.

The migration to reservation areas and the federally subsidized programs continued throughout the 1930 s and 1940s. However, change came to the Indians again in the 1950s. In 1953 Congress passed a resolution to terminate all federal aid to many Indian groups, including the "Seminole" of Florida. The Indians protested, and with some political assistance, successfully convinced the Florida delegation to vote against their termination. The only Indians that favored termination of federal aid were the members of the small political group of conservative Miccosukee-speaking Indians. The threat of being forced to become self reliant caused the majority of the Indians to seek their own limited tribal self-government through the adoption of a federally recognized constitution and bylaws. Again the conservative Miccosukee-speaking Indians expressed dissent from the opinions of majority of the "Seminoles." The majority carried the vote, and in 1957 the seminole Tribe of Indians won federal recognition. By 1961 the members of the more conservative seminoles created their own federally recognized tribe known as the Miccosukee (Kersey 
1991).

Today, the only Indians who own land in Dade County are the Miccosukee, although most of their land is currently located in Broward. The Miccosukee own three categories of land (presented in Figure 11), which is classified as Federal Trust Land, State Leased Land, and National Park Service Use Permit Land. Only a small fraction of this land has been developed by the Miccosukee for commercial activity. The remaining land is either leased out to commercial enterprises or used by the Miccosukee for hunting or camping (Miccosukee Tribe 1994).

According to tribal spokesperson stephen Tiger, the Miccosukees are looking for ways to expand their tribe. It is his belief that this should lead the Miccosukee to become what he calls the "Space Age Indians." This involves an acculturation process that incorporates certain space-age technologies while preserving some of the traditional Miccosukee beliefs and customs.

\section{Environmental Risks and Hazards}

Just as in the pioneer Period, the environmental problem that most influenced Indian land use in the period of Urbanization was the behavior of non-Indians in Dade County. Unlike the majority of the white settlers, the Indians relied more on local resources than imported ones for what they perceived to be an ideal livelihood. Their land use 
pattern was an adaptation to the land, rather than a modification of the land to make it suit them. Therefore, the environmental alterations created by non-Indians greatly affected the efficiency of certain Indian economic behaviors.

This environmental change was responded to primarily by changes in the social and technological areas of Indian life. At the social level, the settlement distribution has changed and their relationship with non-Indians has increased. At the technological level, the Indians make use of various elements of non-Indian material culture. Some of these technologies involve food production and preparation, transportation, communication, and house construction.

\section{Social Dimension}

At the beginning of the period of urbanization the few Indians that lived in Dade county were scattered throughout the eastern Everglades. The distribution of Indian settlements was affected by land drainage and the rapid settlement of non-Indians following the introduction of the railroad to Miami in 1896 (Kersey 1992:105). The introduction of commercial Indian villages in Miami also affected the distribution of Indians. Between 1919 and the 1930s the population of Indians living along the coastal ridge increased. However, the most significant change in Indian settlement during the Urbanization period occurred in 
Figure 11 Indian Lands in Dade County

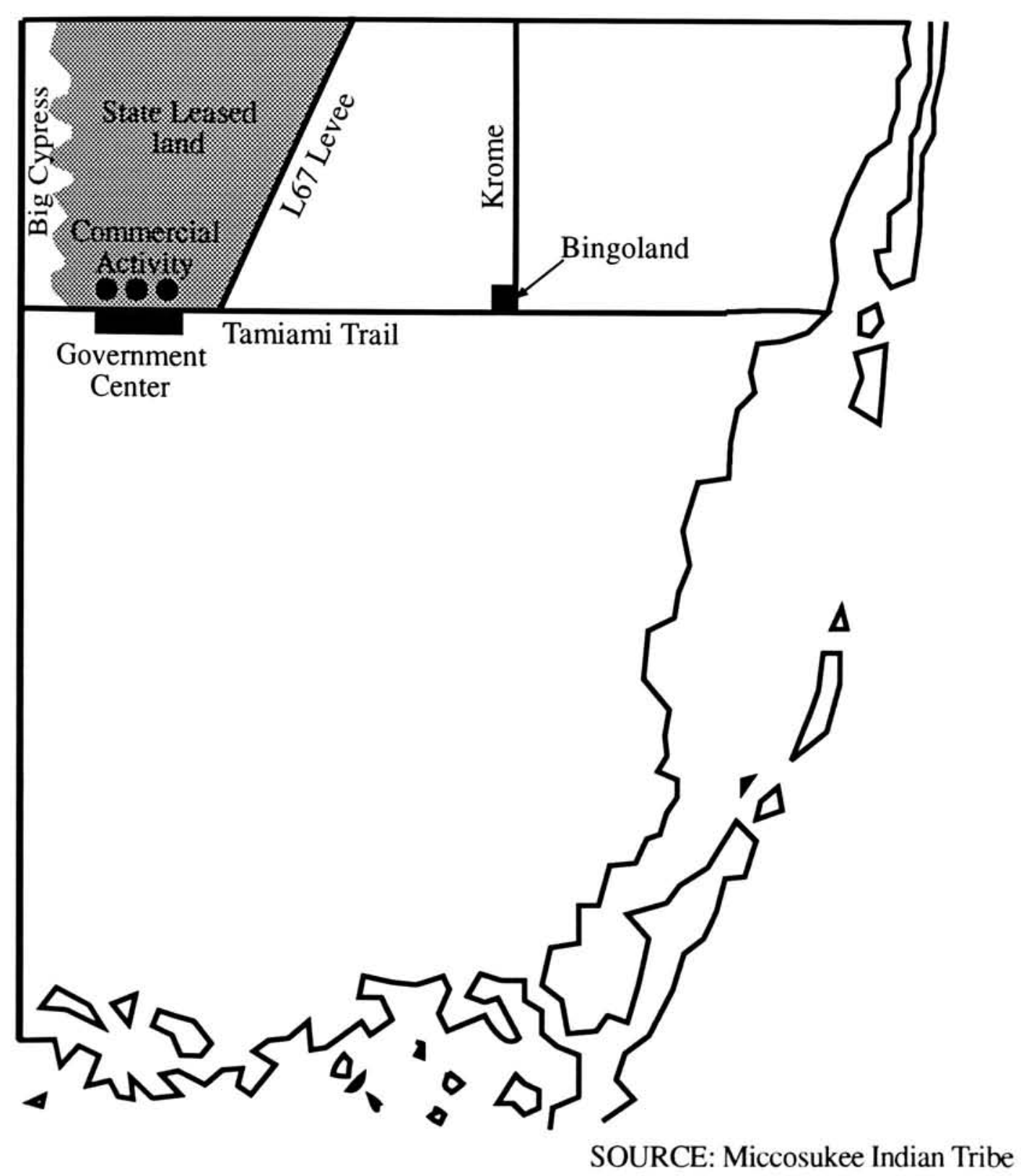


the $1930 \mathrm{~s}$ and $1940 \mathrm{~s}$. It was then that many of the south Florida Indians relocated to the Dania reservation grounds to work in the projects funded by the New Deal. Deviating from this resettlement pattern were a few conservative Miccosukee-speakers who lived near Tamiami Trail and in the western Everglades (Kersey 1991). Today, they and their descendants make up the Miccosukee Indian Tribe. The land the Miccosukee own in Dade County includes 4.7 acres of Federal Trust Land located on the north side of the Tamiami canal, 189,000 acres of State Leased Land located within Water Conservation Area $3 A$, and 333.3 acres of National Park Service Use Permit Land located on the south side of Tamiami Trail.

\section{Technology}

The technologies of the Indians most directly involved with land use were hunting, fishing, gathering, and small scale horticulture. Some of these technologies were essential to Indian white trade which peaked in the $1870^{\prime} \mathrm{s}$ and persisted up to 1930. Trading declined rapidly following the drainage activities of the early 1900's. This decline was further exacerbated by the collapse of the international fashion market at the end of WWI. The fashion industry has been one of the biggest purchasers of the pelts, plumes, and skins provided by the Indians (Kersey 1992: 105). Drainage also had a significant impact on many 
of the Indian cultural traditions. The environmental changes that drainage produced caused native seasonal migrations, certain hunting techniques, and sailing to be quickly lost (West 1981).

In 1913, and again in 1917 the Everglades experienced unusually dry conditions due to the combined effects of a drought and drainage. The water levels in the Everglades were so low that Indians were no longer able to use their canoes to bring trade items to Miami. By 1917 Indian trade became so adversely impacted that many of them sought jobs in Miami's tourist attractions. At the time Henry Coppinger's Tropical Garden, located at N.W. 20th Avenue and the Miami River, was the only attraction. It lasted until 1940. In 1919 John Roop established the Musa Isle Grove at N.W. 16th Street and 25th Avenue. It lasted until 1959 under several different owners (West 1981).

The owners of the attractions provided the Indians with wages, food, and yard goods, which were supplemented by trade. Innovations of crafts and activities which were of traditional Miccosukee or Seminole origin were commercialized for the tourists. Both residents and visiting Indians benefitted from these ventures. Indians engaged in commercialized alligator wrestling, snake handling and other activities that were not of traditional custom. Outsiders benefitted from the trade in animal products and the selling of crafts (West 1981). 
Prior to the opening of the Tamiami Trail in 1928, the Indians who lived in commercial villages brought with them elements of their material culture such as their household goods, dogs, chickens, and hogs. There they practiced a sexual division of labor in which the men built canoes and women made the clothes, while craftmaking was done by both sexes. All Indians continued to fish, hunt, and gather fruits with traditional techniques, although this was done to supplement the diet rather than for basic subsistence (West 1981).

Since their incorporation in 1961, the Miccosukee land use has become more bureaucratically determined along geographical boundaries. The state Leased Land is used for hunting, fishing, frogging, subsistence agriculture, and for other traditional activities, including the Green corn religious ceremony. The Miccosukee own the mining rights on this land. In addition, they receive a small lease fee from the Florida Game and Freshwater Commission for use of this land as part of the Everglades Wildlife Management Area. The National Park Service Use Permit Land is used to house the Miccosukee Government Center and Community Development projects, including Tamiami Trail reservation. The permit to use this land was issued in 1964 and expires in 2014. This land can only be used for administrative and educational facilities, and as a place to live and to make and sell handicrafts (Miccosukee Tribe 1994). 
Cognitive Dimension

Much of the Miccosukee belief system has remained intact despite their increased contact with outsiders. The old customs of having women give birth away from camps and villages, and keeping the men away from their newborn children for a period of four days, were observed in the tourist camps. Also observed in these camps were rituals associated with the ancestral spirits (West 1981). According to Sturtevant (1955:342), the Miccosukee believed that lonesome ancestral spirits sometimes return to villages to steal the souls of their living relatives. In order to chase the souls from the village gunshots were fired into the sky and a plant medicine was used as protection from the dead (West 1981).

Today the Miccosukee still observe the Green corn Ceremony, an annual event that is usually carried out in June or July. The actual date and location for the ceremony are determined by the medicine man. The details of the ceremony vary among the different Miccosukee groups.

Preparations begin several days prior to the ceremony and involve gathering, hunting, and cleaning of the village. Previously, there used to be one big hunt on the day preceding the ceremony. Today, the scarcity of game has forced the people to purchase the food from supermarkets. A detailed description of this ceremony may be found in Neill (1956) and sturtevant (1955). 


\section{SUMMARY OF CHAPTER V}

Many of the critical environmental factors that had previously limited non-Indian settlement and population growth in Dade county were resolved during the Urbanization Period largely due to technological innovations. The introduction of the railroad eliminated the remoteness of Dade County and eliminated the need to brave the hazards of marine travel or the terrestrial wilderness. The drainage and clearing of land enhanced it for the construction of buildings and roads, and for agriculture. This process reduced the habitats and population of what were perceived as "dangerous" and "worthless" wildlife. The use of fertilizers enriched the poor soils and pesticides helped control the large number of plant eating insects, thereby furthering the commercial cultivation of crops. Other problems, such as stressful weather events and the presence of mosquitos and other pests, were made more tolerable with the advent of concrete buildings and air conditioning. Unfortunately, the resolution of most of these problems involved the alteration of the land in such a way as to create many new environmental problems, such as freshwater and soil deterioration, and a decrease in biodiversity. I suggest that the creation of these new problems resulted from land use patterns because of anonalies in the adaptive process and structure that were caused by certain trends in 
the cultural evolution of Dade County's population. A review of how land use patterns during the Urbanization Period led to the rise of current environmental problems is presented below.

The introduction of the railroad in Miami connected Dade County to the rest of the nation. This allowed the population to obtain most of their material goods from areas far way from the local environment. Concern over the disturbance of the local environment was negligible during this period.

Decisions about how to develop the new territory were being made by individuals and organizations without knowledge of how development may affect the natural environment, or how natural forces might affect their situation. As long as economic prosperity and population growth boomed, there did not appear to be any problem or need for concern. Even when the first signs of environmental problems caused by drainage began to be noticed in the 1920 s and 1930s, the population's needs were still amply supplied by imported resources. The response to these environmental problems was delayed since they did not cause immediate stresses on the majority of the county ${ }^{1} \mathbf{s}$ population. This is an example of how negative feedback in the process of cultural adaptation can be inhibited by temporary perceptions of well being. Although the Indians were greatly affected by the problems of development, they 
were in a poor position to stop the emerging land use pattern. Instead, they adjusted by migrating to reservations and commercial Indian villages.

only after the county was flooded by hurricane rains did the environmental problems caused by drainage cause enough concern to generate a response. Several permanent structures were built to prevent flooding and to make it suitable for agricultural use. The decision to drain the Everglades and the use of structural controls created new environmental problems and limited the form of future adaptations to these problems. All subsequent responses to environmental problems relied upon the manipulation of these structural controls, and the success of these adaptations was limited to how well the controls could be managed. An adaptation to living in wet lands, or that helped cope with flooding, may have reduced the environmental impact and would have allowed more flexibility in the way future problems were dealt with.

A similar argument is made concerning the pattern of urban sprawl that emerged in the 1930 s and continued throughout the 1970s. The desirability of automobile transportation within Dade County led developers to construct permanent roads and highways in grid-like fashion without concern for the impact on the natural environment. The impact caused by the construction of buildings or roads is exceedingly difficult to resolve or reverse. As with 
water management, the environmental problems caused by urban development are responded to by regulating how these structures are used. Although a few new "planned" development projects are being constructed, they are still based on dry-land development and automobile transportation.

Additional environmental problems arise from the intensification and increased specialization of vegetable cultivation, particularly tomatoes. The most obvious problems involve using large amounts of fertilizers and pesticides and the use of irrigation systems to make the land suitable for cultivation.

In conclusion, tremendous changes in the natural, technological, social, and cognitive areas occurred in Dade County during the Urbanization Period. Earlier perceptions about the land as "worthless" and the desire to alter it for settlement and agriculture led to the use of technological developments that permanently changed the environment and stimulated population growth. Although the majority of the population was still restricted to the Miami Rock Ridge region, technology allowed for sprawling expansion regardless of land type. The harmful effects of this land use pattern no longer may be ignored. Changes in the environmental policies are currently taking place, as evidenced by the increase in environmental legislation. But it is still not clear whether these changes will succeed in affecting changes in Dade County's cultural adaptation. 


\section{CHAPTER VI: CONCLUSION}

In the introduction of this thesis, I discussed several environmental problems associated with modern land use in Dade County, and documented how particular land use patterns emerged and changed over time in response to environmental and technological conditions. I also identified trends of the adaptive processes that led to detrimental environmental consequences. The first section of this conclusion reviews the chronology of environmental conditions and the adaptive strategies developed to cope with them. The second section provides a summary of the conclusions generated by this thesis. The third and final section presents some suggestions for future land use.

\section{SUMMARY OF SOUTH FLORIDA LAND USE_RATTERNS}

Little is known about the environment of the PaleoIndians, the hazards they had to cope with, or the specific strategies developed to cope with them. Prior to 10,000 B.P., Paleo-Indians probably hunted big-game in the inland savannah-like grasslands, and it is likely that they procured shellfish and small bony fish from the ocean shore. By 6,500 B.P. all big-game became extinct, and smaller animals were hunted more intensively. Many of the smaller animals that were hunted by the paleo-Indians are still 
hunted today. The most popular of these species is the white tail deer. It is likely that plant foods have always served as a minor supplement to the Indian diet in south Florida. But plant materials were used in the making of tools, shelters, clothing, and other objects.

During the Archaic Period the South Florida environment changed significantly. In the Early Archaic, the climate became exceedingly hot and dry, and the sea level rose and inundated land areas. These changes reduced the availabilities of some resources, perhaps leading to a mass emigration from South Florida. By the Late Archaic period, the climate became less extreme and was cooler and moister and resource availability increased. As a consequence, the human population increased.

There is some evidence that both inland and coastal zones were used as sites for habitation and resource procurement during the Archaic. There are insufficient data to determine whether these sites were occupied year round or seasonally. Tree islands were the most frequently occupied inland areas. In the coastal zone, areas near rivers or creeks were the preferred occupation sites, a pattern that persisted until the beginning of the Urbanization Period.

Some of the more frequently found Archaic remains include those of freshwater species such as turtles and bony fish. The diet included mud turtles, pond turtles, softshell turtles, and gar. The popularity of gar remained high 
throughout the Pre-Columbian period and is still eaten by the Miccosukee Indians. The growing population and their improved exploitative technologies during the Late Archaic Period may have led to the near-depletion of turtles and bony fish in inland areas.

During the Formative period, the predictability of the climate and resource availabilities continued to increase. The response to the changing environment of the Formative period included an intensification of the subsistence strategies developed in the Archaic Period, specially the technologies for marine exploitation. There was also an increase in the use of resources beyond Dade County's present boundaries due to the relationship that existed between the east coast Tequesta and the west coast Calusa.

Both the inland and coastal zones were used on a seasonal basis. Coastal zone habitation (mainly on the Miami Rock Ridge) was most common during the dry months. During the wet season most Indians migrated to Key Biscayne or other barrier islands. Wet seasons were also ideal for deer hunting in the inland zone, and small hunting groups formed for that purpose.

Biscayne Bay and the Atlantic Ocean were the most valuable regions for basic subsistence during the Formative Period. Most of the subsistence biomass was obtained from requiem sharks, rays, and sea turtles caught in those regions. Although deer remains infrequently are found in 
the archaeological record for this period, they also represented a high percentage of the estimated dietary biomass throughout the Formative Period. The same turtles and bony fish caught during the Archaic Period were also important to the inland diet during the Formative Period.

During the Formative and Spanish Contact Periods, coastal residents used only a small number of floral species available to them. All species used are associated with hammock communities, and some with pinelands, beaches, and mangroves. Inland residents used an even less diverse selection of plants, all of which were also associated with hammock or tree island communities. The species most commonly used during these periods were the cocoplum, cabbage palm, sea grape, and pigeon plum, and hog plum.

Spanish land use during the Spanish Contact Period was limited to the area immediately around the mouth of the Miami River. The Spaniards relied on a similar, but less diverse, selection of the same local resources that the Indians used, plus a few imported goods. Although spanish settlement in Dade County was very brief, they continued to extract resources from the land well into the 1800s. This was mostly done by non-resident Spanish fishermen who practiced commercial fishing from boats as early as 1750 . The primary fish they caught included mullet, kingfish, and mackerel.

The Spanish introduced several exotic animals and plants, 
and initiated some minor drainage projects. Many of the exotic species introduced by the spaniards survived but most did not upset the ecological basis of native subsistence. The extent of Spanish drainage projects was so minor that its impact on the environment was insignificant.

Spanish hogs and cattle survived in the local environment and were later used in the Pioneer Settlement and Urbanization Periods. Exotic plants such as several varieties of figs, pomegranates, oranges, grapes, and mulberries may have been introduced into Dade county by the late 1500s. In addition, various root crops and garden vegetables may have also been introduced.

The natural environment of Dade County did not change very much during the pioneer settlement Period. The land use patterns during this period did not impact the environment greatly because pioneers had neither the numbers nor the technology to alter the landscape. The main change was an increased presence of exotic plant and animal species. Hunting, fishing, and gathering were still the predominant means of providing the basic subsistence, but the specific forms they took were influenced by the location of settlement sites and cultural traditions of the new residents. The two main adaptive patterns of the Pioneer Settlement Period, were those of the coastal sectlers and the inland Indian settlers.

The Pioneers settled within the coastal zone. They used 
the hammocks and pinelands of the Miami Rock Ridge for their homesteads. Beaches were scavenged for material goods washed in from shipwrecks and usually served as the main routes of communication between homesteads. The estuaries of Biscayne Bay and the reefs of the Atlantic Ocean region were often exploited for fish and other marine resources. They also served as the main passageways into Dade County.

Subsistence still relied predominantly on local resources, but was becoming increasingly influenced by exotic plants. By the late 1700 s and early 1800s, white Conchs had introduced many West Indian fruits and vegetables, including yams, eddys, pounders, and benni. Around 1830 sugar cane and corn was being cultivated. Beginning in the $1870 \mathrm{~s}$ and through the 1890s, Bahamian blacks introduced pigeon pea, star apple, and several species of Annona. The cultivated fruits most used by white pioneers included exotic species such as mango, avocado, and various types of oranges. By 1882, exotic vegetables such as tomatoes, beans, and eggplants were being grown commercially in the northern bank of the mouth of the Miami River. The Indians also relied on exotic plant foods, cultivating sugar cane, corn, potatoes, rice, citrus, pumpkins, pineapples, coconuts, guava, taro, cassava, and banana on tree islands. Many of these plants continue to be cultivated in small-scale gardens by South Florida families. During the Urbanization Period, many of the critical 
environmental problems that had previously limited settlement and population growth in Dade County were resolved with technological developments. The introduction of the railroad eliminated the remoteness of Dade County and eliminated the need to brave the hazards of marine travel or the terrestrial wilderness. The drainage and clearing of land enhanced it for the construction of buildings and roads, and for agriculture. Fertilizers enriched the poor soils, and pesticides controlled herbivores, thereby promoting the commercial cultivation of crops. Other problems such as high temperatures, humidity, hurricanes, and the presence of mosquitos and other pests, were made more tolerable with the building of concrete buildings with air conditioning.

Urban population has now sprawled over all of the land types in Dade County. Yet the coastal zone remains the most intensively utilized area. Most habitation sites and commercial development is located on or east of the Miami Rock Ridge. The southern extreme of the Miami Rock Ridge has been converted into farmland. The Biscayne Bay and Atlantic Ocean are used primarily for recreational activities such as fishing, diving, and many other miscellaneous uses. Most of the land in the Everglades region is now part of the Everglades National Park and used for various recreational purposes including camping, fishing, and hunting. 
The number of animals that are hunted and fish that are caught on a yearly basis has increased, but the diversity of the kill has decreased due to reduced availabilities of some species and protective legislation. The number of exotic plant species has increased tremendously so that their number now reaches into the thousands. Some of the introduced species have turned out to be troublesome weed species. The most notorious of these include cajeput, Brazilian pepper, and the Australian pine tree.

\section{CONCLUSIONS}

Land use during the Urbanization Period has created the most permanent environmental changes in Dade county. The draining and clearing of the land induced many changes. The drainage systems eliminated Dade County's natural watershed and have contributed to flooding during tropical storms and hurricanes. Permanent water control structures had to be built to deal with this flooding. Since the responses to most environmental problems since then have involved the manipulation of these structural controls, opportunity costs may also have grown. This is because the success of structural controls is limited to how well these controls can be managed, reducing the flexibility and potentially the efficiency in the way problems may be dealt with through alternative responses in the future. 
Another example of increasing permanency and scale of responses to environmental problems is the mass construction of buildings and roads. The environmental problems caused by these activities are exceedingly difficult to resolve or reverse. The environmental impact of these structures is linked to the appropriateness of zoning policies and land use planning regulations. Yet, most development projects are still based on dry-land development and automobile transportation.

The quasi-monocrop system of cultivation that has developed in Dade County provides the best example of increasing economic specialization. Agriculture has been responsible for some of the permanent changes to Dade County's environment. One of the agricultural techniques that has caused permanent change to the environment is the process of scarification. In certain places this has resulted in the transformation of soil type. Other consequences of agriculture include the alteration of the quality and quantity of local water resources through irrigation, fertilization, and pesticide application.

One of the major driving forces behind the land use patterns developed in the Urbanization Period has been Dade County's economic system. This system both attracts and depends on economic growth. Although this may be lauded by businesses interested in short term profits, it is also the main cause of the environmental problems faced today. It is 
economic growth that most evoked the explosive population growth of the county. Economic expansion, combined with increasing investment from outside the county's boundaries, have reduced the impact of the local or regional environment on land use decision making.

The current economic structure of Dade County is presented in Table 11. It is dominated by the service and trade industries, which together account for well over half of the total employment and number of firms in Dade county. In 1991 they represented 63.7 percent of total employment and 70.3 percent of the total number of firms (U.S. Department of Commerce 1993). The economy is also strongly influenced by the finance and real estate industries. In fact, Dade County has the largest banking center in the United States (Florida Trend 1994).

What is not apparent in this profile is the huge influence of international businesses and tourism. There are over 300 multinational companies located in Dade County. In addition, there are three Free Trade zones located in the county, including the Miami Free zone, the world's largest privately owned FTz. In 1993 the county experienced \$23 billion in international activity and according to william 0 . Cullom, president of the Greater Chamber of Commerce, it will increase to $\$ 70$ billion by the end of this decade. That same year the tourism industry generated 


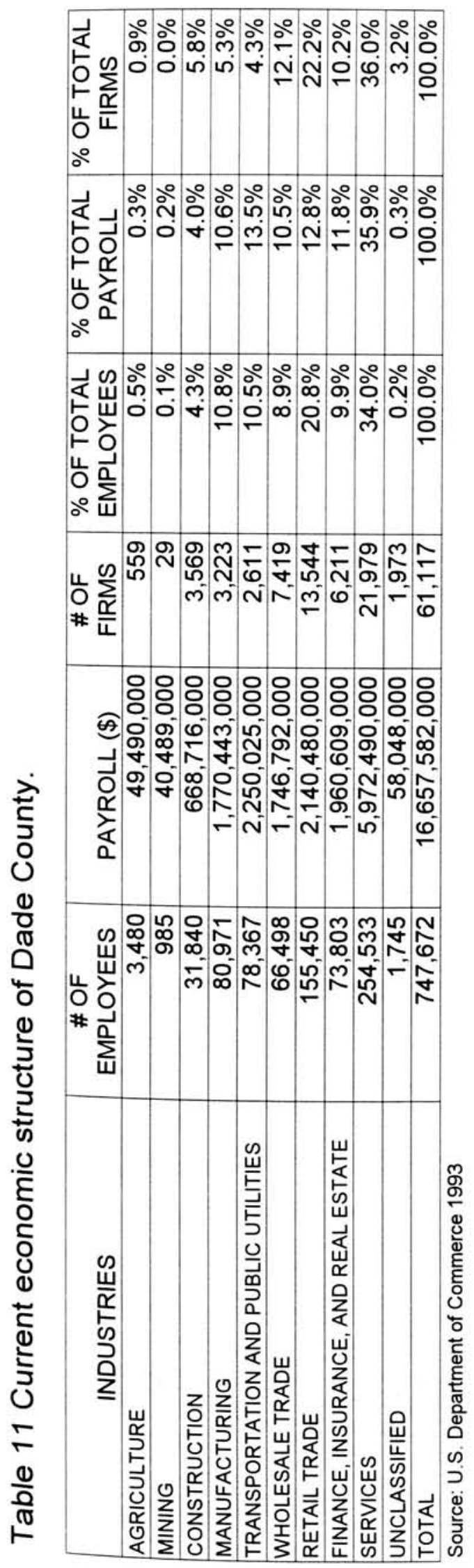


$\$ 12.2$ billion for the local economy (Klein 1994).

other indicators of international influence include the dollar value of imports and exports passing through the county. In 1989 over $\$ 5$ billion worth of imports passed through Miami, about half of which arrive as air cargo. That same year over $\$ 8$ billion worth of exports also passed through Miami, about two thirds of which leave also as air cargo (Winsberg 1992).

\section{FUTURE LAND USE SUGGESTIONS}

This study has revealed that land use patterns during the Urbanization Period were driven primarily by population growth, escalating technology, and the desire for economic growth. Complementing these factors were trends towards increasing centralized social organization and increasing belief in human dominance over nature. Recently these patterns have so inhibited the ability of Dade County's population to identify, acknowledge, and respond to existing environmental stresses that they should be considered maladaptive. I suggest that a more adaptive response for future land use planning should emphasize environmental concerns over growth. Land use should be directed to the restoration, preservation, protection, and maintenance of the natural environment before expanding beyond its current limits. In the section below I present some suggestions as 
to how future land use may achieve these goals. These recomendations include changes in the economic structure of the county, development strategies, and educational curricula. Also included are some environmental restoration designs.

\section{Economy}

The economy needs to change its impetus from a growthoriented base to one of environmental maintenance. This entails requiring that maintenance of existing structures take precedence over growth promoting interests such as new highways and expansion of public facilities. It also involves encouraging the location of businesses whose operations are environmentally compatible to this area. This includes change from a growing international economic role to one that is more regionally self-sufficient, even if it reduces economic growth. This requires increasing the number of firms that are environmentally compatible, such as and native plant landscaping and environmental research.

\section{Development}

Although the ideal strategy concerning future development in Dade County is to limit additional development, it would be naive to assume that the population is going to stop growing. Therefore, any plans for future development should be based on trying to minimize the environmental impact of 
future development as much as possible. One of the ways this can be achieved is by defining a fixed boundary as a limit for westward expansion. Within these limits, new residential and commercial construction should be consolidated in pre-existing urban areas. In these areas the development or reclamation of existing disturbed land should occur prior to developing an undisturbed land.

Another way to curtail the expansion of future development is to replace, renovate or maintain existing structures whenever possible rather than building new ones. When renovating environmentally unsound structures, it should be done to conform to the stricter current environmental code standards.

In addition to curbing expansion, any future development plans should also minimize the fragmentation of the natural environment. Since water flow is one of the most important ecological factors in the South Florida ecosystem, the building of major developments (including highways) should be done in a way that does not divert or modify its natural path. This calls for constructing elevated or diked-in structures in wet or flood-prone areas rather than draining the land for development. Additionally, developments should incorporate the existing native landscape into their designs rather than requiring its removal.

In addition to preserving as much of the natural vegetation as possible, it should also be restored as much 
as possible. This means designing landscaping in residential and commercial developments with indigenous rather than exotic ornamental vegetation. When doing this, the soil types and hydrology of the site should be considered. This would reduce the need of mowing, fertilizing, and irrigating. It would also reduce the potential of an ecological impact caused by the presence of harmful exotics. The layout of the landscape should also be considered in order to help reduce cooling costs by providing shade and appropriate ventilation.

In order to increase the sense of community, neighborhoods should be designed to include residential, recreational, and business activities. Neighborhood development should also emphasize the development of bikepaths, parks, and nature trails. Access to these features would help to strengthen the connection between humans and their environment.

In addition to curbing and redesigning urban development, research to provide new, more environmentally friendly construction materials should also be explored. For example, materials that would allow the construction of a permeable road surface would reduce the alteration of natural water flows. 


\section{Education}

One of the most lacking elements necessary for establishing proper environmental ethics is education. All schools should be required to have an environmental awareness program that involves direct interaction with the local environment. This would help to enhance the appreciation for the ecological and aesthetic value of the environment. It would also inform students of the present dangers the present pattern of urbanization poses to their environment and quality of life.

\section{ECosystem Restoration}

It is imperative to protect, preserve, and restore the integrity of the remaining local, regional, and statewide ecosystems. The first step towards this is to provide legislation to actively insure that no natural ecosystem or species is eliminated. Additionally, efforts of private or public organizations dedicated to purchasing land for the purpose of preservation and restoration should be supported economically and politically.

Perhaps the most critical factor necessary for restoration is the revitalization of the historical water regime. This involves the gradual elimination of structures that create barriers to the natural movement of water and animals. Some suggestions include the elimination of levees and the rebuilding of Tamiami Trail by filling in the 
adjacent canal and raising the road on stilts, like Interstate 75 .

Not only should the natural flows of water be restored, they should also be contained. This may be achieved by creating a series of buffer zones between the Everglades and the east coast cities to capture water that now flows wasted out to sea. Additionally, the construction of any new major drainage canals should be prohibited. The buffer zones would act as water reservoirs for the cities and wild lands.

No restoration could be complete without the rejuvenation of vegetation communities. This should be accomplished by replanting as much of the historical communities as possible. This process should include the removal of troublesome exotic species.

Environmental healing should not stop with the recuperation of remaining ecosystems. Once the existing ecosystems begin to recover, the process of reclaiming other lost wetlands may begin. This could begin with the reconversion of all the land between the Miami Canal and the North New River Canal into a marsh. Another step towards this end includes the widening of all existing canal banks that carry water through agricultural areas from Lake okeechobee to the Everglades and through urban areas. This would dramatically increase the area of interconnected wetlands within Dade County and South Elorida.

It should be noted that none of the suggestions provided 
here are original. Most of them have been recommended

before by men and women of vision. The dangers of urbanization have been anticipated since its beginnings.

Yet, the allure of economic growth and the lack of environmental education or respect have delayed the inception of such strategies. It is my sincere belief that the longer they are postponed the less likely the environment will be able to recover and sustain a physically and spiritually healthy lifestyle for humans. 


\section{REFERENCES CITED}

Alaka, M.M.

1976 Climatology of Atlantic Tropical Storms and

Hurricanes. In Climates of South and Central

America. W. Schwerdtfeger, ed. Pp. 479-509.

Amsterdam: World Survey of Climatology, Elsevier

Science Publishing Company.

Altschuler, Z.S., M.M. Schnepfe, C.C. Silber, and F. O.

Simon

1983 Sulphur Diagenesis in Everglades Peat and Origin of Pyrite in Coal. Science 221:221-227.

Baber, Adin

1942 Food Plants of the De Soto Expedition: 1539-1543.

Tequesta $2: 34-40$.

Bailey, Liberty $\mathrm{H}$.

1949 Manual of Cultivated Plants. New York: Macmillan Company.

Baksh, Michael and Allen Johnson

1990 Insurance Policies among the Machiguenga: An Ethnographic Analysis of Risk Management in a NonWestern Society. In Risk and Uncertainty in Tribal and Peasant Economies. Elizabeth Cashdan, ed. Pp. 193-228. Boulder: Westview Press.

Bartram, william

1791 Travels Through North and South Carolina, Georgia, East and West Florida, the Cherokee Country, the Extensive Territories of the Muscogulges, or Creek Confederacy, and the country of the Cactaws; Containing Observations on the Manners of the Indians. philadelphia: James and Johnson.

Beard, Daniel B.

1938 Wildife Reconnaissance: Everglades National Park Project. Washington D.C.: National Park Service.

Belnigham, P.J.

1991 Landforms Influence Patterns of Hurricane Damage: Evidence from Jamaican Montane Forests. Biotropica $23: 427-439$.

Bennett, John W.

1969 Northern Plainsmen: Adaptive Strategy and Agrarian Life. Arlington Heights: AHM Publishing Corp. 
1976 The Ecological Transition: Cultural Anthropology and Human Adaptation. New York: Pergamon Press.

1984 Ecosystems, Environmentalism, Resource Conservation, and Anthropological Research. In The Ecosystem Concept in Anthropology. Emilio F. Moran, ed. Pp. 289-310. Boulder: Westview Press.

Birnhak, B.I. and J.P. Crowder

1974 An Evaluation of the Extent of Vegetative Habitat Alteration in South Florida, 1943-1970. Ecology Report Number DI-SFEP-74-22 of South Florida Environmental Project, Bureau of sport Fishing and Wildlife. Atlanta: United States Department of the Interior.

Black, Hugo L., III

1981 Richard Fitzpatrick's South Florida, 1822-1840: Part II, Fitzpatrick's Miami River Plantation. Tequesta $41: 33-68$.

Blackman, E.V.

1977 Miami and Dade County, Florida: Its Settlement, Progress, and Achievement. Chuluota: Mickler House Publishers. Reprinted edition from 1921 original.

Blake, Nelson M.

$1980^{\circ}$ Land into water - water into Land: A History of Water Management in Florida. Tallahassee: University Presses of Florida.

Bloom, Arthur L.

1983 Sea Level and Coastal Changes. In Late Quarternary Environments of the United States, Volume 2. H.E. Wright Jr., ed. PP. 42-51. Minneapolis: University of Minnesota Press.

Boas, Franz

1896 The Limitation of the Comparative Method in Anthropology. Science 4:901-908.

1911 The Mind of the Primitive Man. New York: MacMillan.

Borhegyi, Stephen F. de

1961 Shark Teeth, Stingray Spines, and Shark Fishing in Ancient Mexico and Central America. Southwestern Journal of Anthropology $17: 273-296$. 
Brooks, H.K.

1982 Guide to the Physiographic Divisions of Florida. Gainesville: Florida Cooperative Extension Service, Institute of Food and Agricultural Sciences, University of Florida.

Browder, Joan, Charles Littlejohn, and Don Young

1976 The South Florida Study: South Florida, Seeking a

Balance of Man and Nature; Land, water, and Energy

Use for the Long Range Vitality in South Florida.

Tallahassee: Center for Wetlands, University of

Florida and Bureau of Comprehensive Planning,

Division of state Planning, Florida Department of Administration.

Brown, Nancy

1985 Land Use. In The Dade County Environmental story. S. Ross, D. M. Ross, J, Rosner, and H. Rosner eds. Pp. 190-192. Miami: The Environmental Education Consortium.

Buchanan, James E.

1978 Miami: A Chronological and Documentary History, 15131977. Dobbs Ferry: Oceana Publications Inc.

Bureau of Economic and Business Research

1993 Florida Statistical Abstract. Edition Number 27. College of Business Administration. Gainesville: University Presses of Florida.

Burkhardt, Mrs. Henry

1952 Starch Making: A Pioneer Florida Industry. Tequesta $7: 47-53$.

Canter, Bram D.E. and Donna R. Christie

1985 Water Regulations and Policies. In water Resources Atlas of Florida. E.A. Fernald and D.J. Patton, eds. Pp. 130-137. Tallahassee: Institute of Science and Public Affairs, Florida state University.

Carbone, Victor A.

1983 Late Quarternary Environments in Florida and the Southeast. Florida Anthropologist 36:3-17.

Carney, James $\mathrm{J}$.

1946 Population Growth in Miami and Dade County, Florida. Tequesta $6: 50-55$.

Carr, Robert $S$.

1981 The Brickell store and Seminole Trade. Florida Anthropologist $34(4): 180-199$. 
1985 Prehistoric Circular Earthworks in South Florida. Florida Anthropologist 38:288-301.

1986 Preliminary Report on Excavations at the Cutler Fossil Site (8 Da 2001) in Southern Florida. A Paper Presented at the 51st Annual Meeting of the Society for American Archaeology, New Orleans. Miami: Archaeological and Historical Conservancy.

Carr, Robert $S$, and John G. Beriault

1984 Prehistoric Man in South Florida. In Environments of South Florida: Present and Past, Memoir II. Patrick J. Gleason, ed. Pp. 1-14. Coral Gables: Miami Geological Society. Revised edition.

Carr, Robert S., M. Yasar Iscan, and Richard A. Johnson 1984 A Late Archaic Cemetery in South Florida. Florida Anthropologist $37: 172-188$.

Chapman, Arthur E.

1991 History of South Florida. In South Florida: Winds of Change. T.D. Boswell, ed. Pp. 31-42. Coral Gables: University of Miami Press.

Chardon, Roland E.

1976 A Geographical History of the Biscayne Bay Area. In Biscayne Bay: Past/Present/Future. Anitra Thoraug, ed. Pp. 235-243. Coral Gables: University of Miami Press.

Chen, Ellen and John F. Gerber

1990 Climate. In Ecosystems of Florida, Ronald L. Myers and John J. Ewel, eds. Pp. I1-34. Orlando:

University of Central Florida Press.

Clausen, Carl J., A.D. Cohen, Cesare Emiliani, and J.J. Stipp

1979 Little Salt Spring, Florida: A Unique Underwater Site. Science 203:609-614.

Cockrell, W.A. and Larry Murphy

1978 Pleistocene Man in Florida. Archaeology of Eastern North America $6: 1-13$.

Cohen, Arthur D.

1984 Evidence of Fires in the Ancient Everglades and Coastal Swamps of Southern Florida. In Environments of South Florida: Present and Past, Memoir II, Revised edition. Patrick J. Gleason, ed. Pp. 459464. Coral Gables: Miami Geological Society. 
Conrad, Mary D.

1957 Homesteading in Florida During the 1890's. Tequesta $17: 3-30$.

Craig, Alan $\mathrm{K}$.

1991 The Physical Environment of South Florida. In South Florida: The Winds of Change. Thomas D. Boswell, ed. Pp. 1-16. Coral Gables: University of Miami Press.

Craighead, F.C. Sr.

1971 Trees of South Florida. Coral Gables: University of Miami Press.

1974 Hammocks of South Florida. In Environments of South Florida: Present and Past, Memoir II. Patrick J. Gleason, ed. Pp. 53-60. Coral Gables: Miami Geological Society.

1984 Hammocks of South Florida. In Environments of South Florida: Present and Past, Memoir II, Revised edition. Patrick J. Gleason, ed. Pp. 191-198. Coral Gables: Miami Geological Society.

D'Amato, Richard

1973 The Movement of Effluent from the City of Miami Sewage Ocean outfall. Coral Gables: University of Miami sea Grant Program.

Davis, Frederick T.

1935 Juan Ponce de Leon's Voyages to Florida. Florida Historical Quarterly 14:4-70.

Davis, J.H., Sr.

1943 The Natural Features of South Florida. Florida State Geological survey Bulletin 25. Tallahassee:

Department of Conservation.

de Velasco, Juan Lopez

1893 Geografia $y$ Descripcion Universal de Las Indias $(1571-1574)$. Madrid: D. Justo Zaragoza.

de Sylva, Donald P.

1976 Fishes of Biscayne Bay. In Biscayne Bay: Past/Present/Future. Anitra Thoraug, ed. Pp. 185197. Coral Gables: University of Miami Press.

Delcourt, P.A. and Hazel R. Delcourt

1981 Vegetation Maps for Eastern North America: 40,000 YR B.F. to Present. In Geobotany II. Robert C. Romans, ed. Pp. 123-165. New York: Plenum Press. 
Department of the Interior Census Office

1883 Compendium on the Tenth Census (June 1, 1880) Part 1. Washington D.C.: Government Printing Office.

Dineen, Walter $\mathrm{J}$.

1984 The Fishes of the Everglades. In Environments of South Florida: Present and Past, Memoir II, Revised edition. Fatrick J. Gleason, ed. Pp. 258-268.

Coral Gables: Miami Geological Society.

Dobbyns, Henry F.

1983 Their Number Becomes Thinned. Knoxville: University of Tennessee Press.

Dupuis, John G.

1954 History of Early Medicine, History of Early Public Schools, and History of Early Agricultural Relations in Dade County. Miami: John Dupuis.

Ewel John J.

1990 Introduction. In Ecosystems of Florida. Ronald L. Myers and John J. Ewel eds. Pp. 3-10. Orlando: University of Central Florida Press.

Fairbridge, Rhodes $W$.

1974 The Holocene sea Level Record in South Florida. In Environments of South Florida: Present and Past. Patrick J. Gleason, ed. Pp. 223-255. Coral Gables: Miami Geological Society.

1984 The Holocene Sea Level Record in South Florida. In Environments of South Florida: Present and Past, Memoir II, Revised edition. Patrick J. Gleason, ed. Pp. 427-436. Coral Gables: Miami Geological Society. Revised edition.

Fernald, Edward A. and James W. May

1992 Infrastructure and Planning. In Atlas of Elorida. E.A. Fernald and E.D. Purdum, eds. Pp. 236-237. Gainesville: University Press of Florida.

Fontaneda, Hernado d'Escalante

1944 Memoir of Do. d'Escalante Fontaneda Respecting Florida: Written in Spain, About the Year 1575. Translated from the Spanish by Buckingham Smith, washington, 1854 . D.O. True, ed. Reprinted with revisions, 1973. Miami: University of Miami and Historical Association of Southern Florida. 
Forde, C. Daryll

1934 Habitat, Economy, and Society. New York: Harcourt Brace.

Fradkin, Arlene

1978 Archaeological Evidence of Snake Consumption Among the Aborigines of Florida. Florida Anthropologist $31: 36-43$.

Francis, Philip

1966 Florida Fish and Fishing. New York: Macmillan.

Galen

1952 Airs, Water and Spaces. In Hippocratic Writings on the Natural Faculties. Translated by John Brock.

Pp. 12-19. Chicago: Encyclopedia Britannica. Originally written circa 400 B.C.

Galletta, Kay

1992 Plantfinder: Wholesale Guide to Foliage and Ornamental plants. Cooper City: Betrock Information Systems, Inc.

Gearhart, Earnest G., Jr.

1952 South Florida's First Industry. Tequesta 7:55-57.

Geertz, Clifford

1963 Agricultural Involution: The Process of Change in Indonesia. Berkley: University of California Press.

Gifford, John C.

1944 Five Plants Essential to the Indians and Early Settlers of Florida. Tequesta 4:36-44.

Gilliland, Marion Spjut

1975 The Material Culture of Key Marco, Florida. Gainesville: University Presses of Florida.

Ginsburg, R.N. and H.A. Lowenstam

1958 The Influence of Marine Bottom Communities on the Depositional Environment of Sediments. Journal of Geology $66: 310-318$.

Gleason, Patrick J.

1984 Introduction. In Environments of South Florida: Present and Past, Memoir II. Patrick J. Gleason, ed. Pp. viii-xxi. Coral Gables: Miami Geological Society. Revised edition.

Goggin, John $M$.

1940 The Tekesta Indians of Southern Florida. Florida Historical Quarterly $18: 274-284$. 
1947 A Preliminary Definition of Archaeological Areas and Periods in Florida. American Antiquity 13:114-127.

1949 Cultural Traditions in Florida Prehistory. In The Florida Indian and His Neighbors. John W. Griftin, ed. Pp. 13-44. Winter Park: Rollins College.

Goggin, John M. and William C. Sturtevant

1964 The Calusa: A Stratified Nonagricultural Society (with notes on sibling marriage). In Explorations in Cultural Anthropology: Essays in Honor of George

Peter Murdock. Ward H. Goodenough, ed. Pp. 179-219. New York: McGraw-Hill.

Gornitz, V. S. Lebedeff, and J. Hansen

1982 Global sea Level Trend in the Past century. Science 215: 1611-14.

Gresham, C.A., T.M. Williams, and D.J. Lipscomb

1991 Hurricane Hugo Wind Damage to Southeastern United States Coastal Forest Tree Species. Biotropica $23: 324-335$.

Griffin, John W.

1979 A History of Hialeah. Jacksonville: Shepard Associates.

1982 Conclusion. In Excavations at the Granda Site: Archaeology and History of the Granada Site 1 . John W. Griffin, ed. Pp. 365-394. Tallahassee: Florida Division of Archives, History, and Records Management.

1988 The Archaeology of Everglades National Park: A Synthesis. National Park Service. Tallahassee: Southeast Archaeological Center.

Hann, John H.

1987 Translation of the 1743 Alana-Monaco Report of the Miami Area. Tallahassee: Florida Bureau of Archaeological Research.

Haq, B.U., J. Hardenbol, and P.R. Vail

1987 Chronology of Fluctuating sea Levels since the Triassic. Science 238:1156-1167.

Harper, Roland $M$.

1927 Natural Resources of Southern Florida. Florida Geological Survey, 18 th Annual Report. Pp. 27-206. Tallahassee. 
Harris, Marvin

1979 Cultural Materialism: The Struggle for a Science. New York: Random House.

Harris, L.D. and Vickers, C.R.

1984 Some Faunal Community Characteristics of Cypress Ponds and the Changes Induced by Perturbations. In Cypress Swamps. K.C. Ewel and H.T. Odum, eds. Pp. 171-185. Gainesville: University Presses of Florida.

Harsheberger, J.W.

1914 The Vegetation of South Florida. Trans Wagner Free Institute of Scientific Philosophy 3:51-189.

Hartman, Brad

1978 Description of Major Terrestrial and Wetland Habitats of Florida. In Rare and Endangered Biota of Florida. Peter C.H. Pritchard, series ed. Pp. xiii-xvi. Gainesville: University Presses of Florida.

Hoffmeister, J.E.

1974 Land From the Sea, the Geologic story of South Florida. Coral Gables: University of Miami Press.

Hollingsworth, Tracy

1949 History of Dade County, Florida. Coral Gables: Glade House.

Huber, wayne $C$. and James P. Heaney

1985 Drainage, Flood Control, and Navigation. In Water Resources Atlas of Florida. E.A. Fernald and D.J. Patton, eds. Pp. 116-121. Tallahassee: Institute of Science and Public Affairs, Florida state University.

Hul1, J.E. and F.W. Myer

1973 Salinity Studies in East Glades Agricultural Area Southeastern Dade County, Florida. Florida Bureau of Geology Report of Investigation Number 66.

Huntington, Ellsworth

1945 Mainsprings of Civilization. New York: J. Wiley and Sons.

Jaap, Walter C. and Pamela Hallock

1990 Coral Reefs. In Ecosystems of Florida. Ronald L. Myers and John J. Ewel, eds Pp. 574-616. Orlando: University of Central Florida Press. 
Johnson, Ann F. and Michael G. Barbour

1990 Dunes and Maritime Forests. In Ecosystems of Florida. Ronald L. Myers and John J. Ewel, eds. Pp. 429-480. Orlando: University of Central Florida Press.

Kerrigan, Anthony (translator)

1951 Barcia's Chronological History of the Continent of Florida [1722]. Gainesville: University of Florida Press.

Kersey, Harry A. Jr.

1975 Pelts, Plumes, and Hides: White Traders Among the Seminole Indians, 1870-1930. Gainesville: The University Presses of Florida.

1987 The Seminole and Miccosukee Tribes: A Critical Bibliography. Bloomington: Indiana University Press.

1992 Seminoles and Miccosukees: A Century in Retrospective. In Indians of the Southeastern United States in the Late 20th Century. J. Anthony Paredes, ed. Pp. 102-119. Tuscaloosa: The University of Alabama Press.

Klein, Roberta

1994 Coming of Age in a Global Community. Florida Trend vol. 37 , No. 3, July.

Klukas, R.W.

1973 Control Burn Activities in Everglades National Park. Proceedings from Tall Timbers Fire Ecology Conference $12: 397-425$.

Kreitman, Abe and Leslie A. Wedderburn

1984 Hydrogeology of South Florida. In Environments of South Florida: Present and Past, Memoir II, Revised edition. Patrick J. Gleason ed. Pp. 405-426. Coral Gables: Miami Geological Society.

Kroeber, Alfred

1939 Cultural and Natural Areas of Native North America. Berkley: University of California Press.

Kuhn, Donna

1992 Mosquitos Can Be Bearable. In Alligator Pears and Grease: An Oral History of South Dade County. J. McDonald, ed. Pp. 67-68. Homestead: Miami Dade Community College. 
Kushlan, James $A$. and $T$. Jacobsen

1990 Environmental Variability and the Reproductive Success of Everglades Alligators. Journal of Herpetology $24(2): 176-184$.

Kushlan, James A.

1990a Avian Use of Fluctuating Wetlands. In Werlands and Wildlife. R. Sharotz and w. Gibbons, eds. DOE Technical Publishing Services.

1990b Freshwater Marshes. In Ecosystems of Florida. Ronald L. Myers and John J. Ewel, eds. Pp. 324-363. Orlando: University of Central Florida Press.

Larson, Lewis $\mathrm{H}$.

1980 Aboriginal Subsistence Technology on the Southeastern Coastal PIain During the Late Prehistoric Period. Gainesville: University Presses of Florida.

Laxson, Dan D.

1962 Excavations in Dade, Broward Counties, 1959-1961.

Florida Anthropologist 17:177-181.

Layne, James $\mathrm{N}$.

1984 The Land Mammals of South Florida. In Environments of South Florida: Present and Past, Memoir II, Revised edition. Patrick J. Gleason ed. Pp. 269 295. Coral Gables: Miami Geological Society.

Livingston, Robert $\mathrm{J}$.

1990 Inshore Marine Habitats. In Ecosystems of Florida. Ronald L. Myers and John J. Ewel, eds. Pp. 549-573. Orlando: University of Central florida Press.

Long, Robert $\mathrm{W}$.

1984 Origin of the Vascular Flora of Florida. In Environments of South Florida: Present and Past, Memoir II, Revised edition. Patrick J. Gleason, ed. Pp. 118-126. Coral Gables: Miami Geological Society.

Long, Robert $\mathrm{W}$, and 0 . Lakela

1976 A Flora of Tropical Florida. Miami: Banyan Books.

1978 A Flora of Tropical Florida. Coral Gables: University of Miami Press.

Lord, Linda $\bar{A}$.

1993 Guide to Florida Environmental Issues and Information. Winter Park: Florida Conservation Foundation. 
Low, Bobbi $S$.

1990 Human Responses to Environmental Extremeness and Uncertainty: A Cross Cultural Perspective. In Risk and Uncertainty in Tribal and Peasant Economies. Elizabeth Cashdan, ed. Pp. 229-255. Boulder: Westview Press.

Lyon, Eugene

1976 The Enterprise of Florida. Gainesville: University Presses of Florida.

MacCauley, Clay

1887 The Seminole Indians of Florida. In Bureau of American Ethnology Annual Report 5:469-531.

Washington D.C.: Government Printing Office, 18831884 .

Malinowski, Bronislaw

1948 Magic, Science, and Religion, and Other Essays. Boston: Beacon Press.

Marchmann, W.P.

1947 The Ingraham Everglades Exploring Expedition, 1892. Tequesta $7: 3-43$.

Marett, R.R.

1909 The Threshold of Religion. London: Methuen.

Marks, Henry S.

1958 Earliest Land Grants in the Miami Area. Tequesta $8: 15-22$.

Marois, K.C. and John J. Ewel

1983 Natural and Management-Related Variation in Cypress Domes. Forestry science 29:627-640.

Marx, Karl

1986 The Critique of Political Economy. In Karl Marx: A Reader. John Elster, ed. P. 187. Cambridge: Cambridge University Press. Originally published in 1859 .

Masson, Marilyn A. and steven Hale

1991 Faunal Remains from the Honey Hill Site (8Da411): Reconstructing a Prehistoric Wetland Foraging Economy in the Everglades. In Historical and Archaeological Investigations at the Honey Hill Site, Dade Councy. Florida, Report No. 25. R. Carr, A. Felmly, and P. West, eds. Miami: Archaeological and Historical Conservancy. 
McNicoll, Robert E.

1941 The Caloosa Village Tequesta: A Miami of the Sixteenth Century. Tequesta 1:11-20.

McGoun, William E.

1993 Prehistoric Peoples of Solth Florida. Tuscaloosa: University of Alabama Presses.

McGregor, A. James

1974 A Ceramic Chronology for the Biscayne Bay Region of Southeast Florida. M.A. Thesis in Anthropology, Florida Atlantic University, Boca Raton. Ann Arbor: University Microfilms International.

McPherson, B.F.

1973 Vegetation in Relation to water Depth in Conservation Area 3, Florida. Tallahassee: United States

Geological Survey.

McPherson, B.F., G.Y. Hendrix, Howard Klein, and H.M. TYus

1976 The Environment of South Florida, A Summary Report. Geological Survey Professional Paper 1011.

Washington D.C.

Merrick, George E.

1941 Pre-Flagler Influences on the Lower Florida East

Coast. Tequesta $1: 1-10$.

Michel, John F.

1976 The Impact of Man on the Physical Regime of Biscayne Bay. In Biscayne Bay: Past/Present/Future. Anitra Thoraug, ed. Pp. 265-269. Coral Gables: University of Miami Press.

Migliaccio, Christopher P.

1985 The Natural Environment. In The Dade county Environmental Story. S. Ross, D.M. Ross, J. Rosner, and $H$. Rosner, eds. Pp. 4-25. Miami: The Environmental Education Consortium.

Milanich, Jerald $\mathrm{T}$.

1987 Florida Archaeology. Orlando: Academic Press.

Millas, Aristides J.

1985 A Sense of Place: South Miami Beach. In The Dade County Environmental Story. S. Ross, D. M. Ross, J, Rosner, and $\mathrm{H}$. Rosner, eds. Pp. 133-137. Miami: The Environmental Education Consortium. 
Miller, Mabel F.

1985 A Sense of Place: Key Biscayne. In The Dade County Environmental Story. S. Ross, D. M. Ross, J, Rosner, and $\mathrm{H}$. Rosner, eds. Pp. 137-139. Miami: The Environmental Education Consortium.

Millicent, Todd Bingham

1948 Miami: A Study in Urban Geography. Tequesta 8:73108.

Milliman, J.D. and Emery, K.O.

1968 Sea Levels During the Past 35,000 Years. Science $162: 1121-1123$.

Missimer, T.M.

1973 Growth Rates of Beach Ridges on Sanibel Island, Florida. Transamerican Gulf Coast Association Geological Society 23:283-393.

Monroe, Mary B.

1943 Pioneer Women of Dade County. Tequesta 3:49-56.

Montague, Clay L. and Wiegert, Richard G.

1990 Salt Marshes. In Ecosystems of Florida. Ronald L. Myers and John J. Ewel, eds. Pp. 481-516. Orlando: University of Central Florida Press.

Munroe, Ralph M. and Vincent Gilpin

1966 The Commodore's Story. Miami: Historical Association of Southern Florida. Reprinted from the original 1930 edition.

Myers, Ronald L.

1986 Florida's Freezes: An Analog of Short Duration Nuclear winter Events in the Tropics. Florida Scientist $49: 104-115$.

National Atmospheric and Oceanic Adiministration

1986 (Nautical Chart of) Jupiter Inlet to Fowey Rock. Prepared by the United States coast and Geodetic Survey. Filed as chart number 11466 . Washington D.C.: United states Department of Commerce.

1992 (Nautical Chart of) Miami Harbor. Prepared by the United States Coast and Geodetic Survey. Filed as chart number 11468 . Washington D.C.: United States Department of Commerce.

Neal, Marie C.

1965 In Gardens of Hawaii. Honolulu: Bishop Museum Press. 
Neill, wilfred T.

1956 The Story of Florida's Seminole Indians. St. Petersburg: Great Outdoors Publishing Co.

Newman, Christine

1986 A Preliminary Report of Investigations at the Cheetum Site, Dade County, Florida. Miami: Archaeological and Historical Conservancy.

Odum, William E, and Johanes, R.E.

1975 The Response of Mangroves to Man Induced

Environmental stress. In Tropical Marine Pollution. E.J.F. Wood and R.E. Johannes, eds. Pp. 52-62. Amsterdam: Oceanographic Services of Elsevier.

Odum, Eugene

1977 The Emergence of Ecology as a New Integrative Discipline. Science 195:1289-1293.

Odum, William E. and McIvor, Carole C.

1990 Mangroves. In Ecosystems of Florida. Ronald L. Myers and John J. Ewel, eds. Pp. 517-548. Orlando: University of Central Florida Press.

Owre, Oscar

1976 The Avifauna of Biscayne Bay. In Biscayne Bay: Past/Present/Future. Anitra Thoraug ed. Pp. 213-226. Coral Gables: University of Miami Press.

Paige, John C.

1986 Historic Resource study for Everglades National Park. National park Service. Washington D.C.: U.S. Department of the Interior.

Parker, G.G.

1974 Hydrology of the Pre-Drainage System of the Everglades in Southeastern Florida. In Environments of South Florida: Present and Past, Memoir II. Patrick J. Gleason, ed. Pp. 18-27. Coral Gables: Miami Geological Society.

Parks, Arva Moore

1977 The Forgotten Frontier: Florida Through the Lens of Ralph Middleton Munroe. Miami: Banyan Books, Inc.

1982 Where the River Found the Bay: Historical Study of the Granada Site, Florida: Archaeology and History of the Granada Site, Volume II. Tallahassee: Florida Division of Archives, History, and Records Management. 
1985 Dade County's Recorded History. In The Dade County Environmental Story. S. Ross, D. M. Ross, J, Rosner, and H. Rosner, eds. Pp. 39-45. Miami: The

Environmental Education Consortium.

Patton, Donald J. and Edward A. Fernald

1985 Water Problems: Global National, State. In Water Resources Atlas of Florida. E.A. Fernald and D.J. Patton, eds. Pp. 2-8. Tallahassee: Institute of Science and Public Affairs, Florida State University.

Patton, Donald J, and Elizabeth D. Purdum

1992 Tourism and Transportation. In Atlas of Florida. E.A. Fernald and Elizabeth D. Purdum, eds. Pp. 102105. Tallahassee: Institute of Science and Public Affairs, Florida state University.

Peters, Thelma

1980 Lemon City: Pioneering on Biscayne Bay 1850-1925. Miami: Banyan Books, Inc.

1984 Miami 1909, with Excerpts from Fannie Clemon's Diary. Miami: Banyan Books, Inc.

Pierce, James

1825 Notices of the Agriculture, Scenery, Geology, and Animal, Vegetable, and Mineral Productions of the Floridas, and of the Indian Tribes, Made During a Recent Tour in those Countries. American Journal of Science, Series I, 9:119-136.

Pritchard, Peter C.H.

1978 Rare and Endangered Biota of Florida, Volumes 1-4. Gainesville: University Presses of Florida.

Rappaport, Roy A.

1978 Maladaptation in Social Systems. In The Evolution of Social Systems. J. Friedman and M.J. Rowlands, eds. Pp. 49-71. Gloucester: Duckworth.

1984 Pigs for the Ancestors: Ritual in the Ecology of a New Guinea People (A new, enlarged edition). New Haven: Yale University Press.

Ratzel, Friedrich

1882 Anthropogeographie. Stuttgart: J. Engel horn. 
Reitz, Elizabeth J.

1990 Zooarchaeological Evidence for Subsistence at La Florida Missions. In Columbian Consequences, Volume 2: Archaeology and History of the Spanish Borderlands East. David H. Thomas, ed. Pp. 507-516. Washington D.C.: Smithsonian Institution Press.

1993 Evidence for Animal Use of the Missions of Spanish Florida. In The Spanish Mission of La Florida. Bonnie G. McEwan, ed. Pp. 376-398. Gainesville: University Press of Florida.

Reuther, Walter, Herbert J. Webber, and Leon D. Batchelor eds.

1967 The Citrus Industry, Volume 1: History, world

Distribution, Botany, and Varieties. Berkley: University of California Agricultural Services.

Robbin, Daniel M.

1984 A New Holocene Sea Level Curve for the upper Florida Keys and Florida Reef Tract. In Environments of South Florida: Past and Present, Memoir II. Patrick J. Gleason, ed. Pp. 437-458. Coral Gables: Miami Geological society. Revised edition.

Robertson, W.B. Jr.

1953 A Survey of the Effects of Fire in Everglades National park. Homestead: National Park Service.

1962 Fire and Vegetation in the Everglades. Proceedings from Tall Timbers Fire Ecology Conference. 1:67-80.

Robinson, Ralph

1942 Henry Perrine, Pioneer Horticulturalist of Florida. Tequesta 2: 16-24.

Romans, Bernard

1775 A Concise Natural History of East and West Florida. Gainesville: University of Florida Press. 1962 facsimile edition.

Ross, Sande

1990 The Nature of Dade County: A Hometown Handbook. Miami: Environmental Information Service of Friends of the Everglades.

Scarry, Margaret C.

I982 Paleoethnobotany of the Granada Site. In Excavations at the Granada Site, Volume I. John W. Griffin, ed. Pp. 181-204. Tallahassee: Florida Division of Archives, History, and Records Management. 
Scarry, C. Margaret, Glen H Doran, and J. Anthony Paredes 1991 Roughage of the Lizard Eaters: Fruits and Toiletries of Everglades Aborigines at the Honey Hill Site. In Historical and Archaeological Investigations at the Honey Hill Site, Dade County, Florida, Report No. 25. R. Carr, A. Felmly, and P. West, eds. Miami: Archaeological and Historical Conservancy.

Scarry, C. Margaret and Elizabeth J. Reitz

1990 Herbs, Fish, Scum, and Vermin: Subsistence strategies in Sixteenth Century Spanish Florida. In Columbian Consequences, Vol. 2: Archaeology and History of the Spanish Borderlands East. David H. Thomas, ed. Pp. 343-354. Washington D.C.: Smithsonian Institution Press.

Scholl, David $W$. and Minze Stuiver

1967 Recent Submergence of Southern Florida: A Comparison with Adjacent Coasts and Other Eustatic Data.

Geological Society of America Bulletin 78:437-454.

Scholl, David W., Frank C. Craighead, and Minze Stuiver

1969 Florida Submergence Curve Revised: Its Relation to Coastal Sedimentation Rates. Science 163:562-564.

Sears, william $\mathrm{H}$.

1982 Fort Center: An Archaeological site in Lake okeechobee Basin. Gainesville: University Presses of Florida.

Semple, Ellen C.

1911 Influences of Geographic Environment on the Basis of Ratzel's System of Anthropo-Geography. New York: Henry Holt and Company.

Shappee, Nathan

1959 Flagler's Undertakings in Miami in 1897. Tequesta $19: 3-13$.

Shaw, C.

1975 The Pine and Hammock Forestlands of Dade County. In Published Report of Florida Division of Forestry.

Shinn, E.A.

1980 Geologic History of Grecian Rocks, Key Largo Coral Reef Marine Sanctuary. Bulletin of Marine Sciences $30: 646-656$. 
Shinn, E.A., J.H. Hudson, R.B. Halley, and B. Lidz

1977 Topographic Control and Accumulation Rate of Some Holocene Coral Reefs: South Florida and Dry Tortugas. Proceedings from the 3 rd International Coral Reef Symposium, Miami, Florida 1:1-17.

Simpson, C.T.

1920 In Lower Florida Wilds. New York: G.P. Putnam's Sons.

Smal1, John $\mathrm{K}$.

1913 Flora of Miami. New York: John K. Small.

Smith, Howard Van

1975 Hassle in the Everglades. Florida Agriculture, July: $4-7$.

Smith, Marvin $\mathrm{T}$.

1985 Proposal to Prepare Archaeological Synthesis:

Everglades National Park, Collier, Dade, and Monroe Counties Florida. Submitted to National Park Service, Southeast Regional office, Atlanta. Paper in File at Miami Historical Society.

Snyder, James $\mathrm{R}$.

1986 The Impact of wet Season and Dry Season Prescribed Fires on Miami Rock Ridge Pineland, Everglades National Park. Homestead: Everglades National Park South Florida Research Center.

Snyder, James R., Alan Herndon, and William R. Robertson Jr.

1990 South Florida Rockland. In Ecosystems of Florida. Ronald L. Myers and John J. Ewel, eds. Pp. 230-274. Orlando: University of Central Florida Press.

Stapor, Frank W. Jr., Thomas D. Mathews, and Fonda E. Lindfors-Kearns

1991 Barrier Island Progradation and Holocene Sea-Level History in Southwest Florida. Journal of Coastal Research 7:815-838.

Statutory Revision Division of the Joint Legislative Management Committee

1993 Official Florida Statutes. Tallahassee: State of Florida.

1971 Official Florida Statutes. Tallahassee: State of Florida.

1969 Official Florida statutes. Tallahassee: State of Florida. 
Steward, Julian

1955 Theory of Culture Change: The Methodology of Multilinear Evolution. Urbana: University of Illinois Press.

Stockman, K.W. R.N. Ginsburg, and E.A. Shinn

1967 The Production of Lime Mud by Algae in South Florida. Journal of Sediments and Petrology 37(2):633-648.

Stone, P.A.

1978 Floating Islands-Biogeomorphic Features of Hillsboro Marsh, Northeastern Everglades, Florida, Master's Thesis Department of Geography, Florida Atlantic University. Ann Arbor: University Microfilms International.

Struever, Stuart

1968 Problems, Methods, and Organization: A Disparity in the Growth of Archaeology. In Anthropological Archaeology in the Americas. B.J. Meggers, ed. Washington D.C. Anthropological Society of washington.

Sturtevant, William C.

1955 The Mikasuki Seminole: Medical Beliefs and Practices. Ph.D. Dissertation, Yale University. Ann Arbor: University Microfilms International.

1956 R.H. Pratt's Report on the Seminole in 1879. Florida Anthropologist $9: 1-24$.

1960 The Significance of Ethnological Similarities Between Southeastern North America and the Antilles. Yale University Publications in Anthropology Number 64.

1978 The Last of South Florida Aborigines. In Tacachale. Jerald T. Milanich and Samuel Proctor, eds. Pp. 141162. Gainesville: University Presses of Florida.

Sullivan, Chip

1985 A Sense of Place: The Structure. In The Dade County Environmental Story. S. Ross, D. M. Ross, J, Rosner, and H. Rosner, eds. Pp. 112-116. Miami : The Environmental Education Consortium.

Taylor, Jean and Rosamond Buskirk

1985 A Sense of Place: Homestead. In The Dade County Environmental Story. S. Ross, D. M. Ross, J, Rosner, and H. Rosner, eds. Pp. 154-157. The Environmental Education Consortium. 
Tacitus, Cornelius

1911 The Agricola and Germany of Tacitus and The Dialogue on Oratory. Translated by Alfred J. Church and William J. Brodribb. London: McMillan and Company, Limited. Originally written in A.D. 98 and first published in 1868 .

Tanner, william F.

1991 The "Gulf of Mexico" Late Holocene Sea Level Curve and River Delta History. Gulf Coast Association of Geological Societies, Transactions 41:583-589.

Tansley, Arthur

1935 Introduction to Plant Ecology. London: George Allen and Unwin Ltd.

Taylor, D.L. and A. Herndon

1981 Impact of 22 Years of Fire on Understory Hardwood Shrubs in Slash pine Communities Within Everglades National Park. National Park service. Homestead: South Florida Research Center.

Tebeau, Charlton $W$.

1968 Man in the Everglades: 2000 Years of Human History in the Everglades National Park. Coral Gables:

University of Miami Press.

1980 A History of Florida. Coral Gables: University of Miami Press.

Thorhaug, Anitra

1976 The Vascular Plants of Biscayne Bay. In Biscayne Bay: Past/Present/Future. Anitra Thoraug, ed. Pp. 95-103. Coral Gables: University of Miami Press.

TRW REDI

1993 Aerial and Map Atlas of Dade County, Florida. Plates 28 A-C. Riverside: TRW REDI Property Data.

Tylor, Edward B

1958' Primitive Culture. New York: Harper Torchbooks. Originally published 1871 .

Unger, Frank A.

1992 Historic Population and County Boundaries. In Atlas of Florida E.A. Fernald and E.D. Purdum, eds. Pp. 90-91. Tallahassee: Institute of Science and Public Affairs, Florida state University.

United States Bureau of the Census

1983 Population Abstract of the United States. Washington D.C.: Government Printing office. 
1993 County Business Patterrs, 1991, Florida. Washington D.C.: U.S. Department of Commerce

1994 Census of Population and Housing, 1990, Public Law 94-171 Data. Washington D.C.: U.S. Department of Commerce.

United States Congress

1846 Senate Resolutions Passed by the Legislature of Florida, Senate Document 35, 29th Congress, lst Session, P. 1.

Jnited States Department of Agriculture

1947 Soil Survey (Detailed Reconnaissance) of Dade County, Florida. Series 1947 , Number 4.

1994 Dade County Soil Survey. Unpublished Draft.

Van Arman, Joel, D. Nealon, S Burns, B. Jones, L. Smith, T. Macvicar, M. Yansura, A. Federico, J. Bucca, M. Knapp, and P. Gleason

1985 South Florida Water Management District. In Water Resources Atlas of Florida. E.A. Fernald and D.J. Patton, eds. Pp. 138-157. Tallahassee: Institute of Science and Public Affairs, Florida state University.

Vayda, Andrew P. and Bonnie J. McCay

1975 New Directions in Ecology and Ecological Anthropology. Annual Review of Anthropology 4:293306.

Vignoles, Charles

1823 observations Upon the Florida. Gainesville: University Presses of Florida. 1977 facsimile edition.

Wagner, Henry

1949 Early Pioneers of South Florida. Tequesta 9:61-72.

Walker, Lawrence R., D. Jean Lodge, Nicholas V.L. Brokaw, and Robert $\mathrm{B}$. Waide

1991 An Introduction to Hurricanes in the Caribbean. Biotropica 23(4a):313-316.

Wallace, A.F.C.

1966 Religion: An Anthropological View. New York: McGrawHill. 
Wanless, Harold R.

1976 Geologic Setting and Recent Sediments of the Biscayne Bay Region, Florida. In Biscayne Bay:

Past/Present/Future. Anita Thoraug, ed. Pp. 1-19.

Coral Gables: University of Miami Press.

Warrick, R.A. and J. Oerlemans

1990 Sea Level Rise. In The IPCC Scientific Assessment. J.T. Houghton, G.J. Jenkins, and J.J. Ephramus, eds. Pp. 257-81. Cambridge: Cambridge University Press.

Watts, W.A.

1975 A Late Quarternary Record of Vegetation from Lake Annie, Southcentral Florida. Geology 3:344-346.

1980 The late Quarternary Vegetation History of Southeastern United States. Annual Review of Ecology and systematics 11:387-409.

Webb, David S.

1990 Historical Biogeography. In Ecosystems of Florida. Ronald L. Myers and John J. Ewel, eds. Pp. 70-100. Orlando: University of Central Florida Press.

West, Patsy

1981 The Miami Indian Tourist Attractions: A History and Analysis of a Transitional Mikasuki Seminole Environment. Florida Anthropologist 34(4):200-224.

White, Leslie A.

1949 The Science of Culture: A Study of Man and Civilization. New York: Farrar, Straus and Giroux.

1959 The Evolution of Culture. New York: McGraw-Hill.

White, W.A.

1970 The Geomorphology of the Florida Peninsula, Geological Bulletin Number 51. Tallahassee: Florida Department of Natural Resources.

Widmer, Randolph $\mathrm{J}$.

1983 The Evolution of the Calusa, a Nonagricultural Chiefdom on the southwest Florida Coast, PhD. Thesis in Anthropology, Pennsylvania State. Ann Arbor: University Microfilms International.

1988 The Evolution of the Calusa: A Nonagricultural Chiefdom on the Southwest Florida Coast. Tuscaloosa: University of Alabama Press.

Wilson, Edward 0.

1975 Sociobiology. Cambridge: Harvard University Press. 
Wing, Elizabeth S. and Jill Loucks

1982 Granada Site Faunal Analysis. In Excavations at the Granada Site. John Griffin, ed. Pp. 259-345. Tallahassee: Division of Archives, History and Records Management.

Winsberg, Morton D.

1991 South Florida Agriculture, In South Florida: The Winds of Change. Thomas D. Boswell, ed. Pp. 17-30. Coral Gables: University of Miami Press.

1992 Energy. In Atlas of Florida. E.A. Fernald and Elizabeth D. Purdum, eds. P. 246. Tallahassee: Institute of Science and Public Affairs, Florida State University.

Wissler, Clark

1917 The American Indian: An Introduction to the Anthropology of the New world. New York: D.C. McMurtrie.

1926 The Relation of Nature to Man in Aboriginal America. New York: Oxford.

Woodworth, P.L.

1990 A Search for Accelerations in Records of European Mean Sea Level. International Journal of Climatology $10: 129-43$.

Zucchetto, James $\mathrm{J}$.

1976 Miami and Dade County, an Urban Area of Decelerating Growth. In Carrying Capacity for Man and Nature in South Florida: Energy Models for Recommending Energy, Water and Land Use for Long Range Economic Vitality in South Florida. Howard T. Odum and Mark T. Brown, eds. Pp. 443-49i. Gainesville: University of Florida presses. 